\title{
MODEL-PREDICTING THE EFFECT OF FRESHWATER INFLOW ON SALTWATER LAYERS, MIGRATION AND LIFE HISTORY OF ZOOPLANKTON IN THE ARCTIC OCEAN: TOWARDS SCENARIOS AND FUTURE TRENDS
}

\author{
Master thesis \\ by \\ Moritz Schmid \\ born 16 February 1987 \\ in Berkeley, United States of America
}

\footnotetext{
Thesis submitted to the Faculty of Biology, Georg-August-Universität Göttingen, in partial fulfillment of the requirements for the integrated bi-national degree
}

MASTER OF SCIENCE / MASTER OF INTERNATIONAL NATURE CONSERVATION (M.SC. / M.I.N.C.)

of Georg-August-Universität Göttingen; Germany and Lincoln University, New Zealand 
Supervisor/Betreuer:

Examiner/Gutachter:

Date of Submission/Abgabedatum: German Title/Deutscher Titel:
Prof. Falk Huettmann, $\mathrm{PhD}$

Prof. Dr. Michael Mühlenberg

01. Mai 2012

Vorhersagemodelle für den Einfluss von Süßwasser Einstrom auf Salzwasser Schichten, Wanderbewegung und Lebenszyklen des Zooplankton im Arktischen Ozean: Szenarien und Trends in der Zukunft 


\section{Abstract}

The Arctic Ocean is warming up and an increasing freshwater inflow is triggering major changes in ocean layers. This model study aims at creating a baseline, and analyzing the effect of freshwater content changes, subsequent freshwater sealing as well as related parameters in the Arctic Ocean on migration and life history of zooplankton such as copepods and euphausiids. Copepods and euphausiids make for a major part of the zooplankton biomass in the Arctic Ocean, and are an important part of the food chain. Analyses are carried out using an ecosystem-based, spatial modeling approach with machine learning algorithms (Salford Systems TreeNet ${ }^{\circledR}$, Random Forests ${ }^{\circledR}$ and R implementations). The underlying data consists of over 100 predictors including a globally unique data set of physical oceanography. Raw data that was used in this project is available as metadata from the Core Science Metadata Clearinghouse (former National Biological Information Infrastructure) and available at http://mercury.ornl.gov/clearinghouse/ and on servers from the University of Alaska Fairbanks. The Canadian Earth System Model 2 (CanESM2) was utilized to model the effect of changing climate on zooplankton for the next 100 years and for a low emission (RCP26) and a high emission scenario (RCP85). The results consist of spatially explicit (where every point in the layer is geo referenced) and predicted layers for Geographic Information Systems (GIS) that show predicted plankton presence/random absence as well as the relative index of depth and life stage distribution where the zooplankton is most likely to occur. The models show a clear trend towards an increasing relative index of depth where zooplankton is most likely to be found for the year 2100. Moreover, a trend towards a diminishing ecological niche for adult life stages of zooplankton was observed. These changes add stress to the life of zooplankton, especially regarding the diel vertical migration of mostly adult life stages. If zooplankton has to migrate a longer way, this will most likely increase energy expenditure and predation risk which ultimately decreases fitness. When accounting for other man-made impacts on the ocean such as ocean acidification and increasing shipping in the Arctic and taking the big picture into account, the outlook and conditions for zooplankton in 2100 are negative. 


\section{Acknowledgements}

I want to express my sincere gratitude towards my supervisor Prof. Falk Huettmann for exceptional support as well as for passing on the vision of science that matters.

Moreover, I want to thank the examiner of my thesis, Prof. Michael Mühlenberg for having me as a student in the M.I.N.C. program and supporting my thesis work.

I am indebted to Prof. Igor Polyakov for insight into Physical Oceanography and reviewing my thesis.

A special thanks goes to Michael Lindgren from the Scenarios Network for Alaska and Arctic Planning (SNAP) office in Fairbanks who helped out with various programming questions and for writing program codes for this project.

Furthermore I want to thank Slava Kharin, Vivek Arora and Jason Cole from the Canadian Centre for Climate Modelling and Analysis for insight concerning the data of their models.

In September 2011 I was lucky to be able to work on board the R/V Tiglax in the Gulf of Alaska. I want to thank Prof. Russel Hopcroft, Prof. Jeremy Mathis and Prof. Ken Coyle for making this possible.

My best to all past and present students at the EWHALE lab for initial ideas as well as friendship and scientific discussions.

I want to express my thankfulness to the Bayer Foundations that have been funding my entire work for this thesis and for seeing the potential in this project.

Moreover, I would like to thank my partner Cynthia Reséndiz for incredible support, thesis discussion and help with technical questions with it my work would have been possible. My love I really appreciate everything you did for me in this new challenge, love you.

Last but not least, none of my work would have been possible without my family and friends. Thanks for the great support over the years and far into the future. 


\section{List of Abbreviations}

\begin{tabular}{|c|c|}
\hline ADCP & Acoustic Doppler Current Profiler \\
\hline AW & Atlantic Water \\
\hline BSBW & Barents Sea branch water \\
\hline CAFF & Arctic Conservation of Flora and Fauna \\
\hline CanESM2 & Canadian Earth System Model 2 \\
\hline cap. & Capital/Capacity \\
\hline CMIP5 & Coupled Model Intercomparison Project Phase 5 \\
\hline $\mathrm{CO}_{2}$ & Carbon dioxide \\
\hline COML & Census of Marine Life \\
\hline DEM & Digital elevation model \\
\hline ECP & Extended Concentration Pathways \\
\hline FSBW & Fram Strait branch water \\
\hline FWC & Freshwater content \\
\hline GDP & Gross Domestic Product \\
\hline GIS & Geographic Information Systems \\
\hline IPCC & Intergovernmental Panel on Climate Change \\
\hline IS92-Scenarios & 1992 IPCC Scenario \\
\hline ISO & International Organization for Standardization \\
\hline ITIS & Taxonomic Information System \\
\hline LOKI & Lightframe Onsight Keyspecies Investigation \\
\hline MPI ESM & Max Planck Institute Earth System Model \\
\hline netCDF & Network Common Data Form \\
\hline OBIS & Ocean Biogeographic Information System \\
\hline PA & Polar Amplification \\
\hline PCMDI & Program for model Diagnosis and Intercomparison \\
\hline PML & Polar Mixed Layer or Mixed Layer \\
\hline PSU & Practical salinity unit \\
\hline $\mathrm{RCP}$ & Representative Concentration Pathway \\
\hline ROC & Receiver Operating Characteristics \\
\hline SA90-Scenarios & 1990 IPCC Scenario A \\
\hline SAT & Surface air temperature \\
\hline SNAP & Scenarios Network for Alaska and Arctic Planning \\
\hline SRES & Special Report on Emissions Scenarios \\
\hline SST & Sea surface temperature \\
\hline TSN & Taxonomic serial number \\
\hline UNEP & United Nations Environment Programme \\
\hline US\$ & United States Dollar \\
\hline USSR & Union of Soviet Socialists Republics \\
\hline WCRP & World Climate Research Programme \\
\hline WMO & World Meteorological Organization \\
\hline
\end{tabular}




\section{Units}

$\begin{array}{ll}{ }^{\circ} \mathrm{C} & \text { Degrees Celsius } \\ \mathrm{cm} & \text { Centimeters } \\ \mathrm{g} & \text { Grams } \\ \mathrm{gC} & \text { Grams of carbon } \\ \mathrm{gC} / \mathrm{J} & \text { Grams of carbon per joules } \\ \mathrm{J} / \mathrm{US} \$ & \text { Joules per United States dollar } \\ \mathrm{K} & \text { Kelvin } \\ \mathrm{kg} & \text { Kilograms } \\ \mathrm{kg} \mathrm{m} \mathrm{m}^{-1} & \text { Kilograms per square meter and } \\ & \text { second } \\ \mathrm{kg} \mathrm{m} \mathrm{m}^{-3} & \text { Kilograms per cubic meter } \\ \mathrm{km} & \text { Square kilometers } \\ \mathrm{km} & \text { Cubic kilometers } \\ \mathrm{m} & \text { Meters } \\ \mathrm{m} / \mathrm{hour}^{3} & \text { Meters per hour } \\ \mathrm{m}^{-2} \text { year } & \text { Square meter per year } \\ \mathrm{m}^{-3} & \text { Cubic meter } \\ \mathrm{mm} & \text { Millimeters } \\ \mathrm{mm} / \mathrm{year} & \text { Millimeters per year } \\ \mathrm{mol} \mathrm{m} \mathrm{m}^{-3} & \text { Mol per cubic meter } \\ \mathrm{W} / \mathrm{m}^{2} & \text { Watts per square meters }\end{array}$




\section{Content}

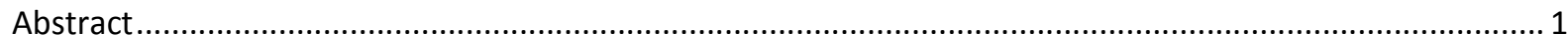

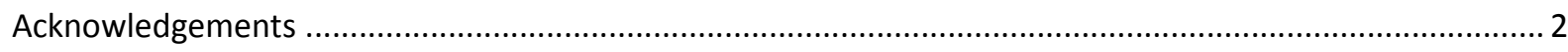

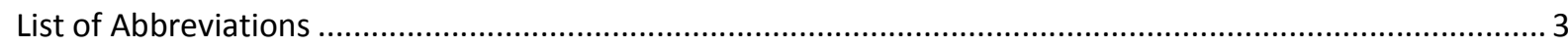

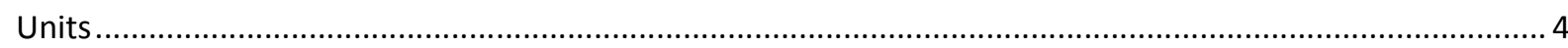

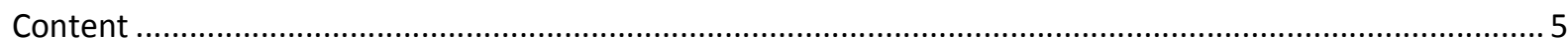

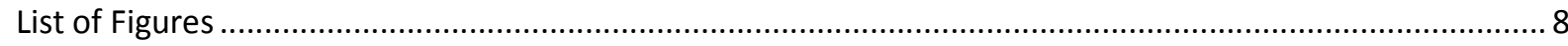

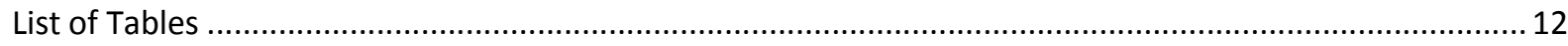

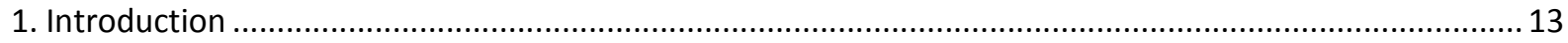

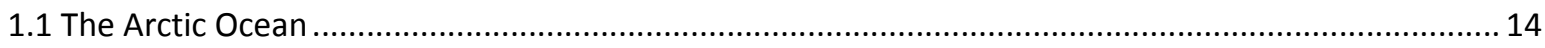

1.1.1 Ocean layers, circulation of water masses and the freshwater system in the Arctic Ocean.......... 15

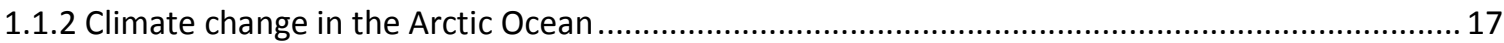

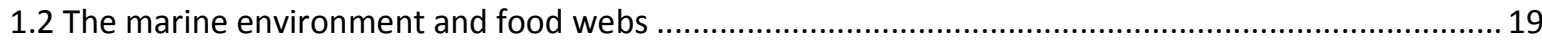

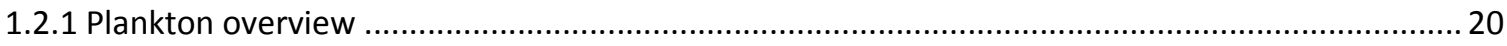

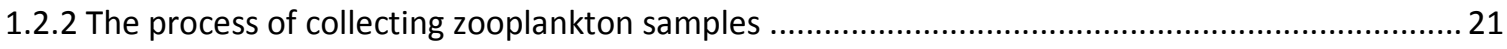

1.2.3 Vertical migration of zooplankton and the impact of freshwater sealing ................................... 22

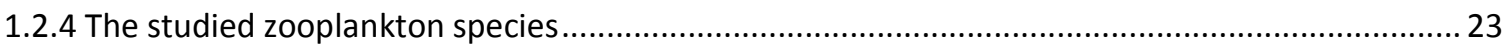

1.3 Future climate - An overview about future climate scenarios................................................. 27

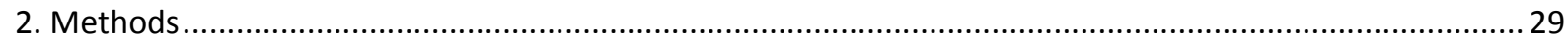

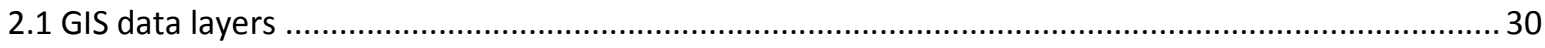

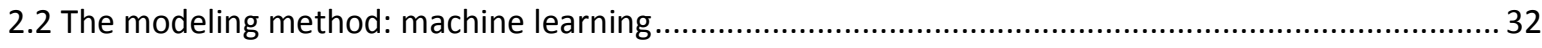

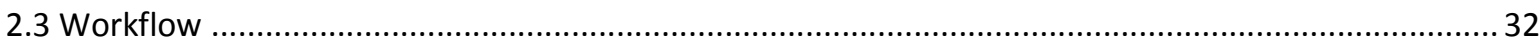

2.4 A comparison between the climate in 2010 and 2100 for two future climate scenarios from the

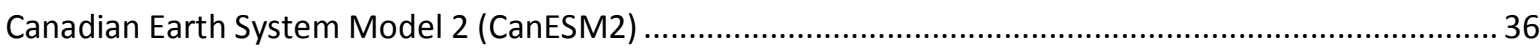

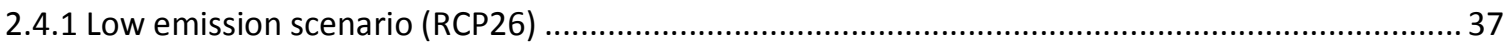

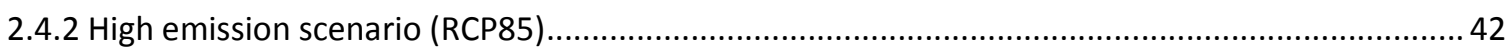

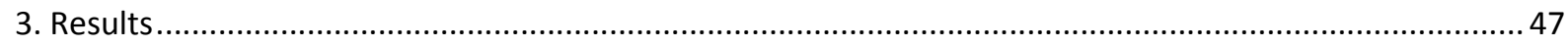

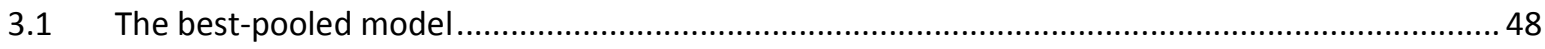

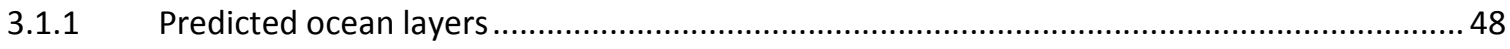




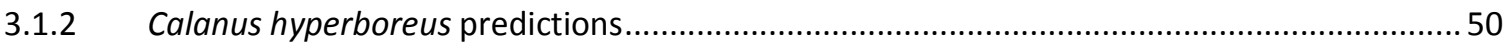

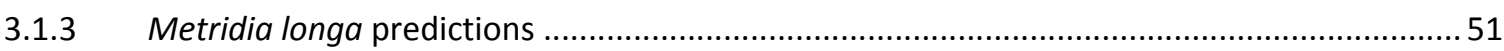

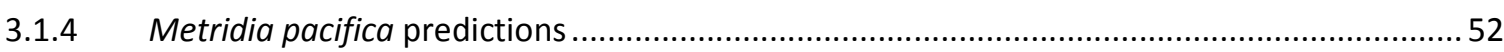

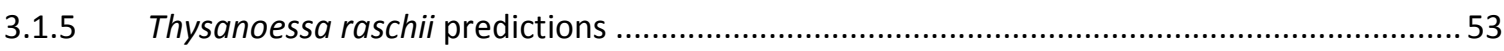

3.2 Low emission (RCP26) future predictions, including ocean Layers ............................................... 54

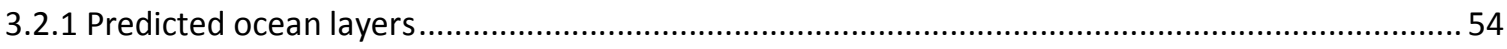

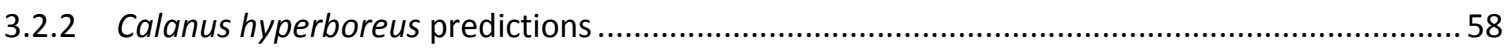

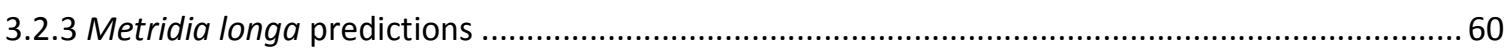

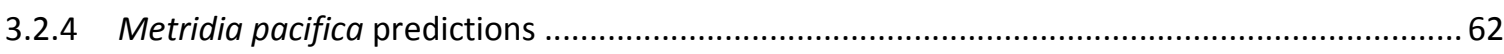

3.3 Low emission (RCP26) future predictions, excluding ocean layers ............................................ 64

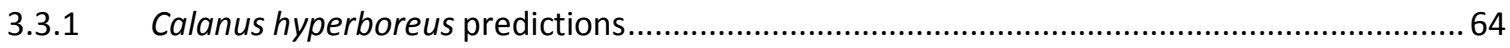

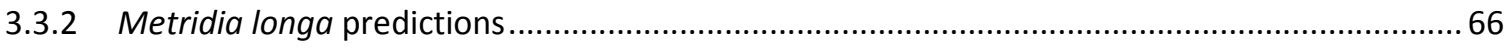

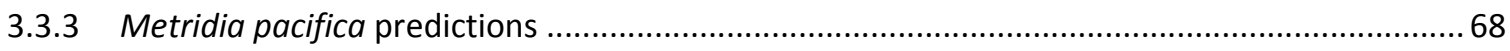

3.4 High emission (RCP85) future predictions, including ocean layers ............................................ 70

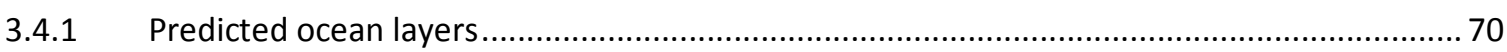

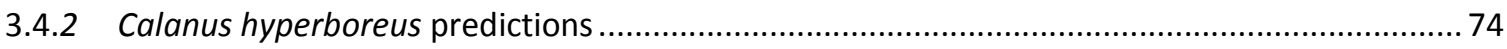

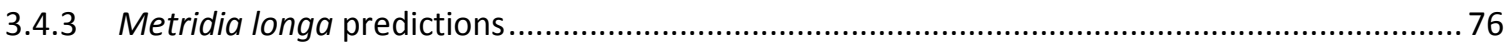

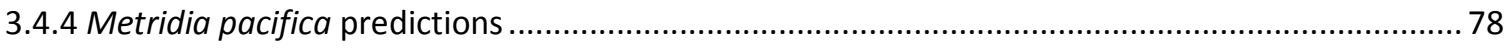

3.5 High emission (RCP85) future predictions, excluding ocean layers............................................. 80

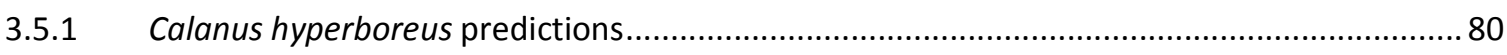

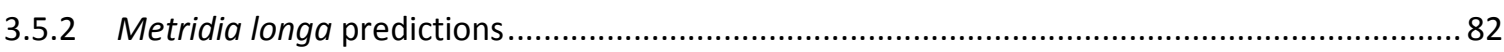

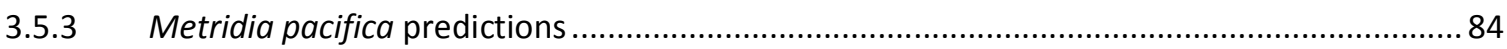

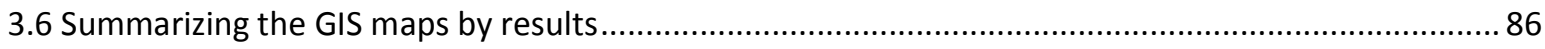

3.6.2 Predictions for the ocean layers in 2010 and 2100 and for the scenarios RCP26 and RCP85 ....... 87

3.6.3 Predictions for Calanus hyperboreus in 2010 and 2100 and for the scenarios RCP26 and RCP 85.88

3.6.4 Predictions for Metridia longa in 2010 and 2100 and for the scenarios RCP26 and RCP 85 ......... 89

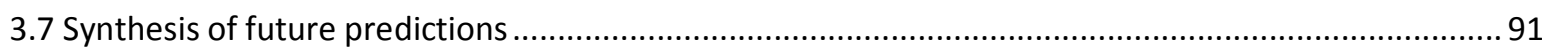

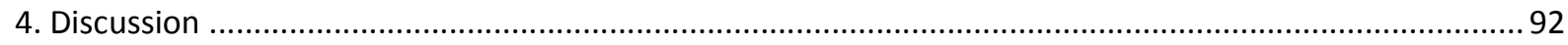

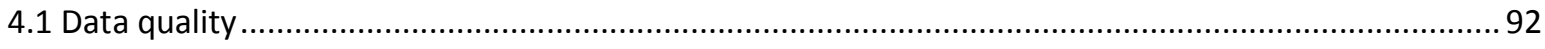


4.2 Machine learning experience and prediction quality ................................................................... 93

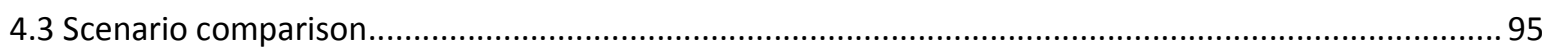

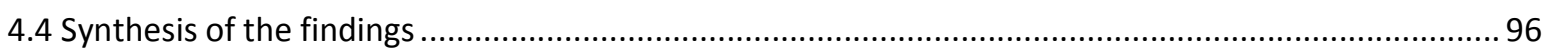

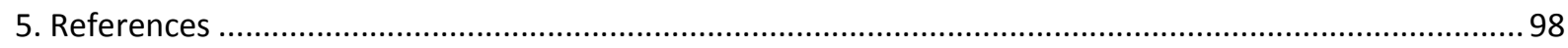

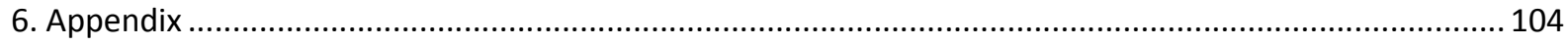

$6.1 \mathrm{~A}$ list of the 107 predictors and their sources used in the best-pooled model. .................................. 104

6.2 The R-code used to extract data from the future climate models ................................................ 105

6.3 Model performances for the best-pooled model ...................................................................... 108

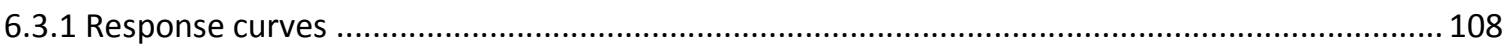

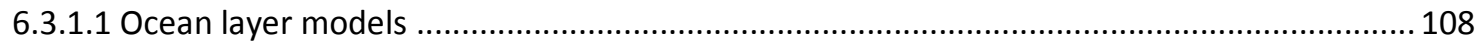

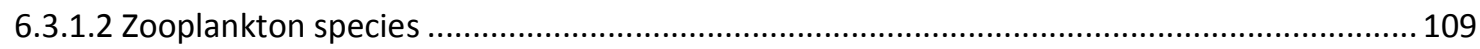

6.3.2 The ten most important predictors for each model ................................................................... 113

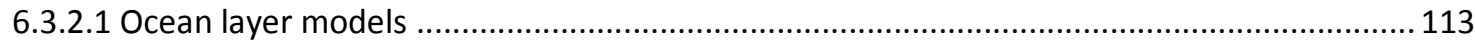

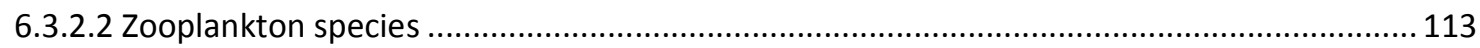

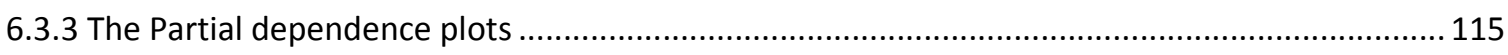

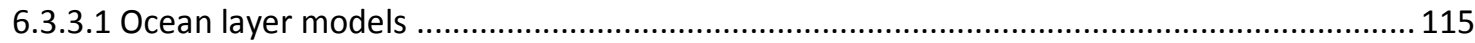

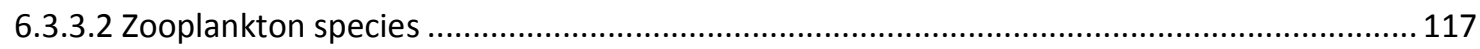

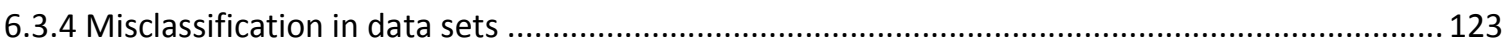

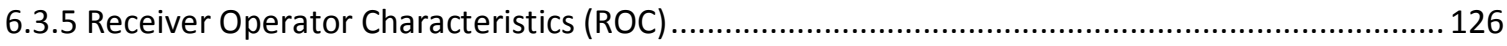

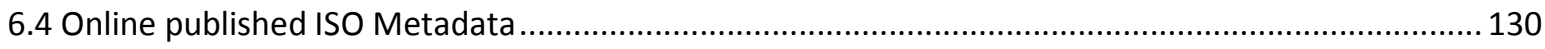

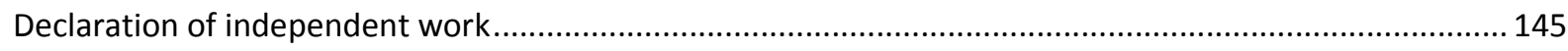




\section{List of Figures}

Figure 1: The Arctic Ocean and its constituent seas. ___ 14

Figure 2: Ocean stratification in the Arctic Ocean.

Figure 3: Circulation of surface water and intermediate Atlantic Water in the Arctic Ocean. ___ 16

Figure 4: Ice area anomalies and water temperature anomalies since 1900.___ 18

Figure 5: Schematic drawing of the different marine environments. ___ 19

Figure 6: Food web in the Arctic.___ 21

Figure 7: A MultiNet plankton sampler onboard the R/V Tiglax in the Gulf of Alaska.__ 22

Figure 8: Handling of zooplankton samples that were then further preserved in a 10\% formalin solution. ___ 22

Figure 9: A backscatter image from an Acoustic Doppler Current Profiler (ADCP. __ 23

Figure 10: $C$. hyperboreus. 25

Figure 11: M. longa.__ 26

Figure 12: M. pacifica. __ 26

Figure 13: T. raschii.___ 27

Figure 14: The different emission scenarios in the fourth assessment report of the IPCC AR4 SYR (2007). _ 28

Figure 15: The diversity of IPCC scenarios over time. __ 28

Figure 16: The new Representative Concentration Pathways scenarios or short RCP currently written up in the $5^{\text {th }}$

assessment report of the IPCC. ___ 29

Figure 17: The complete data set that was provided by Prof. Igor Polyakov. ___ 30

Figure 18: Summary map of the zooplankton sample points.

Figure 19: Digital elevation model (DEM) of the Arctic Ocean and adjacent landmass.__ 31

Figure 20: The four ocean layers that were modeled. ___ 33

Figure 21: Workflow of the model development and application on the research area.

Figure 22: Flowchart describing the model development. ___ 35

Figure 23: The four different scenarios: low emission scenario including ocean layers, low emission scenario excluding ocean layers, high emission scenario including ocean layers as well as high emission scenario excluding ocean layers.

Figure 24: Change in chlorophyll mass concentration [ $\mathrm{kg} \mathrm{m}^{-3}$ ] from 2010 to 2100. Scenario: RCP26.___ 37

Figure 25: Frequency distribution of the change in total chlorophyll mass concentration $\left[\mathrm{kg} \mathrm{m}^{-3}\right.$ ]. Scenario: RCP26. _- 37

Figure 26: Change in total runoff $\left[\mathrm{kg} \mathrm{m}^{-2} \mathrm{~s}^{-1}\right]$ from 2010 to 2100. Scenario: RCP26. __ 38

Figure 27: Frequency distribution of the total runoff $\left[\mathrm{kg} \mathrm{m}^{-2} \mathrm{~s}^{-1}\right]$. Scenario: $R C P 26$.

Figure 28: Change in dissolved nitrate concentration [mol m $\mathrm{m}^{-3}$ from 2010 to 2100. Scenario: RCP26.___ 39

Figure 29: Frequency distribution of the dissolved nitrate concentration [ $\mathrm{mol} \mathrm{m}^{-3}$ ]. Scenario: RCP26. ___ 39

Figure 30: Change in sea surface salinity [psu] from 2010 to 2100. Scenario: RCP26.

Figure 31: Frequency distribution of the sea surface salinity [psu]. Scenario: RCP26.

Figure 32: Change in sea surface temperature [K] from 2010 to 2100. Scenario: RCP26.

Figure 33: Frequency distribution of the sea surface temperature [K]. Scenario: RCP26. Data source: CanESM2. _ 41

Figure 34: Change in chlorophyll mass concentration $\left[\mathrm{kg} \mathrm{m}^{-3}\right]$ from 2010 to 2100. Scenario: $R C P 85$.__ 42

Figure 35: Frequency distribution of the change in total chlorophyll mass concentration $\left[\mathrm{kg} \mathrm{m}^{-3}\right]$. Scenario: $R C P 85$. _ 42

Figure 36: Change in total runoff $\left[\mathrm{kg} \mathrm{m}^{-2} \mathrm{~s}^{-1}\right]$ from 2010 to 2100. Scenario: RCP85. ___ 43

Figure 37: Frequency distribution of the total runoff $\left[\mathrm{kg} \mathrm{m}^{-2} \mathrm{~s}^{-1}\right]$. Scenario: $R C P 85$.

Figure 38: Change in dissolved nitrate concentration [mol m $\mathrm{m}^{-3}$ ] from 2010 to 2100. Scenario: RCP85. __ 44

Figure 39: Frequency distribution of the dissolved nitrate concentration [ $\mathrm{mol} \mathrm{m}^{-3}$. Scenario: $R C P 85$. __ 44

Figure 40: Change in sea surface salinity [psu] from 2010 to 2100. Scenario: RCP85.

Figure 41: Frequency distribution of the sea surface salinity [psu]. Scenario: RCP85.

Figure 42: Change in sea surface temperature [K] from 2010 to 2100. Scenario: RCP85.

Figure 43: Frequency distribution of the sea surface temperature [K]. Scenario: RCP85.

Figure 44: The pan-arctic prediction of the H1 ocean layer for the best-pooled model.__ 49

Figure 45: The pan-arctic prediction of the H2 ocean layer for the best-pooled model.___ 49 
Figure 46: The pan-arctic prediction of the H3 ocean layer for the best-pooled model. 49

Figure 47: The pan-arctic prediction of the Wx ocean layer for the best-pooled model. 49

Figure 48: The predicted pan-arctic presence/random absence layer overlaid with the predicted relative index of depth for C. hyperboreus. 50

Figure 49: The predicted pan-arctic presence/random absence layer overlaid with the predicted life stages for $C$. hyperboreus. 50

Figure 50: The predicted pan-arctic presence/random absence layer overlaid with the predicted relative index of depth for M. longa.

Figure 51: The predicted pan-arctic presence/random absence layer overlaid with the predicted life stages for $M$. longa. 51

Figure 52: The predicted pan-arctic presence/random absence layer overlaid with the predicted relative index of depth for M. pacifica.

Figure 53: The predicted pan-arctic presence/random absence layer overlaid with the predicted life stages for $M$. pacifica. 52

Figure 54: The predicted pan-arctic presence/random absence layer overlaid with the predicted relative index of depth for $T$. raschii.

Figure 55: The predicted pan-arctic presence/random absence layer overlaid with the predicted life stages for $T$. raschii.

Figure 56: The pan-arctic prediction of the $\mathrm{H} 1$ ocean layer in 2010, RCP26. 55

Figure 57: The pan-arctic prediction of the H1 ocean layer in 2100, RCP26.

Figure 58: The pan-arctic prediction of the $\mathrm{H} 2$ ocean layer in 2010, RCP26.

Figure 59: The pan-arctic prediction of the $\mathrm{H} 2$ ocean layer in $2100, R C P 26$.

Figure 60: The pan-arctic prediction of the H3 ocean layer in 2010, RCP26.

Figure 61: The pan-arctic prediction of the $\mathrm{H3}$ ocean layer in 2100, RCP26.

Figure 62: The pan-arctic prediction of the Wx ocean layer in 2010, RCP26.

Figure 63: The pan-arctic prediction of the Wx ocean layer in 2100, RCP26.

Figure 64: Overlay of presence/random absence with predicted relative index of depth in 2010 for C. hyperboreus. _ 59

Figure 65: Overlay of presence/random absence with predicted relative index of depth in 2100 for C. hyperboreus. 59

Figure 66: Overlay of presence/random absence with predicted life stages in 2010 for C. hyperboreus.

Figure 67: Overlay of presence/random absence with predicted life stages in 2100 for C. hyperboreus.

Figure 68: Overlay of presence/random absence with predicted relative index of depth in 2010 for M. longa. __ 61

Figure 69: Overlay of presence/random absence with predicted relative index of depth in 2100 for $M$. longa. __ 61

Figure 70: Overlay of presence/random absence with predicted life stages in 2010 for M. longa. __ 61

Figure 71: Overlay of presence/random absence with predicted life stages in 2100 for M. longa. __ 61

Figure 72: Overlay of presence/random absence with predicted relative index of depth in 2010 for M. pacifica. _ 63

Figure 73: Overlay of presence/random absence with predicted relative index of depth in 2100 for M. pacifica. __ 63

Figure 74: Overlay of presence/random absence with predicted life stages in 2010 for M. pacific __ 63

Figure 75: Overlay of presence/random absence with predicted life stages in 2100 for M.pacifica.___ 63

Figure 76: Overlay of presence/random absence with predicted relative index of depth in 2010 for C. hyperboreus, RCP26.

Figure 77: Overlay of presence/random absence with predicted relative index of depth in 2100 for $C$. hyperboreus, RCP26.

Figure 78: Overlay of presence/random absence with predicted life stages in 2010 for C. hyperboreus. 65

Figure 79: Overlay of presence/random absence with predicted life stages in 2100 for C.. hyperboreus.___ 65 Figure 80: Overlay of presence/random absence with predicted relative index of depth in 2010 for M. longa, RCP26._67 Figure 81: Overlay of presence/random absence with predicted relative index of depth in 2100 for M. longa, RCP26._67 Figure 82: Overlay of presence/random absence with predicted life stages in 2010 for M. longa, RCP26. 67

Figure 83: Overlay of presence/random absence with predicted life stages in 2100 for M. longa, RCP26. 67

Figure 84: Overlay of presence/random absence with predicted relative index of depth in 2010 for M. pacifica, RCP26.

Figure 85: Overlay of presence/random absence with predicted relative index of depth in 2100 for M. pacifica, RCP26. 
Figure 86: Overlay of presence/random absence with predicted life stages in 2010 for M. pacifica, RCP26. 69

Figure 87: Overlay of presence/random absence with predicted life stages in 2100 for M. pacifica, RCP26.

Figure 88: The pan-arctic prediction of the H1 ocean layer in 2010, RCP85.

Figure 89: The pan-arctic prediction of the H1 ocean layer in 2100, RCP85.

Figure 90: The pan-arctic prediction of the H2 ocean layer in 2010, RCP85.

Figure 91: The pan-arctic prediction of the H2 ocean layer in 2100, RCP85.

Figure 92: The pan-arctic prediction of the H3 ocean layer in 2010, RCP85.

Figure 93: The pan-arctic prediction of the H3 ocean layer in 2100, RCP85.

Figure 94: The pan-arctic prediction of the Wx ocean layer in 2010, RCP85.

Figure 95: The pan-arctic prediction of the Wx ocean layer in 2100, RCP85.

Figure 97: Overlay of presence/random absence with predicted relative index of depth in 2100 for C. hyperboreus, RCP85.

Figure 98: Overlay of presence/random absence with predicted life stages in 2010 for C. hyperboreus, RCP85. 75

Figure 99: Overlay of presence/random absence with predicted life stages in 2100 for C. hyperboreus, RCP85.

Figure 96: Overlay of presence/random absence with predicted relative index of depth in 2010 for $C$.

hyperboreus, RCP85.

Figure 100: Overlay of presence/random absence with predicted relative index of depth in 2010 for M. longa, RCP85. 77 Figure 101: Overlay of presence/random absence with predicted relative index of depth in 2100 for M. longa, RCP85. 77 Figure 102: Overlay of presence/random absence with predicted life stages in 2010 for M. longa, RCP85.

Figure 103: Overlay of presence/random absence with predicted life stages in 2100 for M. longa, RCP85.

77

Figure 104: Overlay of presence/random absence with predicted relative index of depth in 2010 for M. pacifica, RCP85.

Figure 105: Overlay of presence/random absence with predicted relative index of depth in 2100 for M. pacifica, RCP85.

Figure 106: Overlay of presence/random absence with predicted life stages in 2010 for M. pacifica, RCP85.

79

Figure 107: Overlay of presence/random absence with predicted life stages in 2100 for M. pacifica, RCP85.

Figure 108: Overlay of presence/random absence with predicted relative index of depth in 2010 for $C$. hyperboreus, RCP85.

Figure 109: Overlay of presence/random absence with predicted relative index of depth in 2100 for $C$. hyperboreus, RCP85. 81

Figure 110: Overlay of presence/random absence with predicted life stages in 2010 for C. hyperboreus, RCP85. 81 Figure 111: Overlay of presence/random absence with predicted life stages in 2100 for $C$. hyperboreus, RCP85. 81 Figure 112: Overlay of presence/random absence with predicted relative index of depth in 2010 for M. longa, RCP85.

Figure 113: Overlay of presence/random absence with predicted relative index of depth in 2100 for M. longa, RCP85. 83 Figure 114: The Overlay of presence/random absence with predicted life stages in 2010 for M. longa, RCP85.

Figure 115: Overlay of presence/random absence with predicted life stages in 2100 for M. longa, RCP85. 83 Figure 116: Overlay of presence/random absence with predicted relative index of depth in 2010 for M. pacifica, RCP85.

Figure 117: Overlay of presence/random absence with predicted relative index of depth in 2100 for M. pacifica, RCP85.

Figure 118: Overlay of presence/random absence with predicted life stages in 2010 for M. pacifica, RCP85. ___ 85

Figure 119: Overlay of presence/random absence with predicted life stages in 2100 for M. pacifica, RCP85. ___ 85

Figure 120: Response curve for the model of ocean layer $\mathrm{H1}$

Figure 121: Response curve for the model of ocean layer $\mathrm{H} 2$

Figure 122: Response curve for the model of ocean layer $\mathrm{H} 3$

Figure 123: Response curve for the model of ocean layer Wx ___ 109

Figure 124: Response curve for the presence/random absence model of C. hyperboreus.___ 109

Figure 125: Response curve for the predicted relative index of depth model of C. hyperboreus.___ 109

Figure 126: Response curve for the predicted life stage model of C. hyperboreus.___ 110

Figure 127: Response curve for the presence/random absence model of M. longa.___ 110 
Figure 128: Response curve for the predicted relative index of depth model of $M$. longa. 110

Figure 129 Response curve for the predicted life stage model of $M$. longa.

Figure 130: Response curve for the presence/random absence model of M. pacifica.

Figure 131: Response curve for the predicted relative index of depth model of M. pacifica.___ 111

Figure 132: Response curve for the predicted life stage model of M. pacifica.

Figure 133: Response curve for the presence/random absence model of T. raschii.

Figure 134: Response curve for the predicted relative index of depth model of T. raschii.___ 112

Figure 135: Response curve for the predicted life stage model of T. raschii.___ 113

Figure 136: Partial dependence plots for the three most important predictors in the H1 ocean layer model. ___ 115

Figure 137: Partial dependence plots for the three most important predictors in the H2 ocean layer model. ___ 116

Figure 138: Partial dependence plots for the three most important predictors in the H3 ocean layer model. ___ 116

Figure 139 Partial dependence plots for the three most important predictors in the Wx ocean layer model. ___ 117

Figure 140: Partial dependence plots for the three most important predictors and for the presence/random absence model of $C$. hyperboreus.

Figure 141: Partial dependence plots for the three most important predictors and for the predicted relative index of depth model of $C$. hyperboreus.

Figure 142: Partial dependence plots for the three most important predictors and for the predicted life stage model of

C. hyperboreus.

Figure 143: Partial dependence plots for the three most important predictors and for the presence/random absence model of M. longa.

Figure 144: Partial dependence plots for the three most important predictors and for the predicted relative index of depth model of $M$. longa.

Figure 145: Partial dependence plots for the three most important predictors and for the predicted life stage model of

M. longa (adult, copepodite and nauplii).

Figure 146: Partial dependence plots for the three most important predictors and for the presence/random absence model of M. pacifica.

Figure 147 Partial dependence plots for the three most important predictors and for the predicted relative index of depth model of M. pacifica.

121

Figure 148: Partial dependence plots for the three most important predictors and for the predicted life stage model of M. pacifica. 121

Figure 149: Partial dependence plots for the three most important predictors and for the presence/random absence model of T.raschii.

Figure 150: Partial dependence plots for the three most important predictors and for the predicted relative index of depth model of T.raschii.

Figure 151: Partial dependence plots for the three most important predictors and for the predicted life stage model of

T.raschii.

Figure 152: ROC curves for the presence/random absence model of C. hyperboreus.

Figure 153: ROC curve for the predicted life stage model of C. hyperboreus.

Figure 154: ROC curve for the presence/random absence model of M. longa. ___ 127

Figure 155: ROC curve for the predicted life stage model of M. longa. 127

Figure 156: ROC curve for the presence/random absence model of M. pacifica. ___ 128

Figure 157: ROC curve for the predicted life stage model of M. pacifica. ___ 128

Figure 158: ROC curve for the presence/random absence model of T. raschii. ___ 129

Figure 159: ROC curve for the predicted life stage model of T. raschii. ___ 129 


\section{List of Tables}

Table 1: Summary of the predictions of the best-pooled model. 86

Table 2: Summary of the predicted ocean layers for 2010 and 2100 and for the scenarios RCP26 and RCP85.

87

Table 3: Summary table for C. hyperboreus. Predictions are given for RCP26 and RCP85 and each for the two time steps

2010 and 2100.

Table 4: Summary table for M. longa. Predictions are given for RCP26 and RCP85 and each for the two time steps 2010

and 2100.

Table 5: Summary table for M. pacifica. Predictions are given for RCP26 and RCP85 and each for the two time steps 2010 and 2100.

Table 6: This table shows the list of predictors in the best-pooled data set. 90

Table 7: Variable importance for the three models of the ocean layers. 104

Table 8: Variable importance for the three models of $C$. hyperboreus. 113

Table 9: Variable importance for the three models of $M$. longa. 114

Table 10: Variable importance for the three models of $M$. pacifica. 114

Table 11: Variable importance for the three models of T. raschii. 114

Table 12: Misclassification for test data and for the presence/random absence model of C. hyperboreus. 115

Table 13: Misclassification for test data and for the predicted life stage model of $C$. hyperboreus. 123

Table 14: Misclassification for test data and for the presence/random absence model of M. longa. 123

Table 15: Misclassification for test data and for the predicted life stage model of M. longa. 124

Table 16: Misclassification for test data and for the presence/random absence model of M. pacifica. 124

Table 17: Misclassification for test data and for the predicted life stage model of M. pacifica. 124

Table 18: Misclassification for test data and for the presence/random absence model of T. raschii. 125

Table 19: Misclassification for test data and for the predicted life stage model of T. raschii. 125 


\section{Introduction}

The Arctic Ocean and the Earth as a whole are subject to climate change, associated with increased atmospheric and oceanic temperatures, loss of summer sea ice resulting in increasing arctic shipping, and which are well described and forecasted (Spiridonov et al. 2012). However, the controversy remains whether freshwater is adding to stratification and therefore sealing off the Arctic Ocean and its ecological processes, leading to a substantial reduction of plankton productivity for instance.

The study area for this research is the Arctic Ocean within the definition of the Arctic Circle at $66^{\circ} 33^{\prime} \mathrm{N}$ (Arctic Circle 2012, Hannemann et al. 2010). The Arctic Ocean is the smallest of the world's five oceans with a size of around 14 million square kilometers (Welsh et al. 1986); it makes for about 1.5 times the size of the Unite States. Despite being the smallest ocean, the Arctic Ocean received major attention in the past and will presumably receive further attention during years to come. Attention in the past was perhaps mostly due to sovereignty issues between the former Union of Soviet Socialists Republics (USSR) and the United States attributed to the Cold War, and nuclear submarine cruises within. Industrial oil and natural resource development started relatively late in the 70s. Nowadays, the Arctic Ocean is in the focus again because of environmental changes and upcoming economic opportunities due to climate change and resource scarcity elsewhere. They may include navigation possibilities making Arctic seaways more profitable due to melting sea ice, but also include traditional questions and issues like the sustainable exploitation of natural resources such as oil and gas, as well as fish, pollution (contamination through disasters on oil platforms, noise pollution, air pollution) and foremost ocean acidification as well as many others. However, those questions are still seen in the light of national sovereignty and strategies (e.g., Berkman and Young 2009, Young 1996; 2012). The difference to the past is simply that those questions are not bound directly to a war anymore. The struggle about resources and the rights to extract them however is as fierce as could be, and might turn out elsewhere and with a delay. Unfortunately, the one side that looses the most in this struggle is not some "Grand Nation" that has to deal with a slight increase in the oil price, but eventually it is nature that suffers from an enormous amount of negative impacts. A decaying environment will also affect the human economy that relies on that ecosystem and carrying capacity overall. Such views were expressed already, e.g. Huettmann (2012) for the three poles (Arctic, Antarctic and Himalayas), but are widely discussed in conservation and sustainability literature (e.g., Naess and Rothenberg 1990). 


\subsection{The Arctic Ocean}

The Arctic Ocean consists of a deep Ocean Basin, and the extensive shelves from the Barents, Kara, Laptev, East Siberian, Chukchi and Beaufort Seas as well as the White Sea, the Lincoln Sea and less prominent shelf regions off the Canadian Arctic Archipelago and northern Greenland (Jakobsson 2002) (Fig. 1).

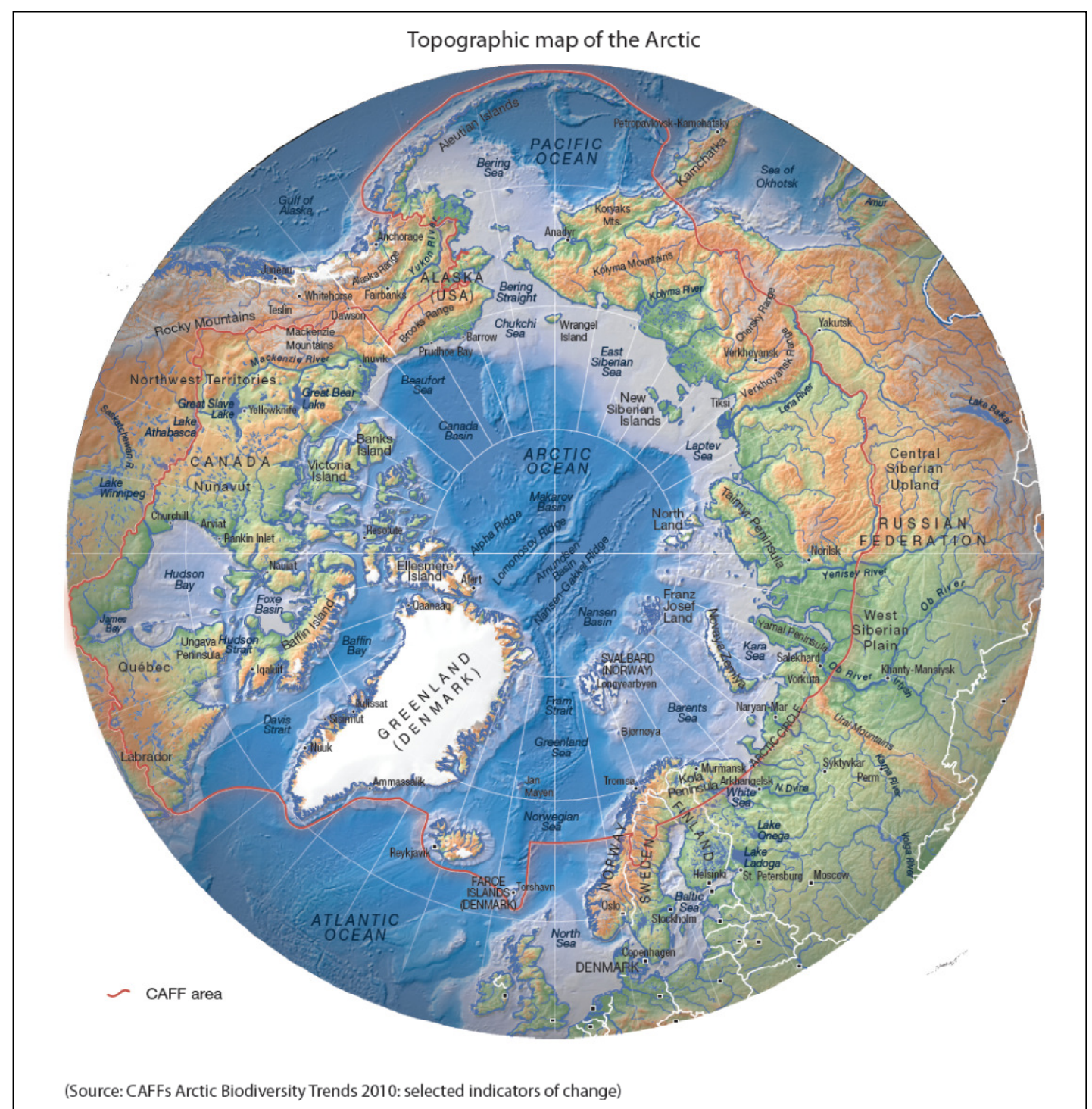

Figure 1: The Arctic Ocean and its constituent seas. Note also the Arctic Conservation Area as delineated by the Arctic Conservation of Flora and Fauna (from CAFF 2010).

Due to the remoteness of the Arctic, the sun, a circulating globe and an Earth axis tilt of about 23.5 degrees, the polar climate is persistently cold and with relatively narrow annual temperature ranges. Winters are characterized by continuous darkness, cold and stable weather conditions as well as clear skies. Summers are characterized by continuous daylight, damp and foggy weather, and weak cyclones with rain or snow (Hannemann et al. 2010, Serreze and Barry 2005, CIA 2009).

The Arctic Ocean shows some of the most extreme conditions known on Earth. There is considerable variation in the length of sunlight and also in the ice cover over the year. Summer is characterized by three months of continuous illumination and winter by continuous darkness of about three months (Thurman 1997). The average depth of the Arctic Ocean is 1,050 meters. The deepest part of the Arctic Ocean is found 
north of the Chuckchi Sea $(5,441 \mathrm{~m})$. The Arctic Ocean is also characterized by the highest percentage of continental shelf of any ocean. $50 \%$ of the Arctic Ocean floors are continental shelf and therefore shallow with the remaining $50 \%$ within the central basin that is divided by the three submarine ridges. The Alpha Ridge, the Nansen-Gakkel Ridge and the Lomonosov Ridge (CIA 2009).

The surface of the Arctic Ocean is covered by a drifting and perennial polar icepack. The icepack is about three meters thick but varies by region and conditions. During the winter months, this sea ice covers most of the Arctic Ocean surface. In summer however, higher temperatures of air and water causes the icepack to shrink by about $50 \%$ of its winter extent. This seasonal variation accounts for a lot of the complex processes happening in the Arctic Ocean such as primary production and stratification of ocean layers.

Natural resources in the Arctic Ocean are neither simple nor cheap to extract due to the extreme environment conditions that affect the work in this environment. Natural resources that are currently extracted from the region are sand and gravel aggregates, placer deposits, polymetallic nodules, oil and gas, fish, marine mammals (seals and whales) (CIA 2009). On the other hand, Euskirchen et al. (in press) estimate the annual cumulated present value cost to society due to climate change in the Arctic to range from $\$ 7.5$ trillion to $\$ 91.3$ trillion in the time from 2010 to 2100 . The range in the values reflects uncertainties in climate change. Other estimates vary between a $5 \%$ and $20 \%$ loss of Gross Domestic Product (GDP) per year depending on the scenario (Stern 2007). This loss in GDP will not be recoverable. Climate change costs society an unimaginable high amount of money.

\subsubsection{Ocean layers, circulation of water masses and the freshwater system in the Arctic Ocean}

The open ocean is well stratified with surface layers much fresher than deeper ones, giving the ocean its basic structure, circulation pattern and regulating productivity in the ocean (Behrenfeld et al. 2006, Levitus et al. 2000). Vertical stratification in the water column is forming as a consequence of water masses with different temperatures and subsequent densities. Density is strongly influenced by temperature and salinity. Warmer and fresher water is less dense.

Cold and fresh surface water is separated from intermediate $(150-800 \mathrm{~m})$ Atlantic Water (AW) of the Arctic Ocean by a halocline. In the halocline, salinities increase to $34.8 \mathrm{psu}$ and at $\sim 200-300 \mathrm{~m}$ (Schauer et al. 1997; 2002).

Water with a low salinity from the Pacific Ocean flows into the Arctic Ocean via the Bering Strait (MacDonald and Bewers 1996). This colder water forms a sub-surface layer beneath the arctic water at the surface. Surface water occupies the upper $50 \mathrm{~m}$ of the Arctic Ocean and form the PML (Polar Mixed Layer or Mixed Layer) (Fig. 2). The polar halocline (a layer of cold water with a steep salinity gradient) forms below the PML and limits the exchange between surface and deep ocean water masses. 


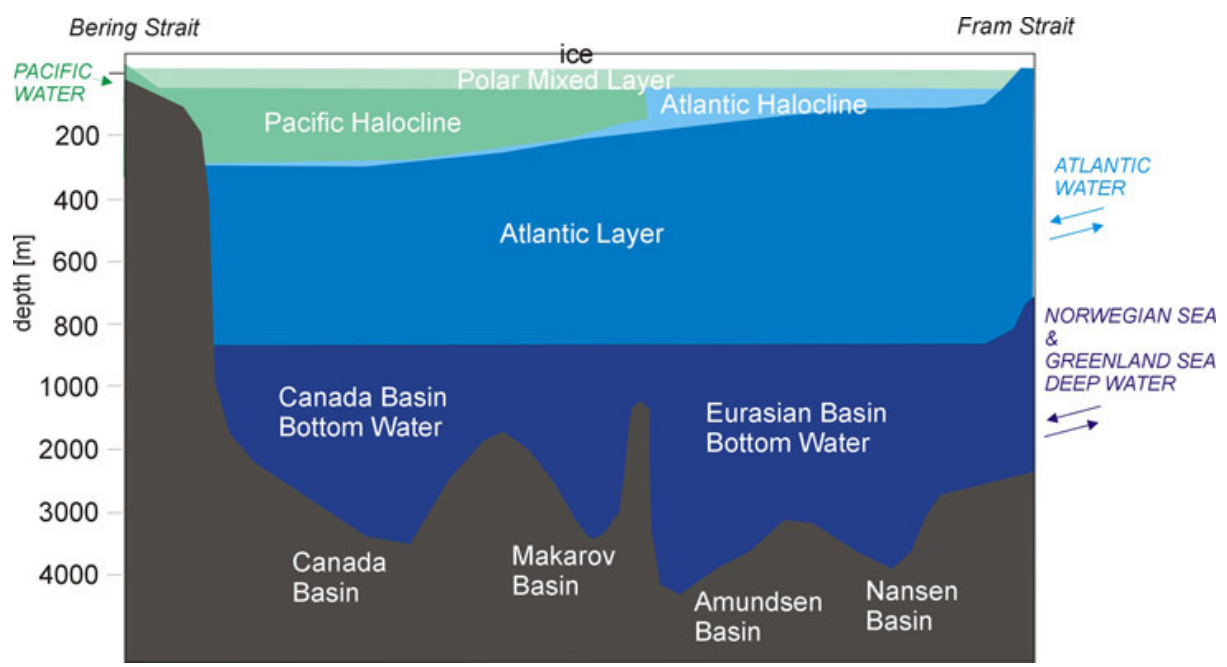

Figure 2: Ocean stratification in the Arctic Ocean (modified from MacDonald and Bewers 1996).

Therefore, the polar halocline acts as an insulating layer between surface water masses and sea-ice from warm deep water and thus is vital for the existence of perennial sea ice cover. Traditionally, the interior of the Arctic Ocean is covered with perennial pack ice, while a seasonal (first-year) ice-cover is formed on the marginal seas from October to June. The spatial extent of this sea ice cover varies between 14-15 million $\mathrm{km}^{2}$ in March and about 6-7 million $\mathrm{km}^{2}$ in September.

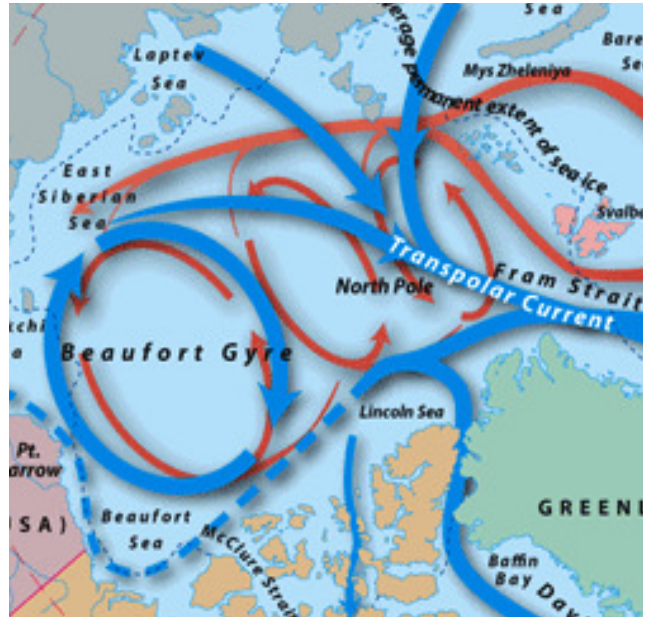

Figure 3: Circulation of surface water (in blue) and intermediate Atlantic Water (AW, in red) in the Arctic Ocean (from the Woods Hole Oceanographic Institution: www.whoi.edu)
The transition layer between halocline and temperature maximum in the Atlantic layer is referred to as the thermocline and with a strong increase in salinity (Rudels et al. 1991). The $0^{\circ} \mathrm{C}$ isotherm then separates the polar halocline from deeper and colder Atlantic waters. An important element of water structure is the frontal boundary between water masses of Atlantic and Pacific (McLaughlin et al. 1996) and it is roughly aligned with the Transpolar Drift.

AW from the North Atlantic is carried through the Arctic Ocean interior by the pan-Arctic boundary current and transport occurs in the form of near-slope cyclonic boundary currents (Aagaard 1989) (Fig. 3, red arrows).

Two major inflows supply the polar basins with AW: the Fram Strait branch water (FSBW) and the Barents Sea branch water (BSBW) (Rudels et al. 1994).

The surface circulation pattern in the Arctic Ocean is dominated by the clockwise Beaufort Gyre (in the Canadian Basin) and the Transpolar Drift. The trans-polar drift (also transpolar current) is a very important feature in the Arctic Ocean which is characterized by near-freezing surface waters that are driven by wind and ice drift. This current transports water from the Siberian Arctic towards the Fram Strait (Fig. 3). Cold surface waters with low salinity are transported out of the Arctic Ocean and towards North Atlantic Ocean via the East Greenland Current and through the Canadian Archipelago. On the other hand, warm water, high in salinity from the Atlantic flows into the Arctic Ocean via the Fram Strait and the Barents Sea. 
Zooplankton distribution is largely driven by the currents since they determine where nutrient rich waters are. Therefore, circulation patterns can explain a lot of the observed zooplankton distribution and potential changes.

The Arctic Ocean is a significant reservoir of fresh water (Aagaard and Carmack 1989). Freshwater is delivered to the marine Arctic by atmospheric transport through precipitation and by ocean currents, and to the coastal regions through river inflows (Zimov 1997, Prange and Gerdes 1999). This freshwater has major influence on stratification and water column stability as well as on ice formation (IASC and McGinley 2010, Morison 2012). Without freshwater input, there would be less freezing, less ice cover, and less brine rejection (Aagaard and Carmack 1989, Carmack 2000).

Mixing, especially in the surface layer of the Arctic Ocean can be driven by wind and storms, convection. Storms have been shown to create turbulent mixing between water layers. This mixing is crucial for the productivity of an ecosystem (IASC and Duffy 2010). It brings nutrients, that tend to sink to the bottom of the ocean back to the surface and on the other hand makes sure, that oxygen from the surface is mixed into deeper waters. In summer, when substantial warming occurs, waters stratify, trapping phytoplankton in warm surface waters and resulting in a spring bloom in the nutrient rich water. This well documented spring bloom provides then vast amounts of food for many marine animals including and foremost zooplankton that feasts on this availability of phytoplankton (Siegel et al. 2002, Townsend et al. 1992, Sarmiento et al. 2004). While stratification of the water column in general is important and natural, prolonged or strengthened stratification can have negative impacts on zooplankton biomass. For instance an increase in the temperature of coastal waters can lead to a strengthening of the thermocline, which then becomes a stronger boundary. Therefore it is more difficult for deeper, nutrient rich water to reach the surface and mix with surface oxygen which is true as well for the related biotic life. This poses a reduction in upwelling as well as mixing and can result in local or widespread biomass loss. It can change species composition. This mentioned development was already observed between 1951 and 1993 in Southern California where zooplankton biomass then decreased significantly (Roemmich and McGowan 1995). Such an event would most likely also have serious impacts on higher parts of the food chain (e.g., see Ainley et al. 1996) for impacts on seabirds).

\subsubsection{Climate change in the Arctic Ocean}

This brief overview, about the changes in climate that we are dealing with in the Arctic Ocean, is important for understanding the situation of plankton in the Arctic and to be able to put the project in context with the wider picture. This summary however shows how serious the climatological situation in the Arctic really is, and what anthropogenic climate change does to one of the areas on Earth, most sensitive to climate change and disturbances.

A quote by Polyakov et al. (2008) states: "Recent observations show dramatic changes of the Arctic atmosphere-ice-ocean system". This statement is symptomatic for the situation we are dealing with here and for this thesis. Research concluded that Arctic and sub-Arctic regions have undergone substantial changes (Dickson et al. 2002; ACIA 2005, Overland et al. 2004, Curry and Mauritzen 2005, Polyakov et al. 2007, Millennium Ecosystem Assessment (www.maweb.org)).

For example, the amount of freshwater input into the Arctic Ocean, e.g. from glaciers has been increasing for the past decades and the trend is predicted to be continuing (IASC and Draggan 2010). River discharge alone is predicted to increase by $5 \%$ to $25 \%$ depending on the model looked at (IASC and Draggan 2010). Many of the recent flooding events may be linked to this changing situation as well. An increasing inflow of cold, fresh water to the Arctic Ocean from rivers as well as melt water and precipitation has the potential for significant impacts on the thermohaline circulation and therefore affecting global climate (IASC and 
Draggan 2010). This increase is also visible in the data used in our model predictions and as discussed in chapter 2.4 .

On the other hand, the central Arctic Ocean became increasingly saltier with a rate of freshwater loss of $239+/-270 \mathrm{~km}^{3}$ per decade over the twentieth century. In contrast, long-term (1920-2003) freshwater content (FWC) trends over the Siberian shelf show a general freshening tendency with a rate of $29+/-50$ $\mathrm{km}^{3}$ per decade (Polyakov et al. 2008). Polyakov et al. 2008 suggests that ice production and sustained draining of freshwater from the Arctic Ocean in response to winds are the key contributors to the salinification of the upper Arctic Ocean over recent decades. The situation changed dramatically in the 2000s when extreme freshening of the central Arctic Ocean occurred (Polyakov, personal communication).

Moreover, research showed that the sea ice extent was reduced and thinned by climate change. Arctic sea ice has undergone substantial changes (Walsh and Chapman 2001; Meier et al. 2007). Sea ice extent has been decreasing since the last decades by around 5 to $10 \%$ and with a record decrease in the seasonal sea ice cover in summer 2007 (Fig. 4) (Comiso et al. 2008, Stroeve et al. 2008). A virtual entire retreat of summer sea ice is predicted by 2050 (Wang and Overland 2009).

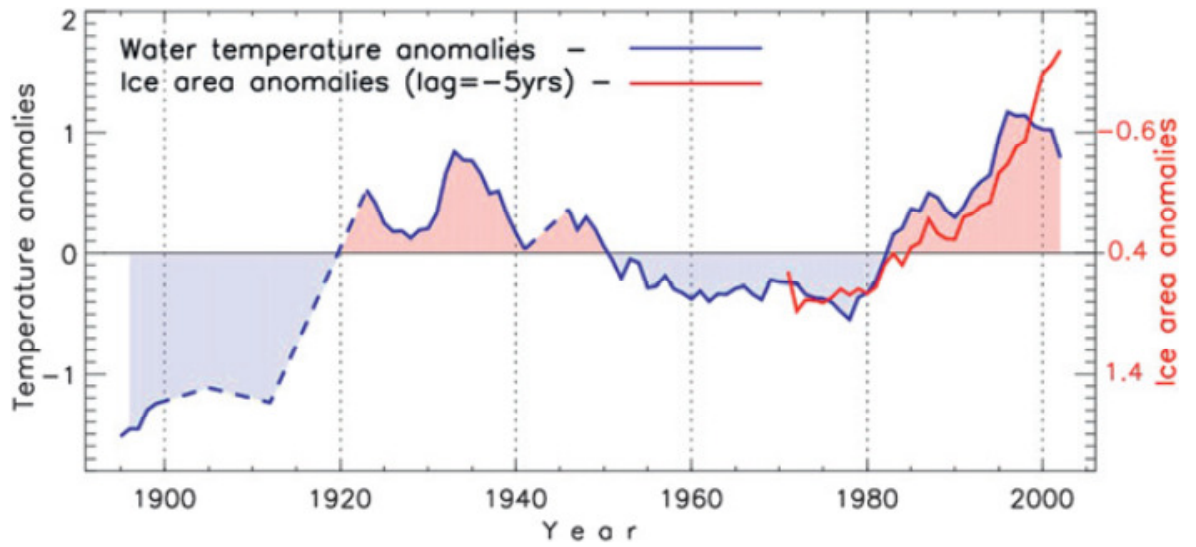

Figure 4: Ice area anomalies and water temperature anomalies since 1900 (from Polyakov et al. 2010).

It has been shown that warm Atlantic water added to the preconditioning that resulted in the extreme decrease in the sea ice extent. The warm water and higher surface temperatures thinned and weakened the ice cap. The major driver however for the record decrease of sea-ice extent in 2007 was anomalous wind that pushed the ice from the Siberian sector to the Canadian sector of the Arctic Ocean (Polyakov personal communication, Polyakov et al. 2010, IASC and Draggan 2010). Climate change is leading to a lengthening of the ice free season and the lengthening is projected to be continuing over the future. Model projections show a decrease of summer sea ice by $50 \%$ till 2100 which would make shipping on the Northern Sea Route possible for an additional two to four months. Future predictions also show that snow cover is projected to decrease further and permafrost thawing is continuing (IASC and Draggan 2010).

The general snow cover has been shrinking substantially since the 1970s (IASC and Draggan 2010) and especially in the northern hemisphere (IPCC AR4 SYR 2007). The temperature of permafrost has been increasing since the last decades by a maximum of $2^{\circ}$ to $3^{\circ} \mathrm{C}$ and therefore is thawing (IASC and Draggan 2010).

Adding to the freshwater inflow into the Arctic Ocean are glaciers, that have been losing mass substantially and which is running of as melt water (IASC and Draggan 2010). Parts of Greenland's coastal regions have been lost this way. Glacier melting during the last decade resulted in a sea level rise of $0.15 \mathrm{~mm}$ to 0.43 $\mathrm{mm} /$ year (IASC and Draggan 2010).

An effect of this melting ice and snow is sea-level rise, a well documented phenomenon and threat to many people especially those living in coastal regions and islands (IPCC AR4 SYR 2007). 
Ocean acidification from increasing atmospheric greenhouse gases is threatening life in the ocean (Gattuso et al. 2011, Hutchins et al. 2007, Orr et al. 2005) and especially the effect on corals and other calciferous life forms is the subject of concern. Research shows however already substantial negative effect on other marine life, such as mussels (Knight 2011).

Another current topic that receives major attention is the role of enhanced high-latitude warming, called polar amplification (PA), in long-term surface air temperature (SAT) variations and modern arctic warming (Bekryaev et al. 2010). Latest research with an extensive new dataset of Arctic SATs showed a high-latitude warming rate of $1.368^{\circ} \mathrm{C}$ for $1875-2008$, and with an exceptionally strong warming rate in the recent decade (Bekryaev et al. 2010).

Changes in the environmental conditions of the Arctic Oceans are affecting important processes such as primary production and have wider implications on species regarding species range shifts, invasive species and diseases.

Climate change is affecting a broad range of biological systems (Dockerty et al. 2003, IASC and McGinley 2010).

\subsection{The marine environment and food webs}

Here, an overview of the marine environment and food webs is given, since the studied zooplankton species are part of this environment and migrating between the different zones described in the following. Moreover, the zooplankton is a very important part of the food chain and should be mentioned here.

The marine ecosystem can be subdivided into several marine environments (Fig. 5). The most common distinction is to divide between the pelagic environment ("open sea") and the benthic environment ("sea bottom") (Lalli and Parsons 1997). The pelagic environment includes the surface waters and extends to the deepest waters. The benthic environment is comprised by the sea floor including shores, lithoral zones, coral reefs and deep seabeds. Another division is made between the oceanic (open ocean) from the neritic (near shore) environment. This definition relies on the distance from land and depth again. The neritic zone extends in general over the shelf areas which vary from area to area but commonly extends to around $200 \mathrm{~m}$ depth. Several subdivisions exist that can be distinguished according to depth and bottom topography (Thurman 1997, Lalli and Parsons 1997) and where zooplankton potentially migrates between.

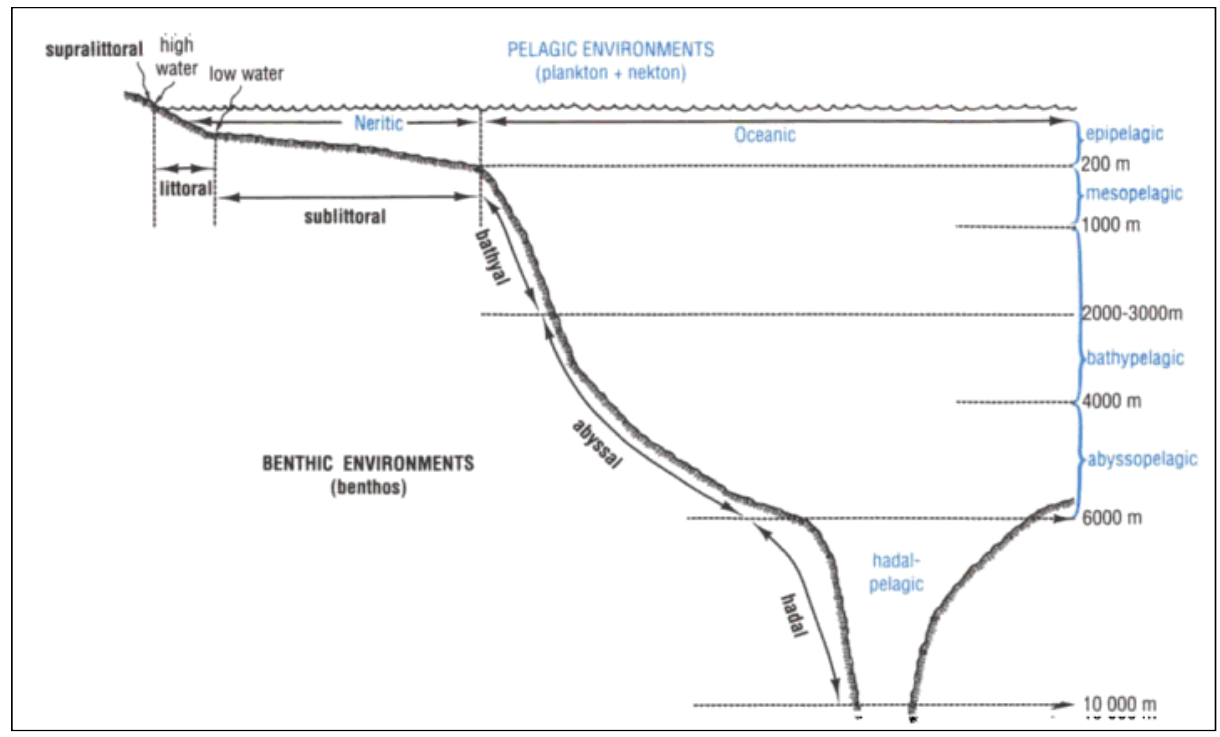

Figure 5: Schematic drawing of the different marine environments (from Lalli and Parsons 1997). 
In order to understand the distribution of life forms in those different zones one has to account for one of the most important sources of energy, which is the Sun. The availability of light represents an important factor and drives life in the upper parts of the ocean and relevant for our project since phytoplankton, the major source of food for zooplankton is highly dependent on the light and therefore phytoplankton is dependent on being able to be at the euphotic surface zones. Three zones with different light intensities are commonly distinguished (Thurman 1997). The euphotic zone is defined as the zone where the light intensity is high enough to maintain photosynthesis. The width of this zone depends on the clarity of the water but is seldom deeper than 100 meters. Second comes the disphotic zone which is characterized by small but still measurable amounts of light. The zone extends to a depth of about 1000 meters. The third zone is called aphotic, characterized by the absence of light, and extends to the ocean floor. Relevant for our project here are mostly the euphotic and disphotic zone as habitat for zooplankton (and phytoplankton).

Photic zones are characterized by biological processes that incorporate carbon and other constituents from the water into tissue and bones. As mentioned, an important process in phytoplankton. The Ocean is in general a sink for carbon since dead organic matter tends to sink to the bottom of the ocean where it accumulates vast amounts of carbon. With mixing and upwelling however some of this carbon is mixed again into higher levels in the water column. This process is referred to as the biological pump and one of the most important processes in the ocean and global carbon cycle (Grant Gross 1995, Grant Gross and Gross 1996, Longhurst and Harrison 1988, Longhurst and Harrison 1989, Thurman 1997). The process has wider effects on productivity of the ocean and beyond. Zooplankton also participates in this cycle since some species feed on detritus, the dead organic matter sinking to the ocean floor. By feeding on the detritus, zooplankton takes up carbon that would otherwise sink to the ocean floor but then is added again to the cycle and potentially incorporated back into other higher trophic organisms.

\subsubsection{Plankton overview}

Plankton, from Greek "planktos" (passively wandering or drifting) inhabits together with nekton the pelagic environment. In comparison to the passively wandering plankton, nekton is capable of swimming actively against the current (Grant Gross and Gross 1996, Thurman 1997). Pelagic organisms can be categorized according to their size. The size of mesozooplankon on which this project focuses here ranges in general from 0.2 to $20 \mathrm{~mm}$ (Lalli and Parsons 1997). Plankton is divided into phytoplankton, bacterioplankton and zooplankton. Phytoplanton is autotrophic ("self-feeding") and makes for the largest biomass community in the marine environment. They live in the euphotic zone where they use light for photosynthesis to synthesize glucose or other sugars as mentioned. Where an organic compound such as glucose is synthesized from carbon dioxide we refer to primary production which is the basis for most oceanic and freshwater food webs. Primary production in the Arctic Ocean is generally considered relatively low and estimates are an average production of $11 \mathrm{~g}$ to $15 \mathrm{~g} \mathrm{C} \mathrm{m}^{-2}$ year $^{-1}$ (Gosselin et al. 1997, Sakshaug 2003). Apart from light, phytoplankton is dependent on nutrients like nitrate, phosphor, silicic acid (Grant Gross 1995, Nihoul 1998, Thurman 1997). Other types of plankton exist but are not of relevance for this study.

Zooplankton, which is in the focus of my research, is heterotroph. This means that they need organic substrates as energy source. Zooplankton can be described depending on the food sources they use or the time they reside in the pelagic environment. Holoplankton (permanent plankton) spends all life cycles in the water column whereas meroplankton is just a temporary resident of the water column. Meroplankton for instance includes fish larvae or larvae stages of clams and snails (Johnson and Allen 2005, Thurman 1997, Lalli and Parsons 1997). Zooplankton can swim and pursue prey actively but most zooplankton fall into the category of suspension feeders. Suspension feeders filter the surrounding water for food particles using tiny hair. Zooplankton feed on phytoplankton, bacterioplankton, other zooplankton (sometimes even cannibalistic), detritus (or marine snow) and nektonic organisms. Their distribution depends heavily on food 
and nutrient availability (Lalli and Parsons 1993) as well as on current movement. Moreover, zooplankton distribution is limited by temperature and salinity gradients. Zooplankton distribution is heavily driven by the mixing of the water column (upwelling and downwelling) since it determines nutrient availability (Lalli and Parsons 1993). Reproduction of zooplankton is generally limited by a small temperature range (Grant Gross and Gross 1996). Another important role of zooplankton is their role in the food web. At the second position, right behind phytoplankton and bacterioplankton, zooplankton feeds on vast amounts of phytoplankton and is preyed upon by a variety of marine organisms such as seabirds, fish and whales (Fig. 6). They are an important part of the food web and play an important role in the process referred to as the biological pump (Grant Gross and Gross 1996).

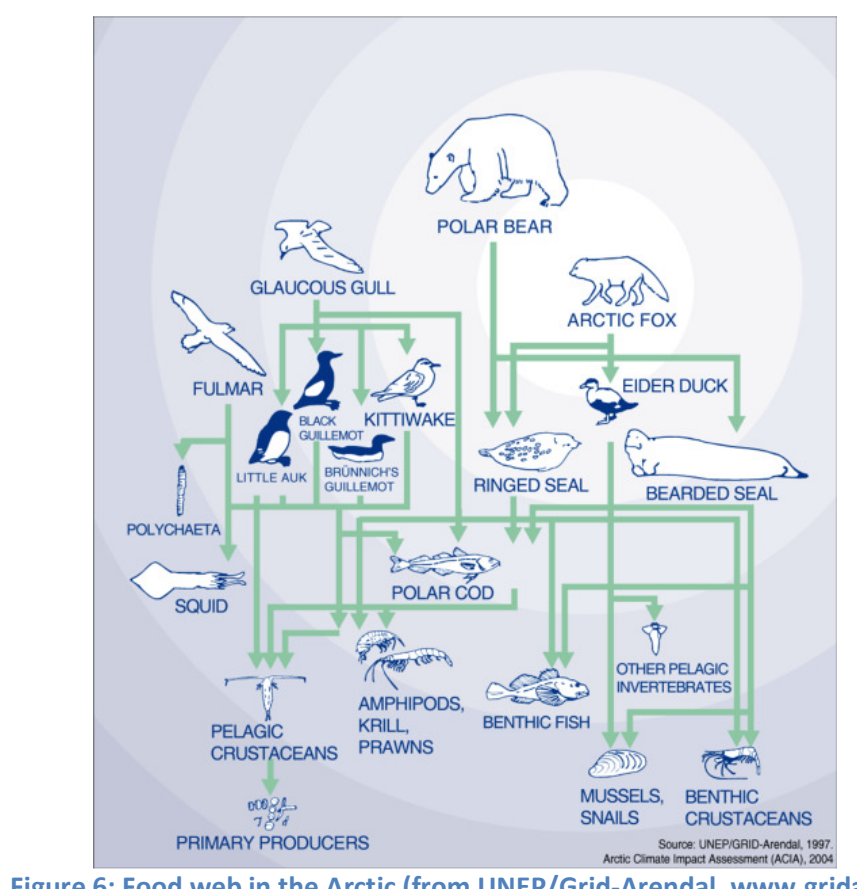

Figure 6: Food web in the Arctic (from UNEP/Grid-Arendal, www.grida.no)

\subsubsection{The process of collecting zooplankton samples}

Prior to the beginning of this thesis I was on a zooplankton sampling trip. Here I want to describe briefly the sampling techniques that are being used to obtain such data and for the last 100 years. Sampling techniques are being updated continuously, however this is the general way and how the data used in our models was obtained.

The first plankton was collected scientifically from the high arctic polar basin in 1893 by Fridtjof Nansen and later described by Sars. Most of the early research in the high arctic was carried out by Russians and Americans before other countries like Germany, Japan or China became interested in this extreme part of the world (Dawson 1978).

The way of collecting zooplankton changed with time and the technical possibilities that were developed. In general some kind of net has to be used. Be it as a simple as a net that is towed behind a ship, a MultiNet plankton sampler that consist of multiple nets that are released in different depths and controlled by computer (Fig.7 and 8), or one of the new and expensive LOKI (Lightframe Onsight Keyspecies Investigation) devices that are towed behind a ship controlled via a computer and use digital underwater cameras to make pictures of plankton that are later on processed via computer algorithms to automatically determine 
species. A major issue with sampling zooplankton is the detection probability of zooplankton and the vertical stratification of samples (Lalli and Parsons 1997). Moreover, in order to catch different zooplankton species one needs according mesh size of the nets.

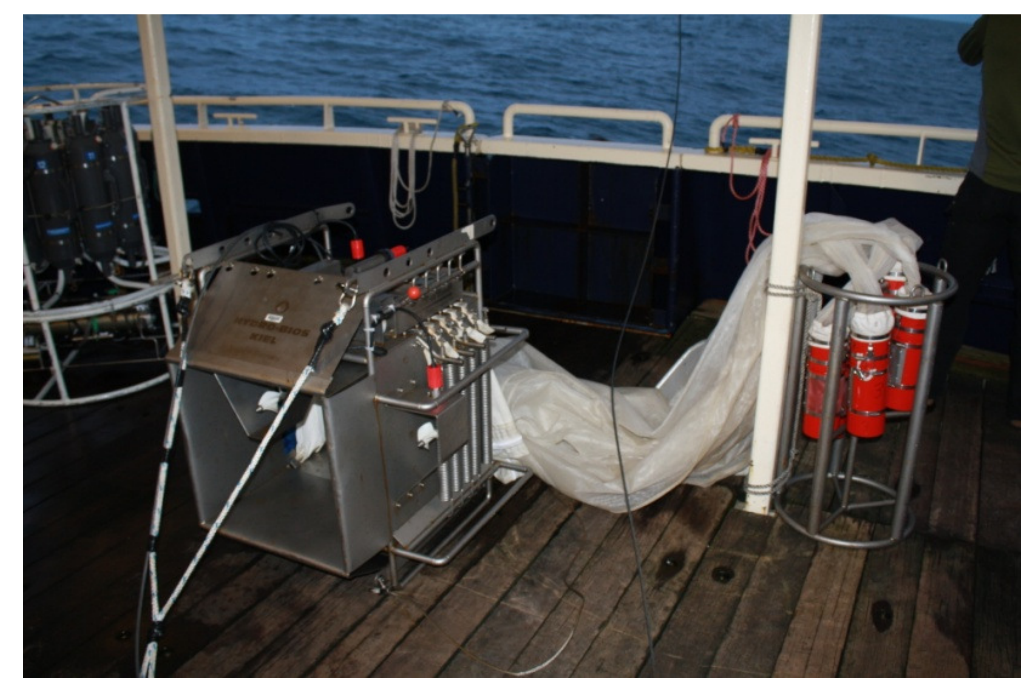

Figure 7: A MultiNet plankton sampler onboard the R/V Tiglax in the Gulf of Alaska.

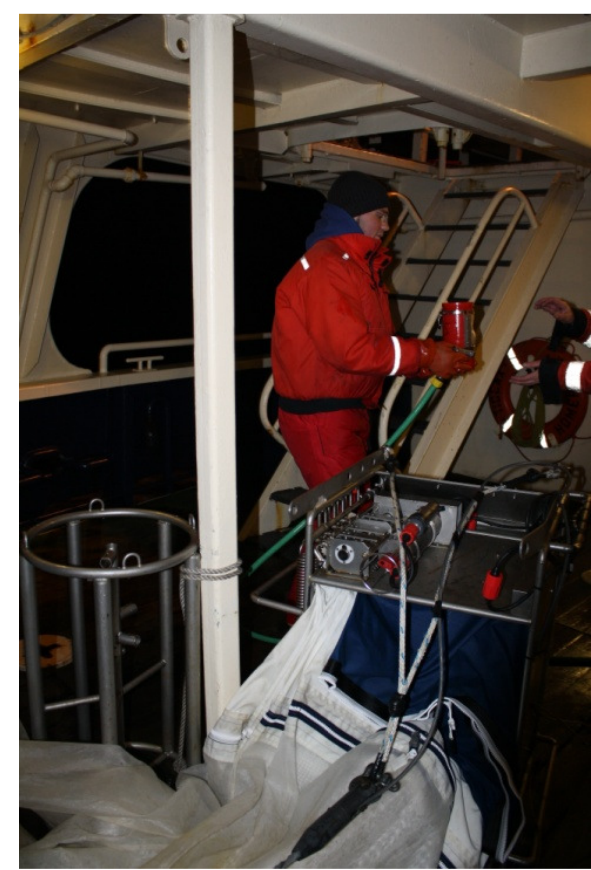

Figure 8: Handling of zooplankton samples that were then further preserved in a $10 \%$ formalin solution.

\subsubsection{Vertical migration of zooplankton and the impact of freshwater sealing}

Vertical migration of zooplankton is basically divided into ontogenetic, seasonal and diurnal (diel) migration. Diel vertical migration normally involves a descent within the water columns of oceans and lakes during the day and an ascent to near surface waters at night (Hays et al. 1994). There are several theories to how and why this migration pattern developed. There are the predator-evasion hypothesis, the changes in light intensity hypothesis, the light-protection hypothesis and the food-availability hypothesis. The most accepted hypothesis however is the predator-evasion hypothesis (Dagg et al. 1997). It describes the movement of zooplankton that migrates into deeper waters during night to avoid predation and migrates 
back to the surface during night to feed on phytoplankton themselves and when predation risk is minimal (Fig. 9). Zooplankton can travel up to $200 \mathrm{~m}$ per hour during this migration (Wiebe et al. 1990). This diel vertical migration is very well studied and performed by many species.

Other forms of migration are ontogenetic migration that describes the migration of zooplankton according to their life stages. This means they spend their life stages in different depths of the ocean (Kobari and Ikeda 2001).

The third form of migration is seasonal migration. This means that zooplankton stays at certain depths, depending on which season it is (Visser and Jonasdottir 1999).

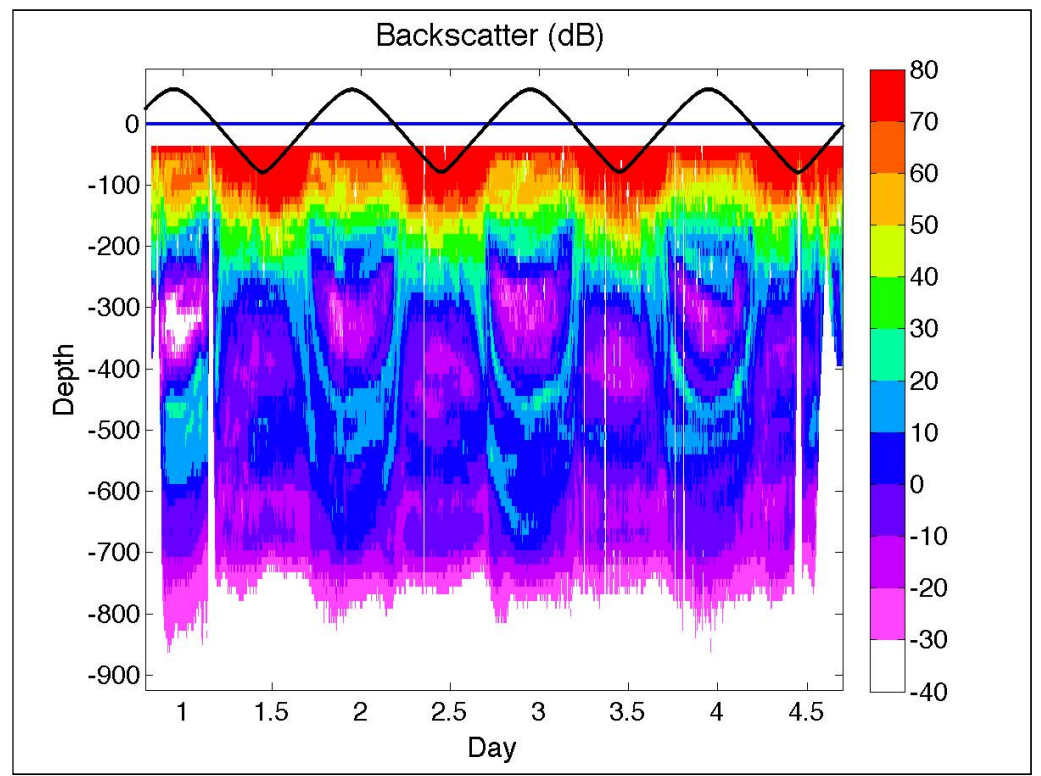

Figure 9: A backscatter image from an Acoustic Doppler Current Profiler (ADCP), a sonar like device used to visualize particle migration in the ocean. Here used to visualize the diel vertical migration of zooplankton. The color depicts backscatter amplitude and the line is the sun elevation angle (from Daniele Bianchi, personal communication).

This project focuses on diel vertical migration. The issue of enhanced freshwater inflow into the Arctic Ocean potentially affects this migration pattern, since physical conditions of ocean layers are changing and subsequent freshwater sealing is occurring. Zooplankton however has to migrate from deeper waters back into surface zones to feed on phytoplankton. This freshwater inflow into the Arctic Ocean is known to have the potential to affect diel vertical migration of zooplankton.

\subsubsection{The studied zooplankton species}

For this project four species of zooplankton were studied. Three types of copepods (Calanus hyperboreus, Metridia longa, Metridia pacifica) and one krill species (Thysanoessa raschii). C. hyperboreus and M.longa are distributed in high abundance throughout the entire Arctic Ocean (Ashjian et al. 2003, Kosobokova and Hirche 2000, Mumm 1993). M. pacifica is predominantly living in the Pacific but is also drifting with currents into the Chuckchi Sea (Batchelder 1985, Brodskii 1950). T. raschii is the most widespread arctic krill and associated with shelf zones (http://www.arcodiv.org/, accessed on 4/5/2012).

Three major criteria were most important for the selection of a species. First criterion was the availability of data for a species. Second criterion was the significance as an Arctic species, and third criterion was the performance of vertical migration. All of the selected species except for $C$. hyperboreus undergo a strong vertical migration. The reason for choosing $C$. hyperboreus however was to have a control group and to find 
out potential changes in the predictions between the species undergoing strong vertical migration and $C$. hyperboreus. Moreover, T. raschii as well as M. pacifica occur only in the outer boundaries of the Arctic Ocean. They were selected to assess a potential range shift due to climate change.

\section{Copepods}

The majority of studied species in the project are copepods. Therefore, an overview is given here on this important group of plankton. Copepods are a group of lower crustaceans. They present the major part of the mesozooplankton in the oceans (Verity and Smetacek 1996). Within the marine zooplankton they account for $90-97 \%$ of all biomass (Bradford-Grieve et al. 1999). Marine copepods are known to be pelagic, benthopelagic or hyperbenthic, benthic, or coexisting with other animals (Bradford-Grieve et al. 1999). In the Arctic Ocean, the biomass of marine zooplankton is dominated by copepods of the order calanoida (Ashjian et al. 2003, Mumm et al. 1998). Calanus species dominate the biomass in the Arctic Ocean followed by M.longa (Ashjian et al. 2003, Hirche and Mumm 1992, Mumm 1993). Copepods play a central role in pelagic food webs, and thus are very important for marine ecosystems (Grant Gross and Gross 1996). They are the link between phytoplankton and consumers on a higher trophic level, such as bowhead whales (Balaena mysticetus), arctic cod (Boreogadus saida) and planktivorous seabirds such as little auks (Alle alle) and least auklets (Aethia pusilla) (Conover et al. 1990, Karnovsky et al. 2003, Kwasniewski et al. 2003, Pittman and Huettmann 2006). Zooplankton undergoes a development in a specific life cycle, starting with the nauplii larvae stage before they moult into the copepodite stage. After several copepodite stages they reach adulthood. Overall the life cycle includes 12 life stages after hatching. Adults can measure from 0.3 to $2 \mathrm{~cm}$ in length. Copepods are found from the surface to the bottom of the ocean but have a preferred depth range in which they are distributed. There is little known how long species in the Arctic live however 3-4 years are the current understanding.

\section{Euphausiids}

One of the studied species, Thysanoessa raschii is an euphausiid. Therefore euphausiids are described here in more detail. Euphausiids belong to the crustaceans as well. Similar to copepods, the euphausiidae (krill) are very important part of the food chain (Agersted et al. 2011) and prey for many animals including seabirds ( Huettmann et al. 2011, Schreiber and Burger 2002). After the copepod group, they range mostly second or third place, however they are not common in the arctic's central basin. They perform a diel vertical migration and are often distributed in big swarms, making their appearance patchy. Similar to copepods, euphyausiids moult into different stages when growing, casting off their exoscelleton. They undergo three larvae stages (nauplius, calyptopis and furcilia) and normally there are 13 different life stages in euphausiids. Euphausiids are found from the surface to the bottom of the ocean but have a preferred depth range in which they are distributed. The generation length of euphausiids in the arctic is about 3-5 years (http://www.arcodiv.org/, accessed on 4/5/2012), but little is known and more research has to be carried out in that direction. In comparison to copepods, krill is much bigger (as adults, 1-15 cm (http://www.arcodiv.org/, accessed on 4/5/2012). Commercially they play only a minor role (Nicol and Foster 2003) with some experimental fishing off British Columbia, Canada and the Gulf of St. Lawrence.

The taxonomy presented here for the following species follows the Integrated Taxonomic Information System (ITIS).

Calanus hyperboreus (Krøyer, 1838), Taxonomic serial number (TSN): 85266

Taxonomy:

Animalia (Kingdom)

Arthropoda (Phylum)

Crustacea (Subphylum)

Maxillopoda (Class)

Copepoda (Subclass)

Neocopepoda (Infraclass)

Gymnoplea (Superorder) 
Calanoida (Order)

Calanidae (Family)

Calanus (Genus)

\section{Distribution and Habitat}

C. hyperboreus (Fig. 10) is a polar species of the open ocean and is associated with cold waters of subzero temperatures (Brodskii 1950). C. hyperboreus can be found in abundance in the Arctic Ocean and also reproduces there (Ashjian et al. 2003). C. hyperboreus can also be found in the North Atlantic (Brodskii 1950, Conover 1988). It inhabits the Barents Sea and the Canadian Arctic (Conover and Huntley 1991, Thibault et al. 1999). Deep-water areas such as the Greenland Sea and the Nansen Basin are inhabited as well. The distribution range ends however at the northern part of the Chuckchi Sea. C. hyperboreus is following a pattern of seasonal ontogenetic migration (Hirche 1997). C. hyperboreus is herbivorous and has a generation length of about 3 years (in the central Arctic Ocean) (Dawson 1978, Hirche 1997, Hirche and Mumm 1992).

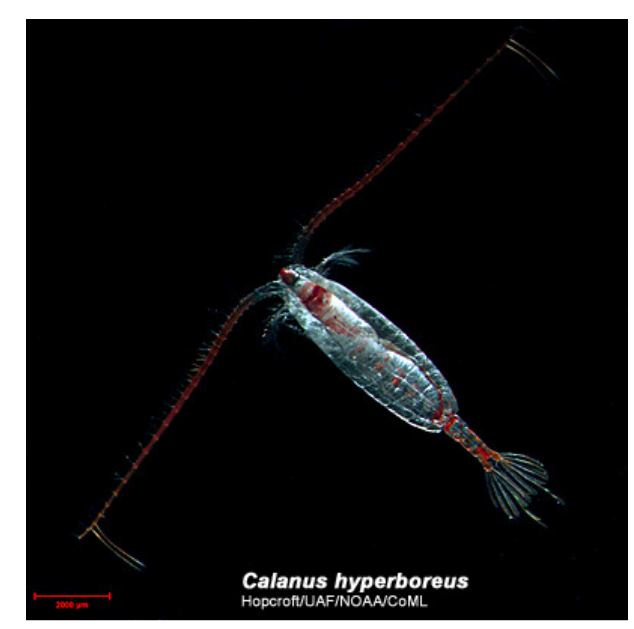

Figure 10: C. hyperboreus. Photo credit: Prof. Russel Hopcroft, University of Alaska Fairbanks.

Metridia longa (Lubbock, 1854), Taxonomic serial number (TSN): 85746

Classification:

Animalia (Kingdom)

Arthropoda (Phylum)

Crustacea (Subphylum)

Maxillopoda (Class)

Copepoda (Subclass)

Neocopepoda (Infraclass)

Gymnoplea (Superorder)

Calanoida (Order)

Metridinidae (Family)

Metridia (Genus)

\section{Distribution and Habitat}

M.longa is an oceanic bathypelagic species of moderate depths (Brodskii 1950) and lives omnivorous (Hirche and Mumm 1992). M. longa performs a strong diel vertical migration (Hopcroft et al. 2005). M.longa (Fig. 11) can be found in the Arctic Ocean and its epicontinental Seas, Greenland, the Norwegian Seas and in the North Atlantic. It was also reported near the Alaska Coast and as far East as the Chuckchi Sea. 


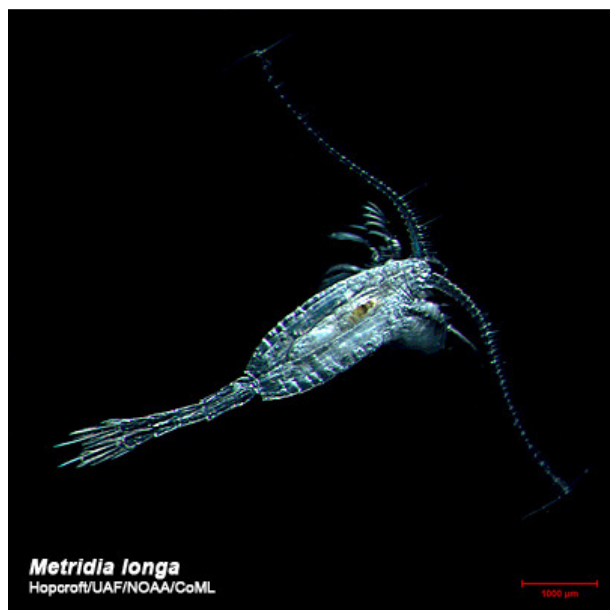

Figure 11: M. longa. Photo credit: Prof. Russel Hopcroft, University of Alaska Fairbanks.

Metridia pacifica (Brodskii, 1950), Taxonomic serial number (TSN): 85748

Taxonomy:

Animalia (Kingdom)

Arthropoda (Phylum)

Crustacea (Subphylum)

Maxillopoda (Class)

Copepoda (Subclass)

Neocopepoda (Infraclass)

Gymnoplea (Superorder)

Calanoida (Order)

Metridinidae (Family)

Metridia (Genus)

\section{Distribution and Habitat}

M. pacifica (Fig. 12) is an oceanic bathypelagic species similar to M. longa (Brodskii 1950). M. pacifica performs a strong diel vertical migration and is preyed on by planktophagous fish (Batchelder 1985, Brodskii 1950). M. pacifica is a common, medium-sized grazing copepod distributed over the entire subarctic Pacific and its marginal seas (Minoda 1971, Batchelder 1985, Hirakawa and Imamura 1993, Liu and Hopcroft 2006). This species prefers warm waters near the surface.

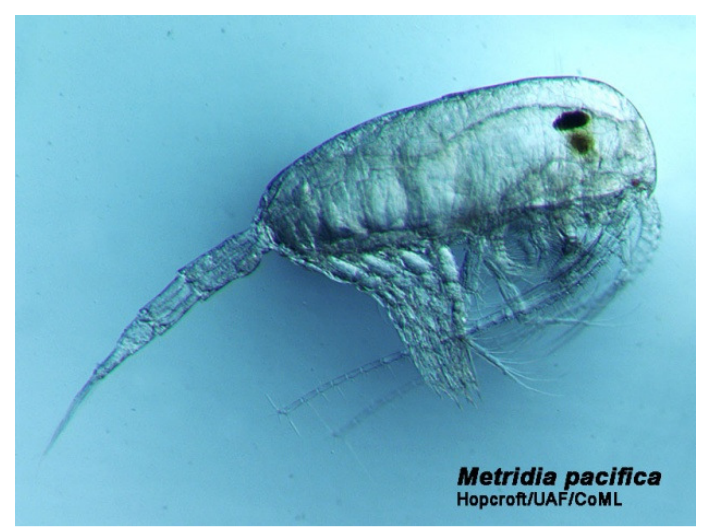

Figure 12: M. pacifica. Photo credit: Prof. Russel Hopcroft, University of Alaska Fairbanks. 
Thysanoessa raschii (Sars, 1864), Taxonomic serial number (TSN): 660852

\author{
Animalia (Kingdom) \\ Arthropoda (Phylum) \\ Crustacea (Subphylum) \\ Malacostraca (Class) \\ Eumalacostraca (Subclass) \\ Eucarida (Superorder) \\ Euphausiacea (Order) \\ Euphausiidae (Family) \\ Thysanoessa (Genus)
}

\title{
Distribution and Habitat
}

T. raschii (Fig. 13) is the most widespread arctic krill (http://www.arcodiv.org/, accessed on 4/5/2012). $T$. raschii inhabits panarctic and subarctic coastal waters (above $200 \mathrm{~m}$ ) and can be abundant in coastal embayments. T. raschii is associated with areas where Atlantic or pacific water flow into the Arctic Ocean. It is not common in the Central Basin but is associated with near-shelf areas(http://www.arcodiv.org/, accessed on 4/5/2012. There is not much known about the life expectancy most likely is 2-3 years.

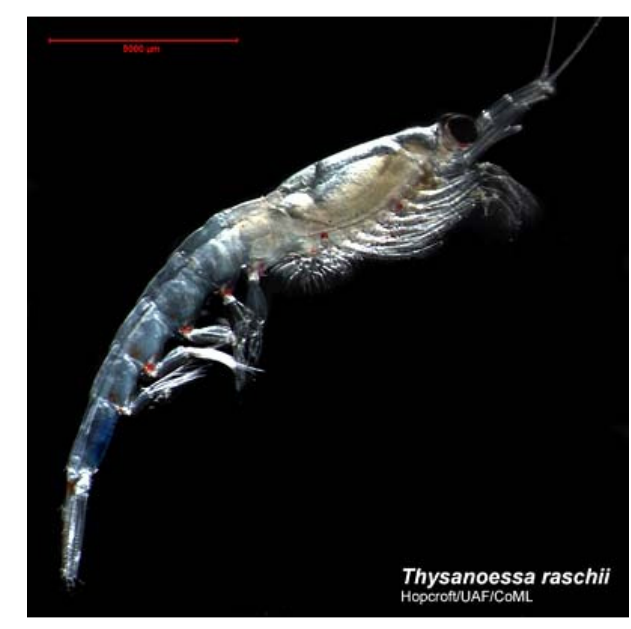

Figure 13: T. raschii. Photo credit: Prof. Russel Hopcroft, University of Alaska Fairbanks.

\subsection{Future climate - An overview about future climate scenarios}

The Intergovernmental Panel on Climate Change (IPCC, www.ipcc.ch) is the overarching institution, established by the United Nations Environment Programme (UNEP) and the World Meteorological Organization (WMO), dealing with the changing climate and establishing guidelines as well as to create a platform to enhance communication between scientists and policy makers. The major part of the work however, is the establishment of scientific guidelines describing the best knowledge on past, present and future climate. The IPCC is probably best known for the publication of the so called assessment reports that summarize findings of the various specialized working groups.

The latest official document summarizing climate change from the IPCC is the forth assessment report, IPCC AR4 SYR (2007) with the fifth assessment report currently being worked on. In the fourth assessment 
report, so called SRES (Special Report on Emissions Scenarios) scenarios were chosen to describe low, medium and high emission scenarios. They were developed and published by the IPCC (2000). The scenarios have in common that they each describe a certain global surface temperature warming. They are based on assumptions from the Kyoto protocol and therefore are outdated. The low emission scenario is known as B1, the medium emission scenario as A1B and the high emission scenario as A2 (Fig. 14).

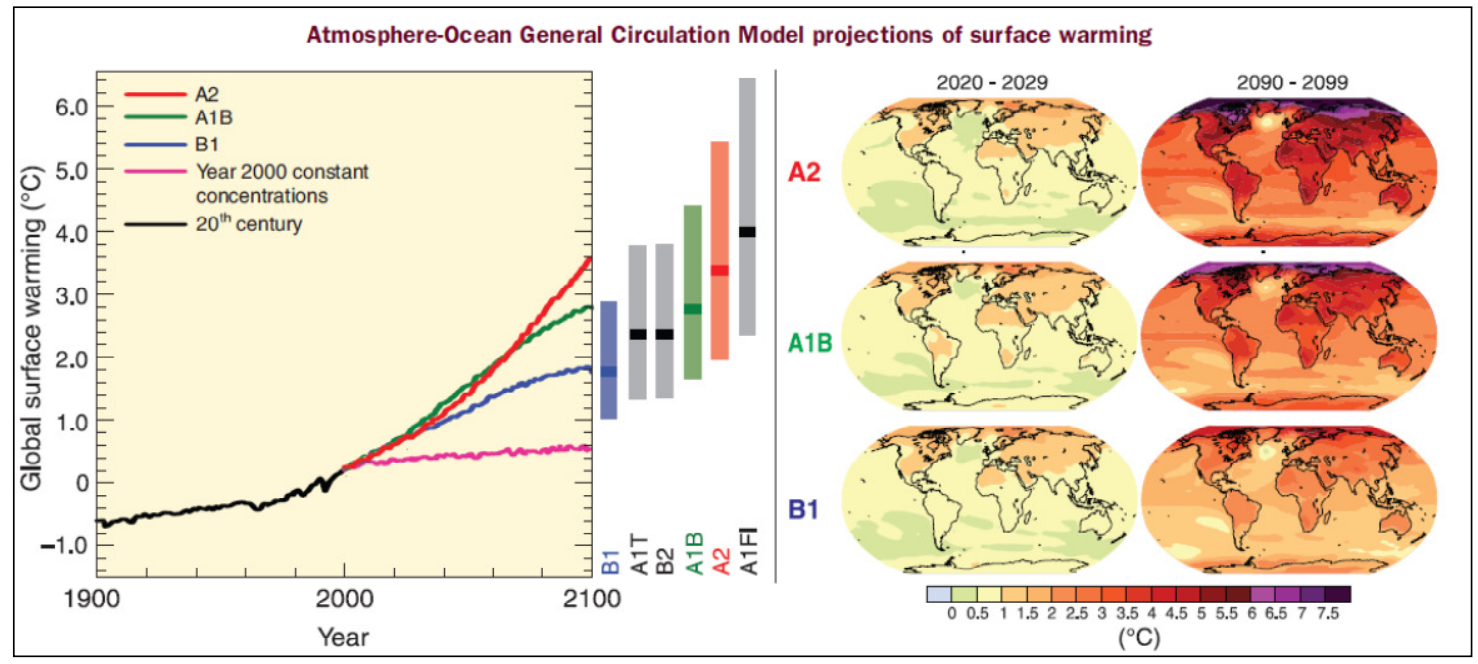

Figure 14: The different emission scenarios in the fourth assessment report of the IPCC AR4 SYR (2007).

Three main scenarios have been developed since the IPCC started its work and they all deal with different values for growth in different sectors like population, income, energy intensity and $\mathrm{CO}_{2}$ emissions (Fig. 15). The earliest scenarios were called SA90-Scenarios (IPCC 1990). The second generation was called IS92Scenarios (IPCC 1995). The third generation of scenarios and currently still in use are the SRES-Scenarios (IPCC 2000).

\begin{tabular}{|c|c|c|c|}
\hline Aspect & SA90-Scenarios (IPCC, 1990a) & IS92-Scenarios (IPCC, 1992a) & SRES-Scenarios (IPCC, 2000a) \\
\hline Number of scenarios & $\begin{array}{l}4 \text {, incl. } \\
1 \text { non-intervention }\end{array}$ & $\begin{array}{l}6 \text {, incl. } \\
5 \text { non-intervention }{ }^{a}\end{array}$ & $\begin{array}{l}\text { 40, with } 6 \text { illustrative scenarios } \\
\text { all non-intervention }\end{array}$ \\
\hline $\begin{array}{l}\text { Structure of scenario spectrum } \\
\text { (based on projected } \mathrm{CO} 2 \\
\text { equivalent emissions from } \\
1990 \text { to the year 2100) }\end{array}$ & & & \\
\hline $\begin{array}{l}\text { Projections of key variables } \\
\text { (units) }\end{array}$ & \multicolumn{3}{|c|}{ Range of projections (growth rate $1990-2100$ in percent per year) } \\
\hline Population (cap.) & 0.7 & $0.2-1.1$ & $0.3-1.0$ \\
\hline Income (US\$ 1990) & 1.5 & $1-2.3$ & $1.3-2.7$ \\
\hline GDP (US\$1990) & 2.2 & $1.2-3$ & $2.2-3.0$ \\
\hline Energy intensity (J/US\$ 1990) & -1 to -1.6 & -0.8 to -1.2 & -0.8 to -2.2 \\
\hline Carbon intensity $(\mathrm{gC} / \mathrm{I})$ & 0.1 to -1.2 & -0.2 to -0.7 & 0.0 to -1.9 \\
\hline $\mathrm{CO}_{2}$-Emissions (gC) & 1.3 to -0.6 & 1.6 to -0.25 & 1.5 to -0.3 \\
\hline
\end{tabular}

Figure 15: The diversity of IPCC scenarios over time (from Girod et al. 2009).

However, there has been substantial criticism on the SRES-Scenarios pointing out major flaws in definitions and applicability (e.g., Girod et al. 2009).

Since then models have been updated and more complex processes have been added. Moss et al. 2010 pointed out the need for new scenarios. The IPCC then requested input from the scientific community on the development of new models. The new scenarios that were developed are called Representative Concentration Pathways or short RCP and are based on radiative forcing. The new low emission scenario leads to a radiative forcing of $2.6 \mathrm{~W} / \mathrm{m}^{2}$, the medium scenario to $4.5 \mathrm{~W} / \mathrm{m}^{2}$ and the high emission scenario to $8.5 \mathrm{~W} / \mathrm{m}^{2}$ (Fig. 16, van Vuuren et al. 2011.) 


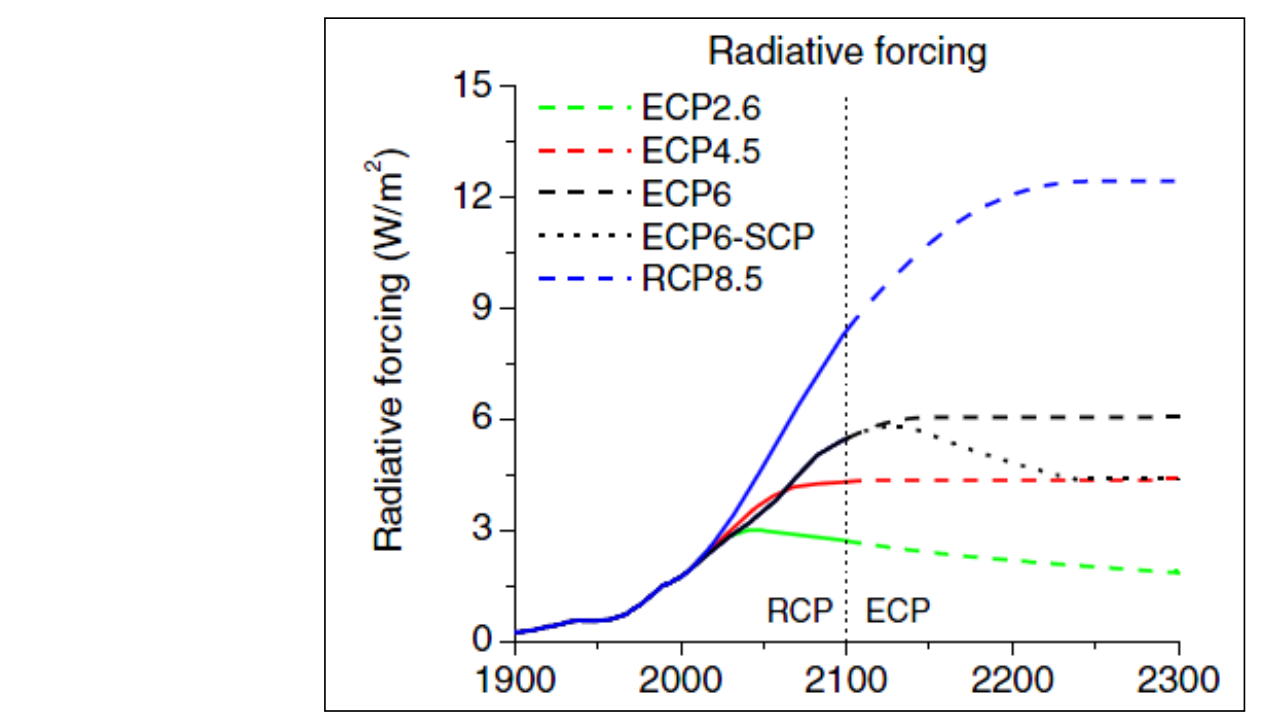

Figure 16: The new Representative Concentration Pathways scenarios or short RCP currently written up in the $5^{\text {th }}$ assessment report of the IPCC (modified from Van Vuuren et al. 2011).

The World Climate Research Programm (WCRP) and the Program for model Diagnosis and Intercomparison (PCMDI) are working hand in hand with the IPCC and were the major drivers for the development of the new scenarios. The new scenarios were assembled in the so called Coupled Model Intercomparison Project Phase 5 (CMIP5) (http://cmip-pcmdi.llnl.gov/cmip5/) and are currently under review. This part must not be mistaken with the actual model output. The WCRP, PCMDI and the CMIP5 developed the framework and the guidelines for the model. The actual model output that predicts future climate however comes from the various institutions that are situated in the leading climate research countries. Such institutions and models are for instance the Canadian Earth System Model 2 (CanESM2) developed by the Canadian Centre for Climate Modelling and Analysis or the Max Planck Institute Earth System Model (MPI ESM) developed by the Max-Planck-Institute in Germany. Such models represent the state of the art in climate research and are currently used to develop the fifth assessment report by the IPCC.

\section{Methods}

Here, a Geographical Information System (GIS) and machine learning algorithms were used to predict presence/random absence, relative index of depth and life stage distribution maps of selected zooplankton species. Natural ocean layers were predicted that are important as boundaries for the zooplankton species and migration in the Arctic Ocean. Predicted ocean layers were also used as predictor variables for the predictions of the mentioned zooplankton parameters. A best-pooled scenario was developed which is the state of the art and based on a multitude of $107 \mathrm{GIS}$ data layers. Moreover, future scenarios were predicted based on future climate data from the Canadian Earth System Model 2 and for the low emission scenario RCP26 and high emission scenario RCP85 for the two time steps 2010 and 2100 . Based on those five different models the predicted change in the presence/random absence, relative index of depth and life stage distribution of zooplankton was evaluated.

The predicted presence/random absence models were based on observed presence data. No confirmed absence data was available and absence data was applied randomly in GIS. Therefore, the predicted layers were named predicted presence/random absence. The predicted relative index of depth layers were based on sampled depths from plankton tows. However, if processed in a machine learning algorithm like TreeNet, the output data is a relative index of the input data. Therefore, the layers were named as predicted relative index of depth. 
The predicted life stage distribution layers are based on observed life stages as determined by the scientists responsible for the analysis of the data sets. The different copepodite life stages were summarized to one group copepodites.

In the following the data sets used for our predictions are described.

\subsection{GIS data layers}

The data that was used in the predictions was divided into four groups.

\section{Group 1, ocean layer data set}

Group 1 was a unique dataset on physical oceanography that consisted of pooled data from the early 20th century to the 21 st century. The dataset was collected from different platforms such as drift stations and ship based measurements. The dataset had an amazing coverage and was compiled by Prof. Igor Polyakov from the International Arctic Research Center and kindly provided to us (Fig. 17). A subset of the data set where only measurements obtained in August were used was created as well as a GIS map of the data.

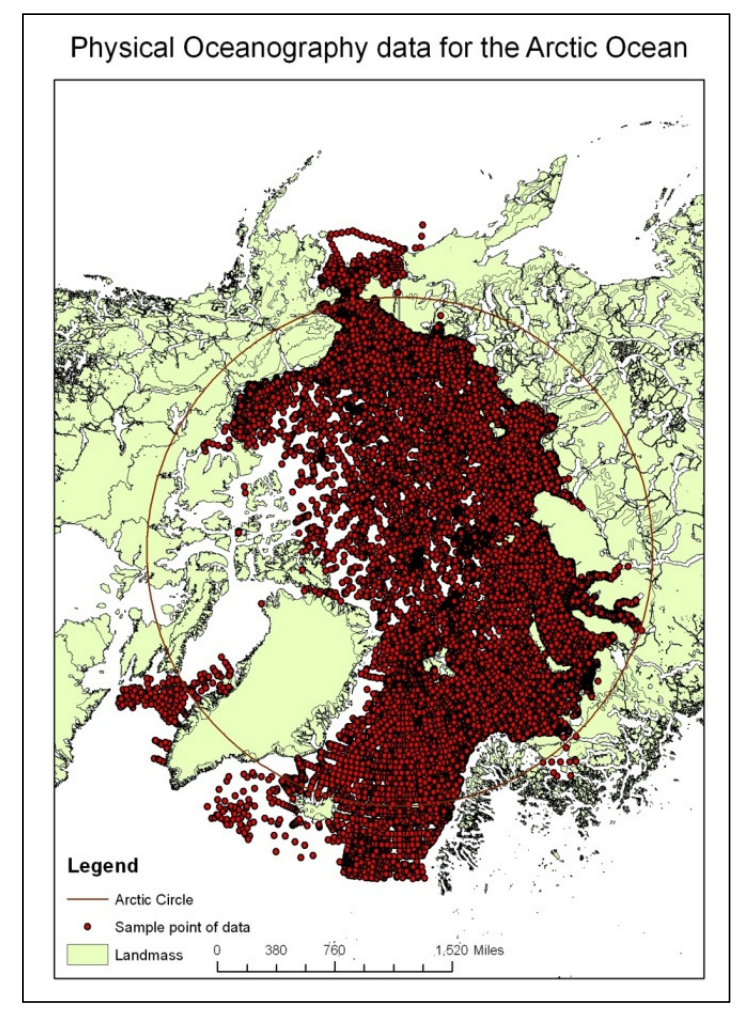

Figure 17: The complete data set that was provided by Prof. Igor Polyakov.

\section{Group 2, zooplankton data set}

Group 2 was an extensive dataset on zooplankton. The data was collected entirely from the open access platform OBIS (http://www.iobis.org/) on the internet. A subset from this data was created showing only zooplankton points for August (Fig. 18) 


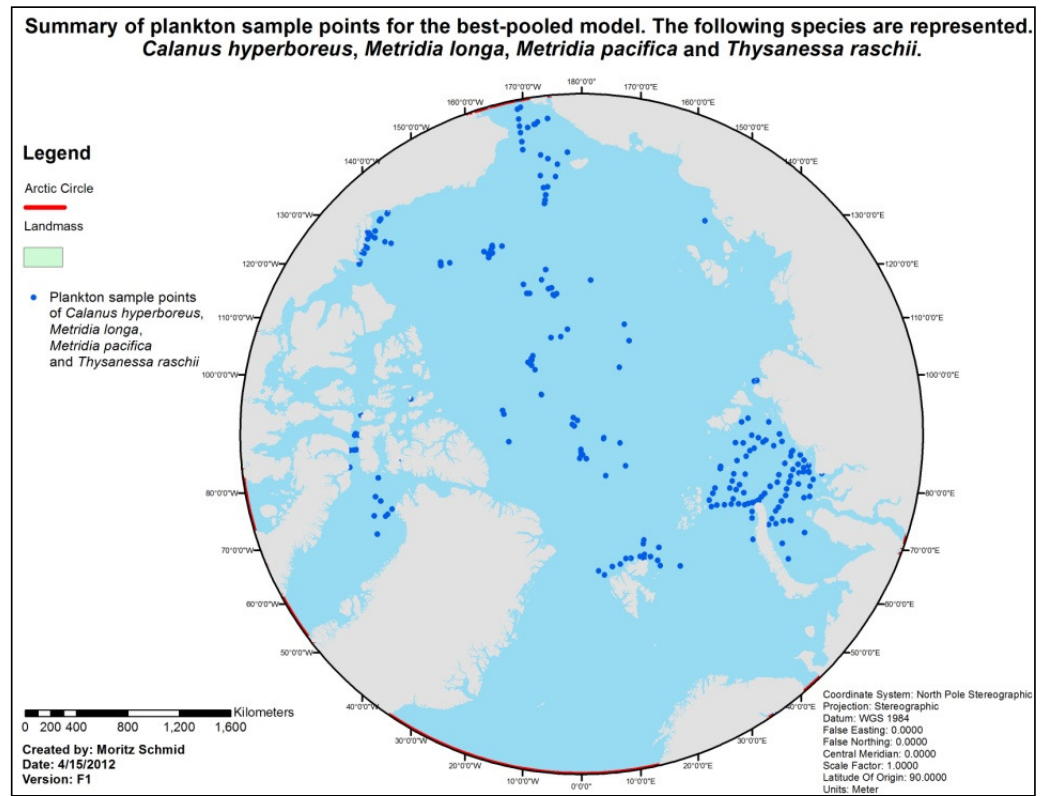

Figure 18: Summary map of the zooplankton sample points. Sample points of different species are overlapping, making only one point visible where points of two different species are though.

\section{Group 3, best-pooled (model) data}

Group 3 was the most extensive dataset on environmental variables and other factors for the Arctic Ocean that I know of. 103 environmental predictors were collected describing the state of the art in the Arctic Ocean. In addition four ocean layers were predicted using those 103 predictors and added to the predictor pool for further model development. Environmental data that was used included for example bathymetry, freshwater inflow, sea ice cover, salinity and sea surface temperature (SST) as well as temperature in different depths (Fig. 19). For a complete list of predictors in this data set please consult the appendix, chapter 6.1 (Table 6).

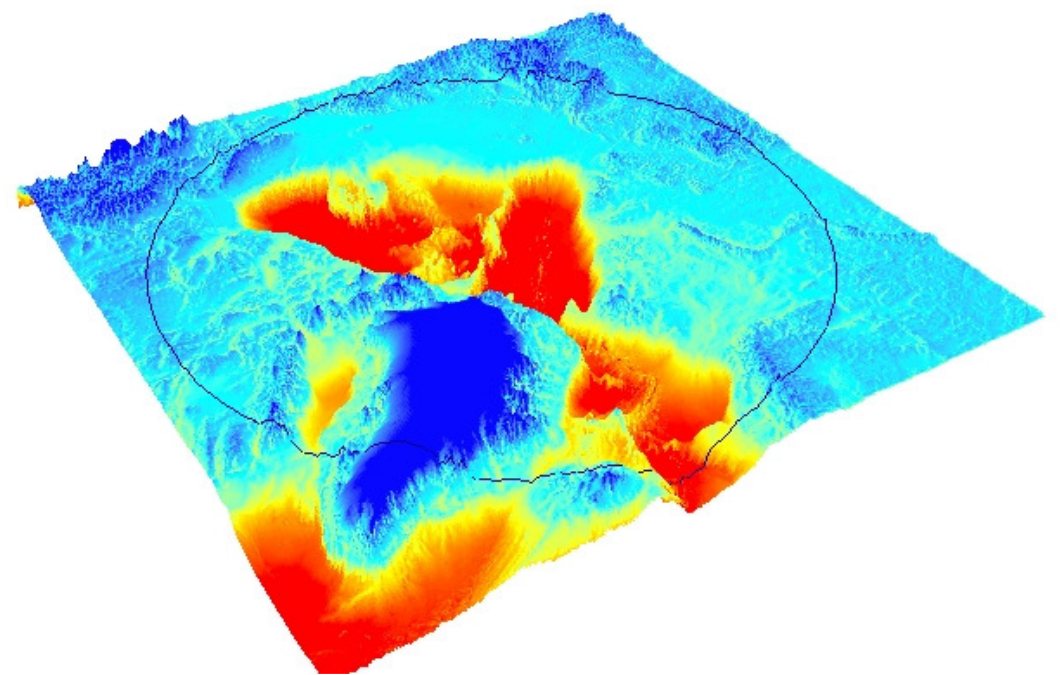

Figure 19: Digital elevation model (DEM) of the Arctic Ocean and adjacent landmass. Here used as bathymetric layer. Red color delineates deep ocean and blue delineates higher altitude. Note the big blue area in the lower half of the graph delineating Greenland. The inserted circle is the Arctic Circle at $66^{\circ} 33^{\prime} \mathrm{N}$. 


\section{Group 4 Future climate data from the Canadian Earth System Model 2}

Group 4 was the future climate data from the CanESM2. Data for chlorophyll concentration, nitrate concentration, sea surface salinity, sea surface temperature and runoff were acquired and for the time steps 2010 and 2100 as well as for the two scenarios: Low emission (RCP26) and high emission (RCP85). This data will be visualized later in this chapter. Therefore I do not provide a graph here.

\subsection{The modeling method: machine learning}

The modeling method utilized here in this project is a type of data mining via machine learning algorithms. Data mining and machine learning have been used by insurance companies as well as in companies like Google, where large quantities of data have to be analyzed following a pattern, for some time. They have been mostly neglected in ecology until recent years though. Nowadays data mining and machine learning algorithms are applied to a variety of research questions (e.g., Kononenko and Kukar 2007 and Huettmann et al. 2011 for seabird distributions).

The modeling platform that was used is called the Salford Predictive Miner, a product of Salford Systems (http://www.salford-systems.com/). There are several applications combined in this software that can be used and that are based on different algorithms.

For this project the TreeNet application was used to model categorical data as well as continuous data. TreeNet and other machine learning algorithms and software are described very well in the literature and with a multitude of research articles and case studies (e.g., Cutler et al. 2007, Elith et al. 2008, Hochachka et al. 2007, Craig and Huettmann 2009, Breiman 2001, Humphries et al. 2010, Friedman 1999; 2002, Oppel and Huettmann 2010).

The TreeNet algorithm is similar to a long series expansion. A characteristic of those expansions and also TreeNet $^{\mathrm{TM}}$ is, that they get more accurate the longer the expansion continues (official Salford Systems TreeNet $^{\mathrm{TM}}$ manual). The interesting part and where TreeNet $^{\mathrm{TM}}$ has its name from is represented in the formula below. In the expansion below each $T\left(T_{1} \ldots T_{M}\right)$ is a small regression tree.

$$
F(X)=F_{0}+\beta_{1} T_{1}(X)+\beta_{2} T_{2}(X)+\ldots+\beta_{M} T_{M}(X)
$$

(from the Salford Systems TreeNet ${ }^{\mathrm{TM}}$ manual (Salford Systems 2003))

The longer the expansion continues, the more of the variance in the dataset is mathematically explained and therefore produces a better model.

\subsection{Workflow}

For the first time, ocean layers in the Arctic Ocean were predicted based on a unique and extensive dataset of physical oceanography. The models referred to here are statistical models according to the description of TreeNet in chapter 2.2. A model is trained on a data set and for a number of observed events. Then the model is predicted to the research area and provides a full coverage of the predicted events, exceeding the number of observed events, e.g. events in the future.

Moreover, presence/random absence models were developed that indicate where the studied zooplankton species is most likely to be present in the Arctic Ocean. Apart from that, the first spatially explicit models known to science were developed that describe the depth in which the studied zooplankton species are most likely to be at, as well as their distribution of life stages. 
This was not only done for one present day scenario. Five different scenarios were modeled and for future climate data. First, ocean layers were model-predicted using the most up to date data from various open access sources, earlier referred to as group 3 of the collected data (see appendix, table 6.1 for a complete list of the data), in a best-pooled model attempt. Further referred to as the best-pooled model.

103 predictors were collected to model-predict the ocean layers $\mathrm{H} 1, \mathrm{H} 2, \mathrm{H} 3$ and $\mathrm{W} x$ for the best-pooled model (Fig. 20).

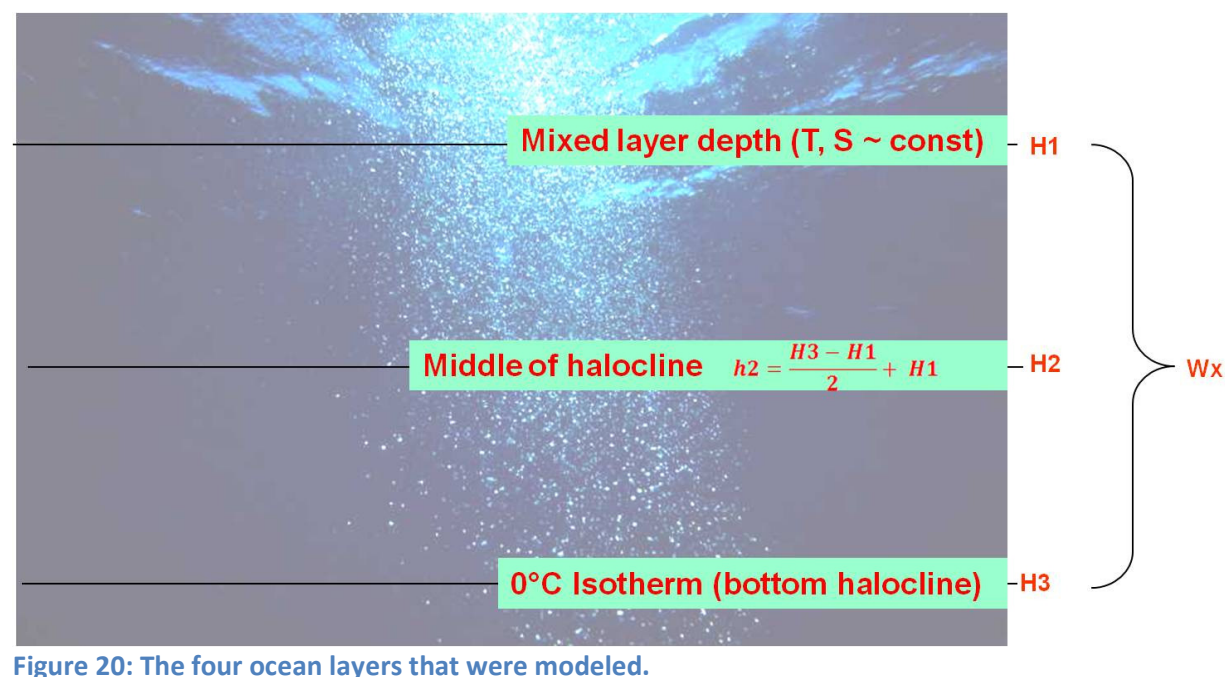

It was decided to model this set of ocean layers after discussions and input of expert knowledge by Professor Igor Polyakov from the International Arctic Research Center at the University of Alaska Fairbanks. Those ocean layers were predicted because they are the boundaries and layers that the plankton has to cross for diel vertical migration and a change in those would most likely affect the migration.

Four variables were assigned to the ocean layers. $\mathrm{H} 1, \mathrm{H} 2, \mathrm{H} 3$ and $\mathrm{Wx} . \mathrm{H} 1$ is the lower boundary of the mixed layer depth. In this layer atmospheric disturbance causes mixing of the water, giving the mixed layer its name. $\mathrm{H} 2$, the middle of the halocline is important because in this part of the ocean a strong gradient in salinity and temperature separates water layers. $\mathrm{H3}$, the isotherm is important, because beneath it flows saltier and therefore denser as well as warmer Atlantic water. Wx summarizes the overall width of the described water column.

In the following the development of the first ocean layer models is described in more detail and with some focus on the TreeNet procedure.

TreeNet is capable of handling many predictors but only predicting one response variable. Therefore, in the first case, the response variable was the depth of the $\mathrm{H} 1$ ocean layer and with all 103 variables of the environmental data set being predictor variables. In order to be able to input the data into the modeling program Salford predictive miner, the data had to be in a certain format. Therefore the points of known and observed depth from the $\mathrm{H} 1$ ocean layer were intersected with the 103 environmental layers in ArcGIS, assigning a value of each environmental variable to each point in the $\mathrm{H} 1$ ocean layer. The result was an excel table containing the latitude and longitude of each data point of the $\mathrm{H} 1$ ocean layer data set and the associated environmental values. Based on this table, the Salford predictive miner built a model that explained the ecological niche of the modeled variable. At this point, a trained TreeNet model was developed. This model was then applied to the complete study area and resulted in a predicted layer of the response variable $\mathrm{H} 1$ and for the entire study area (Fig. 21). 


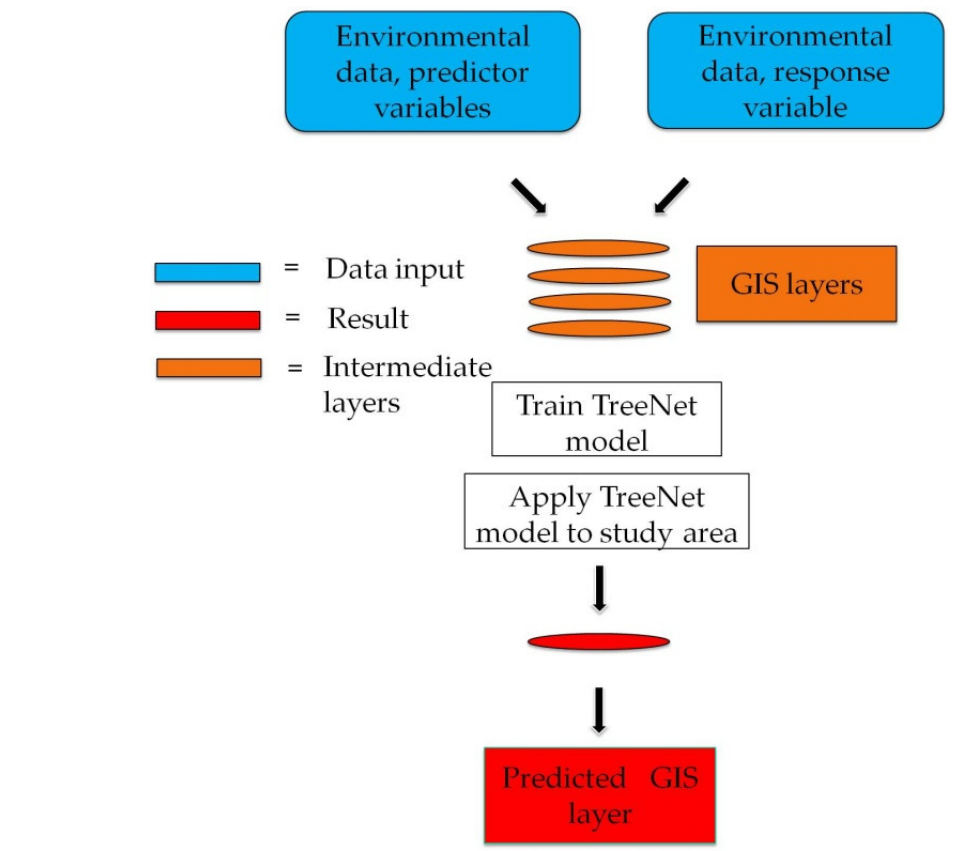

Figure 21: Workflow of the model development and application on the research area.

After the four ocean layers $\mathrm{H} 1, \mathrm{H} 2, \mathrm{H} 3$ and $\mathrm{Wx}$ were predicted in this way and for the pan-arctic research area, they were added as predictors into the next models. By using the above procedure and adding the four new predictor layers to the 103 predictors that were used before, it was possible to model the new presence/random absence, most likely depth and life stage layers for the zooplankton species: $C$. hyperboreus, M.longa, M. pacifica and T. raschii, with the new extended data set of 107 predictors (Fig. 22).

Models derived from this best-pooled dataset of 107 predictors represent the state of the art as well as best known model and practice, therefore referred to as the best-pooled model. Since this type of modeling and in its completeness was carried out for the first time known, a major goal was to develop the workflow and the multitude of steps involved in the modeling.

Second, the ocean layers, presence/random absence, most likely depth of zooplankton and life stages were model-predicted for future climate scenarios, using the newest and most up-to-date future data available (Fig. 22). This data was produced according to guidelines from the CMIP5.

For this project it was decided to utilize the Canadian Earth System Model 2 (CanESM2) developed by the Canadian Centre for Climate Modelling and Analysis: http://www.ec.gc.ca/. Reasons to choose the CanESM2 were availability and access to data. There has not been much evaluation of the new CMIP5 derived models. However, the purpose of this thesis is to create a baseline and to show a possible and general trend in zooplankton response to climate change. The different climate models may differ in details and from region to region. The overall trend however, displayed by the various model is the same and shows a decrease in chlorophyll concentration, an increase in sea surface temperature and a decrease in sea surface salinity. Future research in this area may choose to use the then best performing and evaluated model available. 


\section{Prediction of Ocean Layers}

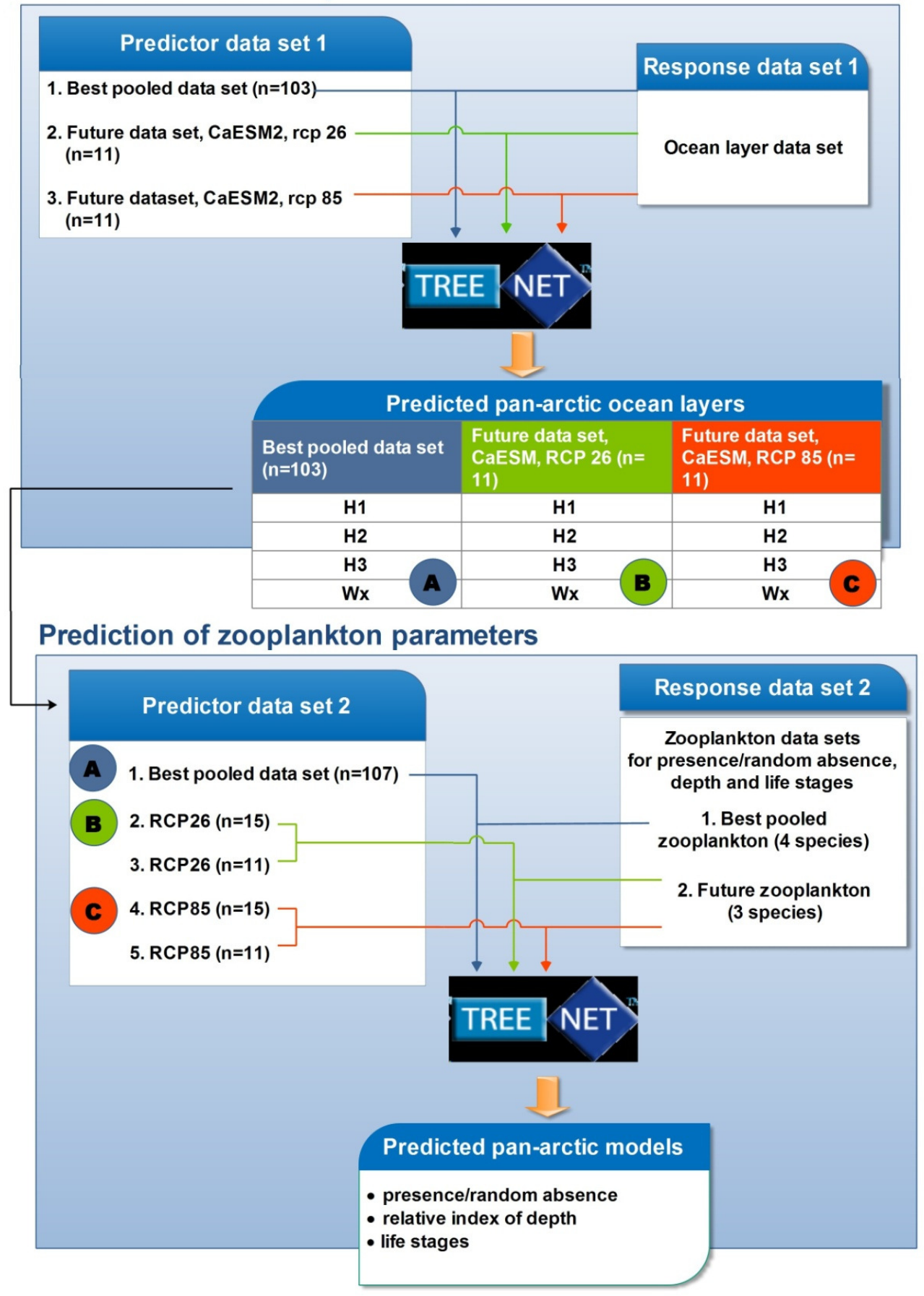

Figure 22: Flowchart describing the model development. The best-pooled predictor data set was used to predict the ocean layers H1, H2, H3 and Wx based on the ocean layer data set leading to the predicted ocean layers for the best-pooled model. According to the same process, the future predictor data sets CanESM2 RCP26 and RCP85 were used to predict the future ocean layers based on the ocean layer data set. Models were trained and applied back onto the study area using the Salfords data miner application "TreeNet". In the next step, the ocean layers were included into the predictor data sets to develop predicted panarctic models of presence/random absence, depth and life stages of the zooplankton species. However, models were developed including and excluding those ocean layers and to determine a possible effect by those layers. The overall outcomes were 5 scenarios predicting the presence/random absence, relative index of depth and life stage distribution for the studied species. One best-pooled model scenario where ocean layers were included and for four species (C. hyperboreus, M. longa, M. pacifica and $T$. raschii) as well as 2 low emission future climate scenarios (one including the ocean layers and one excluding the ocean layers) and $\mathbf{2}$ high emission future climate scenarios (one including the ocean layers and one excluding the ocean layers) and carried out for 3 species (C. hyperboreus, M. longa and M. pacifica). The 4 future scenarios were predicted for 2010 and 2100. 
According to the new CMIP5 guidelines, a low scenario (RCP26) and a high emission scenario (RCP85) were used in the model predictions. After downloading the future data from the homepage of the Canadian Climate Modeling Center, the data was extracted from the netCDF (Network Common Data Form) files they were provided in. The netCDF format is a widely used format for climatological data but unfortunately not very user friendly. Here, Michael Lindgren from the Scenarios Network for Alaska and Arctic Planning (SNAP) at the University of Alaska helped with the project by writing a code to extract the data from the netCDF files and to generate GeoTIFF files for further use in ArcGIS (see the appendix, chapter 6.2 for the Rcode). Programming was carried out in $\mathrm{R}$.

After adjusting the data layers by reprojecting them into the North Pole Stereographic Projection and cutting the future climate layers with worldwide coverage down to the region of the Arctic Circle, the ocean layers were predicted, similar to the best-pooled model and following the same workflow (Fig. 22). The future ocean layers were predicted based on a data set of 11 predictor variables including the future climate layers from the CanESm2 model. The predicted ocean layers were then added to the original set of predictor variables and the extended data set of 15 predictors used to predict the presence/random absence, most likely depth in which zooplankton is present as well as the distribution of life stages for the zooplankton species in the future (Fig. 22).

At this point, work was carried out for three species C. hyperboreus, M.longa, M. pacifica because the available data points for $T$. raschii were outside the coverage of the CanESM2 data layers.

The above description explained the development of the future climate scenarios in general. The procedure was however carried out for several sub scenarios. It was decided to model predict the presence/random absence, most likely depth of zooplankton as well as the life stage distribution once including the ocean layers and once excluding the ocean layers (Fig. 23) to see a potential effect of those layers. Moreover, the scenarios were modeled out using future data of the low emission scenario (RCP26) and also using the same parameters but based on future data of the high emission scenario (RCP85). All four scenarios were built on the CanESM2 data for 2010 and then projected onto the data for the year 2100 (Fig. 23)

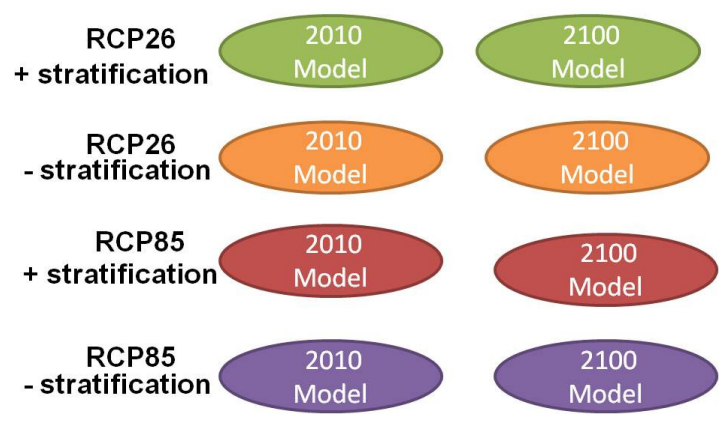

Figure 23: The four different scenarios: low emission scenario including ocean layers, low emission scenario excluding ocean layers, high emission scenario including ocean layers as well as high emission scenario excluding ocean layers. All four scenarios were built on the CanESM2 data for 2010 and then also projected onto the data for the year $\mathbf{2 1 0 0 .}$

\subsection{A comparison between the climate in $\mathbf{2 0 1 0}$ and $\mathbf{2 1 0 0}$ for two future climate scenarios from the Canadian Earth System Model 2 (CanESM2)}

Here, the changes in the raw data from 2010 to 2100 are going to be described and from the low emission scenario (RCP26) to the high emission scenario (RCP85). The changes are visualized in spatially explicit GIS maps including frequency distributions and a set of summary statistics that make it easy to grasp the change. 


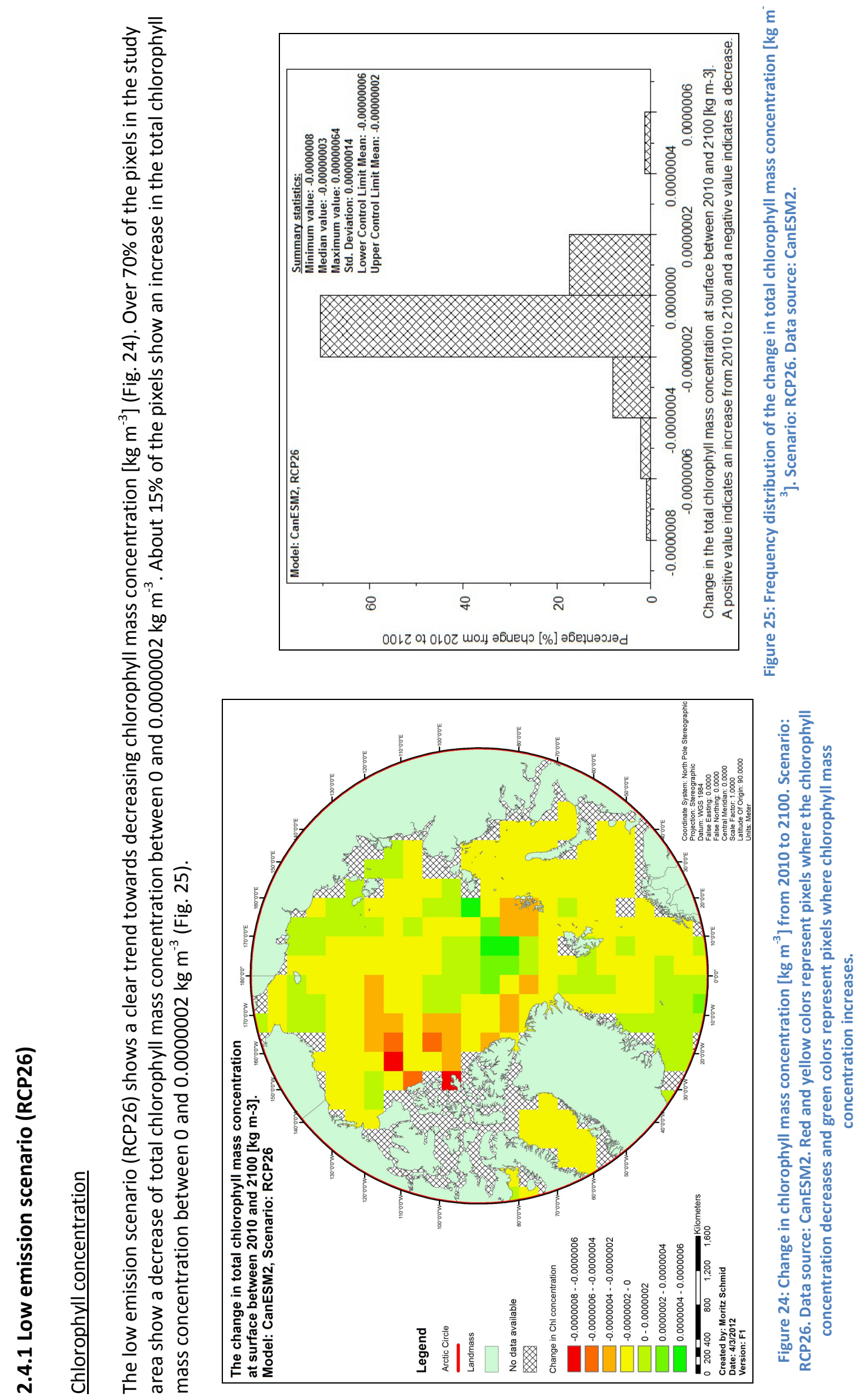

m 

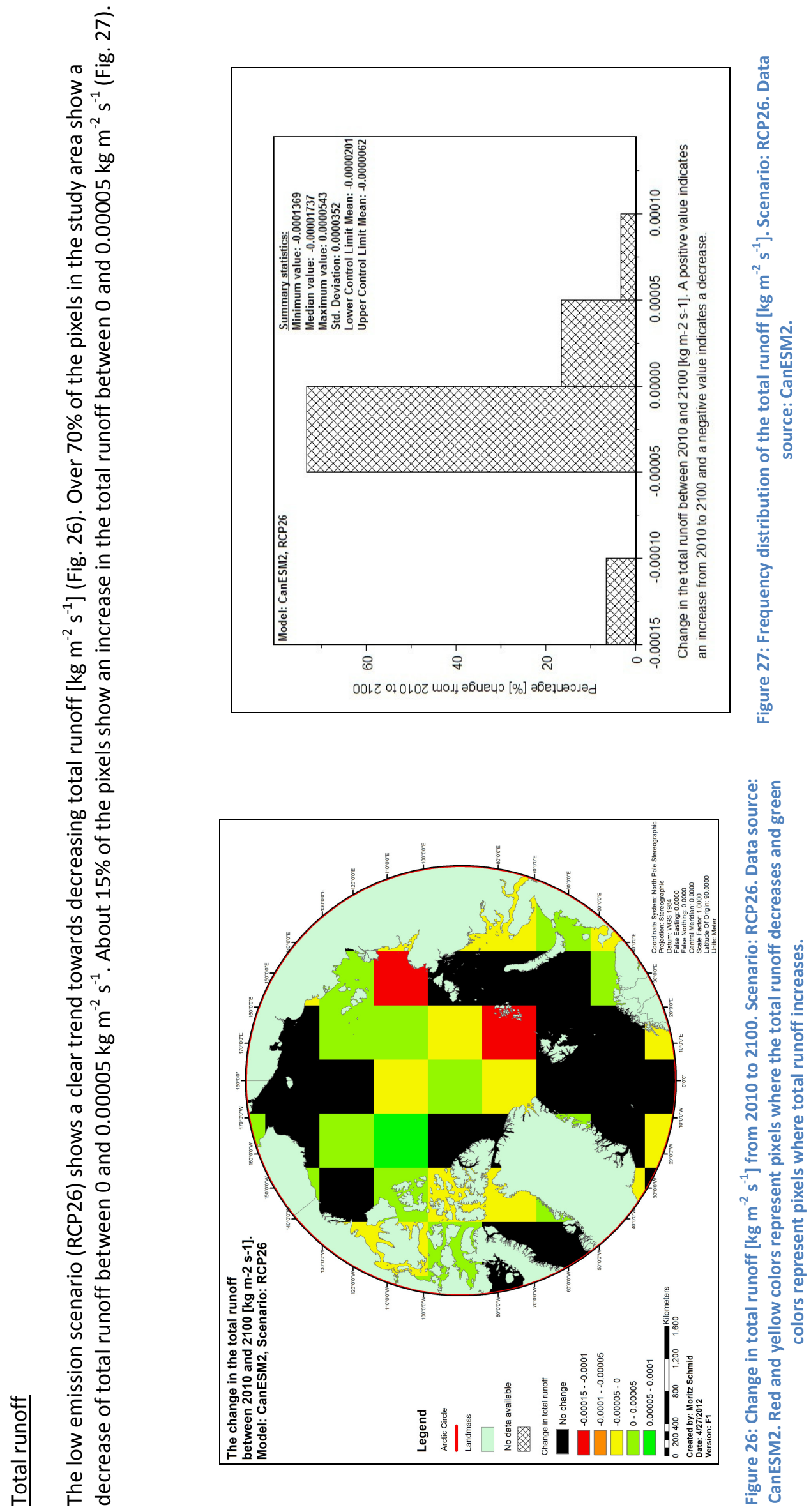


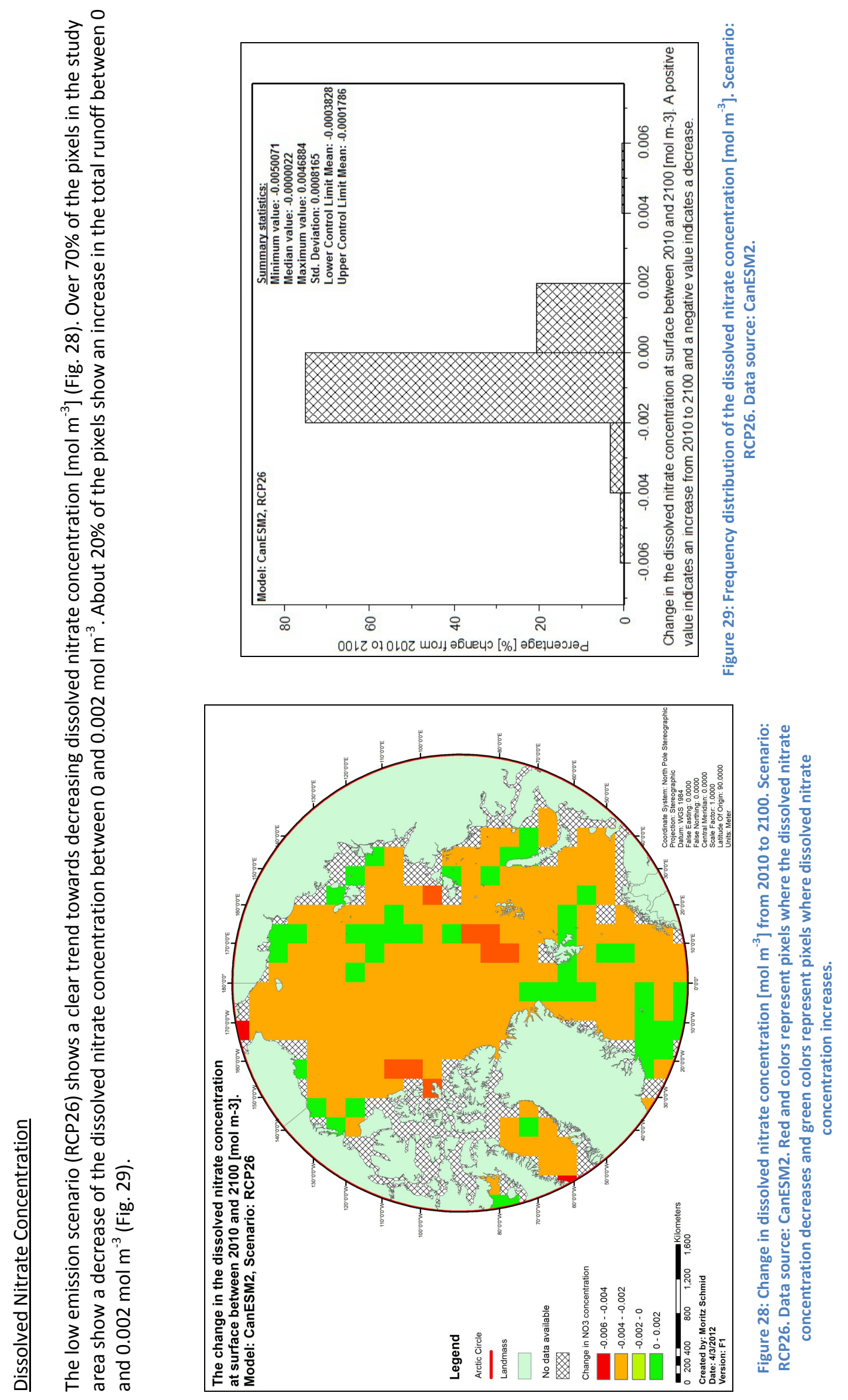




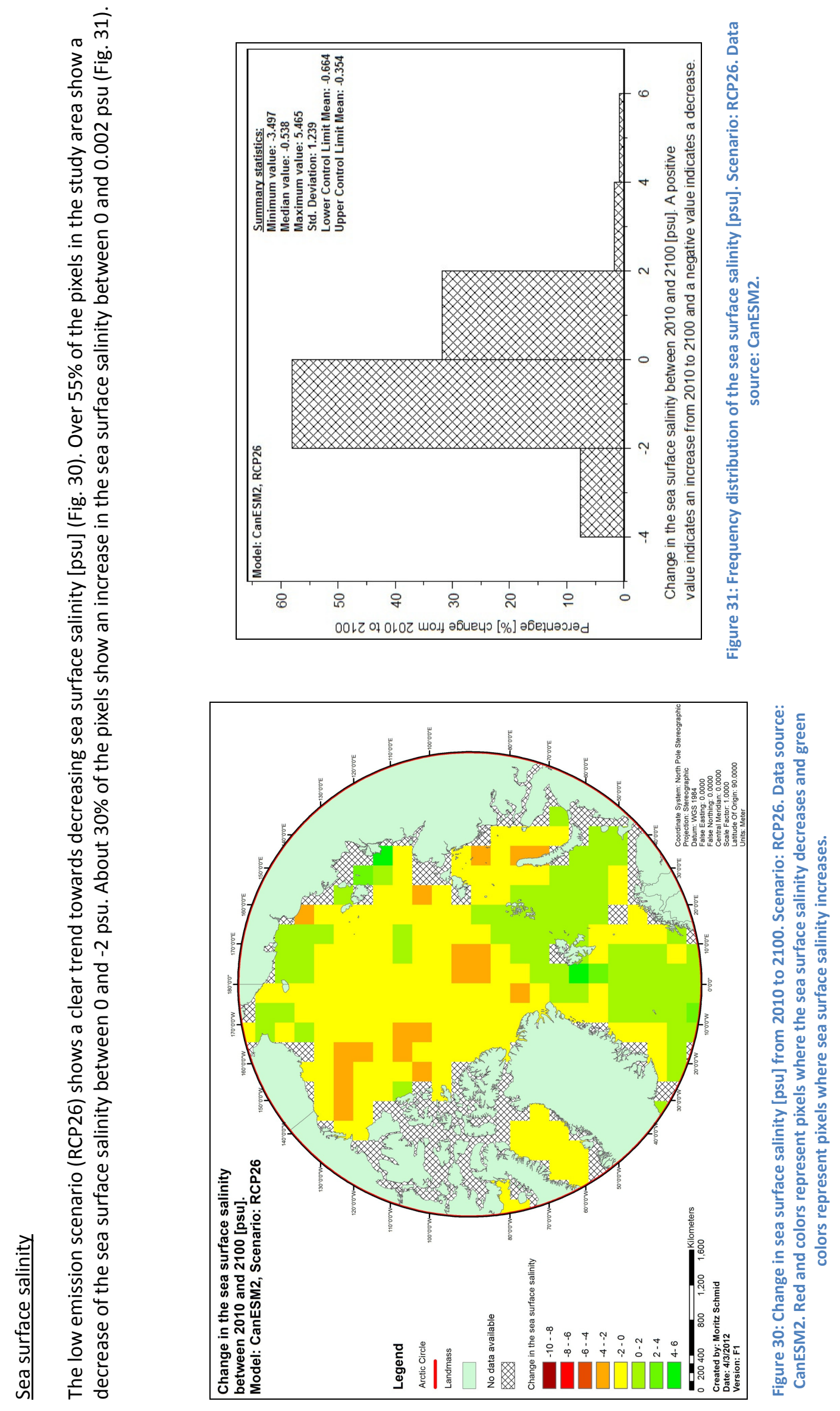




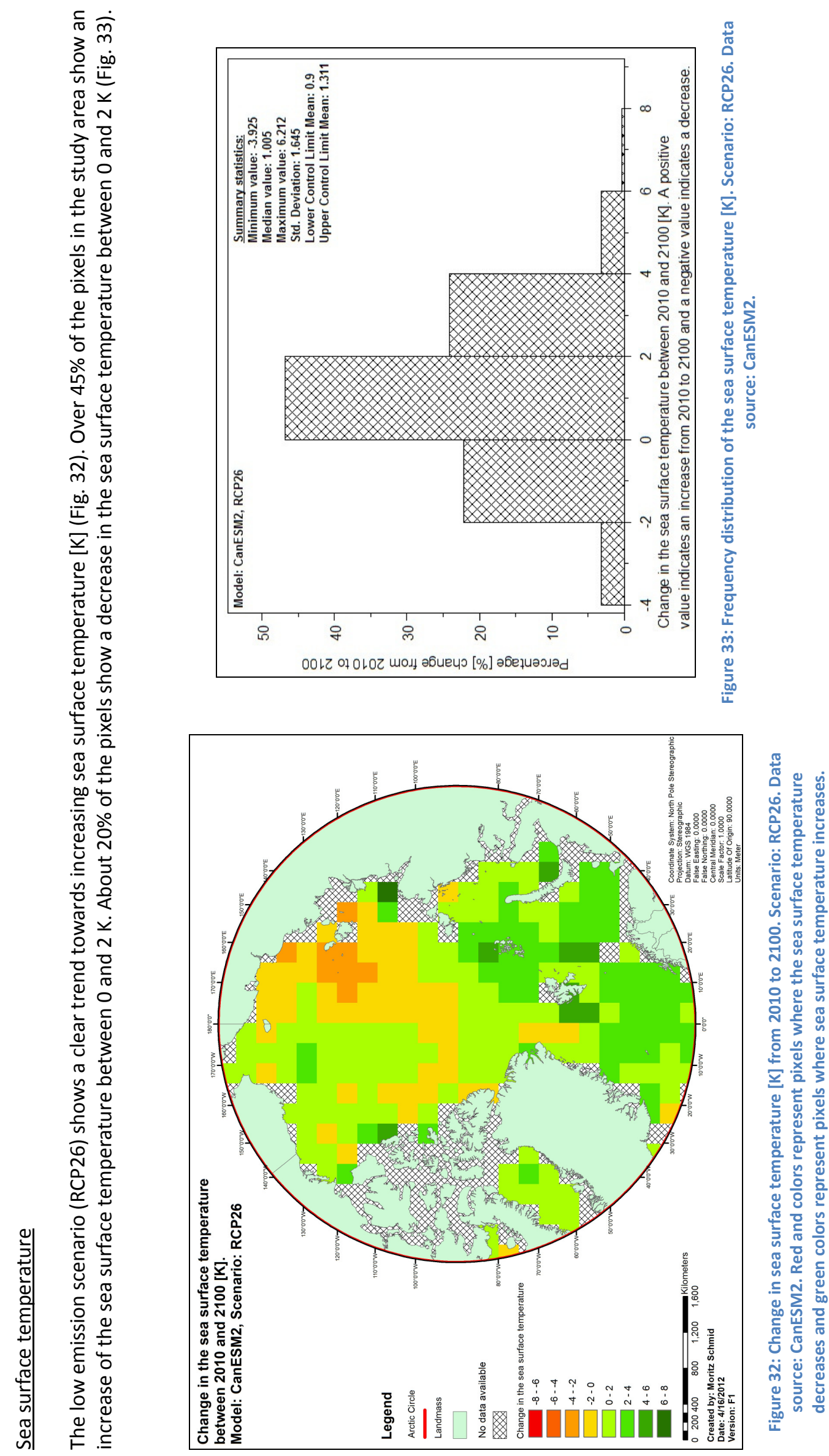




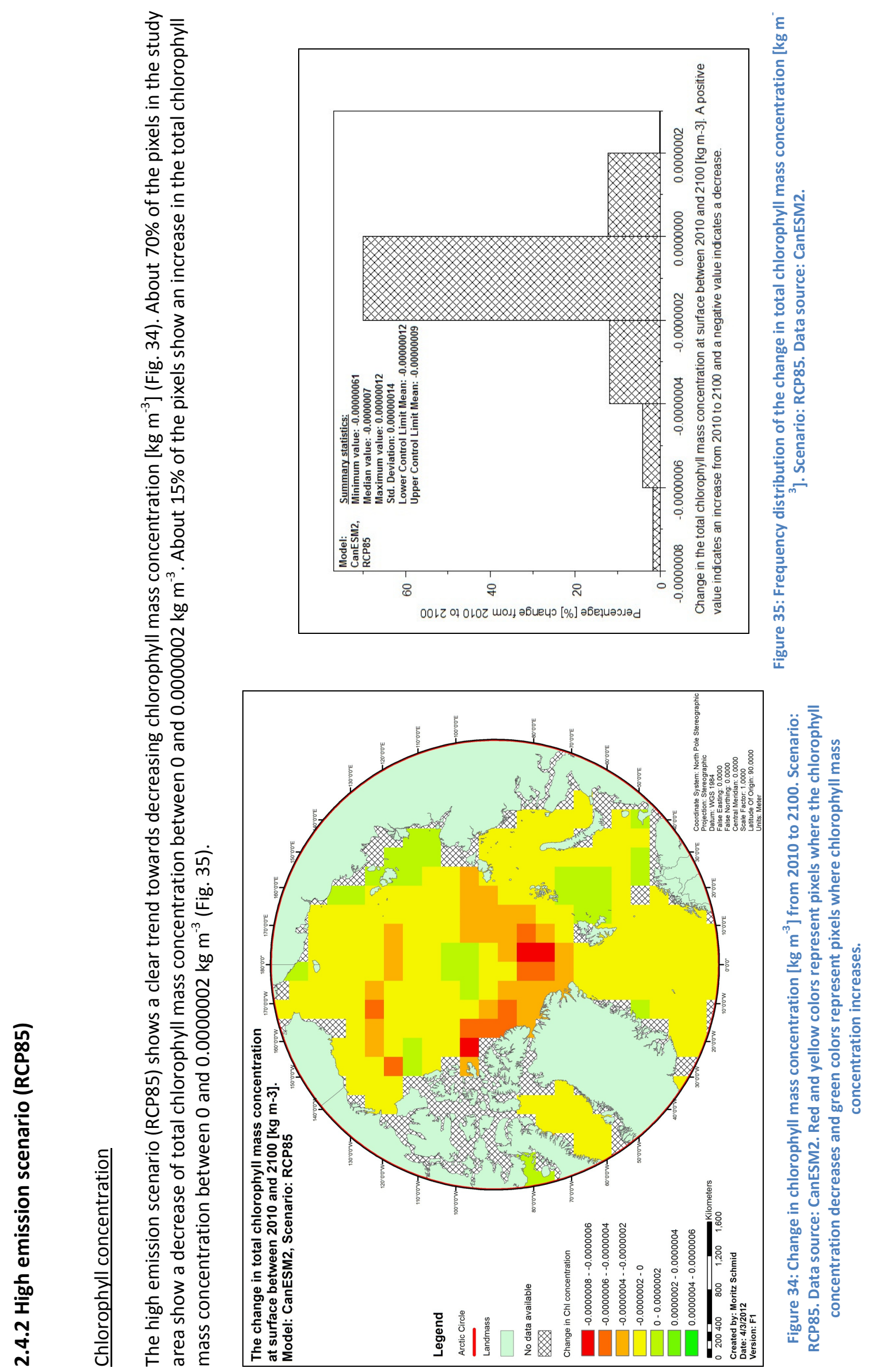




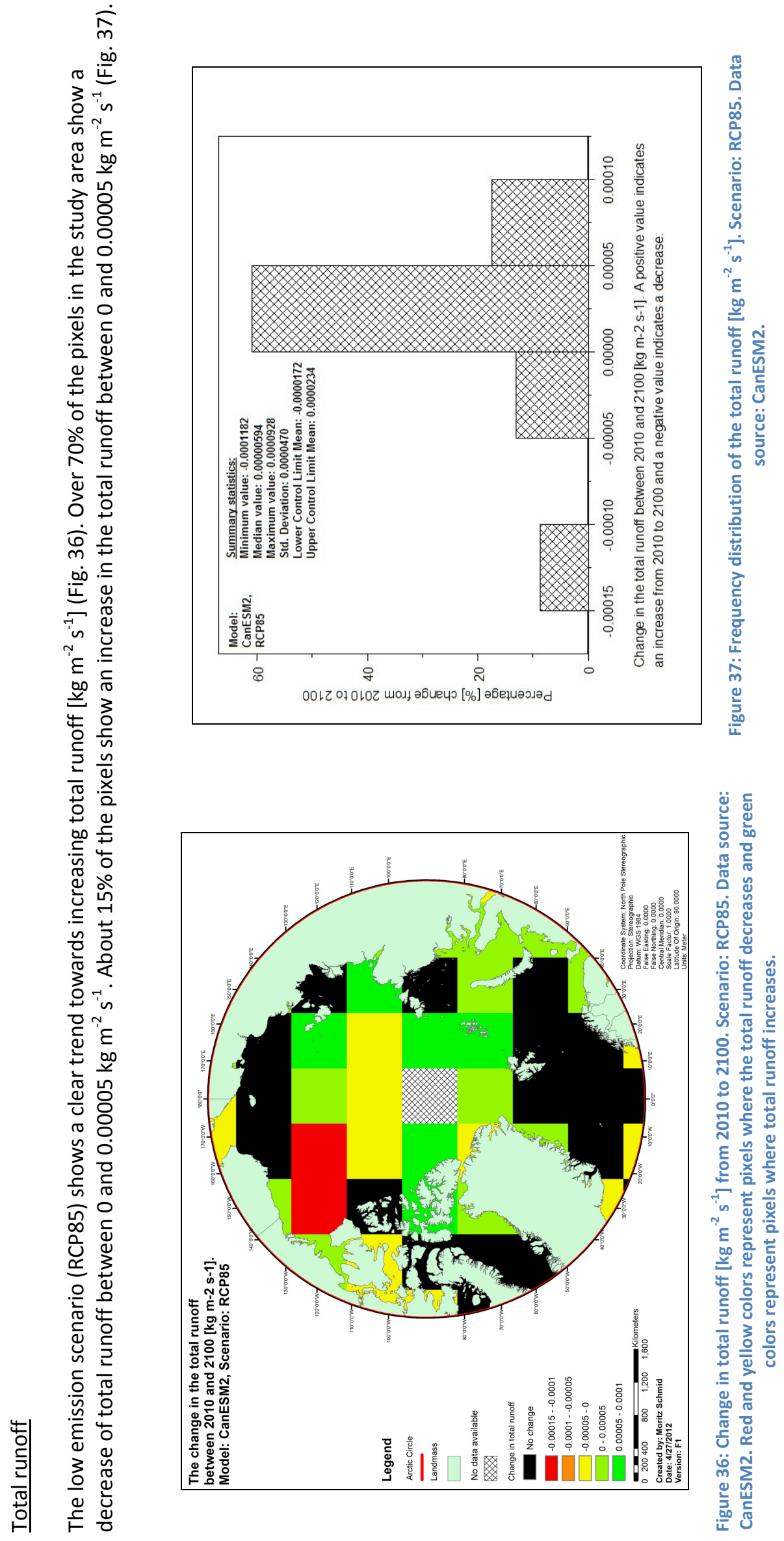



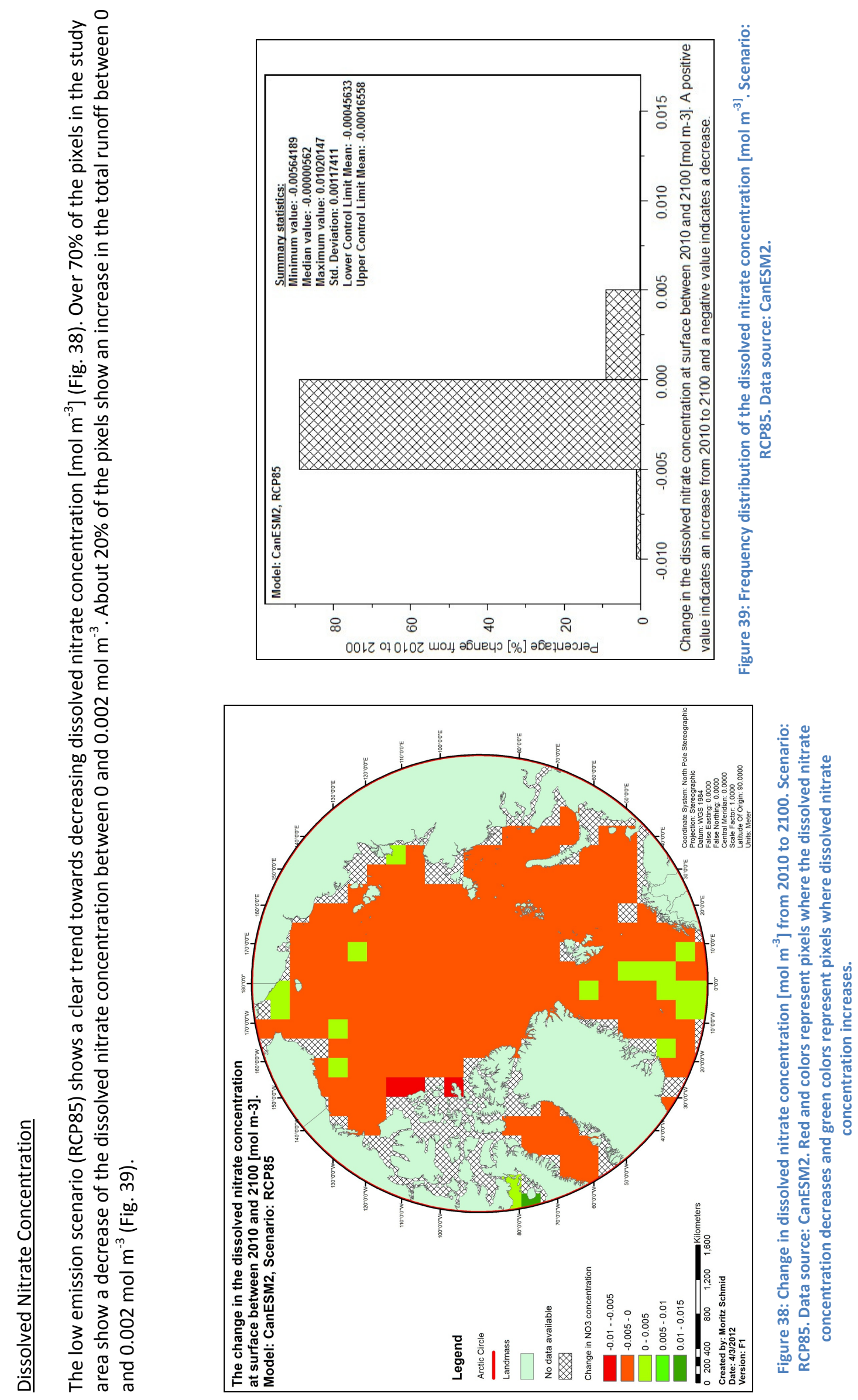


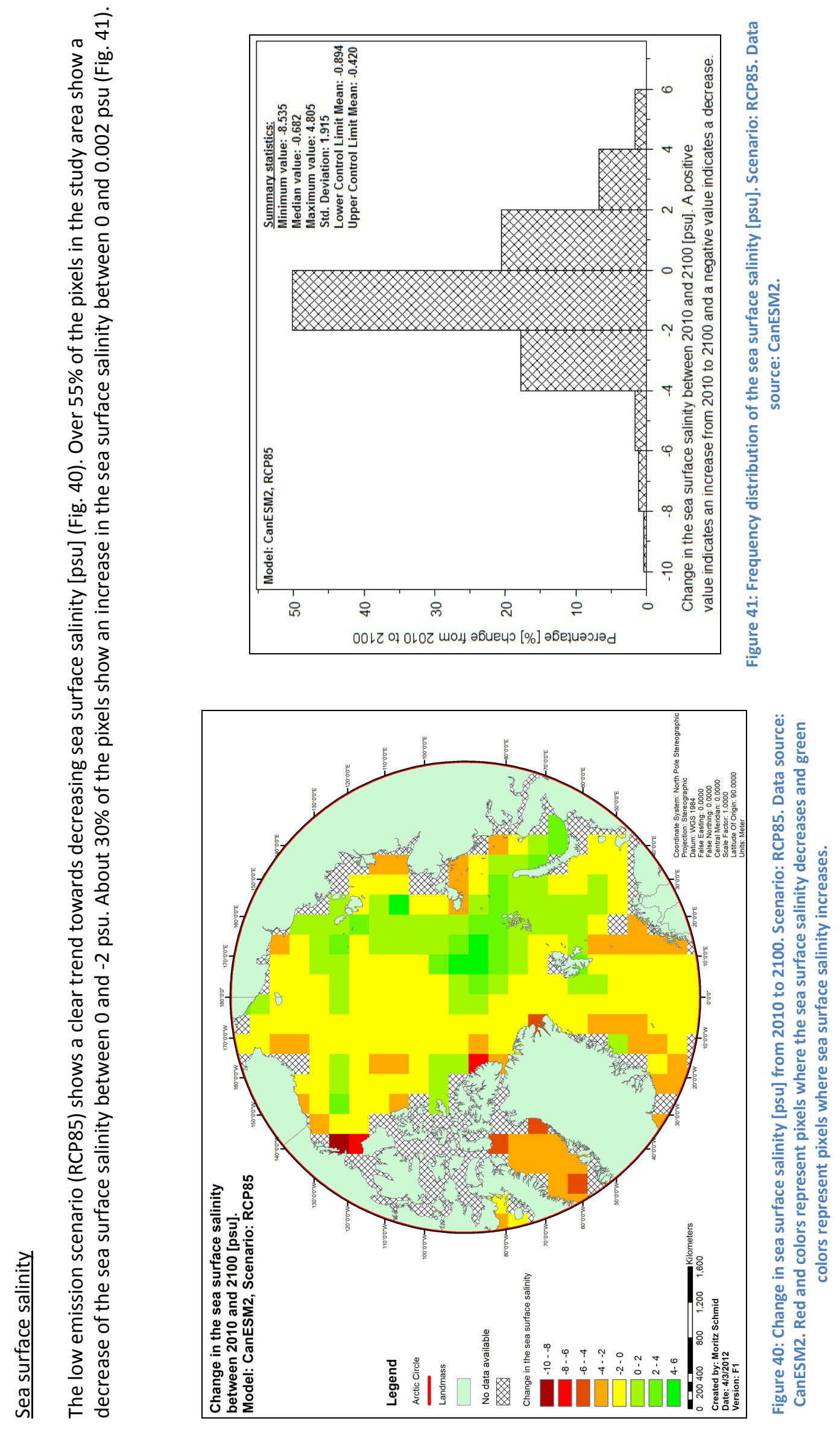




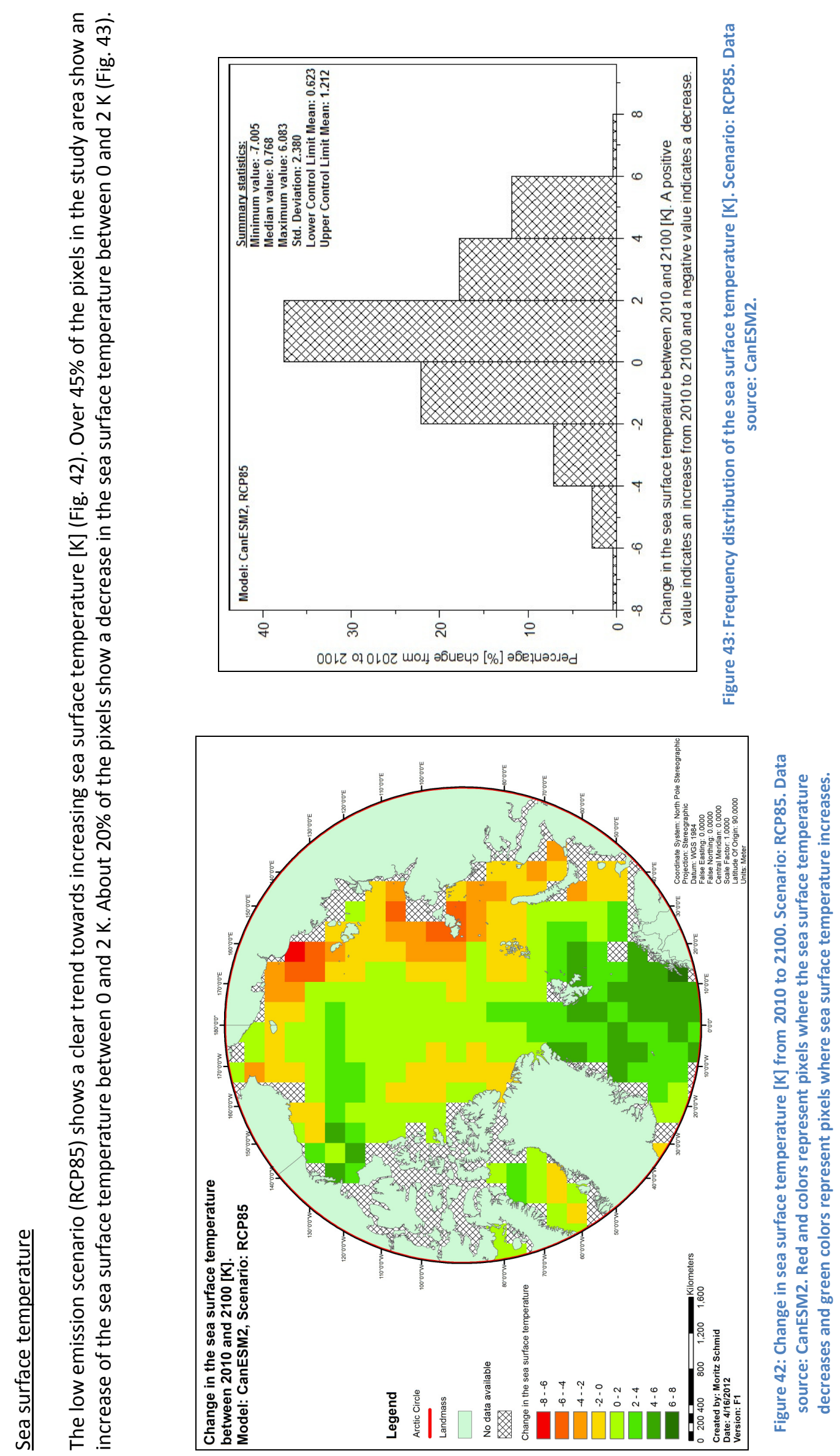




\section{Results}

The results of this project are quite extensive and displayed in various maps and sections. For ease of comprehension, the results are however summarized in a few important key tables at the end of this chapter that display also the changes between the scenarios very good. The different maps however give the reader an understanding of the spatial context and how to relate the tables to the maps.

Note that the legends for the various GIS maps are the same where possible and with the same intervals between displayed classes to make comparison easier. This is not always possible however.

The results chapter follows a general set up according to the five modeled scenarios.

First, the results of the best-pooled model are displayed. Second, the results of the low emission scenario (RCP26) including ocean layers are displayed. Third, the results of the low emission scenario (RCP26) excluding ocean layers are displayed. Fourth, the results of the high emission scenario (RCP85) including ocean layers are displayed. Last but not least, the results of the high emission scenario (RCP85) excluding ocean layers are displayed.

Each results section according to the scenario starts with the predicted ocean layers (where applicable), and then followed by the overlays of the modeled zooplankton parameters. First I show the overlay of the presence/random absence layer with the predicted relative index of depth and second I show the overlay of the presence/random absence layer and the predicted life stages. This scheme is repeated for each species.

The box like patterns in the predictions comes from the way TreeNet selects data and from the resolution of the data used. Since TreeNet fits data in a mathematically best way to the model, it may select wider areas for this and thereby creating the box like patterns. 


\subsection{The best-pooled model}

\subsubsection{Predicted ocean layers}

The mean predicted relative depth of layer $\mathrm{H} 1$ was $-24.54 \mathrm{~m}$ with a maximum depth of $-67.02 \mathrm{~m}$ (Fig. 44)

The mean predicted relative depth of layer $\mathrm{H} 2$ was $-89.27 \mathrm{~m}$ with a maximum depth of $-171.28 \mathrm{~m}$ (Fig. 45 )

The mean predicted relative depth of layer $\mathrm{H} 3$ was $-150.17 \mathrm{~m}$ with a maximum depth of $-331.32 \mathrm{~m}$ (Fig. 46)

The mean predicted relative depth of layer Wx was $-135.77 \mathrm{~m}$ with a maximum depth of $-319.20 \mathrm{~m}$ (Fig. 47)

Note: Layers do not necessarily exist over shallow shelf areas.

In the following figures, the color scale ranges from green areas, where the predicted ocean layer is shallower, to red areas, where the ocean layer is deeper. 

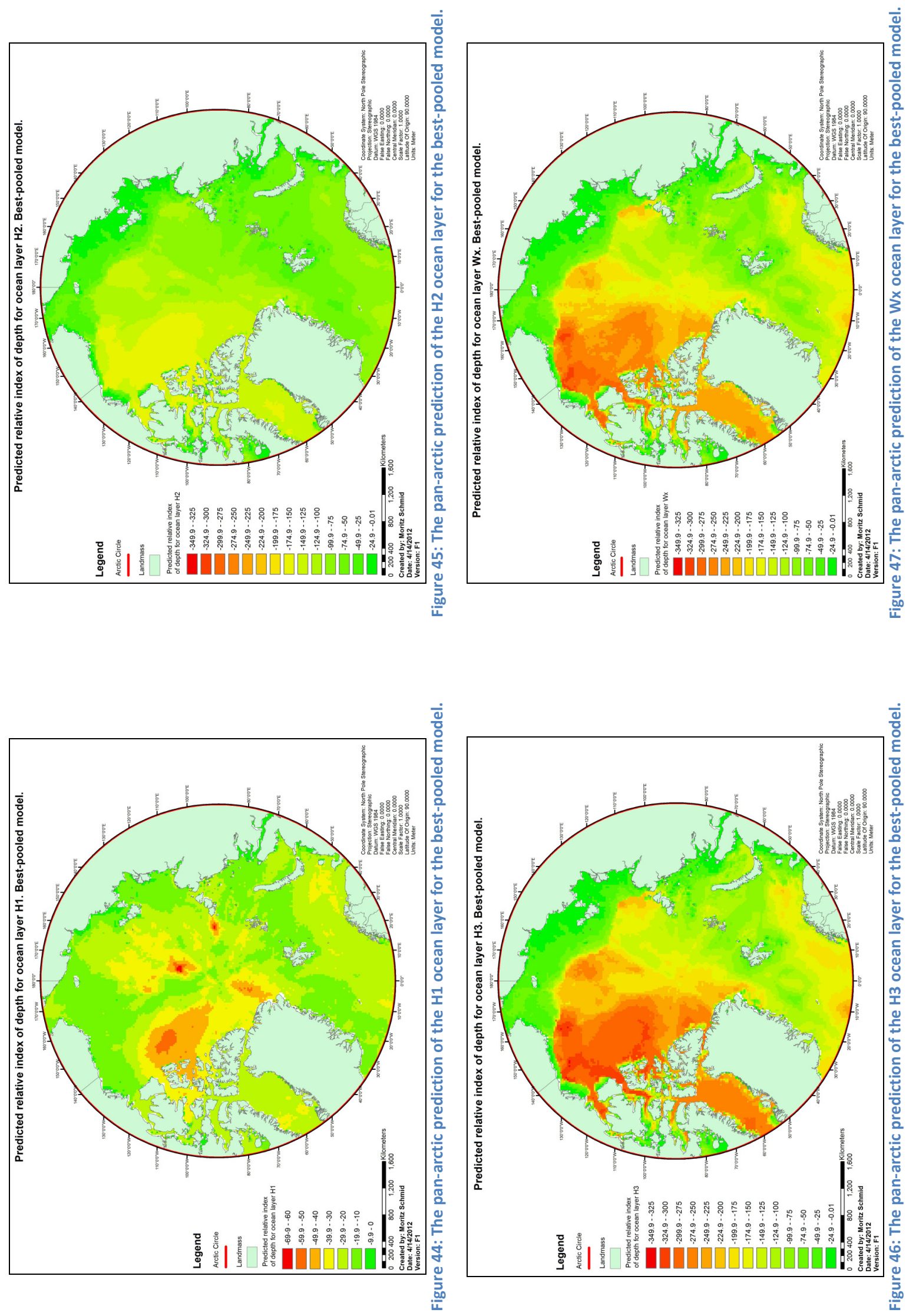


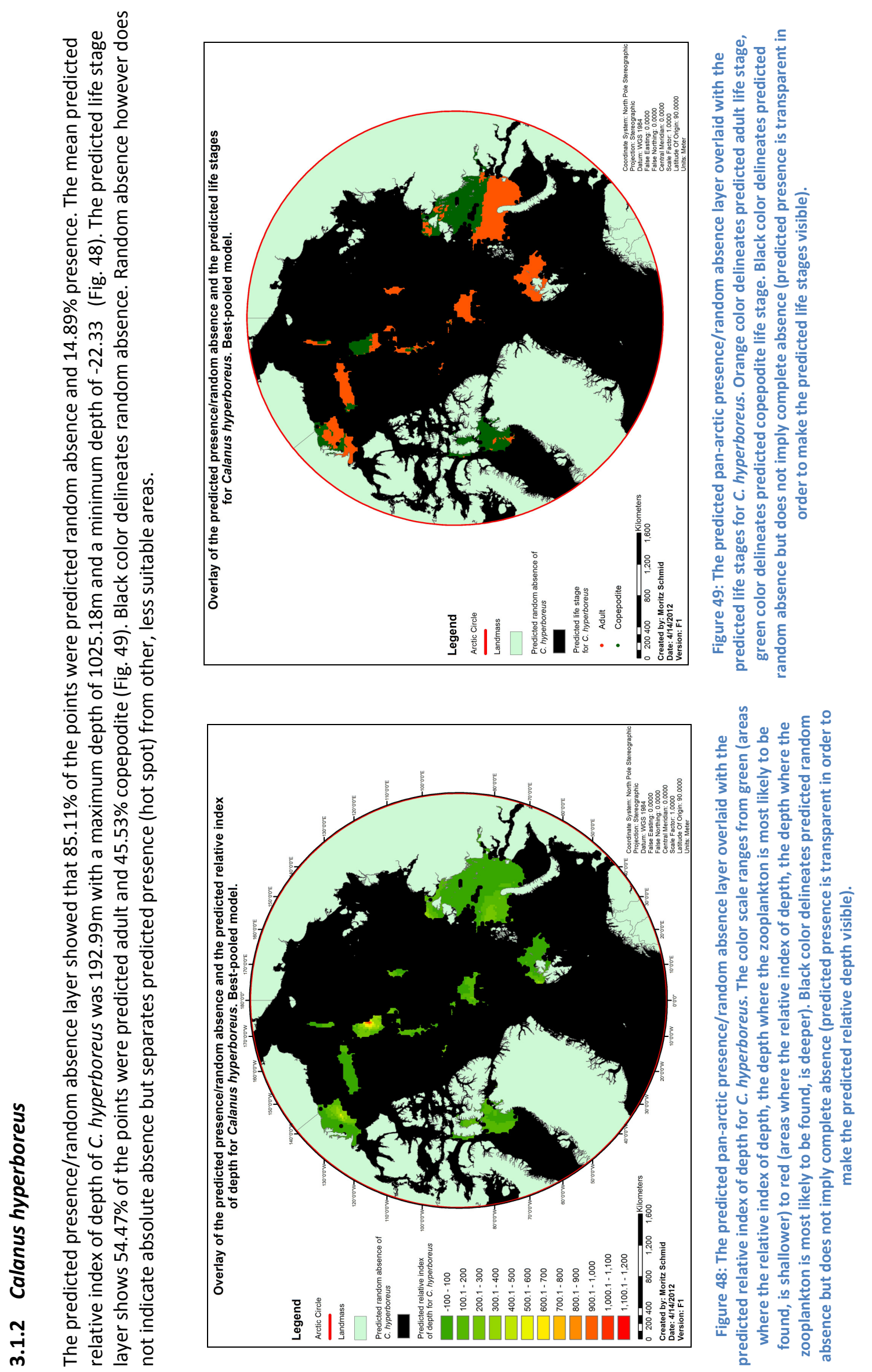




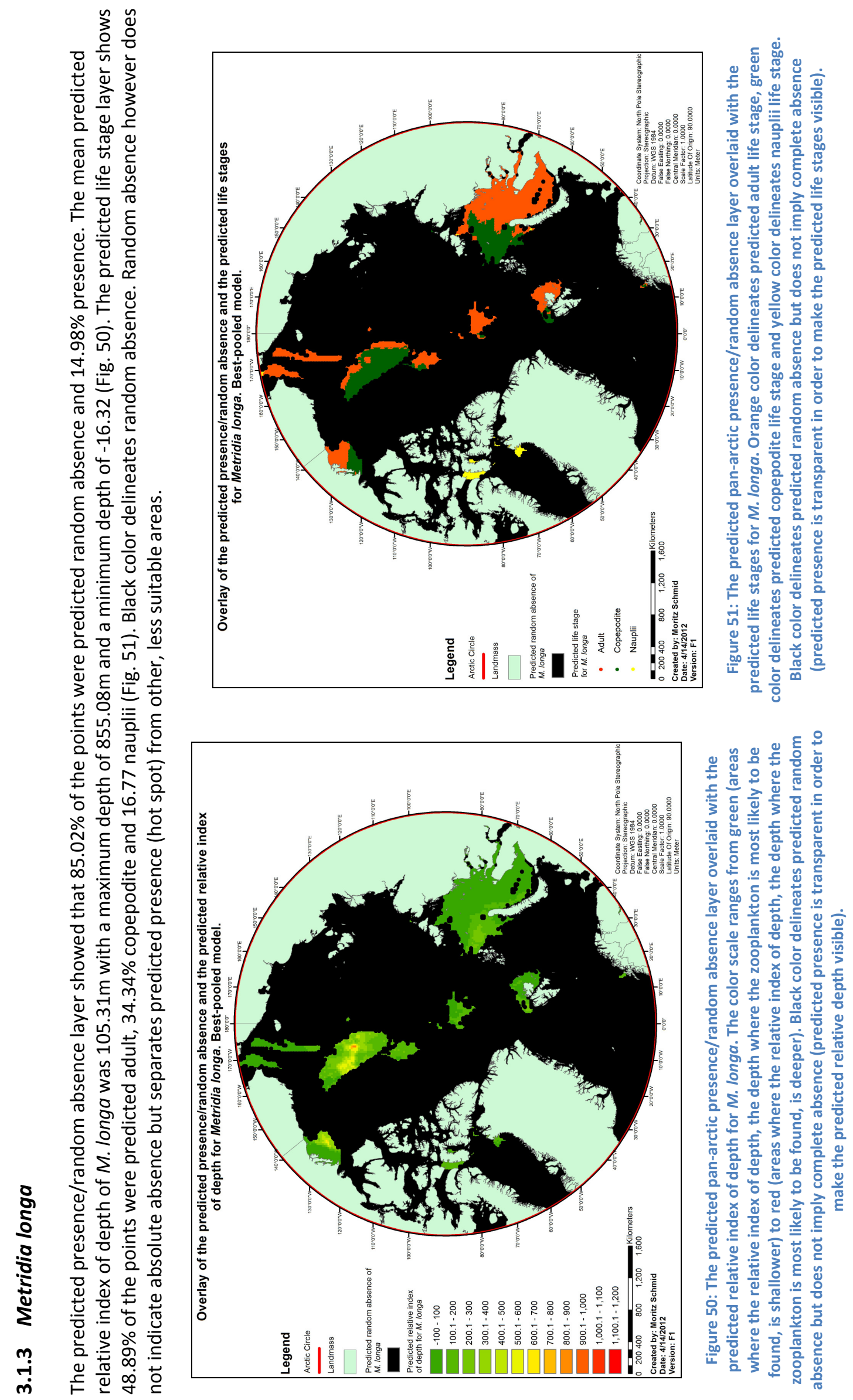



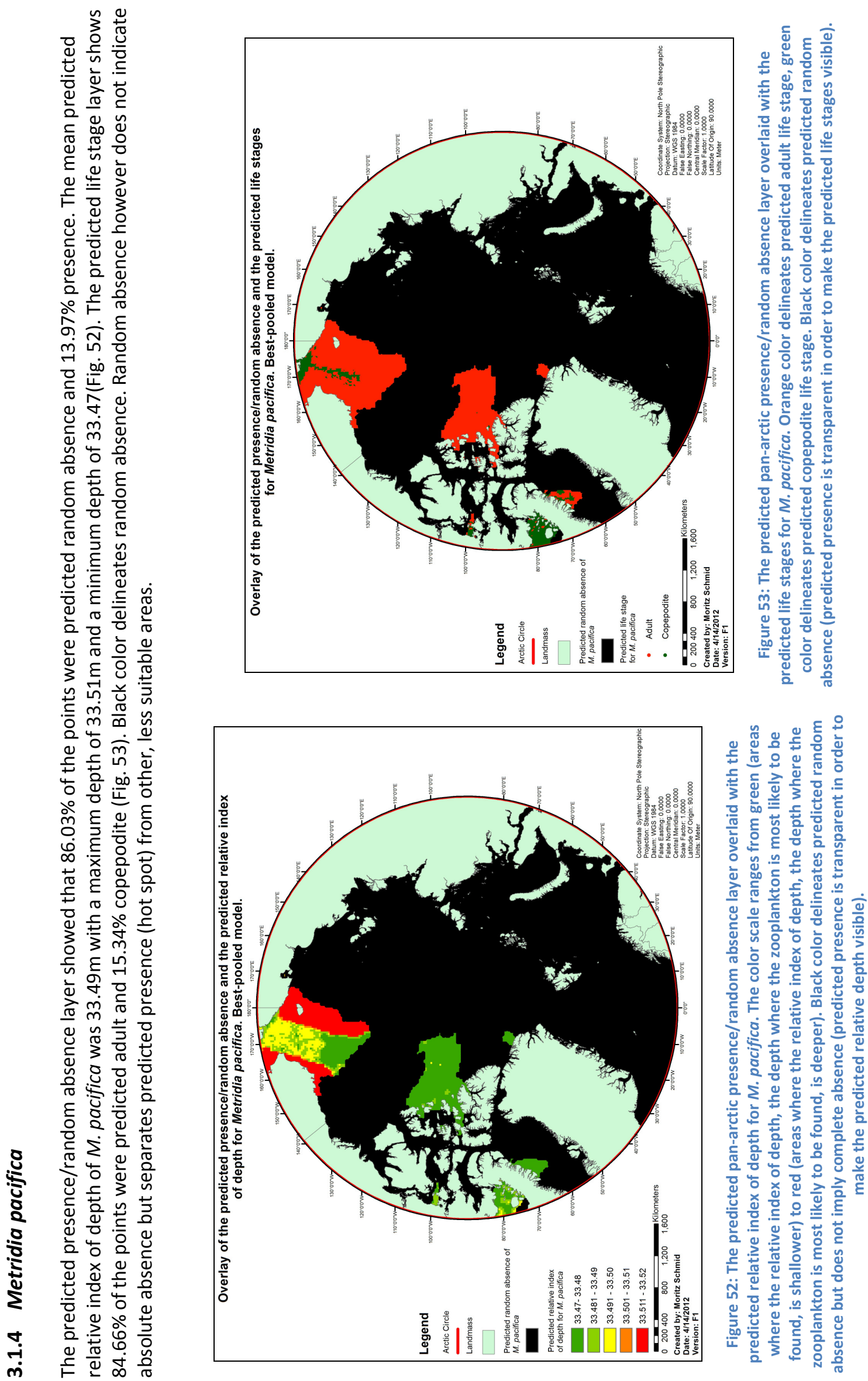

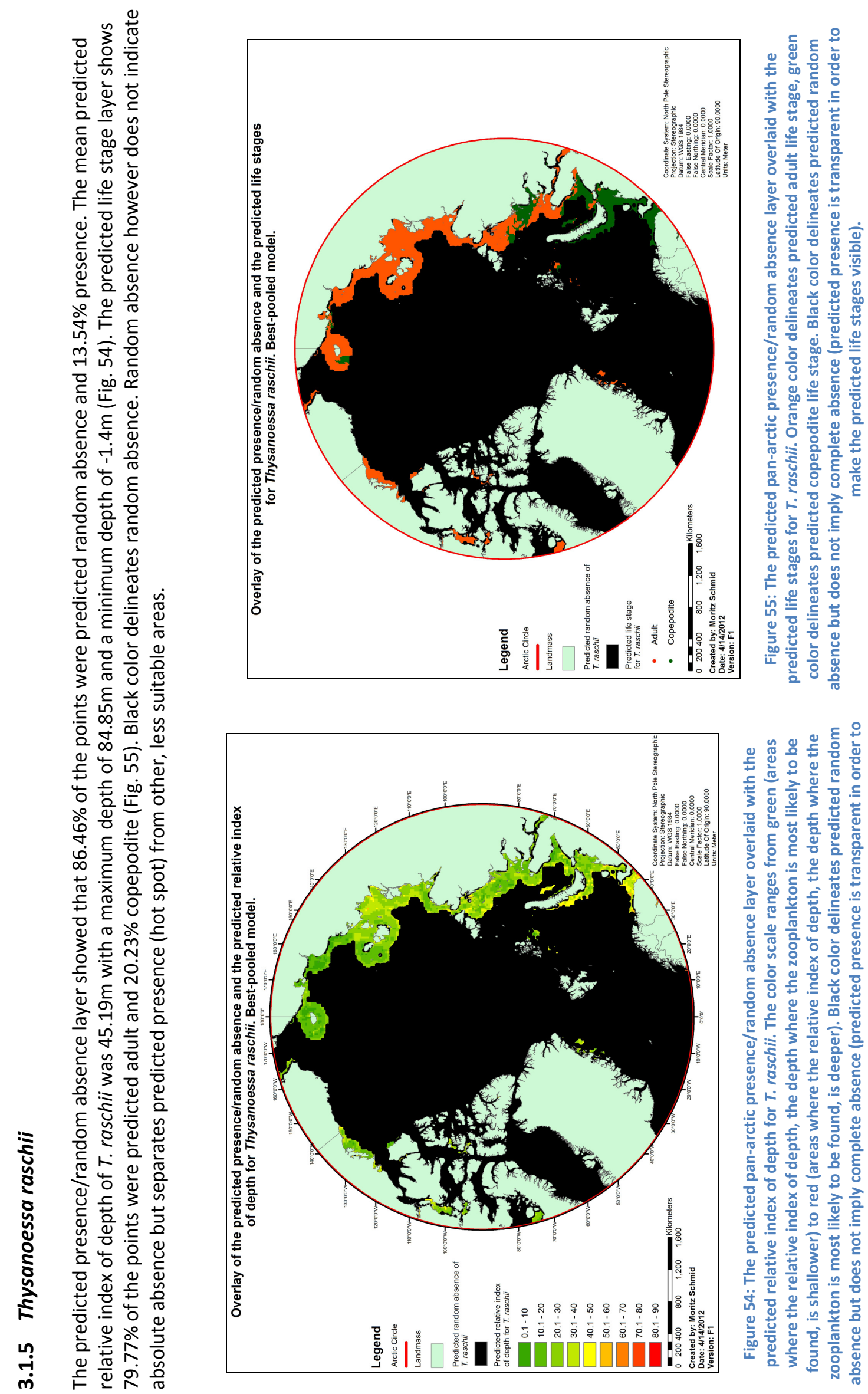

ก
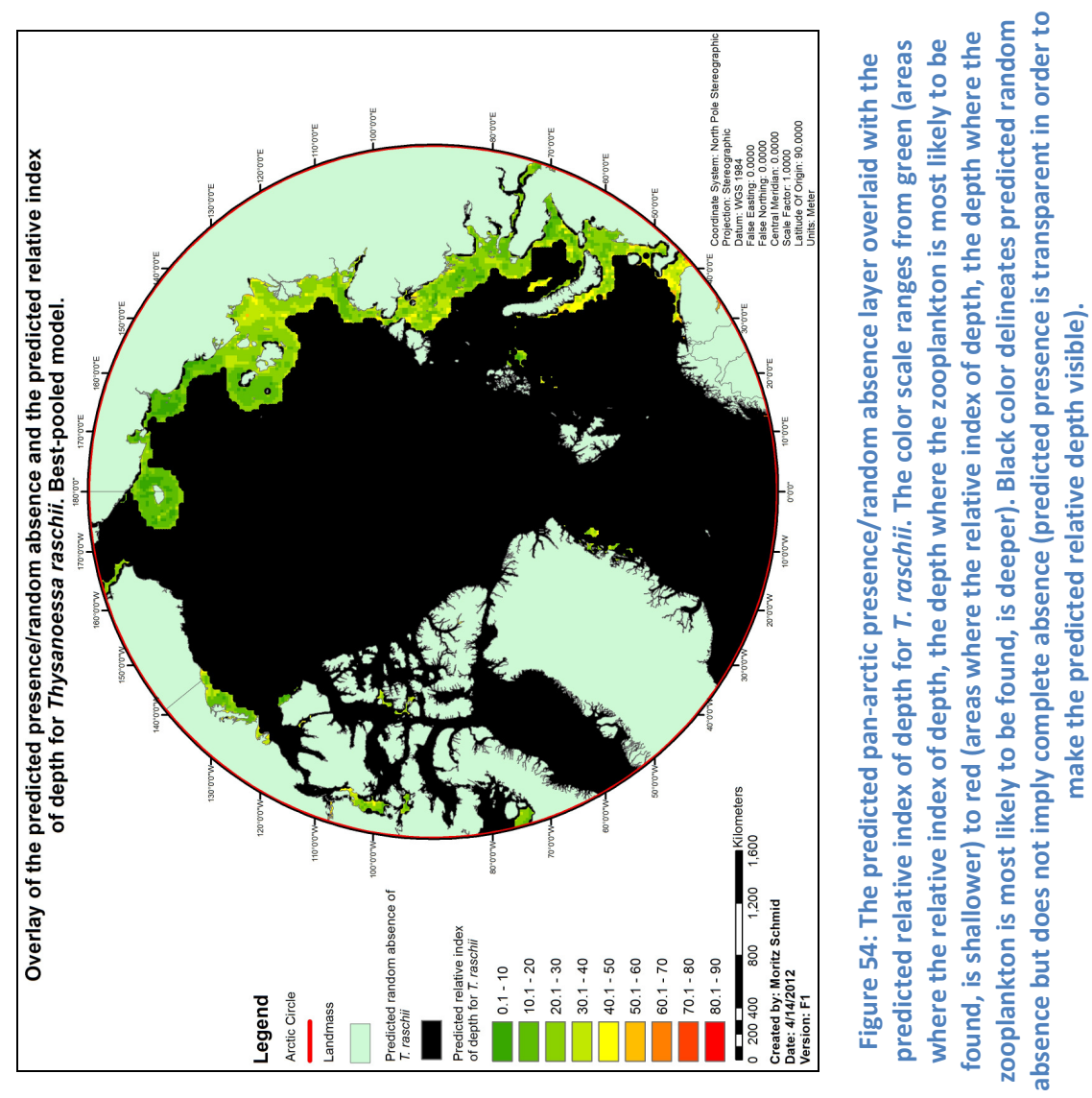


\subsection{Low emission (RCP26) future predictions, including ocean Layers}

\subsubsection{Predicted ocean layers}

The predicted ocean layer $\mathrm{H} 1$ in 2010

The mean predicted relative index of depth of layer $\mathrm{H} 1$ in 2010 was $-25.23 \mathrm{~m}$ with a maximum depth of 50.63m (Fig. 56).

The predicted ocean layer $\mathrm{H} 1$ in 2100

The mean predicted relative index of depth of layer $\mathrm{H} 1$ in 2100 was $-21.15 \mathrm{~m}$ with a maximum depth of 44.32m (Fig. 57).

The predicted ocean layer $\mathrm{H} 2$ in 2010

The mean predicted relative index of depth of layer $\mathrm{H} 2$ in 2010 was $-74.45 \mathrm{~m}$ with a maximum depth of 148.78m (Fig. 58).

The predicted ocean layer $\mathrm{H} 2$ in 2100

The mean predicted relative index of depth of layer $\mathrm{H} 2$ in 2100 was $-80.09 \mathrm{~m}$ with a maximum depth of 176.61m (Fig. 59).

Note: Layers do not necessarily exist over shallow shelf areas.

In the following figures, the color scale ranges from green areas, where the predicted ocean layer is shallower, to red areas, where the ocean layer is deeper. 

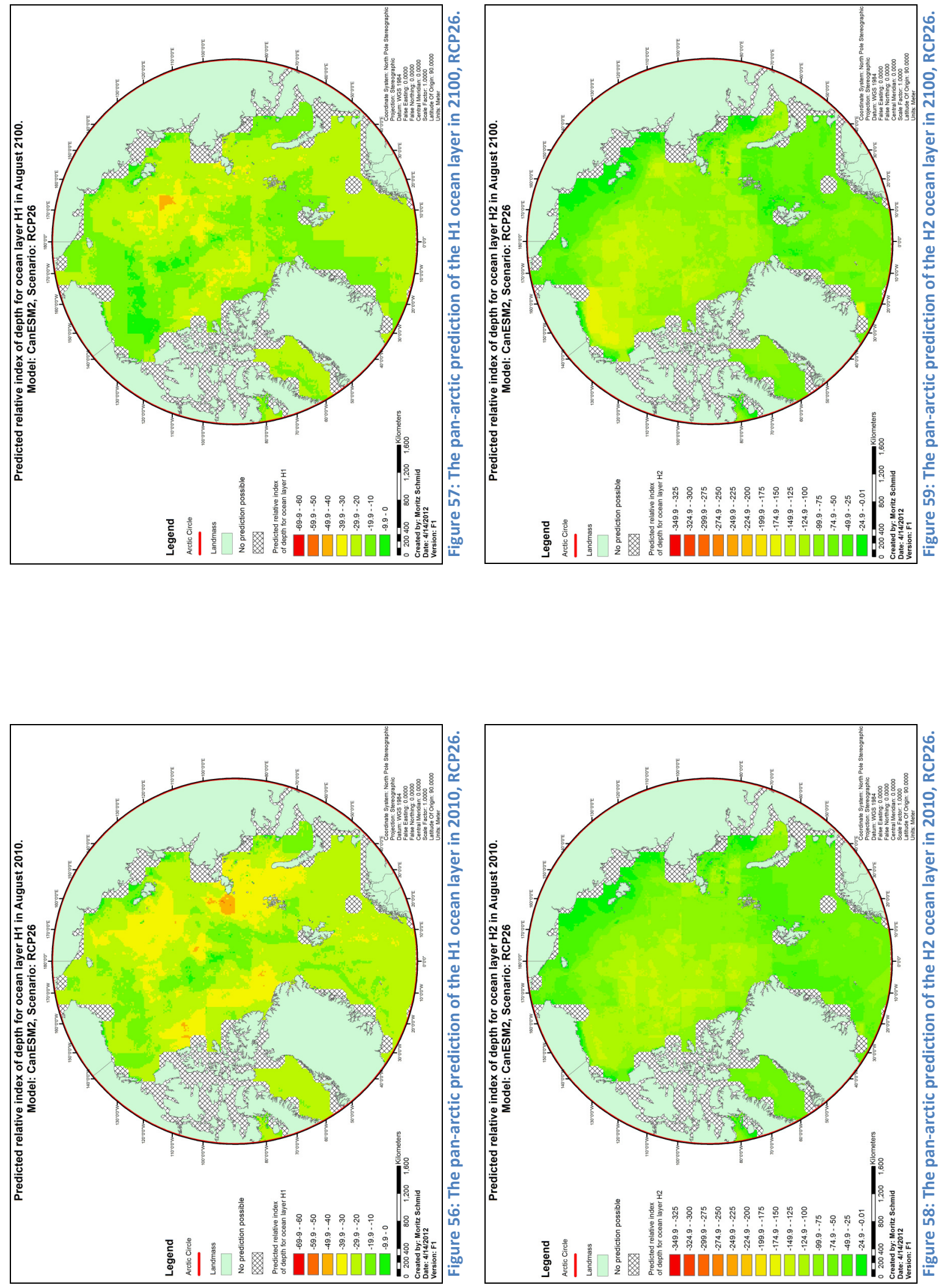


\section{The predicted ocean layer $\mathrm{H} 3$ in 2010}

The mean predicted relative index of depth of layer H3 in 2010 was $-120.66 \mathrm{~m}$ with a maximum depth of 274.30m (Fig. 60). (Note: This layer does not exist over shallow shelf areas).

\section{The predicted ocean layer $\mathrm{H} 3$ in 2100}

The mean predicted relative index of depth of layer $\mathrm{H} 3$ in 2100 was $-129.35 \mathrm{~m}$ with a maximum depth of 340.01m (Fig. 61). (Note: This layer does not exist over shallow shelf areas).

The predicted ocean layer Wx in 2010

The mean predicted relative index of depth of layer Wx in 2010 was $-110.49 \mathrm{~m}$ with a maximum depth of 249.38m (Fig. 62). (Note: This layer does not exist over shallow shelf areas).

The predicted ocean layer Wx in 2100

The mean predicted relative index of depth of layer Wx in 2100 was $-121.97 \mathrm{~m}$ with a maximum depth of 324.97m (Fig. 63). (Note: This layer does not exist over shallow shelf areas).

Note: Layers do not necessarily exist over shallow shelf areas.

In the following figures, the color scale ranges from green areas, where the predicted ocean layer is shallower, to red areas, where the ocean layer is deeper. 

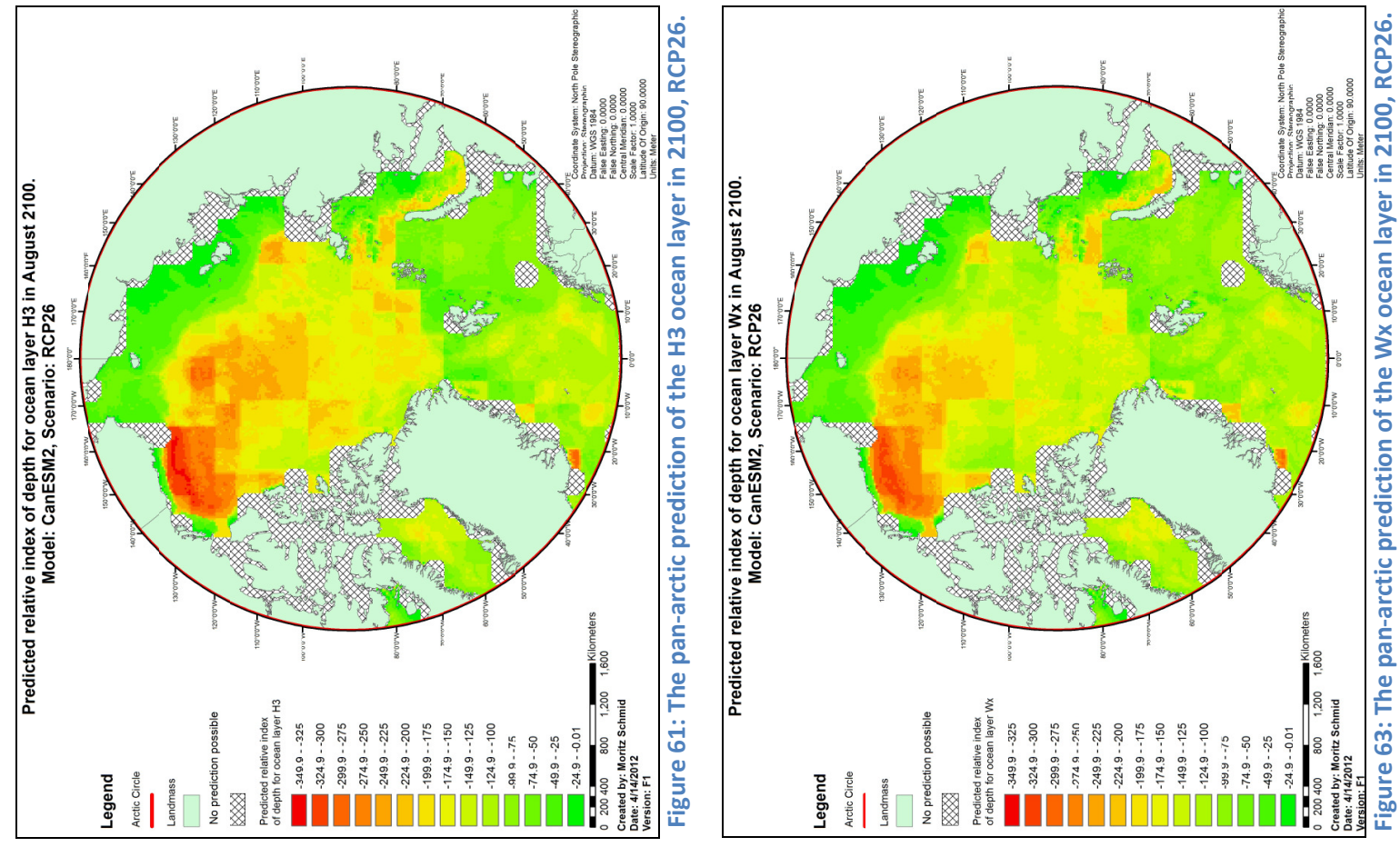

ถิ
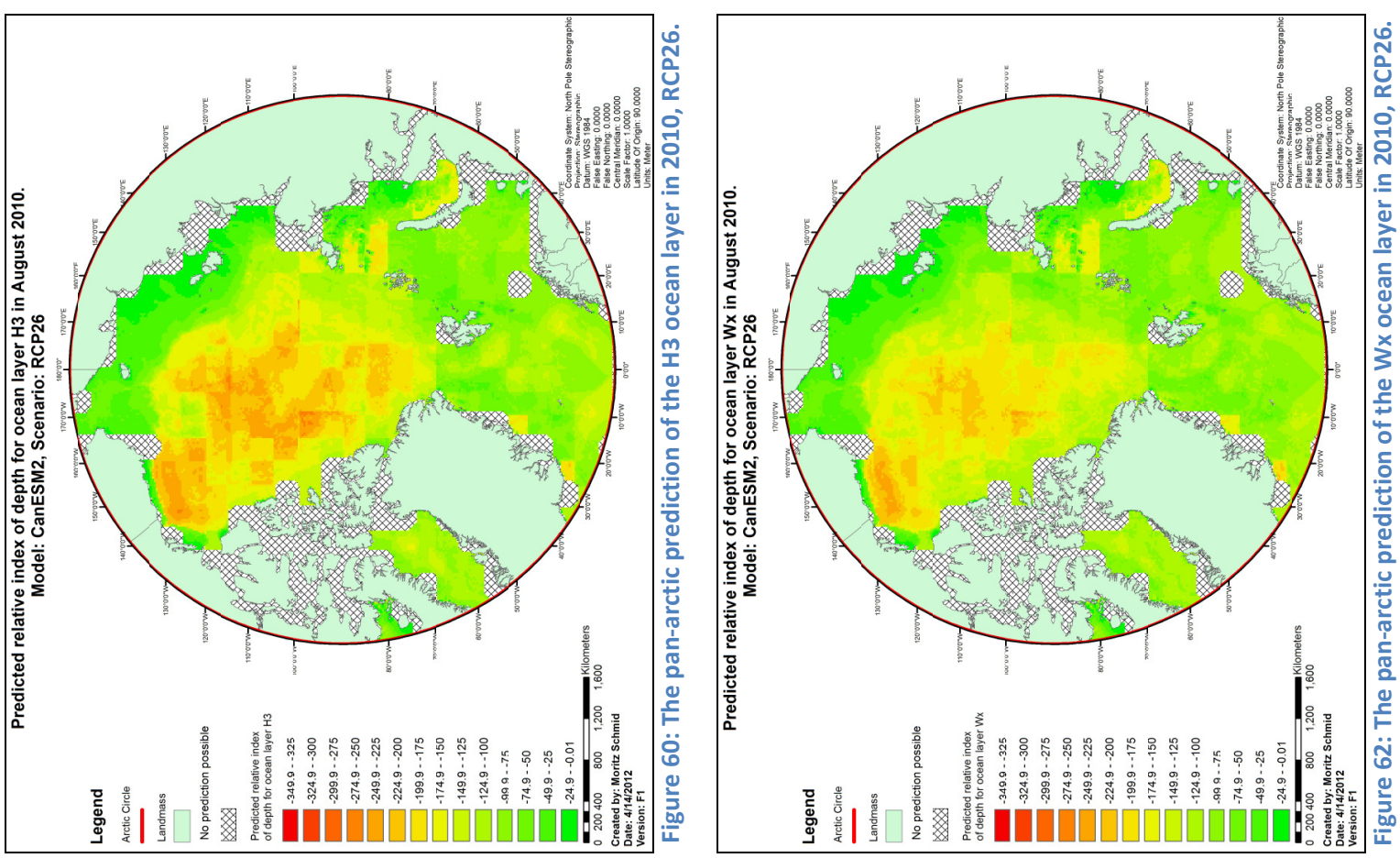


\subsubsection{Calanus hyperboreus predictions}

Overlay of presence/random absence and predicted relative index of depth in 2010

The predicted presence/random absence layer showed that $84.77 \%$ of the points were predicted random absence and $15.23 \%$ presence (Fig. 64). The mean predicted relative index of depth for $C$. hyperboreus in 2010 was $111.84 \mathrm{~m}$ with a maximum depth of $942.19 \mathrm{~m}$ and a minimum depth of $-70.74 \mathrm{~m}$.

Overlay of presence/random absence and predicted relative index of depth in 2100

The predicted presence/random absence layer showed that $73.69 \%$ of the points were predicted random absence and $26.31 \%$ presence (Fig. 65). The mean predicted relative index of depth for $C$. hyperboreus in 2100 was $127.13 \mathrm{~m}$ with a maximum depth of $1190.70 \mathrm{~m}$ and a minimum depth of $-71.21 \mathrm{~m}$.

Overlay of presence/random absence and predicted life stages in 2010

The predicted presence/random absence layer showed that $84.77 \%$ of the points were predicted random absence and $15.23 \%$ presence (Fig. 66). The predicted life stage layer shows $51.94 \%$ of the points were predicted adult and $48.06 \%$ copepodite.

Overlay of presence/random absence and predicted life stages in 2100

The predicted presence/random absence layer showed that $73.69 \%$ of the points were predicted random absence and $26.31 \%$ presence (Fig. 67 ). The predicted life stage layer shows $48.77 \%$ of the points were predicted adult and $51.23 \%$ copepodite.

\section{Explanation for the following figures:}

General: Black color in the presence/random absence layer delineates random absence. Random absence however does not indicate absolute absence but separates predicted presence (hot spot) from other, less suitable areas. Predicted presence is transparent in order to make the underlying layer visible (depth or life stages).

Specific for predicted relative index of depth: The color scale ranges from green where the relative index of depth is shallower to red areas where the relative index of depth is deeper.

Specific for predicted life stages: Orange color delineates predicted adult life stages; green color delineates predicted copepodite life stages. 

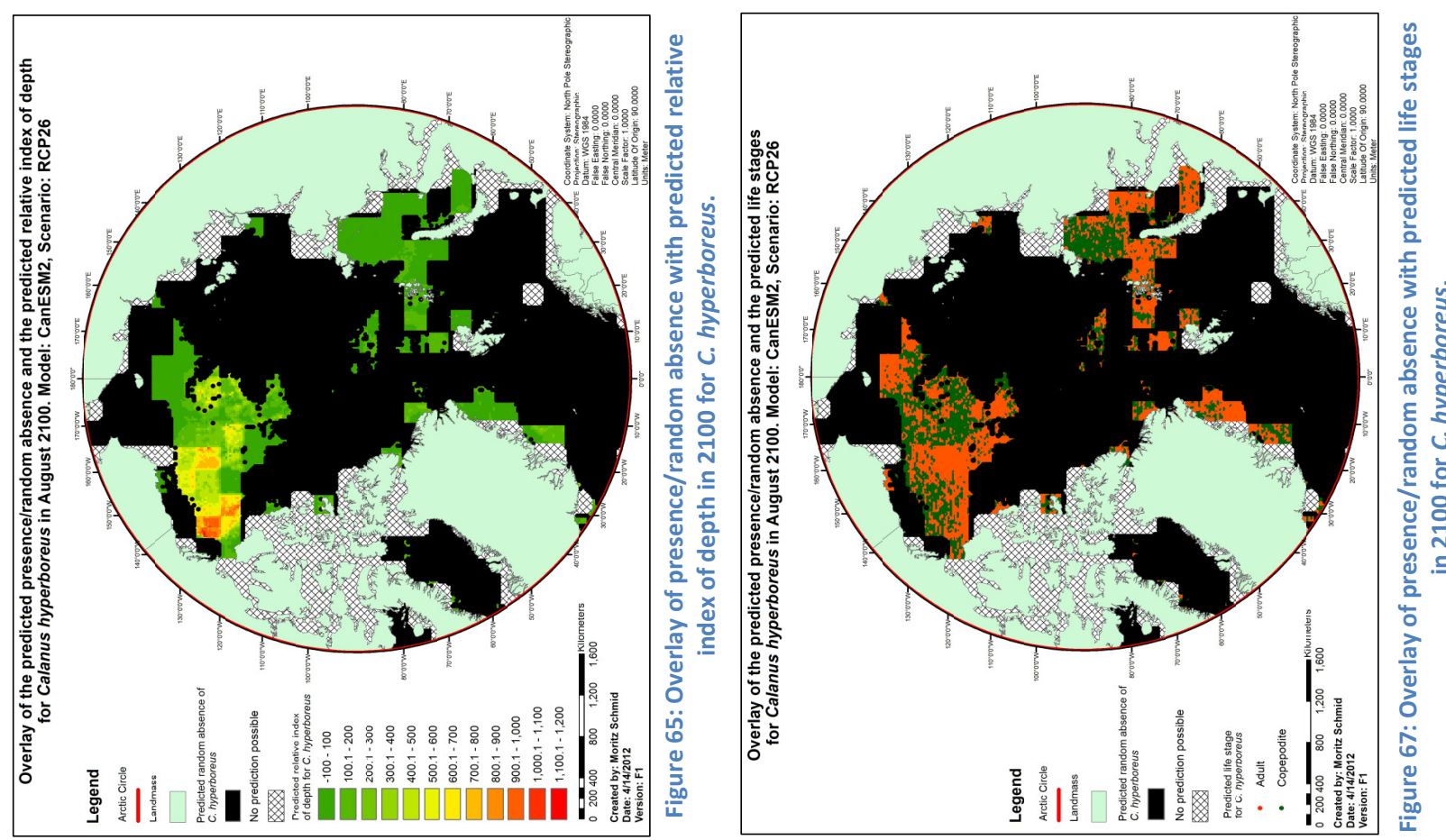

ำ
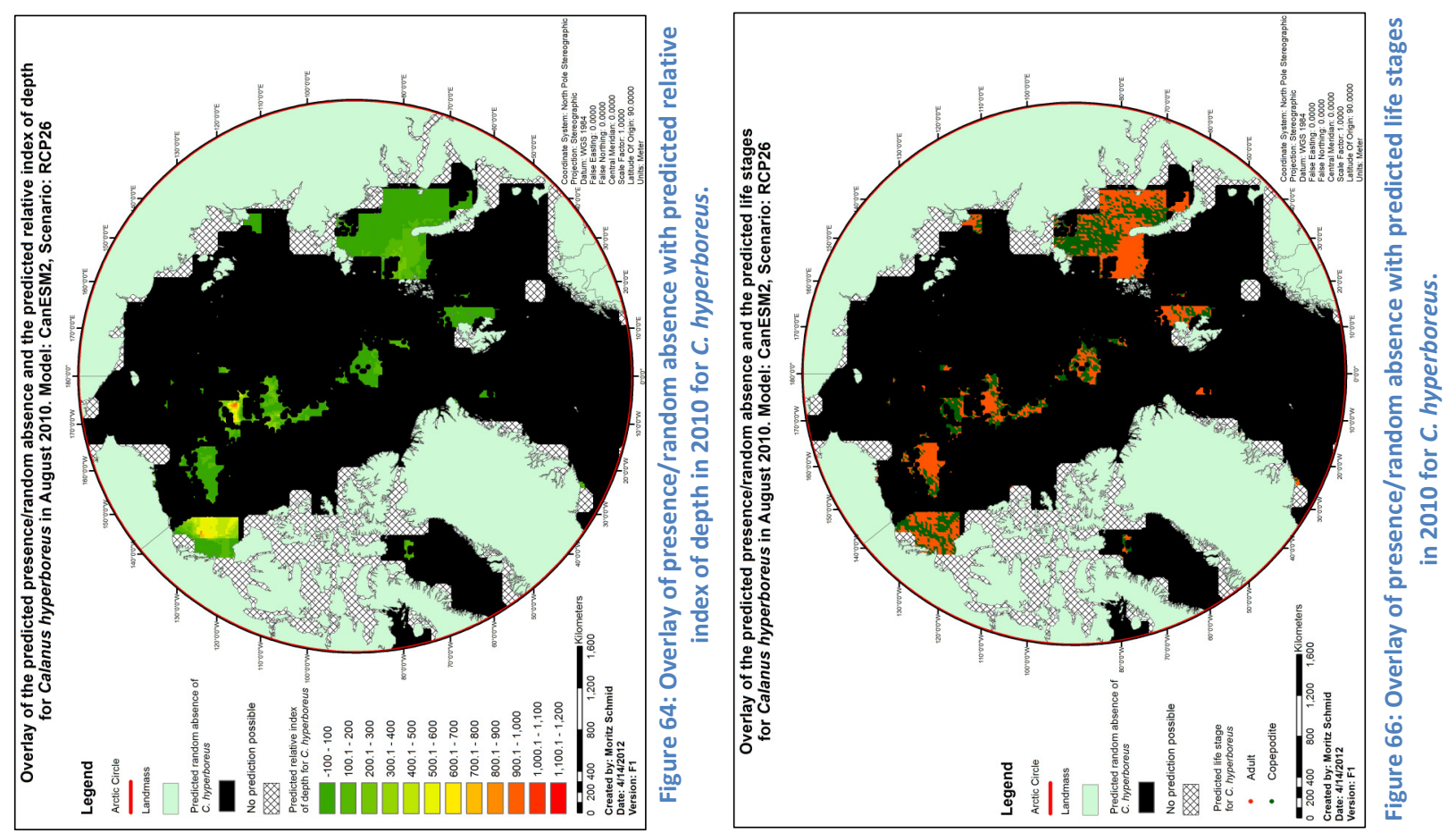


\subsubsection{Metridia longa predictions}

Overlay of presence/random absence and predicted relative index of depth in 2010

The predicted presence/random absence layer showed that $82.61 \%$ of the points were predicted random absence and $17.39 \%$ presence (Fig. 68). The mean predicted relative index of depth for M. longa in 2010 was $124.13 \mathrm{~m}$ with a maximum depth of $556.05 \mathrm{~m}$ and a minimum depth of $-5.73 \mathrm{~m}$.

Overlay of presence/random absence and predicted relative index of depth in 2100

The predicted presence/random absence layer showed that $76.01 \%$ of the points were predicted random absence and $23.99 \%$ presence (Fig. 69). The mean predicted relative index of depth for $M$. longa in 2100 was $134.57 \mathrm{~m}$ with a maximum depth of $696.37 \mathrm{~m}$ and a minimum depth of $-4.76 \mathrm{~m}$.

Overlay of presence/random absence and predicted life stages in 2010

The predicted presence/random absence layer showed that $82.61 \%$ of the points were predicted random absence and $17.39 \%$ presence (Fig. 70). The predicted life stage layer shows $64.19 \%$ of the points were predicted adult, $17.50 \%$ copepodite and $18.31 \%$ nauplii.

$\underline{\text { Overlay of presence/random absence and predicted life stages in } 2100}$

The predicted presence/random absence layer showed that $76.01 \%$ of the points were predicted random absence and $23.99 \%$ presence (Fig. 71 ). The predicted life stage layer shows $63 \%$ of the points were predicted adult, $20.49 \%$ copepodite and $16.5 \%$ nauplii.

Explanation for the following figures:

General: General: Black color in the presence/random absence layer delineates random absence. Random absence however does not indicate absolute absence but separates predicted presence (hot spot) from other, less suitable areas. Predicted presence is transparent in order to make the underlying layer visible (depth or life stages).

Specific for predicted relative index of depth: The color scale ranges from green where the relative index of depth is shallower to red areas where the relative index of depth is deeper.

Specific for predicted life stages: Orange color delineates predicted adult life stages; green color delineates predicted copepodite life stages. 

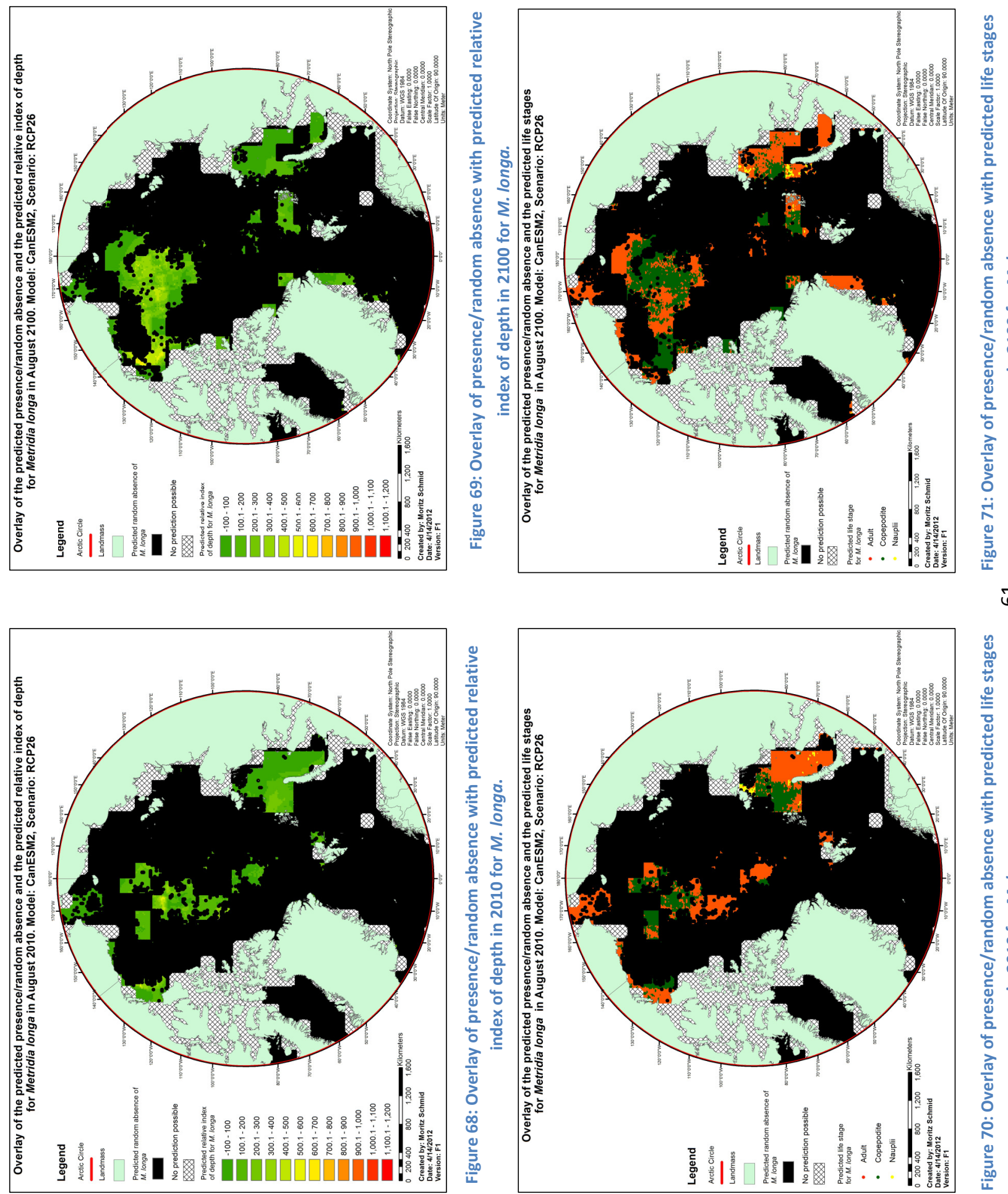

бூ

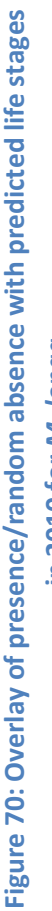




\subsubsection{Metridia pacifica predictions}

Overlay of presence/random absence and predicted relative index of depth in 2010

The predicted presence/random absence layer showed that $92.21 \%$ of the points were predicted random absence and $7.79 \%$ presence (Fig. 72). The mean predicted relative index of depth for M. pacifica in 2010 was $26.25 \mathrm{~m}$ with a maximum depth of $28.18 \mathrm{~m}$ and a minimum depth of $22.14 \mathrm{~m}$.

Overlay of presence/random absence and predicted relative index of depth in 2100

The predicted presence/random absence layer showed that $93.27 \%$ of the points were predicted random absence and $6.73 \%$ presence (Fig. 73). The mean predicted relative index of depth for M. pacifica in 2100 was $25.75 \mathrm{~m}$ with a maximum depth of $28.12 \mathrm{~m}$ and a minimum depth of $22.14 \mathrm{~m}$.

Overlay of presence/random absence and predicted life stages in 2010

The predicted presence/random absence layer showed that $92.21 \%$ of the points were predicted random absence and $7.79 \%$ presence (Fig. 74). The predicted life stage layer shows $98.62 \%$ of the points were predicted adult and $1.38 \%$ copepodite.

Overlay of presence/random absence and predicted life stages in 2100

The predicted presence/random absence layer showed that $93.27 \%$ of the points were predicted random absence and $6.73 \%$ presence (Fig. 75 ). The predicted life stage layer shows $98.62 \%$ of the points were predicted adult and $1.38 \%$ copepodite.

\section{Explanation for the following figures:}

General: Black color in the presence/random absence layer delineates random absence. Random absence however does not indicate absolute absence but separates predicted presence (hot spot) from other, less suitable areas. Predicted presence is transparent in order to make the underlying layer visible (depth or life stages).

Specific for predicted relative index of depth: The color scale ranges from green where the relative index of depth is shallower to red areas where the relative index of depth is deeper.

Specific for predicted life stages: Orange color delineates predicted adult life stages; green color delineates predicted copepodite life stages. 

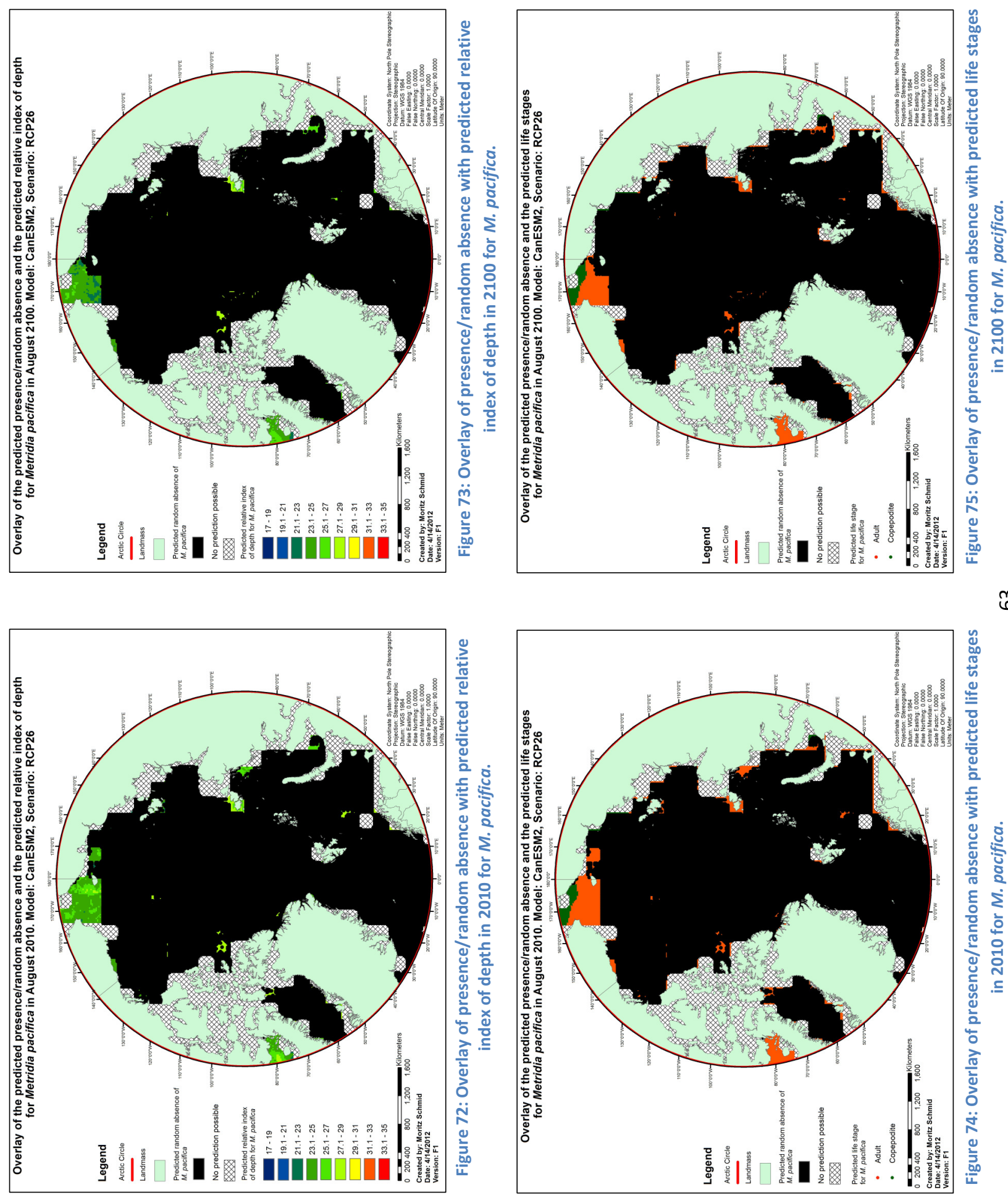

ตี 


\subsection{Low emission (RCP26) future predictions, excluding ocean layers}

\subsubsection{Calanus hyperboreus predictions}

\section{Overlay of presence/random absence and predicted relative index of depth in 2010}

The predicted presence/random absence layer showed that $88.48 \%$ of the points were predicted random absence and $11.52 \%$ presence (Fig. 76). The mean predicted relative index of depth for C. hyperboreus in 2010 was $130.91 \mathrm{~m}$ with a maximum depth of $949.02 \mathrm{~m}$ and a minimum depth of $-44.21 \mathrm{~m}$.

Overlay of presence/random absence and predicted relative index of depth in 2100

The predicted presence/random absence layer showed that $81.54 \%$ of the points were predicted random absence and $18.46 \%$ presence (Fig. 77). The mean predicted relative index of depth for C. hyperboreus in 2100 was $135.54 \mathrm{~m}$ with a maximum depth of $861.02 \mathrm{~m}$ and a minimum depth of $-15.37 \mathrm{~m}$.

Overlay of presence/random absence and predicted life stages in 2010

The predicted presence/random absence layer showed that $88.48 \%$ of the points were predicted random absence and $11.52 \%$ presence (Fig. 78 ). The predicted life stage layer shows $61.30 \%$ of the points were predicted adult and $38.7 \%$ copepodite.

Overlay of presence/random absence and predicted life stages in 2100

The predicted presence/random absence layer showed that $81.54 \%$ of the points were predicted random absence and $18.46 \%$ presence (Fig. 79 ). The predicted life stage layer shows $56.93 \%$ of the points were predicted adult and $43.07 \%$ copepodite.

Explanation for the following figures:

General: Black color in the presence/random absence layer delineates random absence. Random absence however does not indicate absolute absence but separates predicted presence (hot spot) from other, less suitable areas. Predicted presence is transparent in order to make the underlying layer visible (depth or life stages).

Specific for predicted relative index of depth: The color scale ranges from green where the relative index of depth is shallower to red areas where the relative index of depth is deeper.

Specific for predicted life stages: Orange color delineates predicted adult life stages; green color delineates predicted copepodite life stages. 

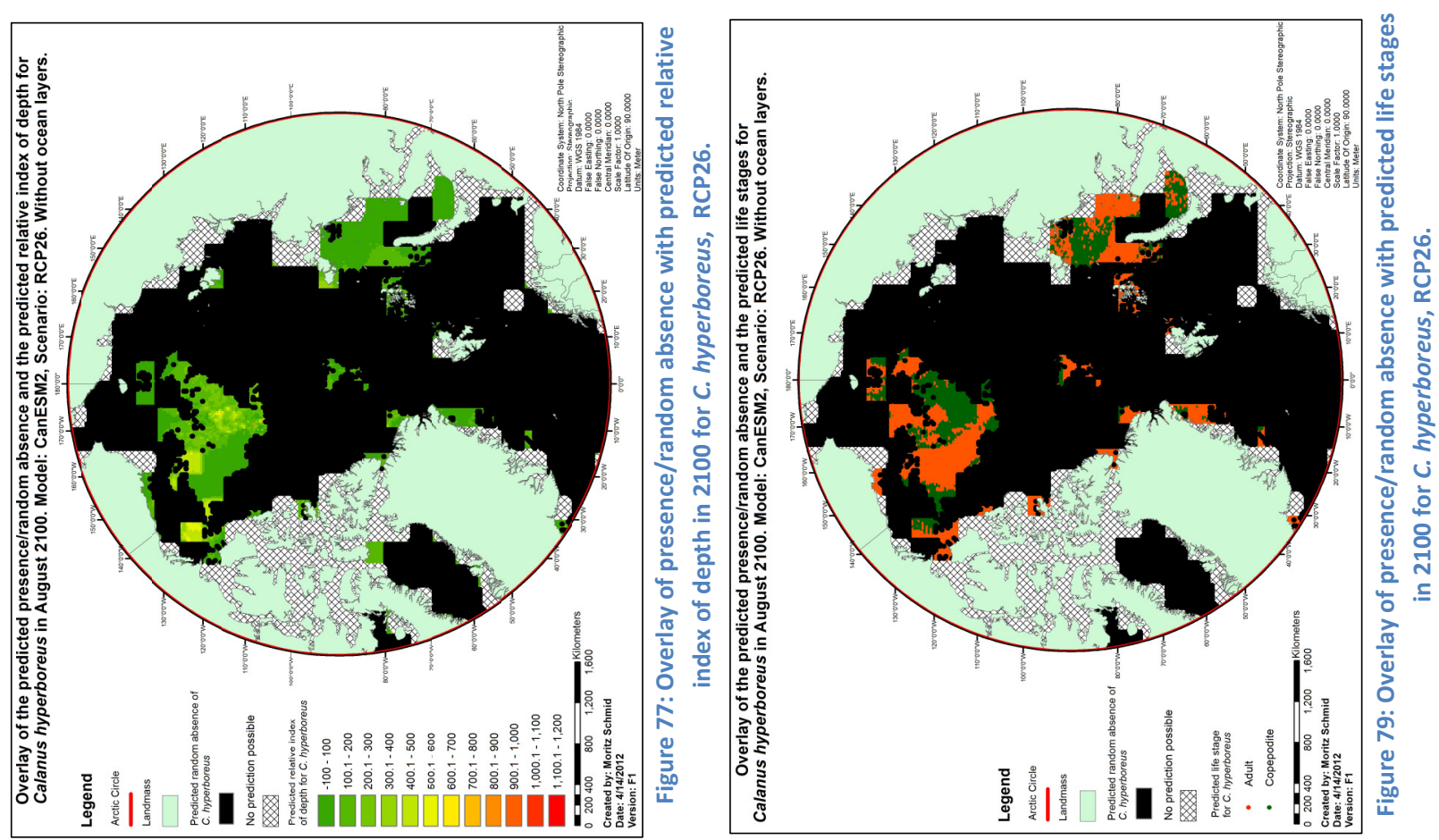

นึ
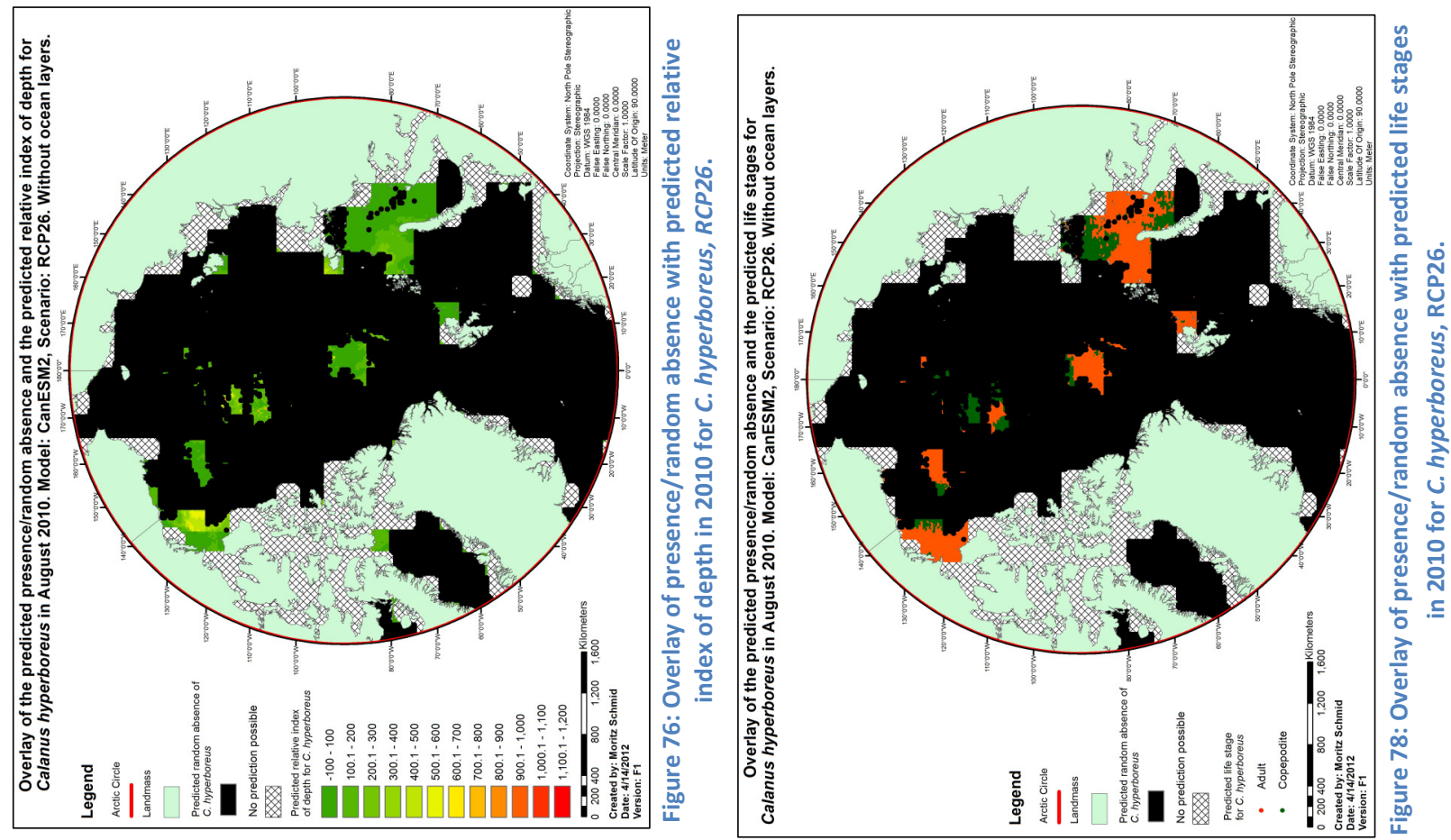


\subsubsection{Metridia longa predictions}

Overlay of presence/random absence and predicted relative index of depth in 2010

The predicted presence/random absence layer showed that $88.55 \%$ of the points were predicted random absence and $11.45 \%$ presence (Fig. 80). The mean predicted relative index of depth for M. longa in 2010 was $127.36 \mathrm{~m}$ with a maximum depth of $845.72 \mathrm{~m}$ and a minimum depth of $-49.28 \mathrm{~m}$.

Overlay of presence/random absence and predicted relative index of depth in 2100

The predicted presence/random absence layer showed that $87.20 \%$ of the points were predicted random absence and $12.80 \%$ presence (Fig. 81 ). The mean predicted relative index of depth for $M$. longa in 2100 was $130.09 \mathrm{~m}$ with a maximum depth of $600.13 \mathrm{~m}$ and a minimum depth of $-26.53 \mathrm{~m}$.

$\underline{\text { Overlay of presence/random absence and predicted life stages in } 2010}$

The predicted presence/random absence layer showed that $88.55 \%$ of the points were predicted random absence and $11.45 \%$ presence (Fig. 82 ). The predicted life stage layer shows $42.42 \%$ of the points were predicted adult, $36.35 \%$ copepodite and $21.23 \%$ nauplii.

$\underline{\text { Overlay of presence/random absence and predicted life stages in } 2100}$

The predicted presence/random absence layer showed that $87.20 \%$ of the points were predicted random absence and $12.80 \%$ presence (Fig. 83 ). The predicted life stage layer shows $36.01 \%$ of the points were predicted adult, $42.39 \%$ copepodite and $21.6 \%$ nauplii.

Explanation for the following figures:

General: Black color in the presence/random absence layer delineates random absence. Random absence however does not indicate absolute absence but separates predicted presence (hot spot) from other, less suitable areas. Predicted presence is transparent in order to make the underlying layer visible (depth or life stages).

Specific for predicted relative index of depth: The color scale ranges from green where the relative index of depth is shallower to red areas where the relative index of depth is deeper.

Specific for predicted life stages: Orange color delineates predicted adult life stages; green color delineates predicted copepodite life stages. 

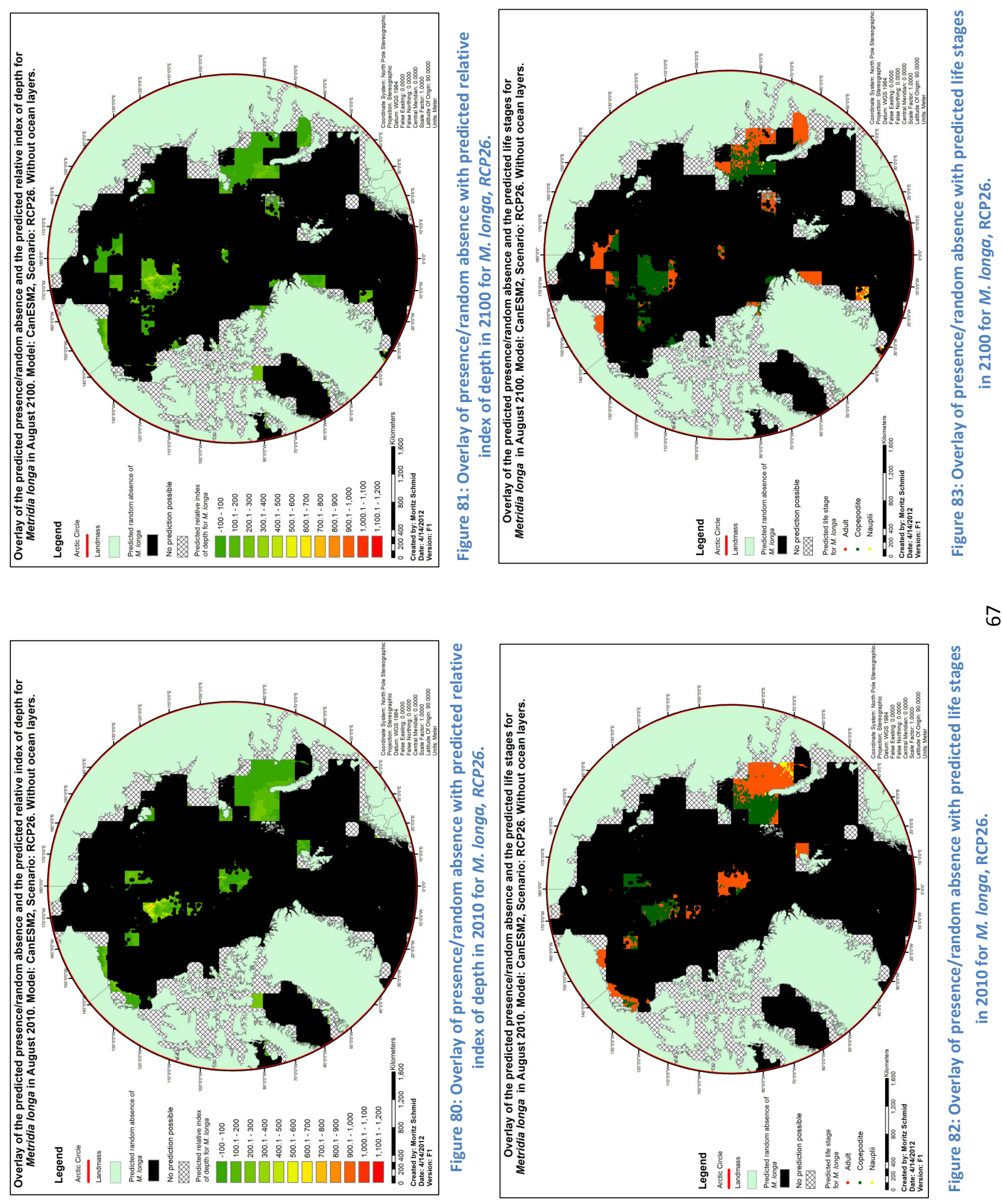

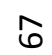

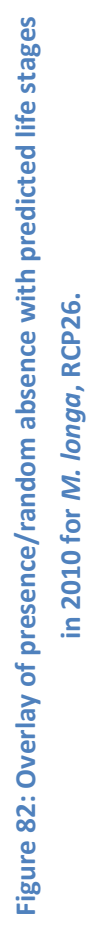




\subsubsection{Metridia pacifica predictions}

Overlay of presence/random absence and predicted relative index of depth in 2010

The predicted presence/random absence layer showed that $94.80 \%$ of the points were predicted random absence and 5.2\% presence (Fig. 84). The mean predicted relative index of depth for M. pacifica in 2010 was $31.06 \mathrm{~m}$ with a maximum depth of $33.27 \mathrm{~m}$ and a minimum depth of $24.68 \mathrm{~m}$.

Overlay of presence/random absence and predicted relative index of depth in 2100

The predicted presence/random absence layer showed that $95.90 \%$ of the points were predicted random absence and $4.1 \%$ presence (Fig. 85). The mean predicted relative index of depth for M. pacifica in 2010 was $31 \mathrm{~m}$ with a maximum depth of $33.27 \mathrm{~m}$ and a minimum depth of $24.68 \mathrm{~m}$.

$\underline{\text { Overlay of presence/random absence and predicted life stages in } 2010}$

The predicted presence/random absence layer showed that $94.8 \%$ of the points were predicted random absence and $5.2 \%$ presence (Fig. 86). The predicted life stage layer shows $99.09 \%$ of the points were predicted adult and $0.91 \%$ copepodite.

$\underline{\text { Overlay of presence/random absence and predicted life stages in } 2100}$

The predicted presence/random absence layer showed that $95.9 \%$ of the points were predicted random absence and $4.1 \%$ presence (Fig. 87 ). The predicted life stage layer shows $99.1 \%$ of the points were predicted adult and $0.9 \%$ copepodite.

Explanation for the following figures:

General: Black color in the presence/random absence layer delineates random absence. Random absence however does not indicate absolute absence but separates predicted presence (hot spot) from other, less suitable areas. Predicted presence is transparent in order to make the underlying layer visible (depth or life stages).

Specific for predicted relative index of depth: The color scale ranges from green where the relative index of depth is shallower to red areas where the relative index of depth is deeper.

Specific for predicted life stages: Orange color delineates predicted adult life stages; green color delineates predicted copepodite life stages. 

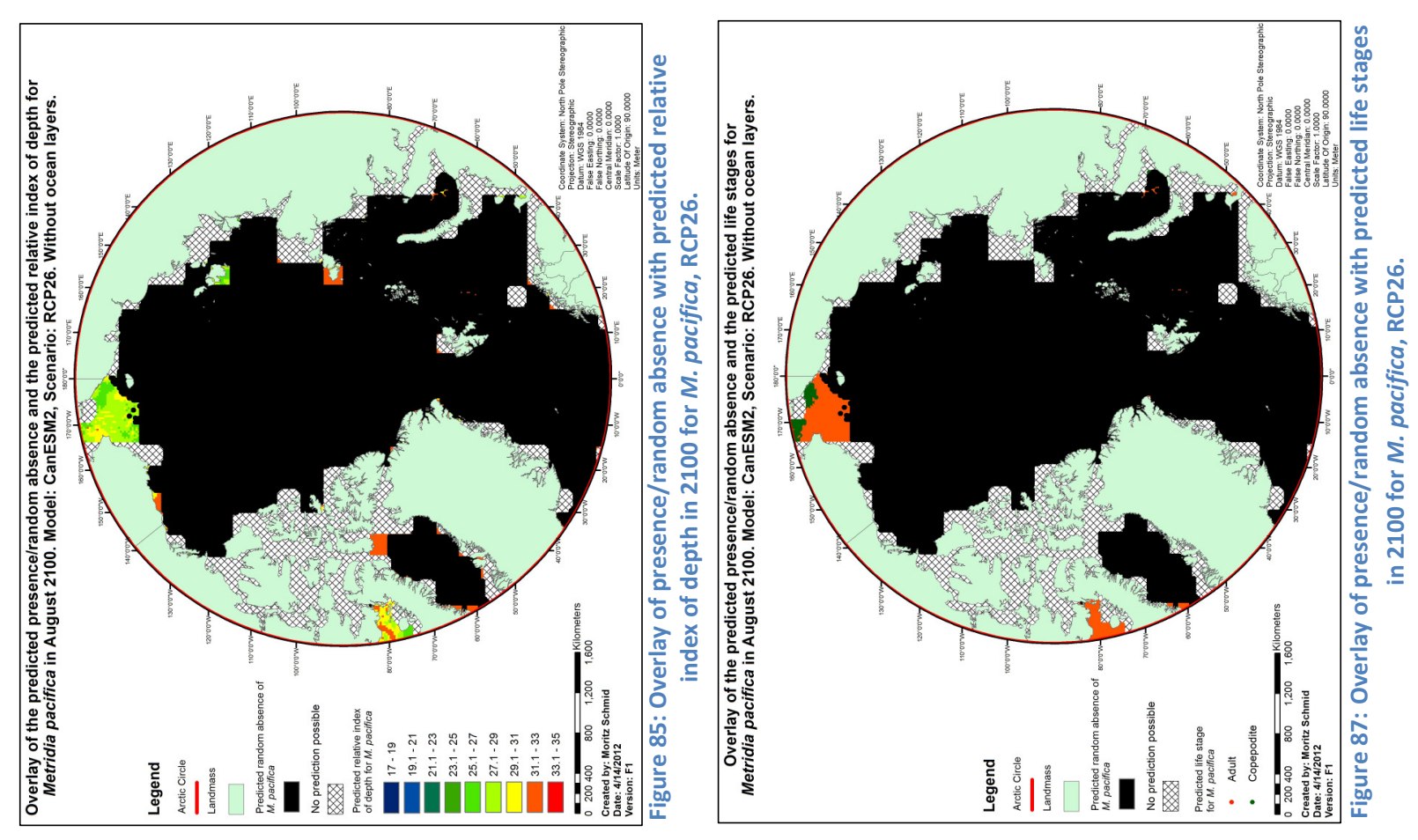

ชู
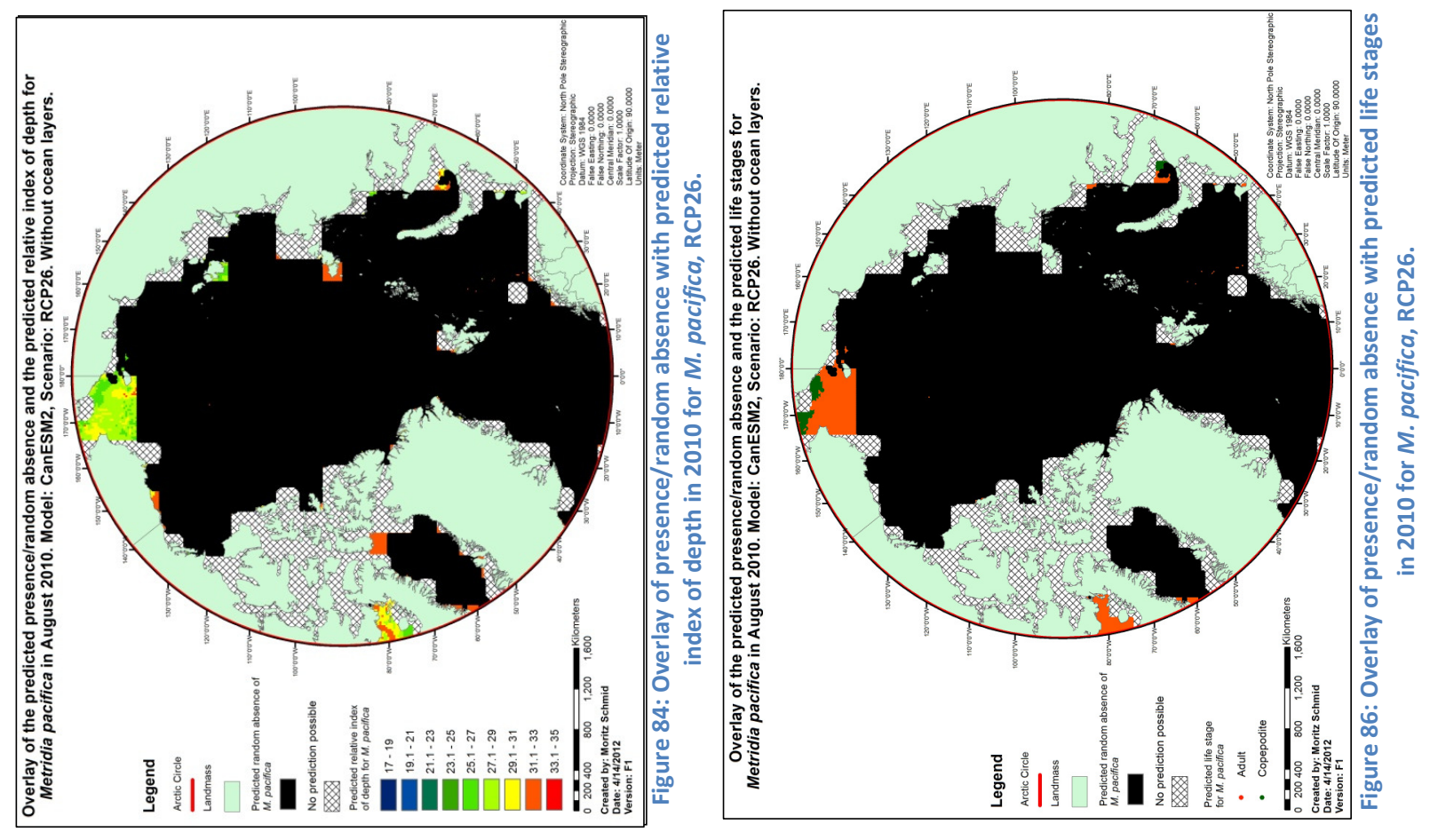


\subsection{High emission (RCP85) future predictions, including ocean layers}

\subsubsection{Predicted ocean layers}

The predicted ocean layer $\mathrm{H} 1$ in 2010

The mean predicted relative index of depth of layer $\mathrm{H} 1$ in 2010 was $-23.99 \mathrm{~m}$ with a maximum depth of 63.08m (Fig. 88).

The predicted ocean layer $\mathrm{H} 1$ in 2100

The mean predicted relative index of depth of layer $\mathrm{H} 1$ in 2100 was $-22.57 \mathrm{~m}$ with a maximum depth of 45.42m (Fig. 89).

The predicted ocean layer $\mathrm{H} 2$ in 2010

The mean predicted relative index of depth of layer $\mathrm{H} 2$ in 2010 was $-86.28 \mathrm{~m}$ with a maximum depth of 179.58m (Fig. 90).

The predicted ocean layer $\mathrm{H} 2$ in 2100

The mean predicted relative index of depth of layer $\mathrm{H} 2$ in 2100 was $-89.44 \mathrm{~m}$ with a maximum depth of 157.10m (Fig. 91).

Note: Layers do not necessarily exist over shallow shelf areas.

In the following figures, the color scale ranges from green areas, where the predicted ocean layer is shallower, to red areas, where the ocean layer is deeper. 

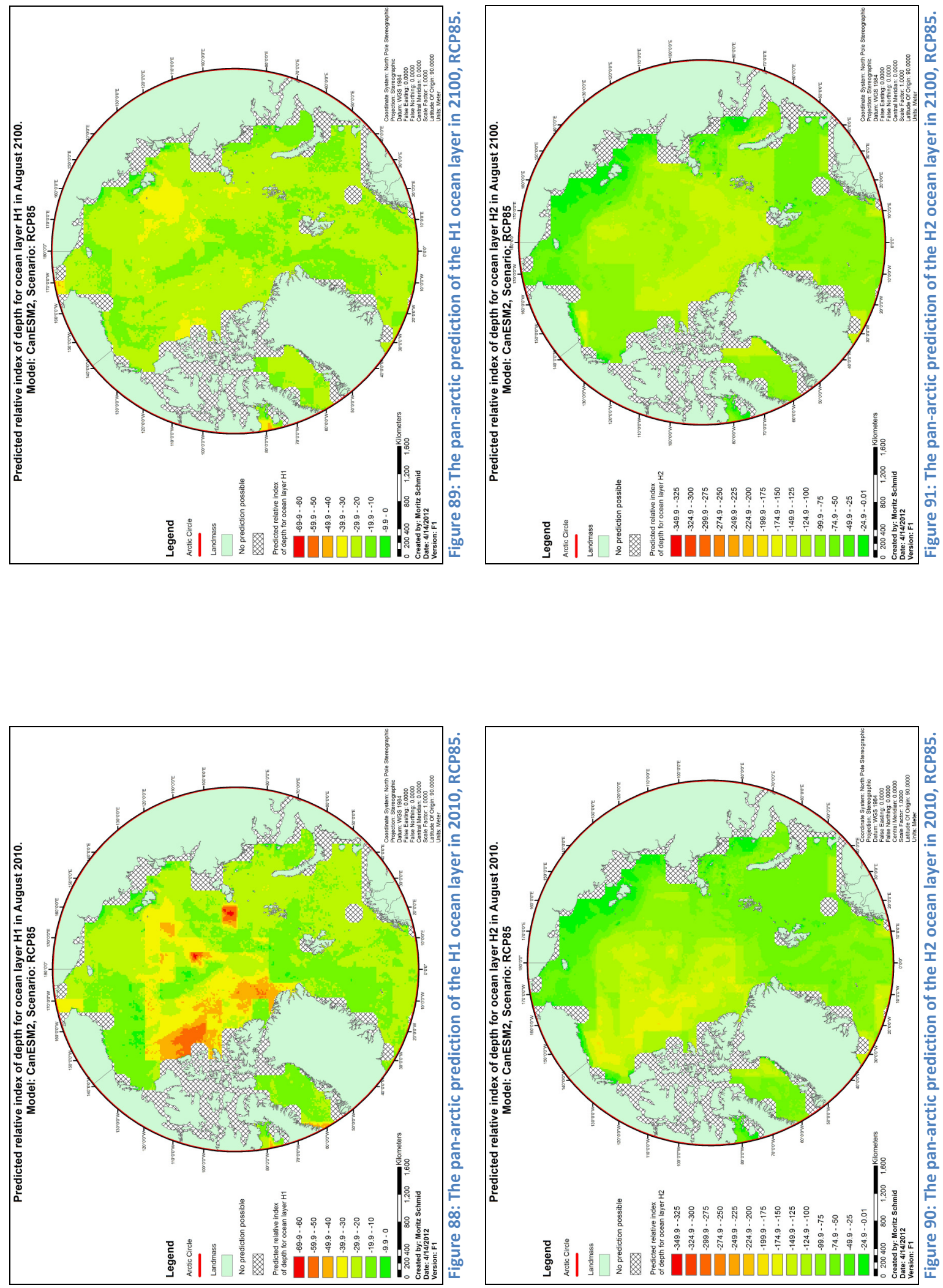


\section{The predicted ocean layer $\mathrm{H} 3$ in 2010}

The mean predicted relative index of depth of layer H3 in 2010 was $-142.55 \mathrm{~m}$ with a maximum depth of 346.25m (Fig. 92).

The predicted ocean layer $\mathrm{H} 3$ in 2100

The mean predicted relative index of depth of layer $\mathrm{H} 3$ in 2100 was $-144.36 \mathrm{~m}$ with a maximum depth of 286.98m (Fig. 93).

The predicted ocean layer Wx in 2010

The mean predicted relative index of depth of layer Wx in 2010 was $-124.20 \mathrm{~m}$ with a maximum depth of 302.19m (Fig. 94).

The predicted ocean layer Wx in 2100

The mean predicted relative index of depth of layer Wx in 2100 was $-125.57 \mathrm{~m}$ with a maximum depth of 245.68m (Fig. 95).

Note: Layers do not necessarily exist over shallow shelf areas.

In the following figures, the color scale ranges from green areas, where the predicted ocean layer is shallower, to red areas, where the ocean layer is deeper. 

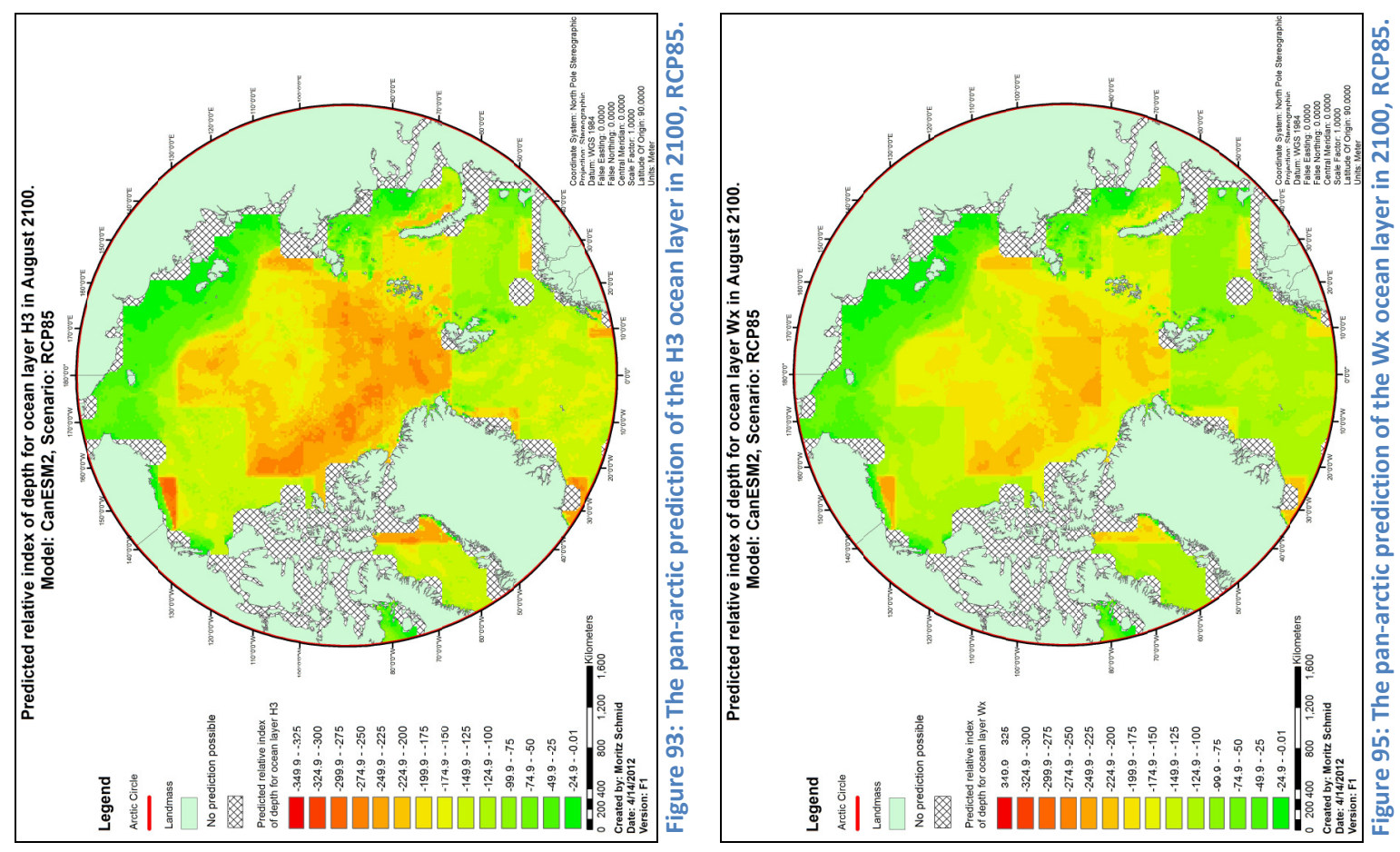

$\stackrel{m}{n}$
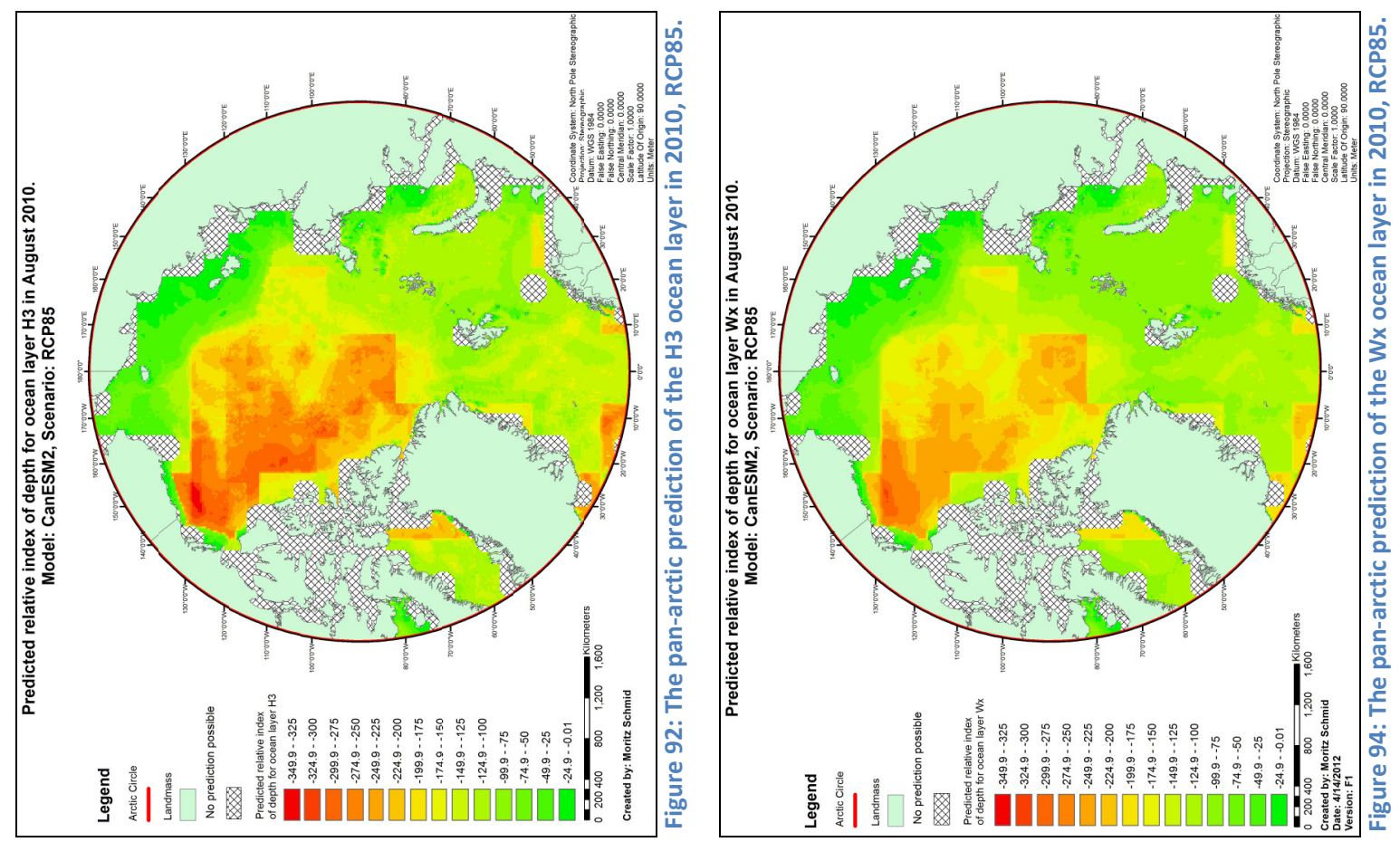


\subsubsection{Calanus hyperboreus predictions}

Overlay of presence/random absence and predicted relative index of depth in 2010

The predicted presence/random absence layer showed that $88.27 \%$ of the points were predicted random absence and $11.73 \%$ presence (Fig. 96). The mean predicted relative index of depth for $C$. hyperboreus in 2010 was $111.84 \mathrm{~m}$ with a maximum depth of $942.19 \mathrm{~m}$ and a minimum depth of $-70.74 \mathrm{~m}$.

Overlay of presence/random absence and predicted relative index of depth in 2100

The predicted presence/random absence layer showed that $82.15 \%$ of the points were predicted random absence and $17.85 \%$ presence (Fig. 97). The mean predicted relative index of depth for $C$. hyperboreus in 2100 was $227.09 \mathrm{~m}$ with a maximum depth of $973.80 \mathrm{~m}$ and a minimum depth of $-43.53 \mathrm{~m}$.

$\underline{\text { Overlay of presence/random absence and predicted life stages in } 2010}$

The predicted presence/random absence layer showed that $88.27 \%$ of the points were predicted random absence and $11.73 \%$ presence (Fig. 98 ). The predicted life stage layer shows $59.82 \%$ of the points were predicted adult and $40.18 \%$ copepodite.

$\underline{\text { Overlay of presence/random absence and predicted life stages in } 2100}$

The predicted presence/random absence layer showed that $82.15 \%$ of the points were predicted random absence and $17.85 \%$ presence (Fig. 99). The predicted life stage layer shows $44.22 \%$ of the points were predicted adult and $55.78 \%$ copepodite.

Explanation for the following figures:

General: Black color in the presence/random absence layer delineates random absence. Random absence however does not indicate absolute absence but separates predicted presence (hot spot) from other, less suitable areas. Predicted presence is transparent in order to make the underlying layer visible (depth or life stages).

Specific for predicted relative index of depth: The color scale ranges from green where the relative index of depth is shallower to red areas where the relative index of depth is deeper.

Specific for predicted life stages: Orange color delineates predicted adult life stages; green color delineates predicted copepodite life stages. 


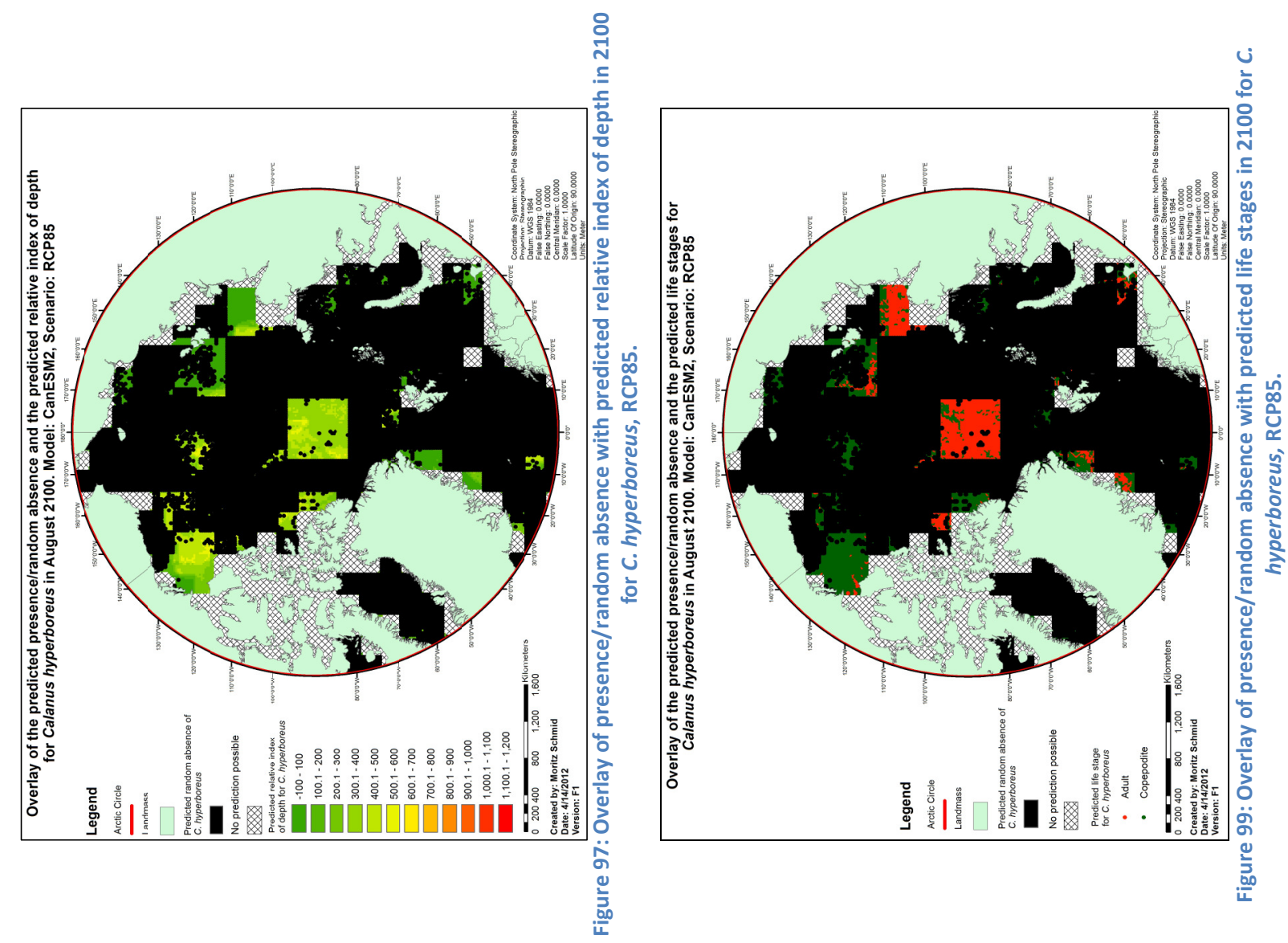

$\stackrel{n}{N}$
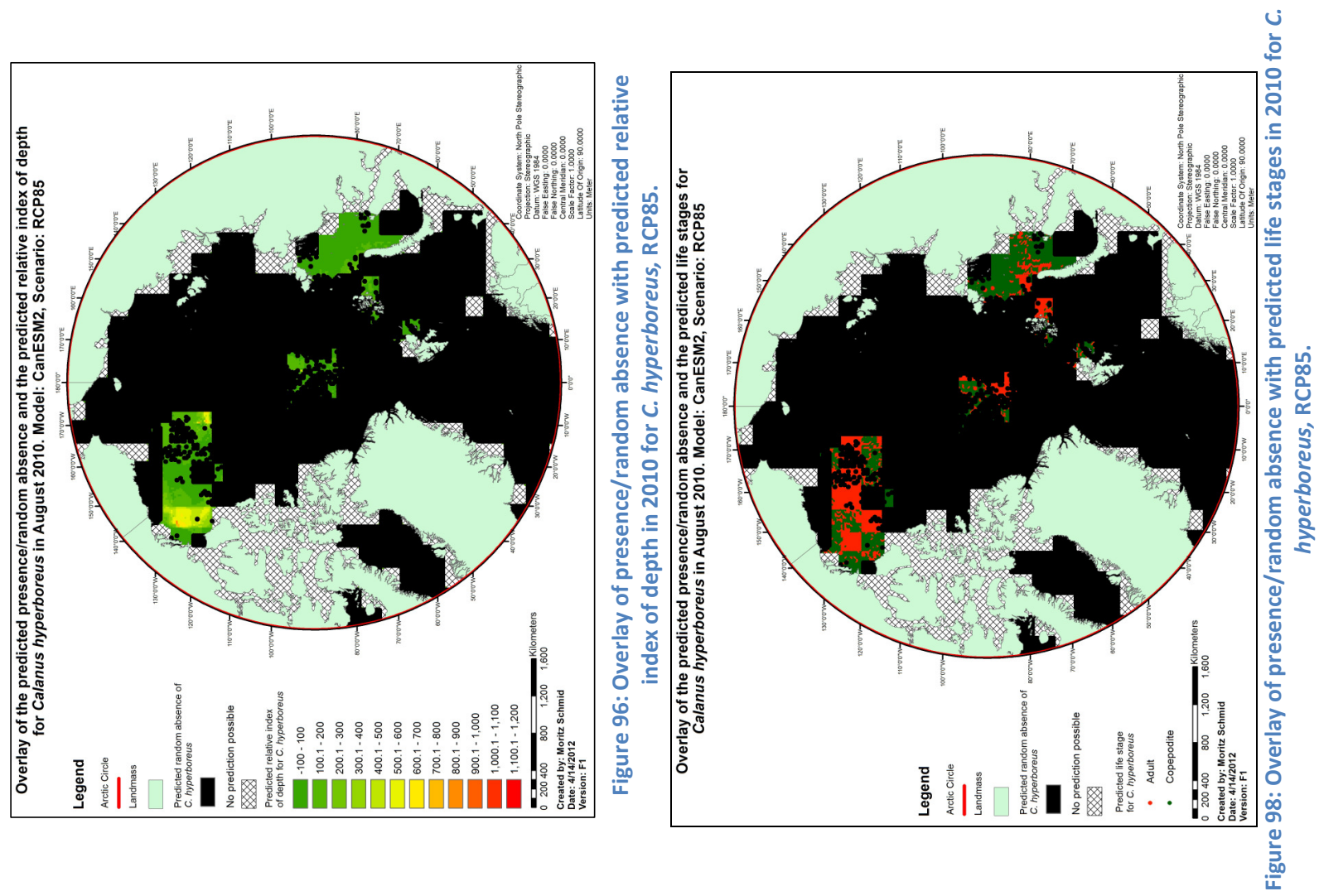


\subsubsection{Metridia longa predictions}

Overlay of presence/random absence and predicted relative index of depth in 2010

The predicted presence/random absence layer showed that $68.63 \%$ of the points were predicted random absence and $31.37 \%$ presence (Fig. 100). The mean predicted relative index of depth for M. longa in 2010 was $124.13 \mathrm{~m}$ with a maximum depth of $556.05 \mathrm{~m}$ and a minimum depth of $-5.73 \mathrm{~m}$.

Overlay of presence/random absence and predicted relative index of depth in 2100

The predicted presence/random absence layer showed that $67.52 \%$ of the points were predicted random absence and $32.48 \%$ presence (Fig. 101). The mean predicted relative index of depth for M. longa in 2100 was $147.13 \mathrm{~m}$ with a maximum depth of $512.75 \mathrm{~m}$ and a minimum depth of $-7.85 \mathrm{~m}$.

Overlay of presence/random absence and predicted life stages in 2010

The predicted presence/random absence layer showed that $68.63 \%$ of the points were predicted random absence and $31.37 \%$ presence (Fig. 102). The predicted life stage layer shows $53.24 \%$ of the points were predicted adult, $25.15 \%$ copepodite and $21.6 \% 1$ nauplii.

$\underline{\text { Overlay of presence/random absence and predicted life stages in } 2100}$

The predicted presence/random absence layer showed that $67.52 \%$ of the points were predicted random absence and $32.48 \%$ presence (Fig. 103). The predicted life stage layer shows $35.63 \%$ of the points were predicted adult, $45.53 \%$ copepodite and $21.17 \%$ nauplii.

Explanation for the following figures:

General: Black color in the presence/random absence layer delineates random absence. Random absence however does not indicate absolute absence but separates predicted presence (hot spot) from other, less suitable areas. Predicted presence is transparent in order to make the underlying layer visible (depth or life stages).

Specific for predicted relative index of depth: The color scale ranges from green where the relative index of depth is shallower to red areas where the relative index of depth is deeper.

Specific for predicted life stages: Orange color delineates predicted adult life stages; green color delineates predicted copepodite life stages. 

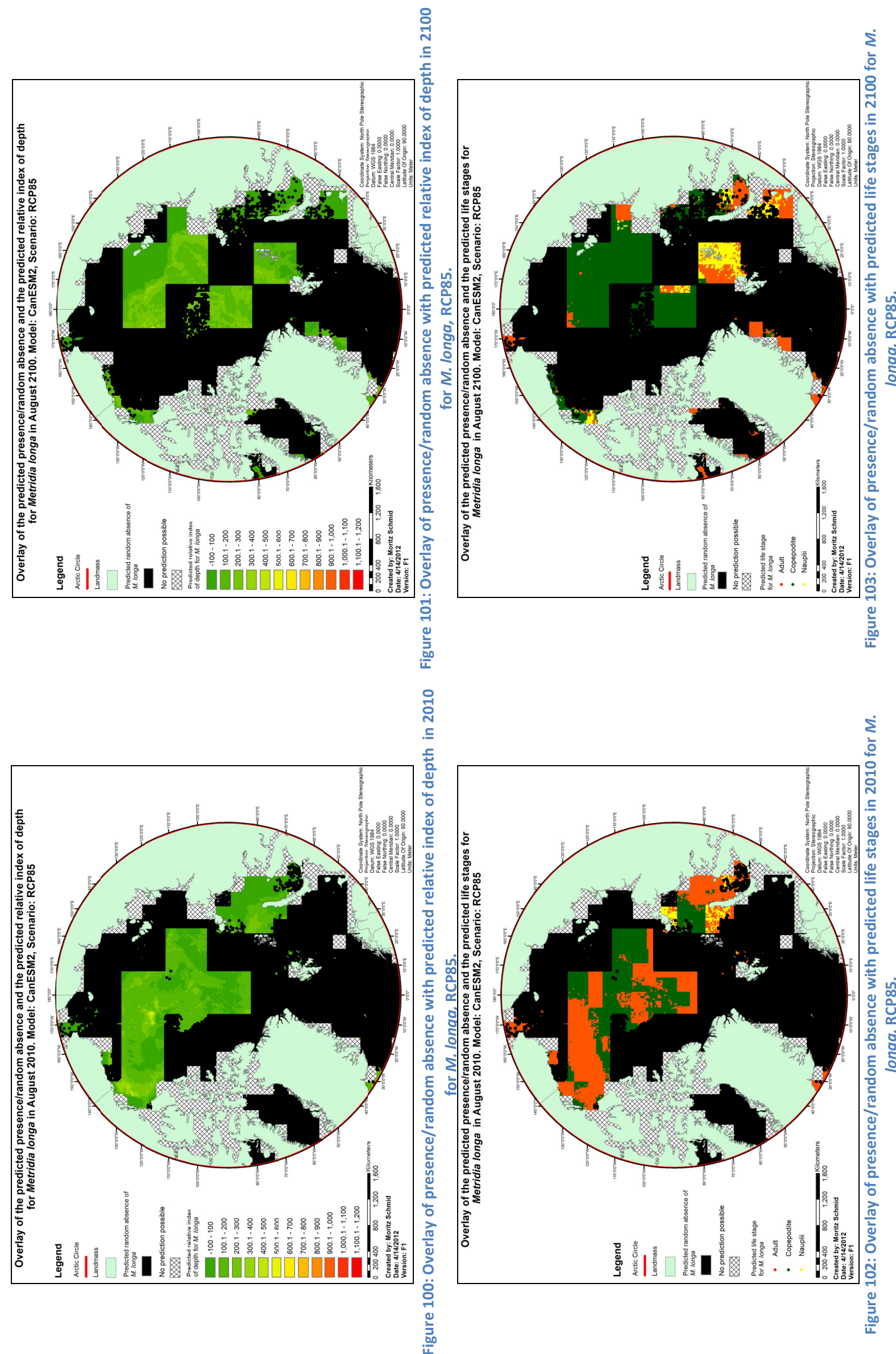

$\curvearrowright$ 


\subsubsection{Metridia pacifica predictions}

Overlay of presence/random absence and predicted relative index of depth in 2010

The predicted presence/random absence layer showed that $96.39 \%$ of the points were predicted random absence and 3.61\% presence (Fig. 104). The mean predicted relative index of depth for M. pacifica in 2010 was $26.25 \mathrm{~m}$ with a maximum depth of $28.12 \mathrm{~m}$ and a minimum depth of $22.14 \mathrm{~m}$.

Overlay of presence/random absence and predicted relative index of depth in 2100

The predicted presence/random absence layer showed that $98.19 \%$ of the points were predicted random absence and $1.81 \%$ presence (Fig. 105). The mean predicted relative index of depth for M. pacifica in 2100 was $21.39 \mathrm{~m}$ with a maximum depth of $22.77 \mathrm{~m}$ and a minimum depth of $17.49 \mathrm{~m}$.

Overlay of presence/random absence and predicted life stages in 2010

The predicted presence/random absence layer showed that $96.39 \%$ of the points were predicted random absence and $3.61 \%$ presence (Fig. 106). The predicted life stage layer shows $99.53 \%$ of the points were predicted adult and $0.47 \%$ copepodite.

Overlay of presence/random absence and predicted life stages in 2100

The predicted presence/random absence layer showed that $98.19 \%$ of the points were predicted random absence and $1.81 \%$ presence (Fig. 107). The predicted life stage layer shows $99.54 \%$ of the points were predicted adult and $0.46 \%$ copepodite.

Explanation for the following figures:

General: Black color in the presence/random absence layer delineates random absence. Random absence however does not indicate absolute absence but separates predicted presence (hot spot) from other, less suitable areas. Predicted presence is transparent in order to make the underlying layer visible (depth or life stages).

Specific for predicted relative index of depth: The color scale ranges from green where the relative index of depth is shallower to red areas where the relative index of depth is deeper.

Specific for predicted life stages: Orange color delineates predicted adult life stages; green color delineates predicted copepodite life stages. 

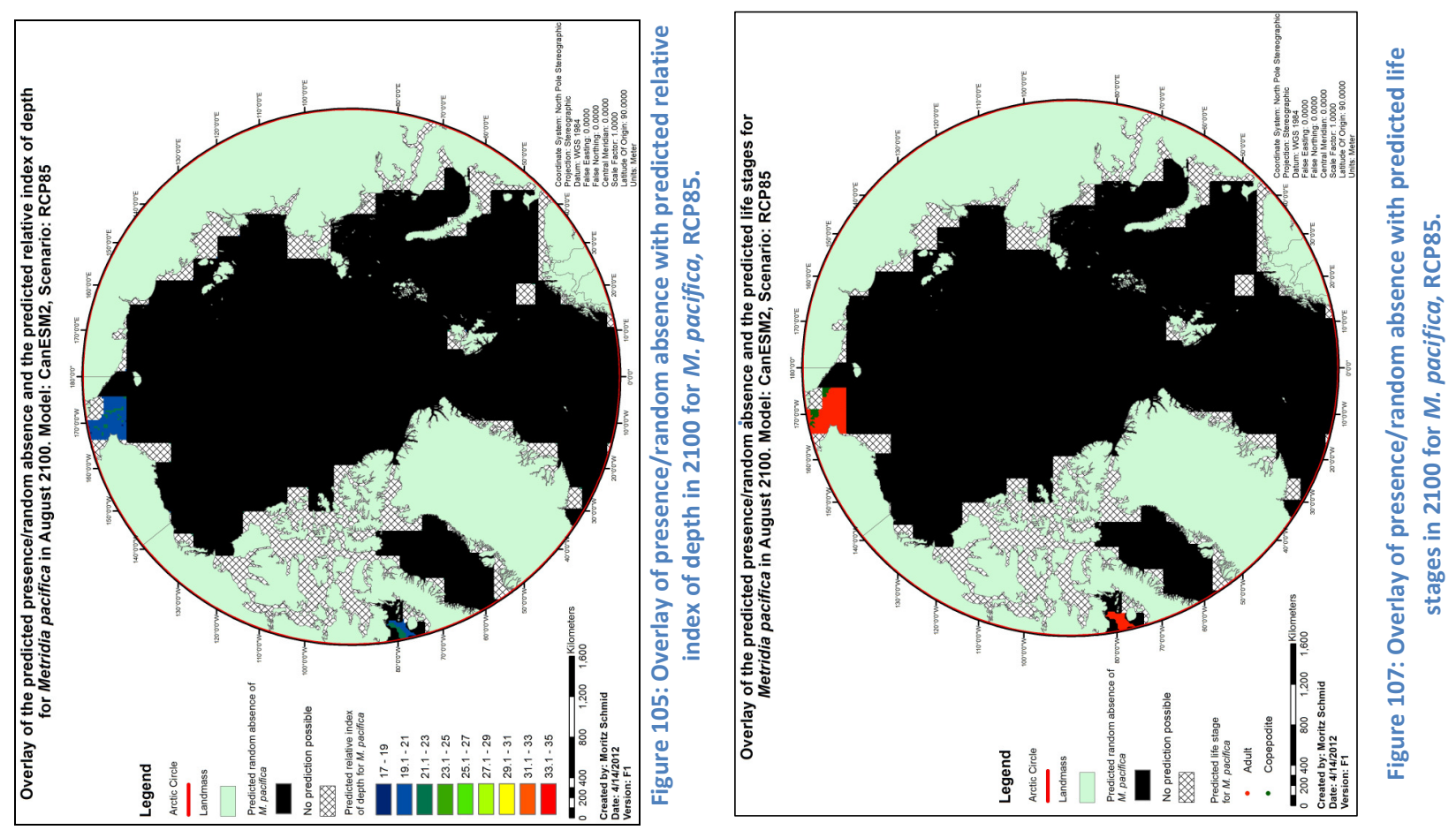

r
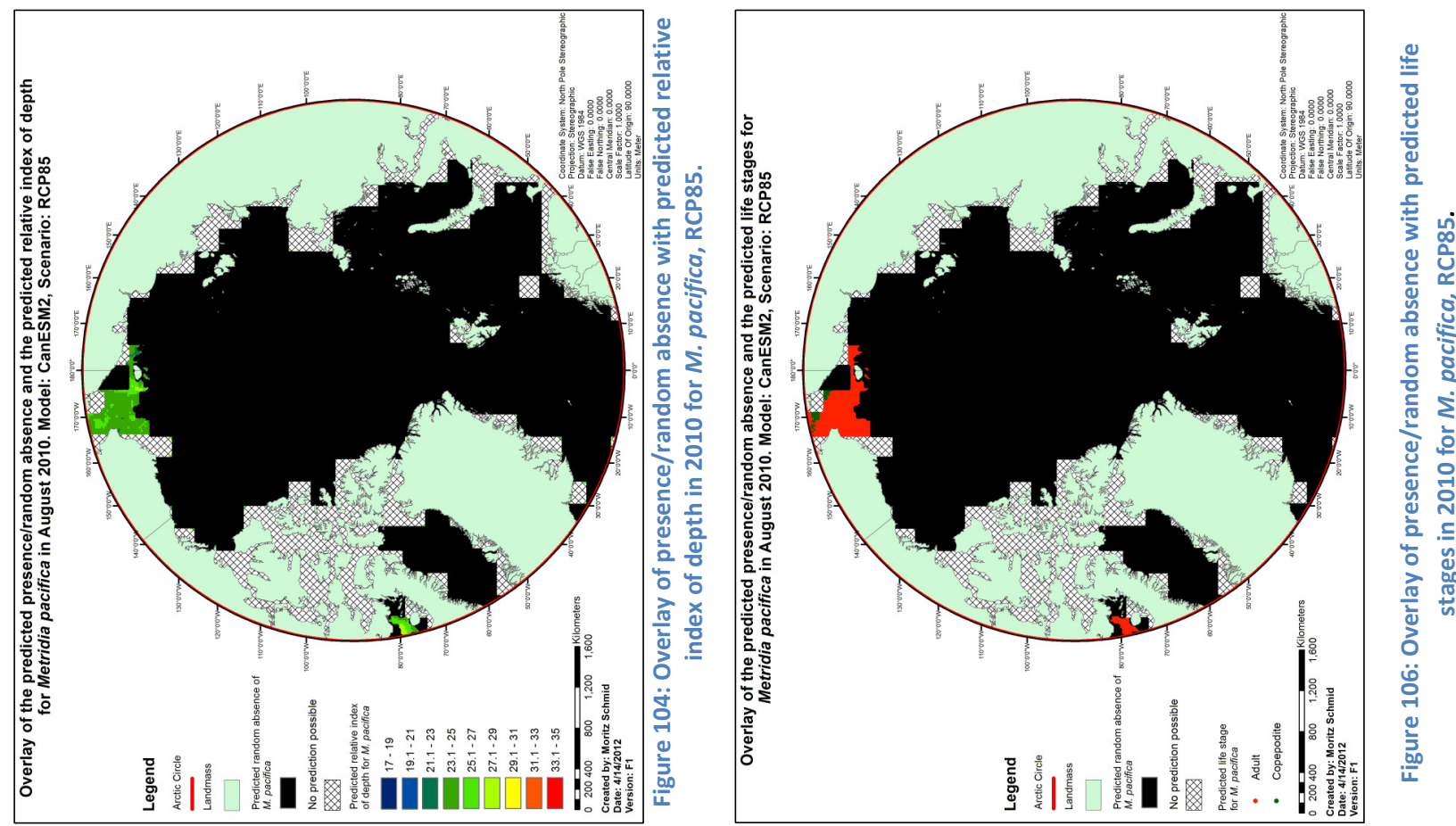


\subsection{High emission (RCP85) future predictions, excluding ocean layers}

\subsubsection{Calanus hyperboreus predictions}

\section{Overlay of presence/random absence and predicted relative index of depth in 2010}

The predicted presence/random absence layer showed that $82.63 \%$ of the points were predicted random absence and $17.37 \%$ presence (Fig. 108). The mean predicted relative index of depth for C. hyperboreus in 2010 was $140.71 \mathrm{~m}$ with a maximum depth of $869.73 \mathrm{~m}$ and a minimum depth of $-71.83 \mathrm{~m}$.

Overlay of presence/random absence and predicted relative index of depth in 2100

The predicted presence/random absence layer showed that $74.11 \%$ of the points were predicted random absence and $25.89 \%$ presence (Fig. 109). The mean predicted relative index of depth for $C$. hyperboreus in 2100 was $284.40 \mathrm{~m}$ with a maximum depth of $947.78 \mathrm{~m}$ and a minimum depth of $-57.26 \mathrm{~m}$.

Overlay of presence/random absence and predicted life stages in 2010

The predicted presence/random absence layer showed that $82.63 \%$ of the points were predicted random absence and $17.37 \%$ presence (Fig. 110). The predicted life stage layer shows $52.42 \%$ of the points were predicted adult and $47.58 \%$ copepodite.

$\underline{\text { Overlay of presence/random absence and predicted life stages in } 2100}$

The predicted presence/random absence layer showed that $74.11 \%$ of the points were predicted random absence and $25.89 \%$ presence (Fig. 111). The predicted life stage layer shows $39.41 \%$ of the points were predicted adult and $60.59 \%$ copepodite.

Explanation for the following figures:

General: Black color in the presence/random absence layer delineates random absence. Random absence however does not indicate absolute absence but separates predicted presence (hot spot) from other, less suitable areas. Predicted presence is transparent in order to make the underlying layer visible (depth or life stages).

Specific for predicted relative index of depth: The color scale ranges from green where the relative index of depth is shallower to red areas where the relative index of depth is deeper.

Specific for predicted life stages: Orange color delineates predicted adult life stages; green color delineates predicted copepodite life stages. 

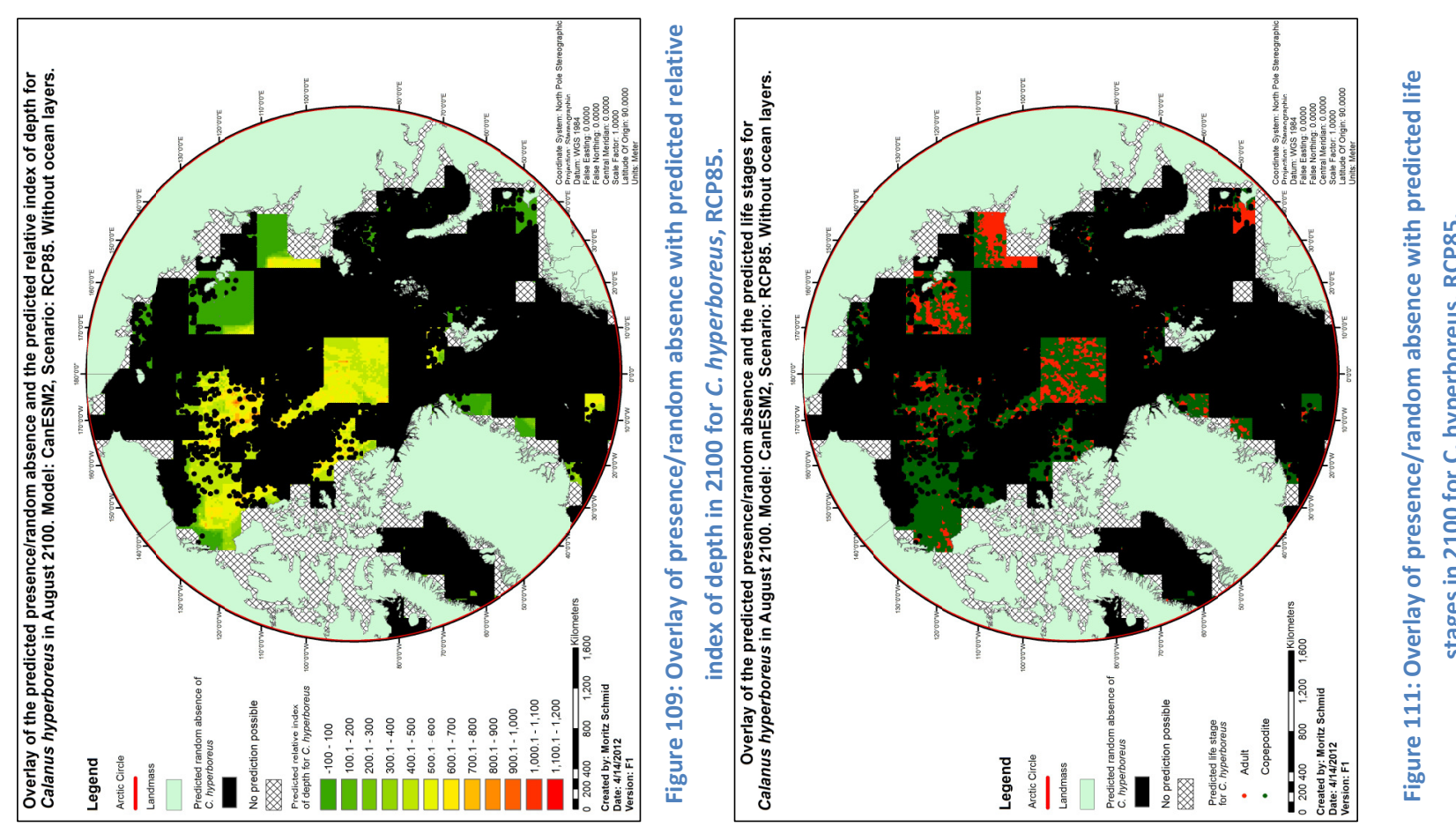

$\vec{\infty}$
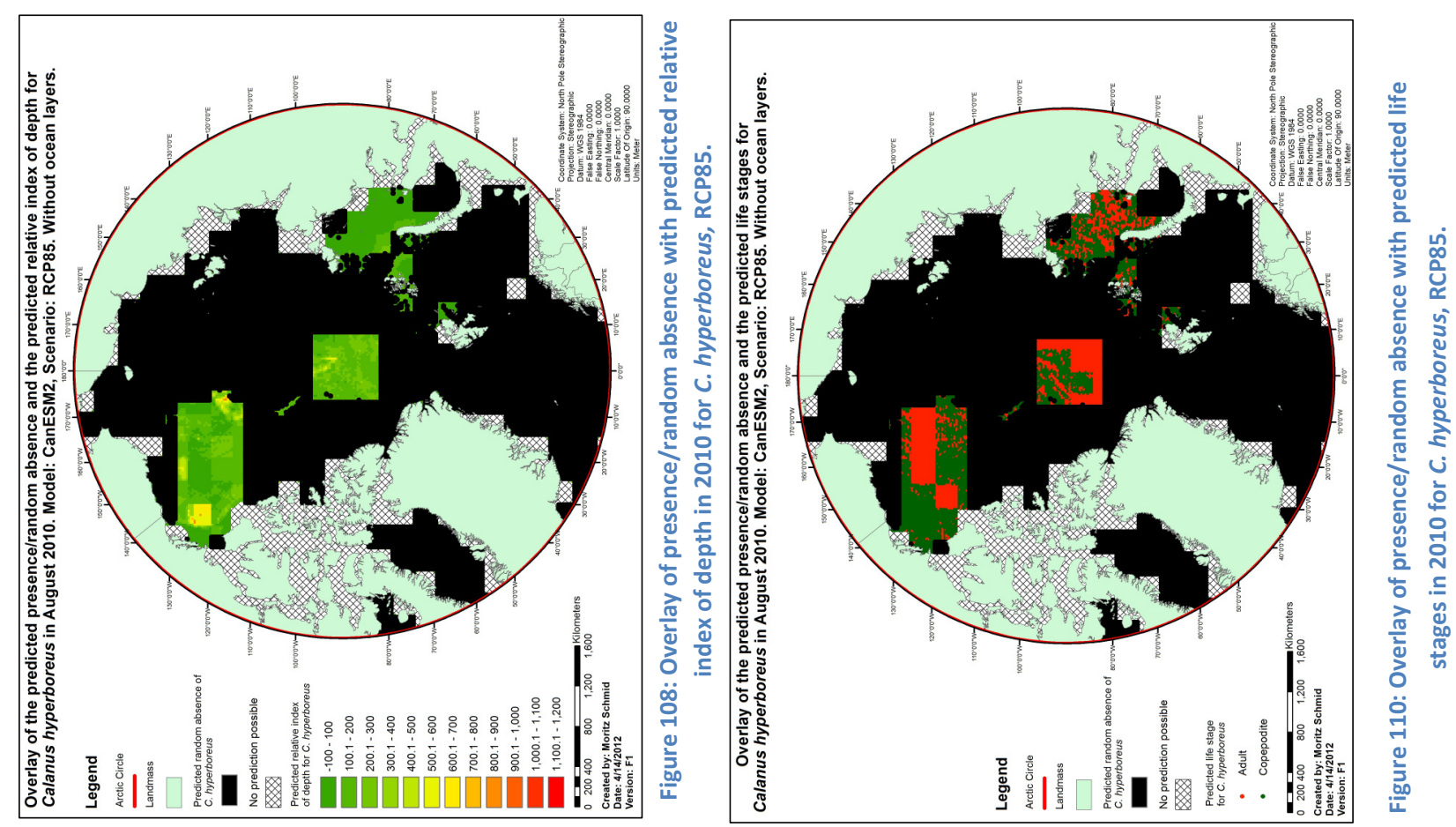


\subsubsection{Metridia longa predictions}

Overlay of presence/random absence and predicted relative index of depth in 2010

The predicted presence/random absence layer showed that $70.48 \%$ of the points were predicted random absence and $29.52 \%$ presence (Fig. 112). The mean predicted relative index of depth for M. longa in 2010 was $139.75 \mathrm{~m}$ with a maximum depth of $657.84 \mathrm{~m}$ and a minimum depth of $-26.79 \mathrm{~m}$.

Overlay of presence/random absence and predicted relative index of depth in 2100

The predicted presence/random absence layer showed that $76.11 \%$ of the points were predicted random absence and $23.89 \%$ presence (Fig. 113). The mean predicted relative index of depth for M. longa in 2100 was $192.59 \mathrm{~m}$ with a maximum depth of $599.95 \mathrm{~m}$ and a minimum depth of $-23.56 \mathrm{~m}$.

$\underline{\text { Overlay of presence/random absence and predicted life stages in } 2010}$

The predicted presence/random absence layer showed that $70.48 \%$ of the points were predicted random absence and $29.52 \%$ presence (Fig. 114). The predicted life stage layer shows $61.88 \%$ of the points were predicted adult, $21.48 \%$ copepodite and 16.64 nauplii.

$\underline{\text { Overlay of presence/random absence and predicted life stages in } 2100}$

The predicted presence/random absence layer showed that $76.11 \%$ of the points were predicted random absence and $23.89 \%$ presence (Fig. 115). The predicted life stage layer shows $54.47 \%$ of the points were predicted adult, $45.53 \%$ copepodite and 13.11 nauplii.

Explanation for the following figures:

General: Black color in the presence/random absence layer delineates random absence. Random absence however does not indicate absolute absence but separates predicted presence (hot spot) from other, less suitable areas. Predicted presence is transparent in order to make the underlying layer visible (depth or life stages).

Specific for predicted relative index of depth: The color scale ranges from green where the relative index of depth is shallower to red areas where the relative index of depth is deeper.

Specific for predicted life stages: Orange color delineates predicted adult life stages; green color delineates predicted copepodite life stages. 

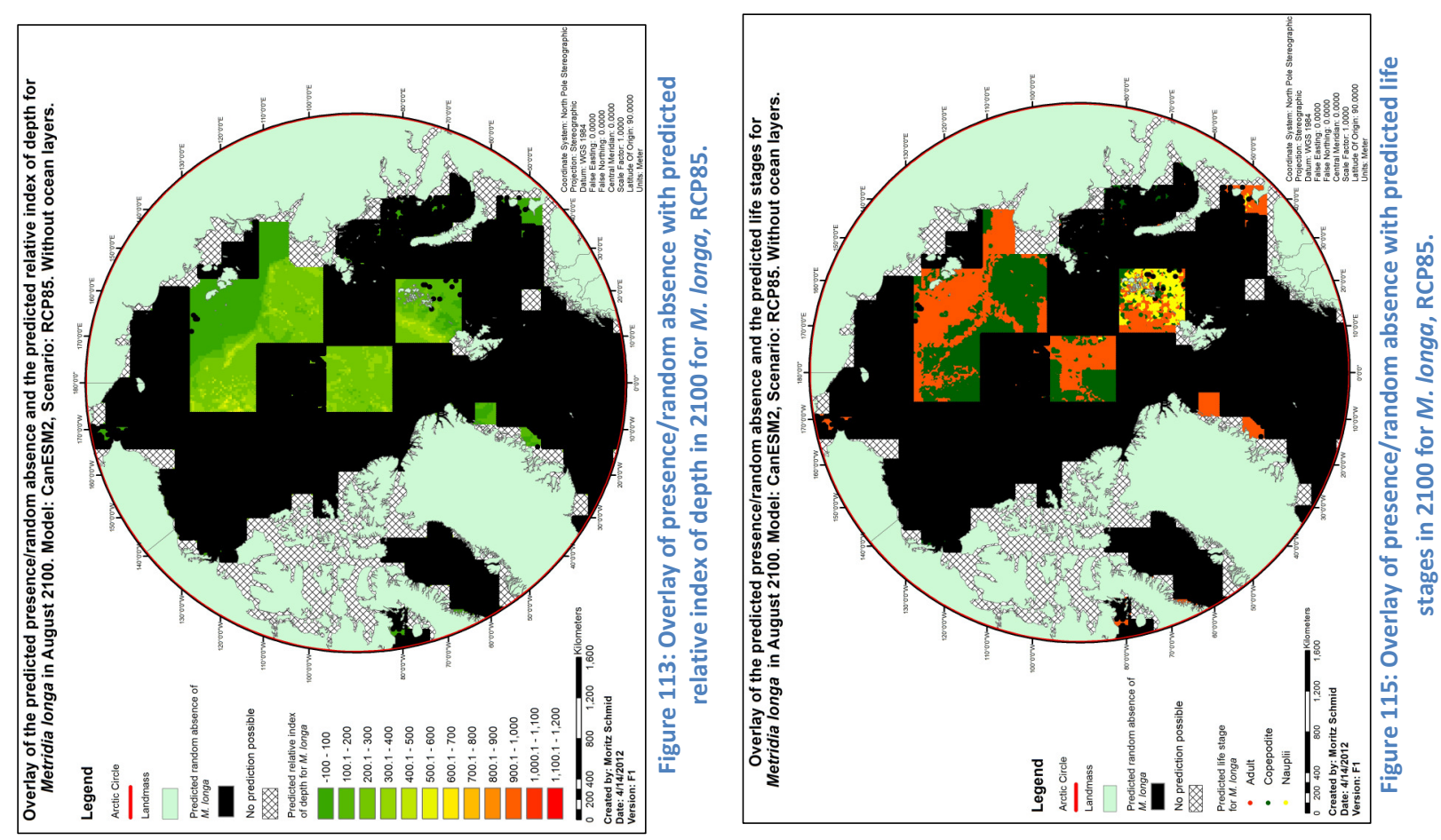

$\stackrel{\infty}{\infty}$
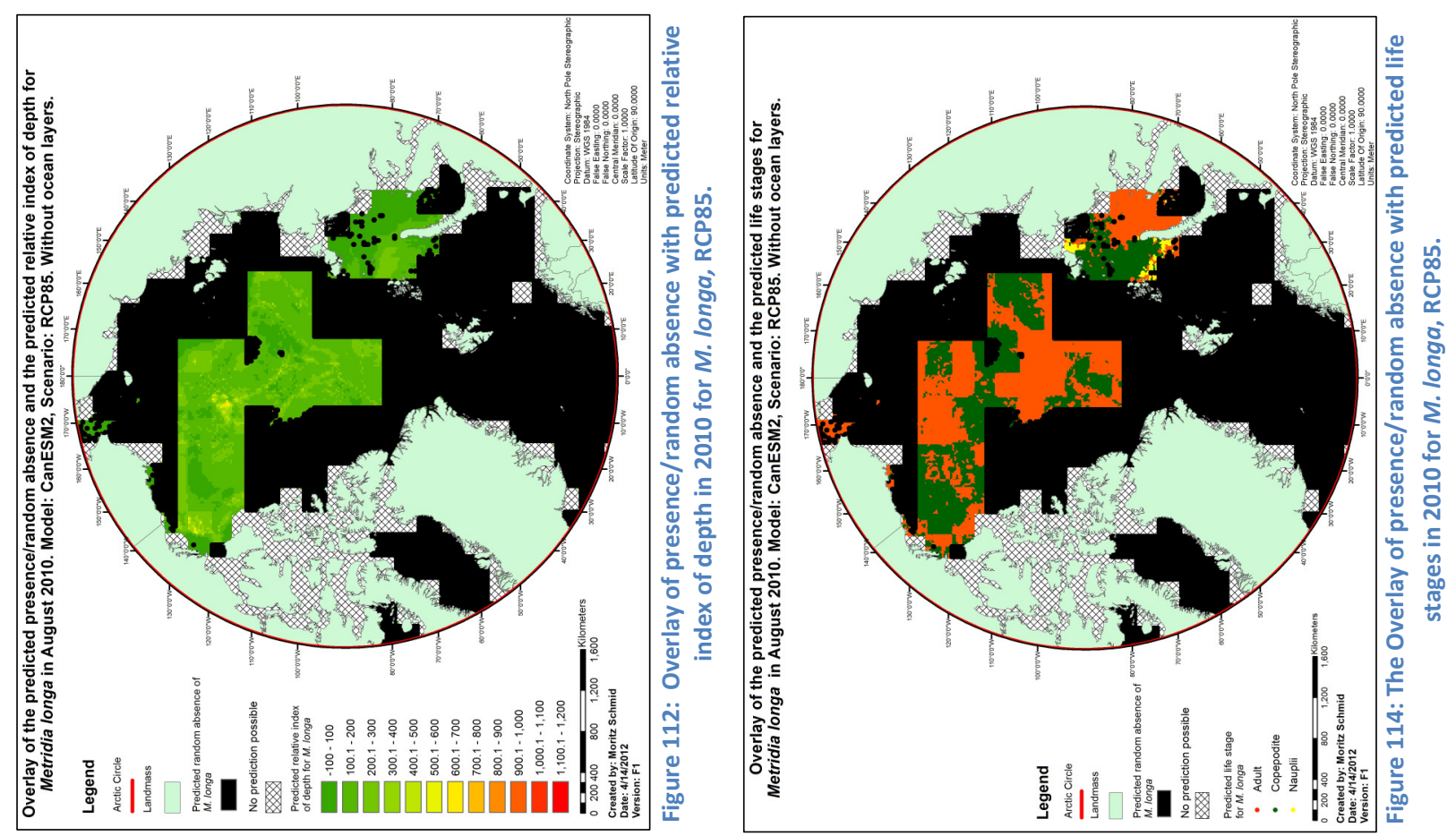


\subsubsection{Metridia pacifica predictions}

Overlay of presence/random absence and predicted relative index of depth in 2010

The predicted presence/random absence layer showed that $95.47 \%$ of the points were predicted random absence and $4.53 \%$ presence (Fig. 116). The mean predicted relative index of depth for M. pacifica in 2010 was $22.30 \mathrm{~m}$ with a maximum depth of $24.39 \mathrm{~m}$ and a minimum depth of $17.12 \mathrm{~m}$.

Overlay of presence/random absence and predicted relative index of depth in 2100

The predicted presence/random absence layer showed that $97.53 \%$ of the points were predicted random absence and $2.47 \%$ presence (Fig. 117). The mean predicted relative index of depth for M. pacifica in 2010 was $22.30 \mathrm{~m}$ with a maximum depth of $24.39 \mathrm{~m}$ and a minimum depth of $17.12 \mathrm{~m}$.

Overlay of presence/random absence and predicted life stages in 2010

The predicted presence/random absence layer showed that $95.47 \%$ of the points were predicted random absence and $4.53 \%$ presence (Fig. 118). The predicted life stage layer shows $98.84 \%$ of the points were predicted adult and $1.16 \%$ copepodite.

$\underline{\text { Overlay of presence/random absence and predicted life stages in } 2100}$

The predicted presence/random absence layer showed that $97.53 \%$ of the points were predicted random absence and $2.47 \%$ presence (Fig. 119). The predicted life stage layer shows $98.87 \%$ of the points were predicted adult and $1.13 \%$ copepodite.

Explanation for the following figures:

General: Black color in the presence/random absence layer delineates random absence. Random absence however does not indicate absolute absence but separates predicted presence (hot spot) from other, less suitable areas. Predicted presence is transparent in order to make the underlying layer visible (depth or life stages).

Specific for predicted relative index of depth: The color scale ranges from green where the relative index of depth is shallower to red areas where the relative index of depth is deeper.

Specific for predicted life stages: Orange color delineates predicted adult life stages; green color delineates predicted copepodite life stages. 

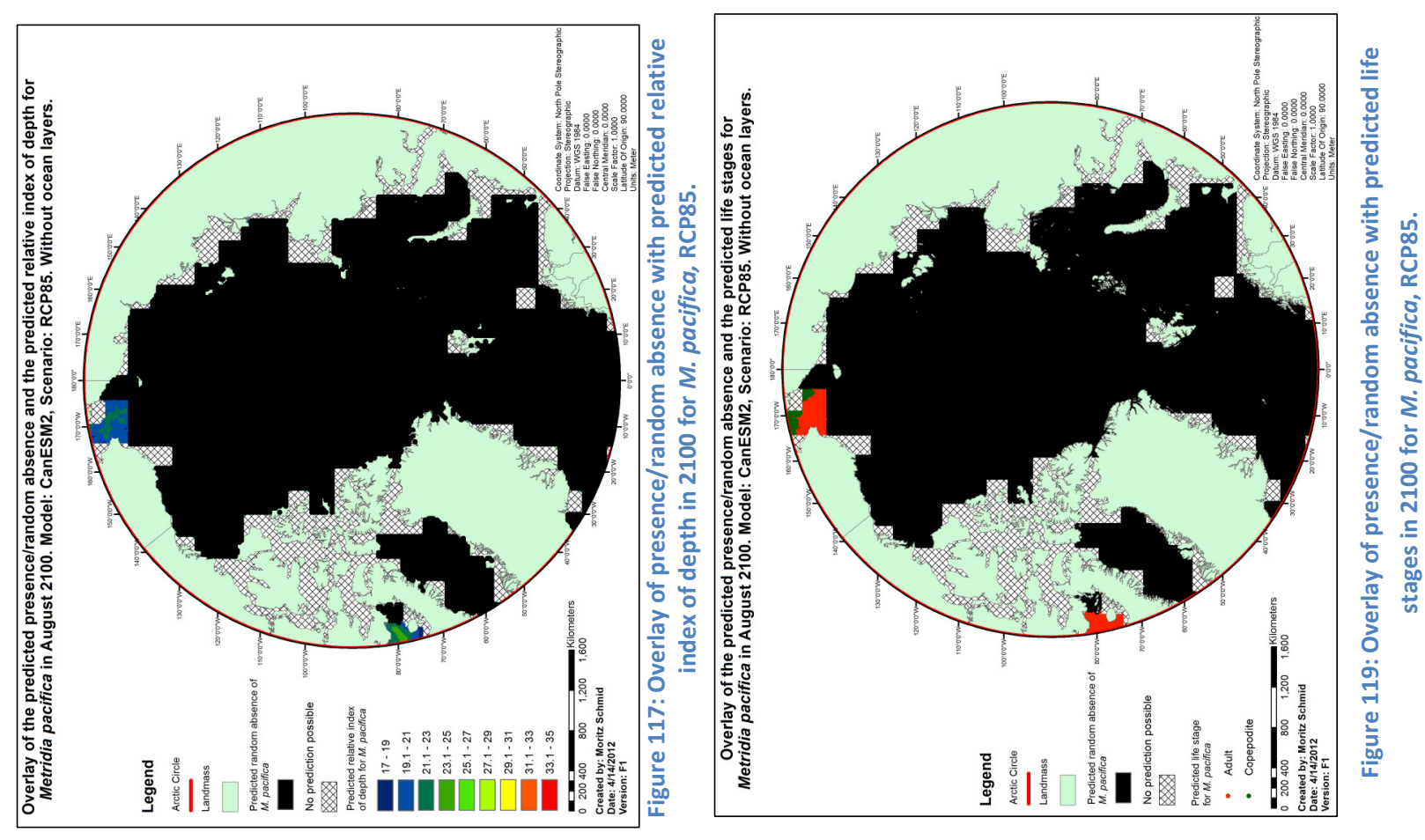

$\stackrel{\infty}{\infty}$
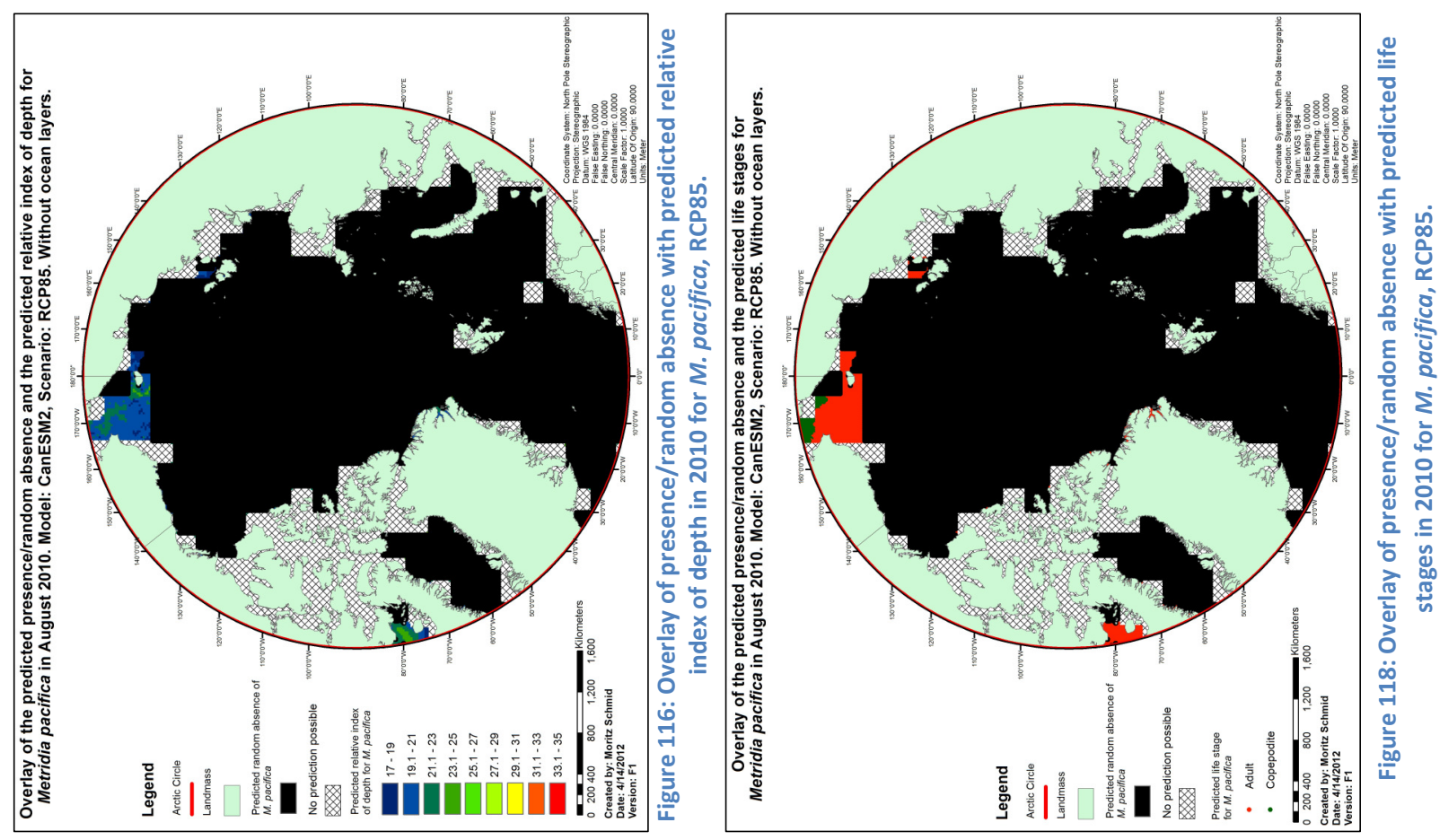


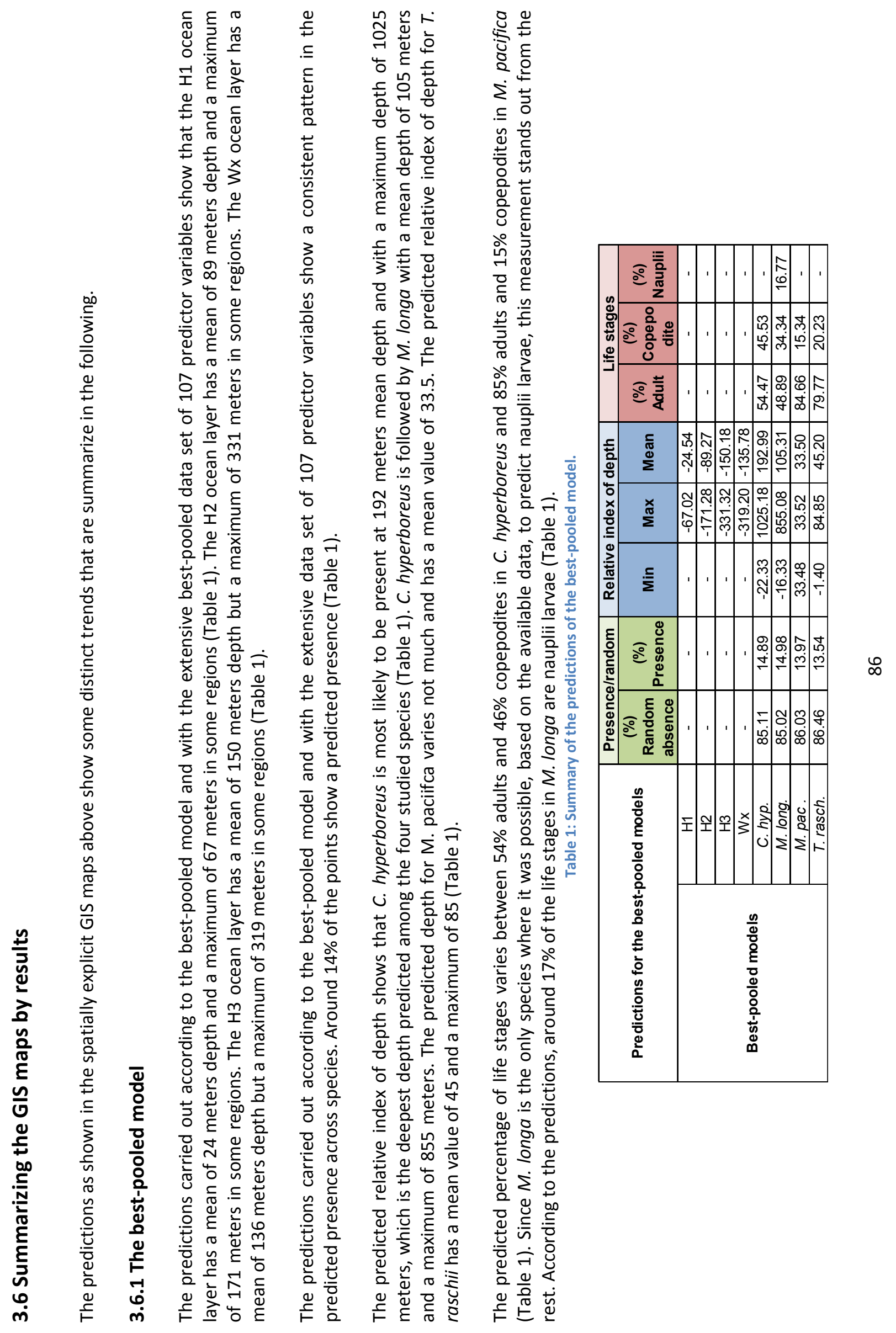




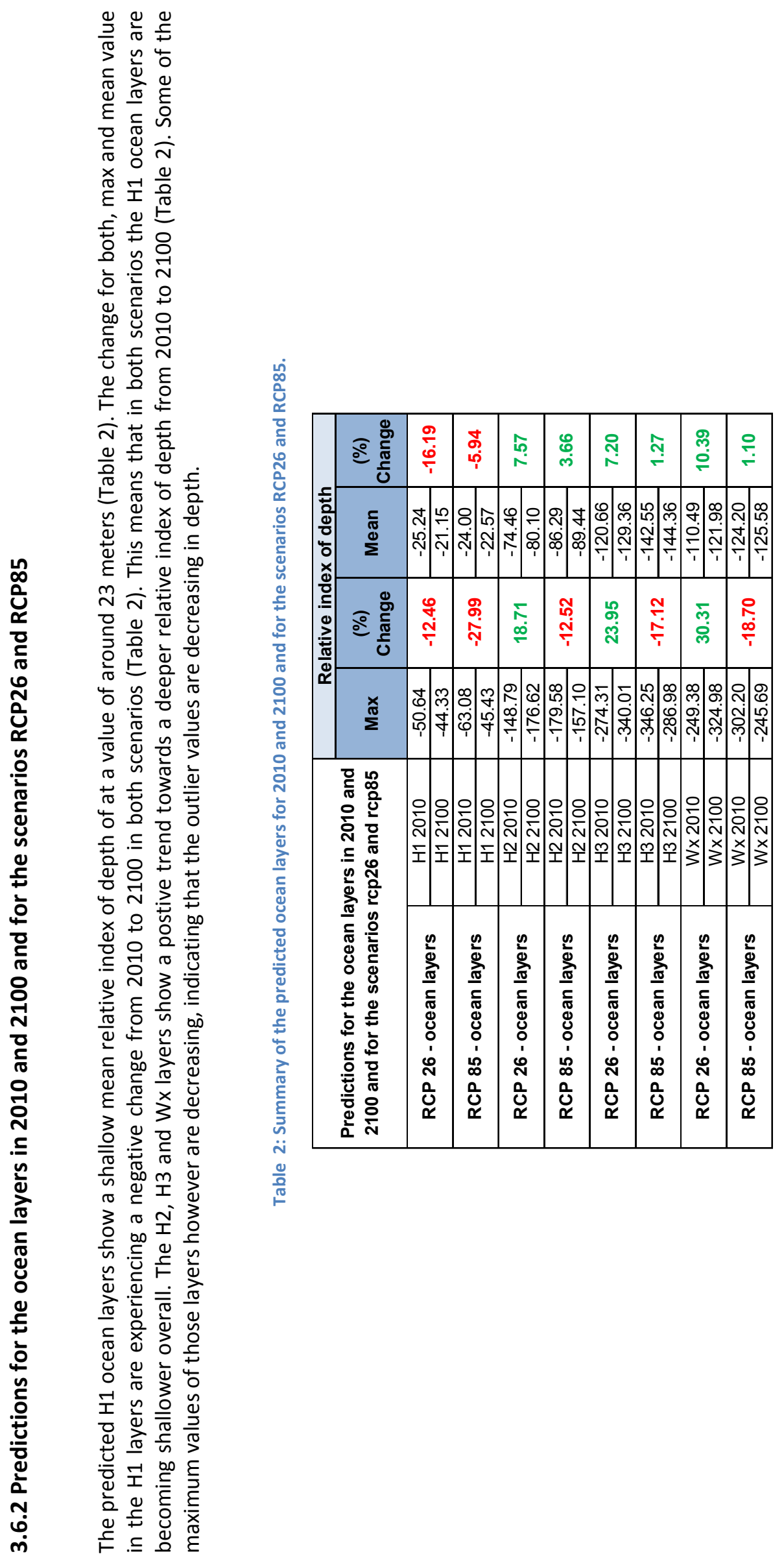



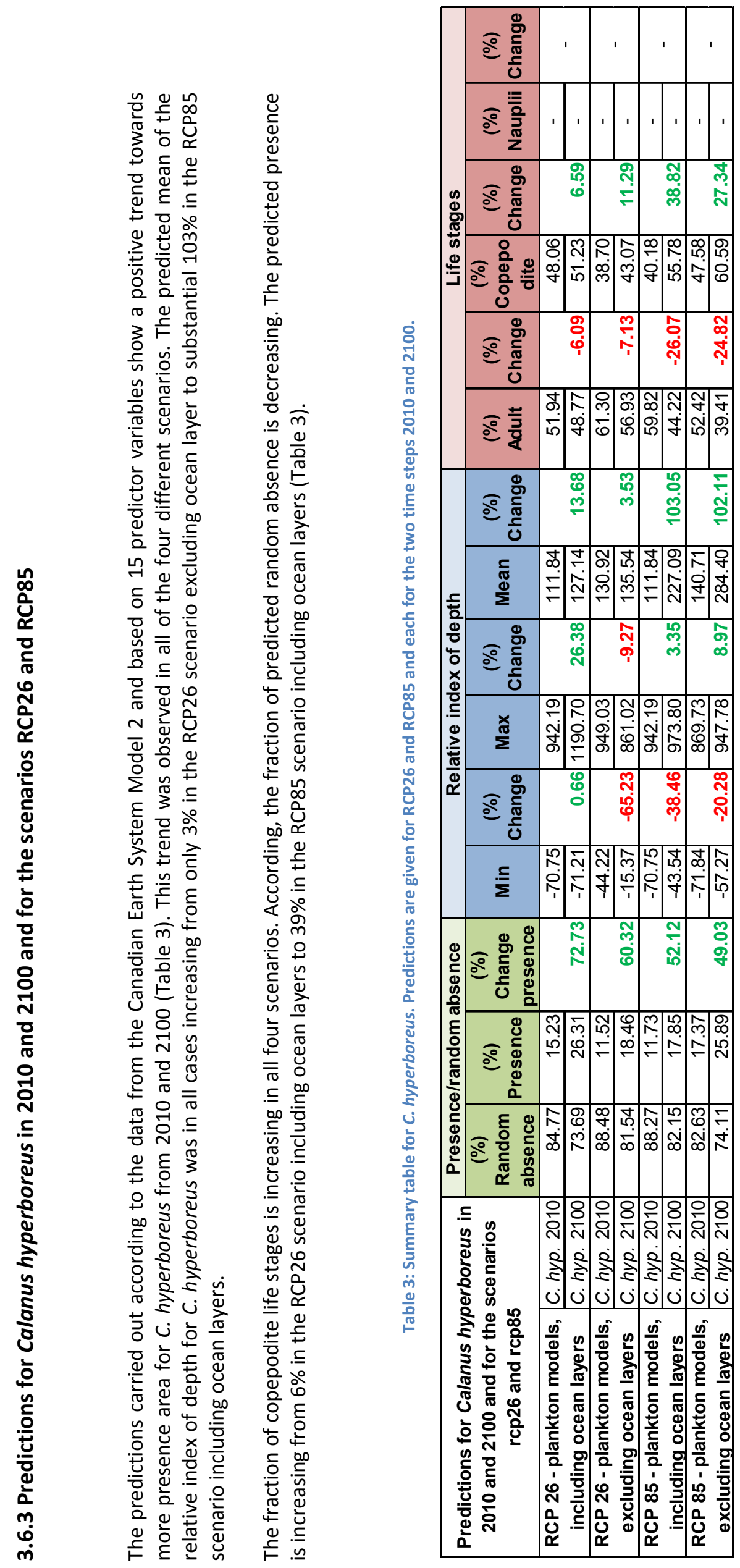


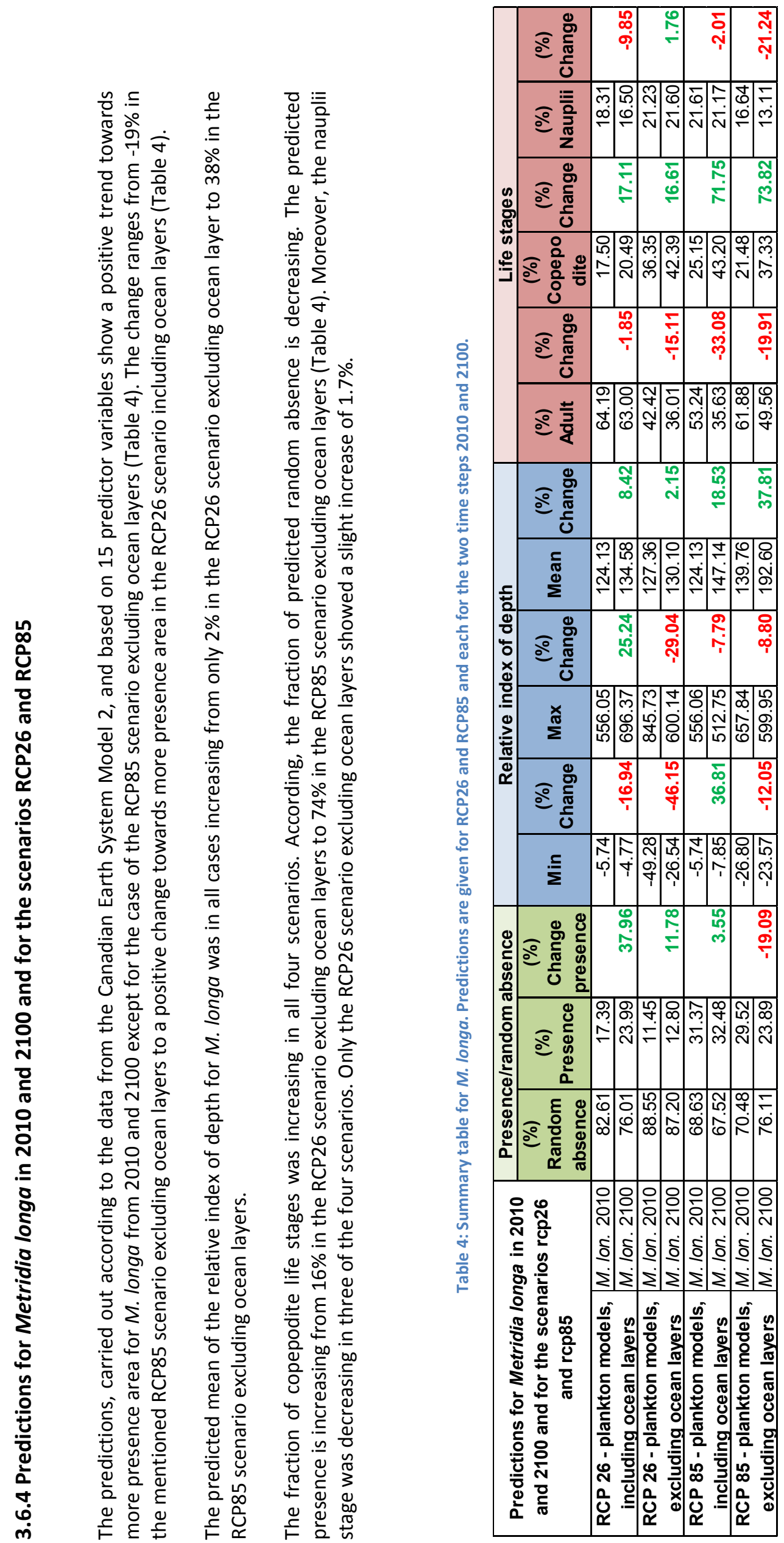



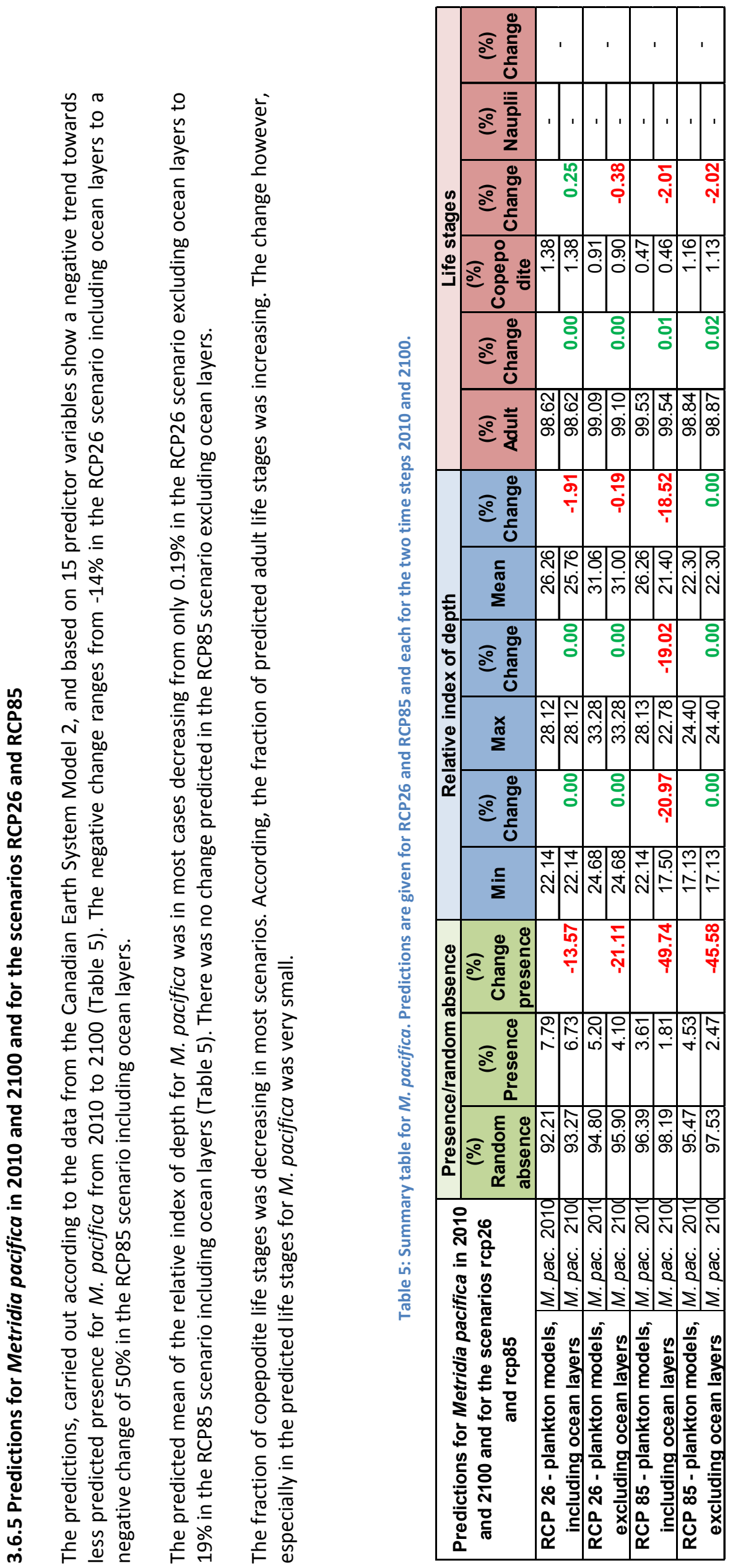


\subsection{Synthesis of future predictions}

Future predictions of the ocean layers show a change in the predicted relative index of depth towards shallower H1 ocean layers in 2100 in comparison to 2010 (Table 2). The H2, H3 and Wx layers however show a change towards a deeper predicted relative index of depth (Table 2). This finding is consistent over the different scenarios.

The predictions for $C$. hyperboreus and $M$. longa occurrence are quite similar and showing the same trends (Table 3 and 4) and as discussed in the following. Predictions for M. pacifica are showing a different trend (Table 5).

Future predictions for $C$. hyperboreus and $M$. longa show a clear trend towards a higher percentage of predicted presence from 2010 to 2100 (Table 3 and 4). This finding is consistent over the different scenarios.

Future predictions for $C$. hyperboreus and $M$. longa show a clear trend in the change from 2010 to 2100 towards a deeper predicted relative index of depth (Table 3 and 4). This finding is consistent over the different scenarios.

Future predictions for 2010 and 2100 show a clear trend in the change of predicted life stages for M. hyperboreus and $M$. longa (Table 3 and 4 ). The trend is towards a higher fraction of copepodite life stages and less adult life stages in 2100. Moreover the nauplli stage of $M$. longa decreases in most of the scenarios.

M. pacifica shows no substantial differences between the different scenarios. The range between the predicted values is very close. The predictions show however a trend towards less predicted presence and a trend towards a shallower predicted relative index of depth (Table 5). 


\section{Discussion}

\subsection{Data quality}

This study presents best available data and algorithms. The results are robust and show clear trends and as stated in chapter 3.6 and 3.7. Most aspects of this discussion shall focus on the problematic aspects of this project and to point out the issues relevant for future improvement.

Lyman and Varian (2003) pointed out that in 1999, worldwide between one and two exabytes of information per year were generated ( 1 exabyte $=1$ billion gigabyte). This study includes all kind of data generated, from newspapers to magnetic storage devices. However those numbers show the vast amounts of data that are available and with a high growth rate that is not likely to slow down. A current issue of global interest is the discussion about open access data and whether it should be anticipated by scientists to make their publications and data freely available (e.g., Beaudouin-Lafon 2010). This issue overlaps with the problem of data quality. A substantial amount of the data available in the scientific community is believed to be of rather bad quality, a statement supported by experience from this project, but also a known problem to scientists and industry (Data Warehousing Institute at http://www.dw-institute.com/, accessed on 4/15/2012) and costing vast amounts of money worldwide. Bad quality means here for instance that data was collected without a clear research design, without goals or simply according to outdated designs and procedure. Those badly designed protocols or the use of outdated protocols and ones that are not reviews can lead then to various implications. For instance, nowadays a scientist might want to model biomass and to assess population trends and declines on a local, regional and global level. Biomass however was not measured in the early days of marine oceanography, and still inconsistently these days. For current day research we need to collect data from new variables though. Therefore research designs and protocols have to be further developed and updated according to the most recent findings in science. A part of the quality of science is already determined in the way field data is sampled. Therefore, an up-to-date research design and field protocols should not be underestimated in order to achieve science-based management of natural resources and best professional practice.

Another problem is data that was collected in the field but not analyzed, or which remain unpublished. Mostly this happens when there is not enough time and money to analyze the collected samples and/or the focus of research changes, e.g. more interesting research is carried out. This can reflect poor planning. Either way, effort and money (mostly money that did not belong to the investigating person itself, but instead was public tax money or similar) have been invested but no major output, accessible to the public has been achieved. This is important regarding ecological stewardship. This must be seen as highly unethical when done on purpose (see examples in Huettmann 2012).

Recent efforts and projects focus on this kind of public data (e.g., Census of Marine Life (COML), trying to safe and digitalize a lot of the mostly old data. Saving the data from rotting and being forgotten (Carlson 2011).

One cause of this problem is that analyzing the field data takes a lot of time and especially when having to analyze zooplankton samples. Future research should focus on robust methods to automate taxonomic analyses as requested by scientists (Janzen 2004), e.g. species recognition though machine learning algorithms. However, further research is necessary to successfully create those automatic systems (Gaston and O'Neill 2004, Trifa et al. 2008). Research on this topic is currently under way and devices such as the LOKI device that are capable of recognizing species using an underwater camera system and species determination software are in use (Schulz et al. 2008).

Moreover, high quality data is rare (about $5 \%$ by experience (Huettmann, personal communication). High quality means here that parameters that are collected are relevant for modern time analysis, with valid 
taxonomy, transparent in their collection procedure, according to best known practice, and publicly available and in a good digital format.

In the specific case of this project it should be pointed out, that initially it looked like there was a lot of data available, e.g. for the species $C$. hyperboreus. When searched for, the term C. hyperboreus shows over 40,000 entries in the Ocean Biogeographic Infroamtion System (OBIS). If however filtered for August and including a depth measurement and a life stage description then from experience, about $10 \%$ of the entries are left. Note that the depth and life stage are some of the most basic measurements and not especially sophisticated. When looking for biomass data in those databases and for $C$. hyperboreus only a few data entries turn up and not sufficient for a scientific project. This should be discussed in the light of extremely expensive research cruises and public money.

Therefore more high quality data is needed that is consistent, following up-to-date research design and measures important new variables like biomass. It should be agreed upon however in the scientific community how such a research design should look like and how implemented and for what reasons.

Another problem lies in the format that is used to distribute data. The future data from the Canadian Government (CanESM2), and most likely all other climate data from other institutions, was provided the netCDF format. It should be pointed out that netCDF files are approximately 20 years old, and that they are a very user-unfriendly data format which is almost everywhere outside pure atmospheric research obsolete by now. It must be possible to have an easy to use overall data format for such things. Why not distribute that information in ASCII or even ArcGIS formats? An ASCIl file could at least be opened by anyone with a text editor and is a standard file format anywhere in the world of computing and across platforms.

Another critical issue of data quality is metadata. For this research, there was a problem with the way metadata was provided for the Canadian Earth System Model 2 and in general documentation of future data models and data produced according to the Intergovernmental Panel on Climate change (IPCC). There are no metadata files, despite the acknowledged relevance of such files throughout the community. How can a public institution produce several terabytes of raw data without describing them adequately? The only information available was in the header of netCDF files and is absolutely insufficient to describe the file. For such big amounts of data that are predicted for several scenarios and with big public and global relevance, there has to be a clearly visible link on the main homepage of the institution describing the data. This does not only make handling easier but adds to transparency and is a good investment.

\subsection{Machine learning experience and prediction quality}

Experiences with machine learning in this project show that TreeNet was performing "good" and it had no relevant problems when predicting presence/random absence of zooplankton. For the presence/random absence predictions, every spatial location had only one presence or random absence entry obviously.

For the depth and life stage predictions however, each spatial location had several entries because in each plankton tow, the same species can be found at several depths and in several life stages. Having multiple entries per position leads to some problems in the predictions and results in a blurry prediction (multiple signals from a unique location); TreeNet has obviously difficulties when the spatial location contains five points of adult life stage and, let's say as an extreme example, 5 points of copepodite life stage. However, data mining is the only valid way we are aware of to get results from this kind of data. Nonetheless, TreeNet still has difficulties to determine what stage it should assign here from the contaminated sample. The mentioned example occurred more than once in the data sets of this project. The same problem occurred when predicting the depth but was less severe there. This might be due to the fact that TreeNet had to decide between a binary choice when predicting most of the life stage scenarios but when predicting the depth it was able to work in a continues range of values. 
The two mentioned problems however make for a new development in predicting zooplankton in the Arctic and worldwide. An attempt to model those parameters has never been undertaken to my knowledge. Nevertheless, TreeNet was capable of incorporating exactly this variability in the data of depth and life stages. On the other hand this shows where the limitations still are and that we have to move even further and have to push back the boundaries in modern modeling techniques.

Overall, the best data mining tool was used to resolve this problem. Still, it must be resolved whether this is a biological or a sampling problem, and how to improve it further.

Another difficulty that obviously exists and that had to be dealt with here is a too small sample size. Even the best modeling software has no chance to develop good models when the input data is too sparse. This adds up to the issue on data quality above.

In this particular case, M. pacifica was modeled despite the fact that it is not (yet) an Arctic species and therefore only some sample points along the outer boundaries of the Arctic Ocean were available. Not due to bad data quality, but according to the natural species range sample sizes were low. Especially regarding climate change modeling this scenario was among the most interesting parts however and with large implications. Clearly, in this study we wanted to find out if a shift in the species range occurs within the different scenarios and from 2010 to 2100 . The question is now why it was not possible to show this proposed shift. It could either be because there is simply no species shift happening because the environmental conditions are (still) not adequate for $M$. pacifica or because the sample size was bot adequate and too low, or because of other unknown flaws. Further research could include newly released data, as well as a wider area around the Arctic Ocean in order to develop a better model of M. pacifica and to capture the environmental range in suitable habitats. When applied back to the Arctic Ocean, such a model could show some stronger results However it is also possible that the range of $M$. pacifica does not shift on a notable scale and what was seen in the models reflects the current outlook on the next 90 years regarding distribution of $M$. pacifica.

The prediction quality varies between the models and scenarios (see chapter 6.3 in the appendix for performance measures). The future data models however will not be discussed here for their performance (in the traditional sense of metrics) since it is impossible to assess an incident that might happen in the future and despite controversial discussions on this topic. The future model predictions of the future scenarios however were developed to be similar to the best-pooled model in order to calibrate them and to model the change from this point in time on. The model approach followed best known practices and performed well when extrapolated spatially in 2010.

The prediction quality of all of the four ocean layers in the best-pooled models was good. Similarly, the predictions of the models leading to the relative index of depth were good in most cases. Both models were built on continuous data that TreeNet was able to handle without a problem. The predicted depth model for M. pacifica was rather bad probably due to the low sample size. The models developed to predict the presence/random absence were in general very good and showed a good model response curve. The model performance to predict the life stages varies between the species. The models for $M$. longa, M. pacifica and $T$. raschii were able to find a good model optimum. The model for $C$. hyperboreus however failed to detect a real trend, probably due to a high amount of overlapping life stages as discussed before. A substantial amount of sampling points had multiple entries for both life stages. This made it difficult for TreeNet to find a trend.

For an assessment of model performance, response curves of the models are provided where applicable indicating how much variance the model explains. Response curves for the ocean layer models can be found in the appendix, chapter 6.3.1.1 as well as response curves for zooplankton species in chapter 6.3.1.2. 
Second, the most important predictors and their relative importance are provided, where the most important variable receives a score of 100. A listing of important predictors for the Ocean layer models are provided in the appendix, chapter 6.3.2.1 as well as for zooplankton species in chapter 6.3.2.2.

Third, partial dependence plots are provided. Partial dependence plots show the effect of a single predictor on the predicted response. Partial dependence plots are one kind of Resource Selection Function (Manly et al. 2002). Moreover, partial dependence plots show the functional non-linear relationships of single predictors in the context off the pooled set of predictors. Graphs of partial dependence plots for the ocean layer models are provided in chapter 6.3.3.1 as well as for zooplankton species in chapter 6.3.3.2.

Fourth, tables that indicate the misclassification for the different models are provided in the appendix, chapter 6.3.4.

Last but not least, Receiver Operating Characteristics (ROC) curves are provided for binary classification models in the appendix, chapter 6.3.5. The ROC curve is a graphical visualization of the true positive rate plotted against the false positive rate in a binary system.

\subsection{Scenario comparison}

In this section the differences between the low emission RCP26 and the high emission RCP85 scenario, and the information gained when comparing both scenarios shall be discussed. If we assess the raw data and as presented in the methods chapter 2.4 it is visible that the overall trend does not change much on a panarctic scale. The change in chlorophyll mass concentration is decreasing from 2010 to 2100 and for both scenarios (RCP26 and RCP85). The median is however changing from $3 \times 10^{\wedge}-8 \mathrm{~kg} \mathrm{~m}^{-3}$ in RCP26 to $7 \times 10^{\wedge}-7 \mathrm{~kg}$ $\mathrm{m}^{-3}$ in RCP85 indicating a higher overall decrease in RCP85 as one would expect. The area of highest decrease shifts also. In RCP26 the highest decrease is in the area of the Canada Basin but in RCP85 the area of highest decrease shifts more towards the Nansen Basin.

The change in total runoff is decreasing from 2010 to 2100 and in the RCP26 scenario. The RCP85 scenario however shows an increase in the median total runoff. The median for the RCP26 scenario is -0.00001737 $\mathrm{kg} \mathrm{m}^{-2} \mathrm{~s}^{-1}$ where the median for the RCP85 scenario is $0.00000594 \mathrm{~kg} \mathrm{~m}^{-2} \mathrm{~s}^{-1}$. The areas of highest decrease and increase shifts also. In RCP26 the highest decrease is in the area of the Nansen Basin and Laptev Sea and with areas of increase in the Canada Basin and the East Siberian Sea. The RCP85 scenario shows a decrease from 2010 to 2100 in the Beaufort Sea and an increase in the Central Basin as well as Kara Sea, Nansen Basin, Amundsen Basin as well as Laptev and East Siberian Sea and some shelf regions around Ellesmere Island.

The change in dissolved nitrate concentration is decreasing from 2010 to 2100 and for both scenarios (RCP26 and RCP85). The median is however changing from $-0.0000022 \mathrm{~mol} \mathrm{~m}^{-3}$ in RCP26 to -0.00000562 $\mathrm{mol} \mathrm{m}^{-3}$ in RCP85 indicating a higher overall decrease in RCP85. The areas of decrease are evenly distributed over the Arctic Ocean indicating a broad scale decrease in dissolved nitrate concentration.

The change in sea surface salinity shows a decrease from 2010 to 2100 and for both scenarios (RCP26 and RCP85). The median is however changing from -0.538 psu in RCP26 to -0.682 psu in RCP85 indicating a higher overall decrease in RCP85. The areas of decrease in the RCP26 scenario stretch from the Beaufort Sea to the Laptev Sea and to the Kara Sea and to the Nansen Basin and include the Canada Basin as well as the Central Basin. An increase of salinity was shown along the Russian coast as well as Barents and Norwegian Sea. The RCP85 scenario shows a shift of decreasing salinity towards Greenland and Baffin Bay with major areas of decrease still stretching from the Bering Strait all the way down to the Norwegian Sea 
and a band of area where salinity is increasing along the Russian shelf regions but reaching even into the Nansen and Amundsen Basin.

The change in SST shows an increase from 2010 to 2100 and for both scenarios (RCP26 and RCP85). The median is however changing from $1.005 \mathrm{~K}$ in RCP26 to $0.768 \mathrm{~K}$ in RCP85 indicating a higher overall decrease in RCP26. The areas of increase in the RCP26 scenario stretch from the Bering Strait down to the Norwegian Sea with the exception of some patches of decreasing sea surface temperature along the Lomonosov Ridge and Makarov Basin. Sea surface temperature is increasing most in Kara, Barents and Norwegian Sea and decreasing most in the East Siberian and Laptev Sea. The RCP85 scenario shows basically the same picture but with a shift of decreasing SST along Northland and the Kara Sea.

Since those are the only input variables into the future scenarios to predict zooplankton parameters and that are changing over time, these parameters are driving our models. The change in the predicted ocean layers and the zooplankton presence/random absence, predicted relative index of depth and life stage distribution can be explained by taking in account the changes in these future climate layers, as described before.

\subsection{Synthesis of the findings}

As stated in chapter 3.6 summarizing the GIS maps, as well as in 3.7 Synthesis of future predictions, clear trends for the future conditions of zooplankton and ocean layers arise within our model predictions. Those trends will be discussed in the following.

The observed trends describe a picture where stress is added to the zooplankton and in its different life stages and their general ecology. The observed clear trends and changes towards a deeper predicted relative index of depth (Table 3 and 4 ) indicate that zooplankton has to migrate longer distances in order to fulfill the daily feeding cycles and to feed on phytoplankton. In the light of diel vertical migration (Hays et al. 1990) and the predator evasion hypothesis (Dagg et al. 1997) mentioned in chapter 1.2.3, this longer way does not only increase energy expenditure but also might increase the predation risk for zooplankton. Climate change and factors like increasing radiative forcing and a decrease in the phytoplankton food source might also have substantial effect on zooplankton and regarding other influences on DMV such as the light intensity (Nesbitt et al. 1996), light protection (Manuel and O'Dor 1997) food availability (Dagg et al. 1997).

Overall, I propose that the shift towards a deeper predicted relative index of depth in both scenarios, low emission (RCP26) as well as high emission (RCP85) scenario, shows the overall impact of anthropogenic disturbance and climate change and the negative effects on zooplankton that we are eventually facing in the future.

Moreover a trend to a higher percentage of copepodite life stages in 2100 (Table 3 and 4) was observed and for both emission scenarios. The substantial decrease in adult life stages could be a response to the predicted ocean layers that show a shift towards deeper depths. Therefore, the additional stress on migrating adults favors the copepodite life stage that does not migrate or at least not to the extent that adult zooplankton does migrate. The change in the life stage distribution makes for an extreme impact on the population dynamics and population structure of zooplankton in the Arctic Ocean. Most likely this has 
serious effects on the food chain and the whole ecosystem Arctic Ocean, all the way up the food chain with medium and top predators such as fish, seabirds, seals and polar bears for instance.

The observed increase in area of predicted presence might be a strategy to evade higher stress when migrating and spreading into a wider area where migration is less stressful (Table 3 and 4). This dispersion into a wider area should not be misunderstood as an increase in zooplankton since in this project only suitable habitat is predicted, not biomass or any other measure that could tell us if there is actually more zooplankton. All that is known is that the ecological niche the zooplankton inhabits is spreading out. Dramatically decreasing mass of phytoplankton are a major indicator that zooplankton most likely suffers dramatic negative changes as well.

The observed changes pose a threat to the zooplankton. This is because of anthropogenic change resulting in higher runoff, freshwater sealing and the various, mentioned negative effects on the Arctic Ocean and as hypothesized. Zooplankton did not evolve to these changing conditions and most likely needs a substantial amount of time to adapt to the changes. The question is, if zooplankton has this time. Looking at the current development in the world (e.g., IPCC AR4 SYR 2007, Millennium Ecosystem Assessment (www.maweb.org), Huettmann 2012) it seems most unlikely that zooplankton can adapt at a sufficient pace to climate change and other anthropogenic disturbances. Zooplankton has to be seen as a whole and in the view of climate change including ocean acidification, invasive species, decreasing ecological services, in the case of the Arctic an increasing shipping activity and further exploitation of natural resources like gas and oil which is directly linked to environmental disasters and extreme disturbance of natural environments.

In this project, based on modeling using latest data and algorithms, there is no evidence for an increase in zooplankton. Potential factors affecting zooplankton are negative and especially when seen in the global picture.

Also, the Arctic Ocean is a substantially more diverse environment than what the models in this project are describing. One has to assume that some species can cope better with changes in their environment than other species and over all there will be few species able to change and adapt to the changes at a sufficient pace and to sustain viable populations. These adjustments are all for man-made ecosystems and due to human impacts; the notion of an untouched arctic wilderness is widely gone. This stress scenario applies not only to the Arctic and our study species bust must be seen in a global view and for many different kinds of plankton all over the world.

Moreover I want to point out that the outlook of our model predictions ends in the year 2100. Life on Earth and zooplankton in the Arctic Ocean however will be around for much longer and therefore it is important to look at this and similar problems and research questions with exceptional forethought. It may take humankind only 50 years to damage the environment to a point where it will take hundreds and thousands of years, if at all, to reverse the changes again and get back to a natural level. Extinction of species and of metapopulations however, is not resilient and cannot be reversed. Many future generations however will live with and suffer from our failure. The current ecological and economical developments in the world make need for future predictions and to see how our doing affects nature in the long term. The precautionary principle and pro-active actions matter and should become the forefront of our action and be emphasized. Perhaps someday world economy will settle into a steady state and humankind lives on Earth according to the carrying capacity? Who knows if future predictions will be necessary then? It seems to be most necessary to look into the future when the current state is most uncertain. I think we are currently living in such a state. 


\section{References}

Aagaard, K. (1989): A synthesis of the Arctic Ocean circulation. Rapports et Procès-Verbaux des Réunions. Conseil International pour l'Exploration de la Mer 188:11-22.

Aagaard, K., and Carmack, E.C. (1989): The role of sea ice and other fresh water in the Arctic circulation. J Geophys Res 94:85-98.

ACIA (2005): Arctic Climate Impact Assessment. Cambridge University Press, Cambridge, 1042 pp.

Agersted, M.D., Nielsen, T.G., Munk, P., Vismann, B. and Arendt, K.E. (2011). The functional biology and trophic role of krill (Thysanoessa raschii) in a Greenlandic fjord. Mar Biol 158:1387-1402.

Ainley, D.G., Spear, L. B. and Allen, S.G. (1996): Variation in the diet of Cassin's Auklet reveals spatial, seasonal, and decadal occurrence patterns of euphausiids off California, USA. Marine Ecology Progress Series 137:1-10.

Arctic Circle (2012): Encyclopædia Britannica Online. Retrieved 12 April, 2012, from http://www.britannica.com/EBchecked/topic/33160/Arctic-Circle.

Ashjian, C.J., Campbell, R.G., Welch, H.E., Butler, M. and Van Keuren, D. (2003): Annual cycle in abundance, distribution, and size in relation to hydrography of important copepod species in the western Arctic Ocean.- Deep-Sea Research Part I Oceanographic Research Papers 50:1235-1261.

Batchelder, H.P. (1985): Seasonal Abundance, Vertical-Distribution, and Life-History of Metridia-Pacifica (Copepoda, Calanoida) in the Oceanic Subarctic Pacific.- Deep-Sea Research Part 1 Oceanographic Research Papers 32:949-964.

Beaudouin-Lafon, M. (2010). The good, the bad, and the ugly. Communications of the ACM 53:32-34.

Behrenfeld, M.J., O'Malley, R.T., Siegel, D.A., McClain, C.R., Sarmiento, J.L., Feldman, G.C., Milligan, A.J., Falkowski, P.G., Letelier, R.M. and Boss, E.S. (2006): Climate-driven trends in contemporary ocean productivity. Nature 444:752-755.

Bekryaev, R. V., I. V. Polyakov, and V. A. Alexeev. 2010. Role of Polar Amplification in Long-Term Surface Air Temperature Variations and Modern Arctic Warming. Journal of Climate 23:3888-3906.

Berkman, P.A. and Young, O.R. (2009): Governance and Environmental Change in the Arctic Ocean. Science 324:339-340.

Bradford-Grieve, J. M., Markhaseva, E.L., Rocha, C.E.F. and Abiahy, B. (1999): Copepoda.- In: D. Boltovskoy (eds.): South Atlantic Zooplankton. Backhuys Publishers, Leiden, 869-890.

Breiman, L. (2001): Statistical Modeling: The Two Cultures. Statistical Science 16:199-231.

Brodskii, K.A. (1950): Calanoida of the Far Eastern Sea and Polar Basin of the USSR.- Zoological Institute, Academy Nauk SSSR, USSR.

CAFF (2010): Arctic Biodiversity Trends 2010: Selected Indicators of Change. CAFF International Secretariat, Akureyri, Iceland, 121 pp.

Carlson, D. (2011): A lesson in sharing. Nature 469:293-293.

Carmack, E.C. (2000): The Arctic Ocean's freshwater budget: sources, storage and export. In: Lewis, E.L., Jones, E.P., Lemke, P., Prowse, T.D., Wadham, P. (Eds.), The Freshwater Budget of the Arctic Ocean. Kluwer Academic Publishers, Dordrecht, pp. 91-126.

CIA. (2009): The World Factbook. Central Intelligence Agency. Washington, DC.

Comiso, J.C., Parkinson, C.L., Gersten, R. and Stock, L. (2008): Accelerated decline in the Arctic sea ice cover. Geophysical Research Letters, 35.

Conover, R.J. (1988): Comparative Life Histories in the Genera Calanus and Neocalanus in High-Latitudes of the Northern Hemisphere.- Hydrobiologia 167:127-142.

Conover, R. and Huntley, M. (1991): Copepods in ice-covered Seas -- Distribution, adaptations to seasonally limited food, metabolism, growth patterns and life cycle strategies in Polar Seas.- Journal of Marine Systems 2:1-41.

Conover, R., Harris, L.R. and Bedo, A.W. (1990): Copepods in cold oligotrophic waters - How do they cope?- In: Uye, Nishida and Ho (eds.): Fourth International Conference on Copepoda. Japan, 177-199. 
Craig, E., and Huettmann, F. (2009): Using "Blackbox" Algorithms such as TreeNet and Random forests for Data-Mining and for Finding Meaningful Patterns, Relationships, and Outliers in Complex Ecological Data: An Overview, an Example Using Golden Eagle Satellite Data and an Outlook for a Promising Future. In: Wang H-F (ed) Intelligent Data Analysis: Developping new Methodologies Through Pattern Discovery and Recovery. Idea Group Inc, Hershey, PA, USA.

Curry, R., and Mauritzen, C. (2005): Dilution of the northern North Atlantic Ocean in recent decades. Science 308:1772-1773.

Cutler, D., Edwards Jr, T., Beard, K., Cutler, A., Hess, K., Gibson, J. and Lawler, J. (2007): Random forests for classification in ecology. Ecology 88:2783-2792.

Dagg, M.J., Frost, B.W. and Newton, J.A. (1997): Vertical migration and feeding behavior of Calanus pacificus females during a phytoplankton bloom in Dabob Bay, U.S. Limnol. Oceanogr. 42: 974-980.

Dawson, J.K. (1978): Vertical Distribution of Calanus hyperboreus in Central Arctic Ocean. Limnology and Oceanography 23:950957.

Dickson, R.R., Yashayaev, I., Meincke, J., Turrell, W.R., Dye, S. and Holfort, J. (2002): Rapid freshening of the deep North Atlantic Ocean over the past four decades. Nature 416, 832-837.

Dockerty, T., Lovett, A. and Watkinson, A. (2003): Climate change and nature reserves: examining the potential impacts, with examples from Great Britain. Global Environmental Change 13:125-135.

Elith, J., Leathwick, J. and Hastie, T. (2008): A working guide to boosted regression trees. Journal of Animal Ecology 77:802-813.

Euskirchen, E.S., Goodstein, E.S., Huntington, H.P. (in press): An estimated cost of lost climate regulation services caused by thawing of the arctic cryosphere. Ecological applications.

Friedman, J. (1999): Greedy Function Approximation: a Gradient Boosting Machine. Technical report, Dept. of Statistics, Stanford University.

Friedman, J. (2002): Stochastic gradient boosting. Computational Statistics \& Data Analysis 38:367-378.

Gaston, K.J., O'Neill, M. (2004): Automated species recognition: why not?. Philosophical Transactions of the Royal Society of London. B 359:655-667.

Gattuso, J.P., Crs. and Jorgensen, A. (2011): Topic: Ocean acidification. In: Encyclopedia of Earth. Eds. Cutler J. Cleveland (Washington, D.C.: Environmental Information Coalition, National Council for Science and the Environment). Retrieved April 12, $2012<$ http://www.eoearth.org/article/Ocean_acidification>

Girod, B., Wiek, A, Mieg, H. and Hulme, M. (2009): The evolution of the IPCC's emissions scenarios. Environmental Science \& Policy 12:103-118.

Gosselin, M., Levasseur, M., Wheeler, P.A., Horner, R.A. and Booth, B.C. (1997): New measurements of phytoplankton and ice algal production in the Arctic Ocean.- Deep-sea Research 2, 44:1623-1644.

Grant Gross, M. (1995): Principles of Oceanography.- Prentice-Hall, Inc., New Jersey.

Grant Gross, M. and Gross, E. (1996): Oceanography, a view of earth.- Prentice-Hall, Inc., New Jersey.

Gnanadesikan, A. (1999): A simple predictive model for the structure of the oceanic pycnocline. Science 283:2077-2079.

Hannemann, N., McGinley, M. and Caley, K.J. (2010): Topic: Arctic. In: Encyclopedia of Earth. Eds. Cutler J. Cleveland (Washington, D.C.: Environmental Information Coalition, National Council for Science and the Environment). Retrieved April 12, 2012 $<$ http://www.eoearth.org/article/Arctic>.

Hays, G.C., Proctor, A., John, A.W.G., Warner, A.J. (1994): Interspecific differences in the diel vertical migration of marine copepods: The implications of size, color, and morphology. Limnol. Oceanogr. 41:1306-1311.

Hirakawa, K. and Imamura, A. (1993): Seasonal abundance and life history of Metridia pacifica (Copepoda: Calanoida) in Toyama Bay, southern Japan Sea. Bull. Plankton Soc. Japan 40:41-54.

Hirche, H.J. (1997): Life cycle of the copepod Calanus hyperboreus in the Greenland sea.- Marine Biology 128:607-618.

Hirche, H. J. and Mumm, N. (1992): Distribution of Dominant Copepods in the Nansen Basin, Arctic-Ocean, in Summer.- Deep-Sea Research Part A-Oceanographic Research Papers 39:485-505. 
Hochachka, W., Caruana, R., Fink, D., Munson, A., Riedewald, M., Sorokina, D. and Kelling, S. (2007): Data-mining discovery of pattern and process in ecological systems. Journal of Wildlife Management 71:2427-2437.

Hopcroft, R.R., Clarke, C., Nelson, R.J. and Raskoff, K.A. (2005): Zooplankton communities of the Arctic's Canada Basin: the contribution by smaller taxa.- Polar Biology 28:198-206.

Huettmann, F. (2012): Protection of the Three Poles. Springer, Tokyo.

Huettmann, F., Artukhin, Y., Gilg, O. and Humphries, G. (2011): Predictions of 27 Arctic pelagic seabird distributions using public environmental variables, assessed with colony data: a first digital IPY and GBIF open access synthesis platform. Marine Biodiversity 41:141-179.

Hutchins, D.A., Fu, F.-X., Zhang, Y., Warner, M.E., Feng, Y., Portune, K., Bernhardt, P.W. and Mulholland, M.R. (2007): $\mathrm{CO}_{2} \mathrm{Control}$ of Trichodesmium $\mathrm{N}_{2}$ fixation, photosynthesis, growth rates, and elemental ratios: Implications for past, present, and future ocean biogeochemistry. Limnology and Oceanography 52:1293-1304.

IASC and Draggan, S. (2010): Topic: Cryosphere and Hydrology in the Arctic. In: Encyclopedia of Earth. Eds. Cutler J. Cleveland (Washington, D.C.: Environmental Information Coalition, National Council for Science and the Environment). Retrieved April 18, 2012 <http://www.eoearth.org/article/Cryosphere_and_Hydrology_in_the_Arctic>

IASC and Duffy, J.E. (2010): Topic: Future change in processes and impacts on Arctic biota. In: Encyclopedia of Earth. Eds. Cutler J. Cleveland (Washington, D.C.: Environmental Information Coalition, National Council for Science and the Environment). Retrieved April 12, 2012 <http://www.eoearth.org/article/Future_change_in_processes_and_impacts_on_Arctic_biota>

Jakobsson, M. (2002): Hypsometry and volume of the Arctic Ocean and its constituent's seas, Geochemistry Geophysics Geosystems 3:2.

IASC and McGinley, M. (2010): Topic: Effects of climate change on the biodiversity of the Arctic. In: Encyclopedia of Earth. Eds. Cutler J. Cleveland (Washington, D.C.: Environmental Information Coalition, National Council for Science and the Environment). Retrieved April 13, 2012 <http://www.eoearth.org/article/Effects_of_climate_change_on_the_biodiversity_of_the_Arctic>

IPCC (1990): Emissions scenarios. Response Strategies Working Group (Ed.). Intergovernmental Panel on Climate Change. Cambridge University Press, Cambridge.

IPCC (1995): In: Bolin, B., Houghton, J.T. (Eds.), Climate Change 1995-The Science of Climate Change. Cambridge University Press, Cambridge.

IPCC (2000): In: Nakicenovic, N., Swart, R. (Eds.), Special report on emissions scenarios. Cambridge University Press, Cambridge.

IPCC (2001): In: Watson, R.T., Albritton, D.L., Barker, T., Bashmakov, I.A., Canziani, O., Christ, R., Cubasch, U., Davidson, O., Gitay, H., Griggs, D., Halsnaes, K., Houghton, J. (Eds.), Third Assessment Report: Climate Change 2001-synthesis report. Cambridge University Press, Cambridge.

IPCC AR4 SYR (2007): Core Writing Team; Pachauri, R.K; and Reisinger, A., ed., Climate Change 2007: Synthesis Report, Contribution of Working Groups I, II and III to the Fourth Assessment Report of the Intergovernmental Panel on Climate Change, IPCC, ISBN 92-9169-122-4.

Janzen, D.H. (2004): Now is the time. Philosophical Transactions of the Royal Society of London. B 359:731-732.

Johnson, W.S. and Allen, D.M. (2005): Zooplankton of the Atlantic and Gulf coasts: a guide to their identification and ecology. The John Hopkins University Press, Baltimore.

Karnovsky, N.J., Kwasniewski, S., Weslawski, J.M., Walkusz, W. and Beszczynskamoller, A. (2003): Foraging behavior of little auks in a heterogeneous environment.- Marine Ecology-Progress Series 253:289-303.

Knight, K. (2011): Ocean acidification seriously impacts mussel larvae. Journal of Experimental Biology 214:I-I.

Kobari, T and Ikeda, T. (2001): Octogenetic vertical migration and life cycle of Neocalanus plumchrus (Crustacea:Copepoda) in the Oyashio region, with notes on regional variations in body size. Journal of Plankton Research 23:287-302.

Kononenko, I. and Kukar, M. (2007): Machine Learning and Data Mining: Introduction to Principles and Algorithms. Horwood publishing.

Kosobokova, K. and Hirche, H.J. (2000): Zooplankton distribution across the Lomonosov Ridge, Arctic Ocean: species inventory, biomass and vertical structure.- Deep-Sea Research Part I-Oceanographic Research Papers 47:2029-2060. 
Kwasniewski, S., Hop, H., Falk-Petersen, S. and Pedersen, G. (2003): Distribution of Calanus species in Kongsfjorden, a glacial fjord in Svalbard.- Journal Of Plankton Research 25:1-20.

Lalli, C.M. and Parsons, T.R. (1997): Biological Oceanography, An Introduction. $2^{\text {nd }}$ Edition. Butterworth-Heinemann, Oxford.

Levitus, S., Antonov, J.I., Boyer, T.P. and Stephens, C. (2000): Warming of the world ocean. Science 287:2225-2229.

Liu, H. and Hopcroft, R.R. (2006): Growth and development of Metridia pacifica (Copepoda: Calanoida) in the northern Gulf of Alaska.- Journal Of Plankton Research 28:769-781.

Longhurst, A.R. and Harrison, W.G. (1988): Vertical Nitrogen Flux from the Oceanic Photic Zone by Diel Migrant Zooplankton and Nekton.- Deep-Sea Research Part A- Oceanographic Research Papers 35:881-889.

Longhurst, A.R. and Harrison, W.G. (1989): The Biological Pump - Profiles of Plankton Production and Consumption in the Upper Ocean.- Progress In Oceanography 22:47-123.

Lyman, P. and Varian, H.R. (2003): How much information? Berkeley, CA: University of California at Berkeley, School of Information Management and Systems.

MacDonald, R.W. and Bewers, J.M. (1996): Contaminants in the arctic marine environment: priorities for protection. ICES J Mar Sci 53:537-563.

Manly, B.F.J., McDonald, L.L., Thomas, D.L., McDonald, T.L. and Erickson, W.P. (2002): Resource Selection by Animals: statistical analysis and design for field studies.- Kluwer, Boston.

Manuel, J.L. and O'Dor, R.K. (1997): Vertical migration for horizontal transport while avoiding predators: I. A tidal/diel model. J. Plankton Res. 19:1929-1948.

McLaughlin, F.A., Carmack, E.C., Macdonald, R.W. and Bishop, J.K.B. (1996): Physical and geochemical properties across the Atlantic/Pacific water mass boundary in the southern Canadian Basin. J Geophys Res 101:1183-97.

Meier, W.N., Stroeve, J. and Fetterer, F. (2007): Whither Arctic sea ice? A clear signal of decline regionally, seasonally, and extending beyond the satellite record. Ann. Glaciol. 46:428-434.

Minoda, T. (1971): Pelagic Copepoda in the Bering Sea and the northwestern North Pacific with special reference to their vertical distribution. Mem. Fac. Fish. Hokkaido Univ. 18:1-74.

Morison, J., Kwok, R., Peralta-Ferriz, C., Alkire, M., Rigor, I., Andersen, R. and Steele, M. (2012): Changing Arctic Ocean freshwater pathways. Nature 481:66-70.

Moss, R.H., Edmonds, J.A., Hibbard, K.A., Manning, M.R., Rose, S.K., van Vuuren, D.P., Carter, T.R., Emori, S., Kainuma, M., Kram, T. et al. (2010): The next generation of scenarios for climate change research and assessment. Nature 463:747-756.

Mumm, N. (1993): Composition and Distribution of Mesozooplankton in the Nansen Basin, Arctic-Ocean, during Summer. Polar Biology, 13:451-461.

Mumm, N., Auel, H., Hanssen, H., Hagen, W., Richter, C. and Hirche, H. J. (1998): Breaking the ice: large-scale distribution of mesozooplankton after a decade of Arctic and transpolar cruises.- Polar Biology 20:189-197.

Naess, A. and Rothenberg, D. (1990): Ecology, Community and Lifestyle: Outline of an Ecosophy. Cambridge University Press, Cambridge.

Nesbitt, L.M., Riessen, H.P. and Ramcharan, C.W. (1996): Opposing predation pressures and induced migration responses in Daphnia. Limnol. Oceanogr. 41:1306-1311.

Nicol, S. and Foster, J. (2003): Recent trends in the fishery for Antarctic krill". Aquatic Living Resources 16:42-45.

Nihoul, J.C.J. (1998): Modelling marine ecosystems as a discipline in Earth Science.- Earth-Science Reviews 44:1-13.

Oppel, S. and Huettmann, F. (2010): Using a Random Forest Model and Public Data to Predict the Distribution of Prey for Marine Wildlife Management. Spatial Complexity, Informatics, and Wildlife Conservation:151-163.

Orr, J.C., Fabry, V.J., Aumont, O., Bopp, L., Doney, S.C., Feely, R.A., Gnanadesikan, A, Gruber, N., Ishida, A., Joos, F., Key, R.M., Lindsay, K., Maier-Reimer, E., Matear, R., Monfray, P., Mouchet, A., et al. (2005): Anthropogenic ocean acidification over the twenty-first century and its impact on calcifying organisms. Nature 437:681-686. 
Overland, J.E., Spillane, M.C. and Soreide, N.N. (2004): Integrated analysis of physical and biological pan-Arctic change. Climatic Change 63:291-322.

Pittman, S. and Huettmann, F. (2006): Seabird Distribution and Diversity.- In: T. Battista, R. Clark and S. Pittman (eds.): An Ecological Characterization of the Stellwagen Bank National Marine Sanctuary Region: Oceanographic, Biogeographic, and Contaminants Assessment. 1-33.

Polyakov, I., Alexeev, V., Belchansky, G., Dmitrenko, I., Ivanov, V., Kirillov, S., Korablev, A., Steele, M., Timokhov, L. and Yashayaev, I. (2008): Arctic Ocean freshwater changes over the past 100 years and their causes. J Clim 21:364-384.

Polyakov, I., Timokhov, L., Alexeev, V., Bacon, S., Dmitrenko, I., Fortier, L., Frolov, I., Gascard, J.-C., Hansen, E., Ivanov, V., Laxon, S., Mauritzen, C., Perovich, D., Shimada, K., Simmons, H., Sokolov, V., Steele, M. and Toole, J. (2010): Arctic Ocean warming contributes to reduced polar ice cap. American Meteorological Society December, pp 2743-2756.

Polyakov, I., Timokhov, L., Dmitrenko, I., Ivanov, V., Simmons, H., Besczynska- Moller, A., Dickson, R., Fahrbach, E., Fortier, L., Gascard, J., Holeman, J., Holliday, P., Hansen, E., Mauritzen, C., Piechura, J., Pickart, R., Schauer, U., Steele, M. and Walczowski, W. (2007): Observational Program Tracks Arctic Ocean Transition to a Warmer State, Eos, Transactions, American Geophysical Union 88:398-399.

Prange, M. and Gerdes, R. (1999): Influence of Arctic river runoff on the circulation in the Arctic Ocean, the Nordic Seas and the North Atlantic.- eds.), 1-6. Bremerhaven.

Roemmich, D., and McGowan J. (1995): Climatic warming and the decline of zooplankton in the California Current, Science, 267: 1324-1326.

Rudels, B., Jones, E.P., Anderson, L.G. and Katner, G. (1994): On the intermediate depth waters of the Arctic Ocean. In: Johannessen RDM OM, Overland JE, editors. The polar oceans and their role in shaping the global environment, vol. 85. Washington (DC) American Geophysical Union; p. 33-46.

Rudels, B., Larsson, A.M., Sehlstedt, P.I. (1991): Stratification and water mass formation in the Arctic Ocean: some implication for the nutrient distribution. Polar Res 10:19-31.

Sakshaug, E. (2003): Primary and Secondary Production in the Arctic Seas. in: Stein, R., MacDonald, R.W., The organic carbon cycle in the Arctic Ocean. Springer, pp 57-81.

Salford Systems, L. (2003): TreeNet 2.0 User Manual-Software TreeNet. http://www.salfordsystems.com. Accessed on 4/20/2012.

Sarmiento, J.L., Gruber, N., Brzezinski, M. and Dunne. J. (2004): High latitude controls of thermocline nutrients and low latitude biological productivity, Nature 426:56-60.

Schauer, U., Loeng, H., Rudels, B., Ozhigin, V.K. and Dieck, W. (2002): Atlantic Water flow through the Barents and Kara Seas. DeepSea Research Part I-Oceanographic Research Papers 49:2281-2298.

Schauer, U., Muench, R.D., Rudels, B. and Timokhov. L. (1997): Impact of eastern arctic shelf waters on the Nansen Basin intermediate layers. Journal of Geophysical Research-Oceans 102:3371-3382.

Schreiber, E.A. and Burger, J. (2002): Biology of marine birds. CRC Press, Boca Raton.

Schulz, J., Mengedoht, D., Barz, K., Basilico, A., Henrich, M., and Hirche, H.-J. (2008): LOKI- Lightframe On-sight Keyspecies Investigation - Remote sensing of zooplankton, in: Observing the coastal sea - An Atlas of Advanced Monitoring techniques, edited by: Doerffer, R., Colijn, F., and van Beusekom, J., LOICZ Reports \& Studies No. 33 Geesthacht, Germany, GKSS Research Centre, ISSN 13834304.

Serreze, M.C. and Barry, R.G. (2005): The Arctic Climate System, Cambridge University Press, New York, 385 pp.

Siegel, D.A., Doney S.C. and Yoder, J.A. (2002): The spring bloom of phytoplankton in the North Atlantic Ocean and Sverdrup's critical depth hypothesis. Science 296:730-733.

Spiridonov, V., Gavrilo, M., Krasnov, Y., Makarov, A, Nikolaeva, N., Sergienko, L., Popov, P. and Krasnova, E. (2012): Toward the New Role of Marine and Coastal Protected Areas in the Arctic: The Russian Case. In: F. Huettmann (ed.): Protection of the Three Poles, Springer Tokyo. ISBN: 9784431540052.

Stern, N. (2007): The Economics of Climate Change: The Stern Review. Cambridge University Press. URL http://www.hmtreasury.gov.uk/independentreviews/sternrevieweconomics climatechange/sternreviewindex.cfm. 
Stroeve, J., Holland, M.M., Meier, W., Scambos, T., Serreze, M. (2007): Arctic sea ice decline: faster than forecast. Geophysical Research Letters, 34, L09501.

Thibault, D., Head, E.J.H. and Wheeler, P.A. (1999): Mesozooplankton in the Arctic Ocean in summer.- Deep-Sea Research Part IOceanographic Research Papers 46:1391-1415.

Thurman, H.V. (1997): Introductory Oceanography.- Prentice-Hall, Inc., New Jersey.

Townsend, D.W., Keller, M.D., Sieracki, M.E. and Ackleson, S.G. (1992): Spring phytoplankton blooms in the absence of vertical water column stability. Nature 360:59-62.

Trifa, V.M., Kirschel, A.N., Taylor, C.E. and Vallejo, E.E (2008): Automated species recognition of antbirds in a Mexican rainforest using hidden Markov models. The Journal of Accoustical Society of America 123:2424-2431.

van Vuuren, D.P., Edmonds, J.A., Kainuma, M., Riahi, K., Thomson, A.M., Hibbard, K., Hurtt, G.C., Kram, T., Krey, V., Lamarque, J.-F., Masui, T., Meinshausen, M., Nakicenovic, N., Smith, S.J. and Rose, S. (2011): The representative concentration pathways: an overview Climatic Change 109:5-31.

Verity, P.G. and Smetacek, V. (1996): Organism life cycles, predation, and the structure of marine pelagic ecosystems.- Marine Ecology-Progress Series 130:277-293.

Visser, A. and Jonasdottir, S. (1999): Lipids, buoyancy and the seasonal vertical migration of Calanus finmarchicus. Fisheries Oceanography 8:100-106.

Walsh, J.E., and Chapman, W.L. (2001): 20th-century sea-ice variations from observational data. Ann. Glaciol. 33:444-448.

Wang, M. and Overland, J.E. (2009): A sea ice free summer Arctic within 30 years? Geophysical Research Letters 36.

Welsh, J.P., Ketchum, R.D., Lohanick, A.W., Farmer, L.D., Eppler, D.T., Burge, R.E. and Radl, C.I. (1986): A compendium of Arctic environmental information. Report 138, Naval Ocean Research and Development Activity, Stennis Space Center, MS.

Wiebe, P.H., Copley, N.J. and Boyd, S.H. (1990): Coarse-scale horizontal patchiness and vertical migration of zooplankton in Gulf Stream warm-core ring 82-H. Deep-Sea Research 99:237-278.

Young, O.R. (1996): Institutional linkages in international society: Polar perspectives. Global Governance 2:1-23.

Young, O.R. (2012): Arctic tipping points: governance in turbulent times. Ambio 41:75-84.

Zimov, S.A., Voropaev, Y.V., Semiletov, I.P., Davidov, S.P., Prosiannikov, S.F., Chapin III, F.S., Chapin, M.C., Trumbore, S. and Tyler S. (1997): North Siberian lakes: A methane source fueled by Pleistocene carbon. Science 277:800-802. 


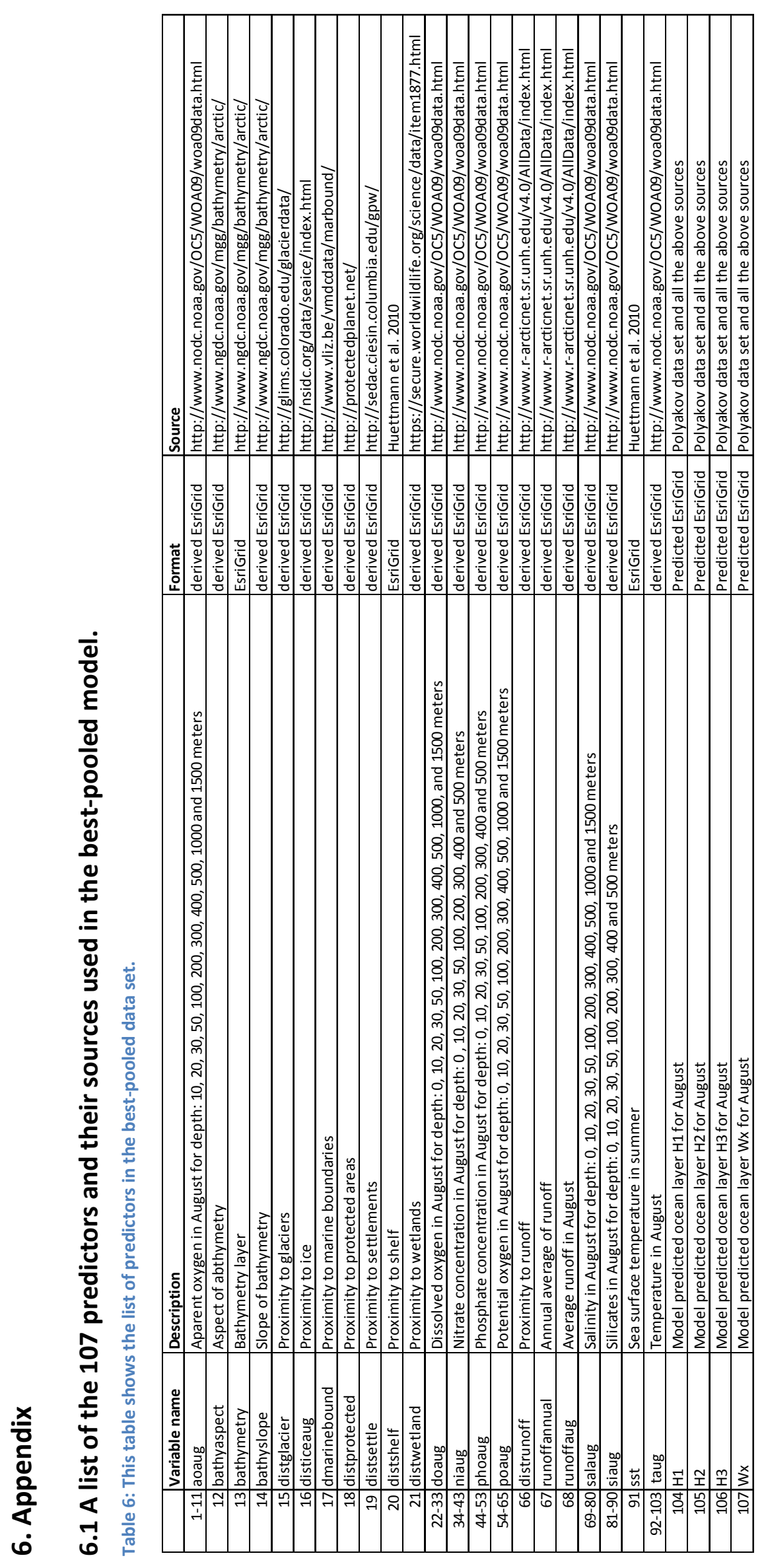




\subsection{The R-code used to extract data from the future climate models}

See below the programming code in R programming language developed by Michael Lindgren from the Scenarios Network for Alaska and Arctic Planning (SNAP) office, and modified by Moritz Schmid, to extract data from netCDF files to a different format. If you are interested, Michael Lindgren would surely be happy to receive an email from you at: malindgren@alaska.edu.

\section{Code start:}

\# This code was written by Michael Lindgren (malindgren@alaska.edu) of The Scenarios Network of Alaska and Arctic Planning at the University of Alaska Fairbanks for the purposes of aiding in the extraction of NetCDF data to a more easily digestible format for commercial GIS softwares. The code reads in the nc file as a raster brick, which allows for easy access to the data in a native $\mathrm{R}$ format, and extracts each layer from 1:N layers in the NetCDF to a *tif file. This does require that the user inputs a few different options to be able to create the proper output filename. This is a bit tedious but was hardwired in this way for use in many applications. Though in the future it would be nice to write in a parser to turn the input filename into one that is for each individual file using some basic tenets of file naming. \#

\# The USER MUST INPUT THE NEEDED INFORMATION INTO THE VARIABLES inside of the \# -- -- -- -- --\#

\# This code is open access / open source and is able to be shared and re-used as needed. Please contact the author (Michael Lindgren) with questions or to send some Kudos (always nice to get!) for writing it and making it available \#

\# The following packages are needed to run this code. If you do not have these packages installed use the R command install.packages('<name of package>') to install it directly from the command line. (this requires internet connection) e.g. install.packages('raster') this will install the raster package. You may need to indicate a mirror to download the data from, just choose the one that is geographically closest to where you are currently working\#

install.packages('rgdal') \# install the gdal r package

require(rgdal) \# this asks $R$ to put the rgdal library into the environments

install.packages('raster')

require(raster)

install.packages('ncdf')

require(ncdf)

$\#$ setwd("YOUR PATH") \# set the working directory

\#this line sets the output directory to wherever you want to write out the rasters 
output.dir <- "YOUR PATH.../" \# BE SURE TO LEAVE THE ENDING '/' !!!!

\#path to the .nc file to be extracted to NetCDF

nc.path <- "YOUR PATH"

\# this line is all it takes thanks to the raster package to create a stack of rasters from the multidimensional array NetCDF file\#

nc.stack <- brick("YOUR PATH")

\# these variables should be set to the 2 or 3 digit variable code used to identify the output data, the model group, the model name, the RCP, and the realization physics run number [ALL OF WHICH CAN BE DERIVED FROM THE INPUT FILENAMES YOU GET FROM THE GROUP]\#

\# ----> this is used to create the output naming convention for the new raster layers and with examples given<----

var <- 'vas'

model.group <- 'cccma'

model.name <- 'CanESM2'

rcp <- 'rcp85'

realizationPhys <- 'r1i1p1'

level <- '1'

\# these two variables should be set to the beginning year in the series and the end year in the series. They are used in creating the output naming convention\#

BeginYear <- 2010

EndYear <- 2100

\#

\# this variable creates a 2-digit scheme for month indicator

months <- c("01","02","03","04","05","06","07","08","09","10","11","12")

count $=0$ 


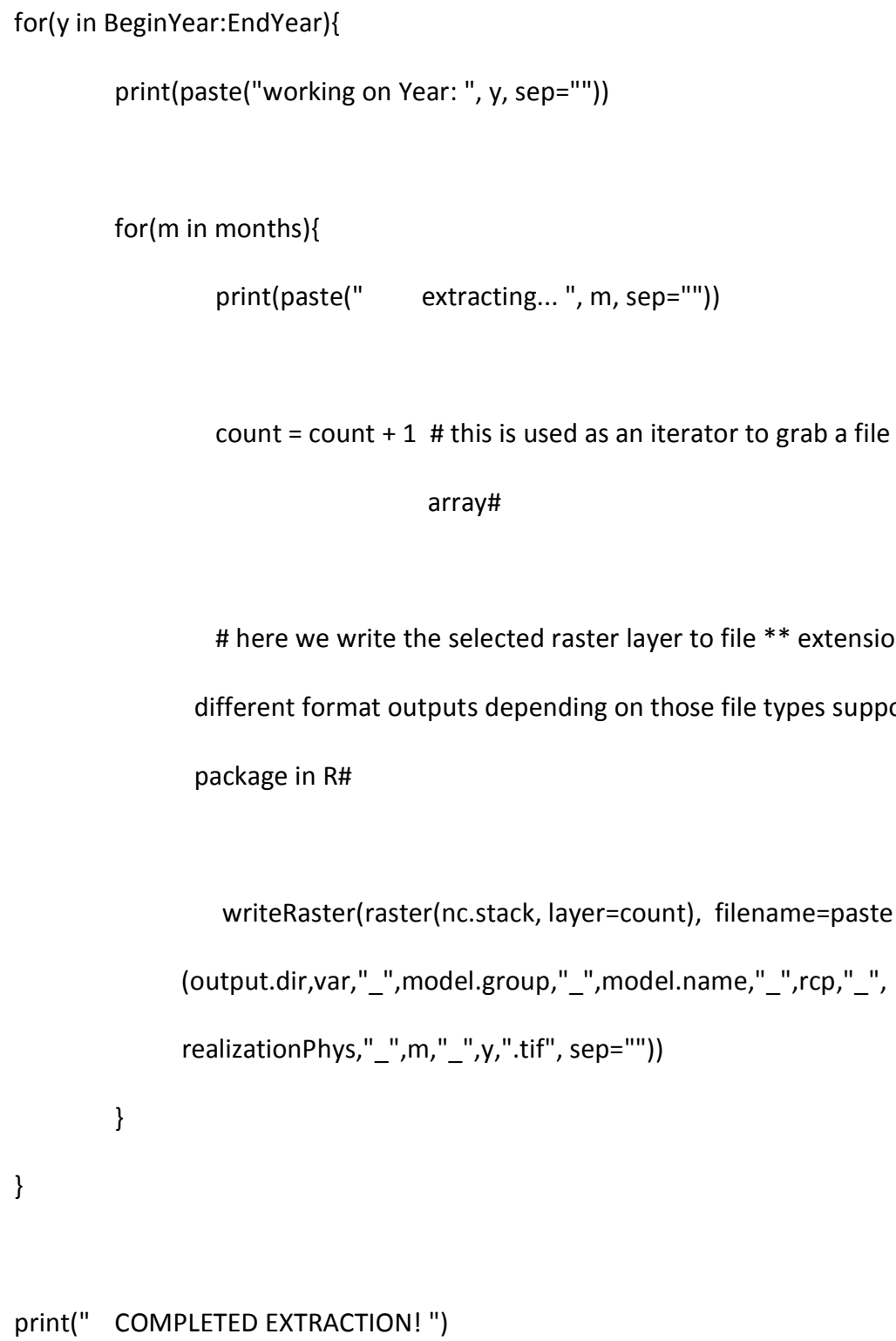




\subsection{Model performances for the best-pooled model}

\subsubsection{Response curves}

\subsubsection{Ocean layer models}

\section{Ocean layer $\mathrm{H} 1$}

The following graph shows the response curve for the model of the ocean layer H1 (Fig. 120).

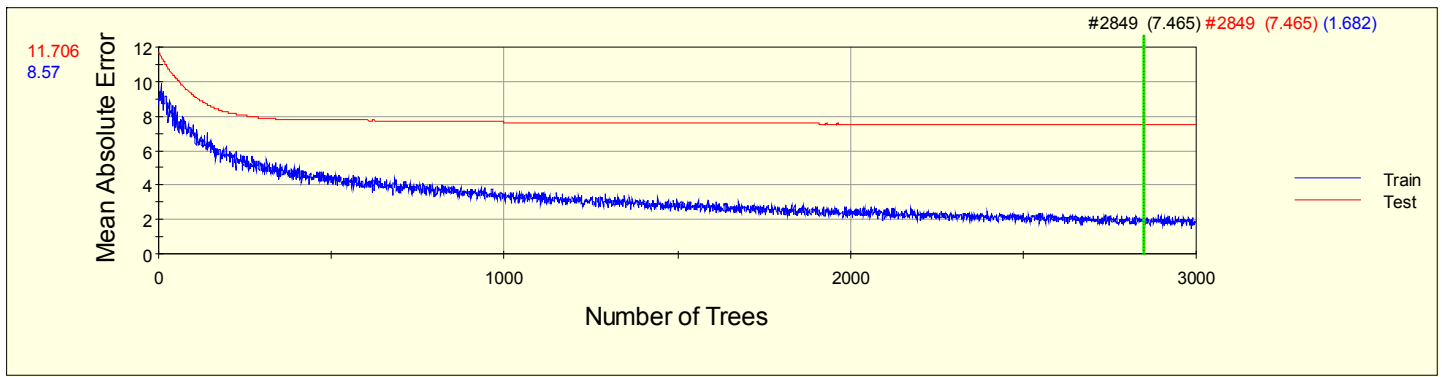

Figure 120: Response curve for the model of ocean layer H1

\section{Ocean layer $\mathrm{H} 2$}

The following graph shows the response curve for the model of the ocean layer $\mathrm{H} 2$ (Fig. 121).

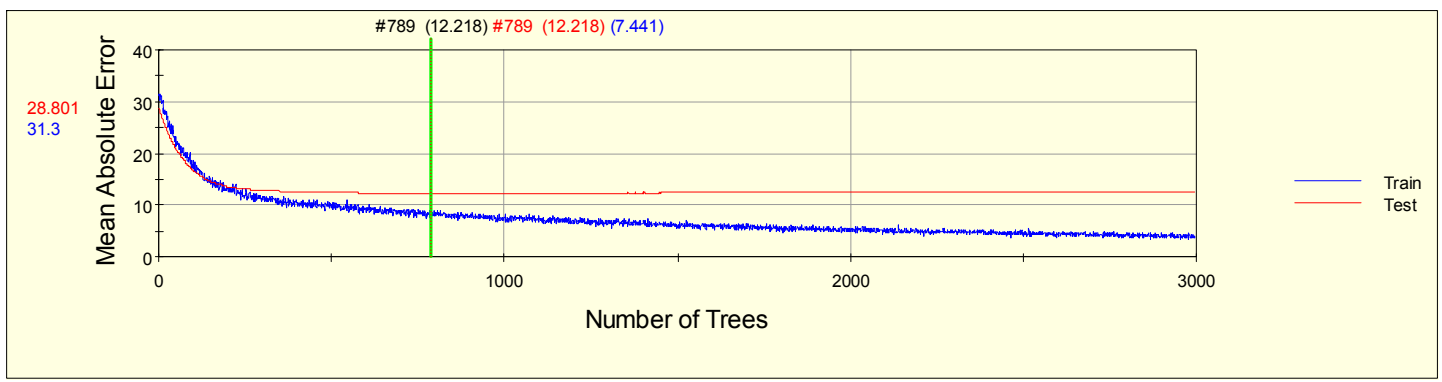

Figure 121: Response curve for the model of ocean layer H2

\section{Ocean layer $\mathrm{H} 3$}

The following graph shows the response curve for the model of the ocean layer H3 (Fig. 122).

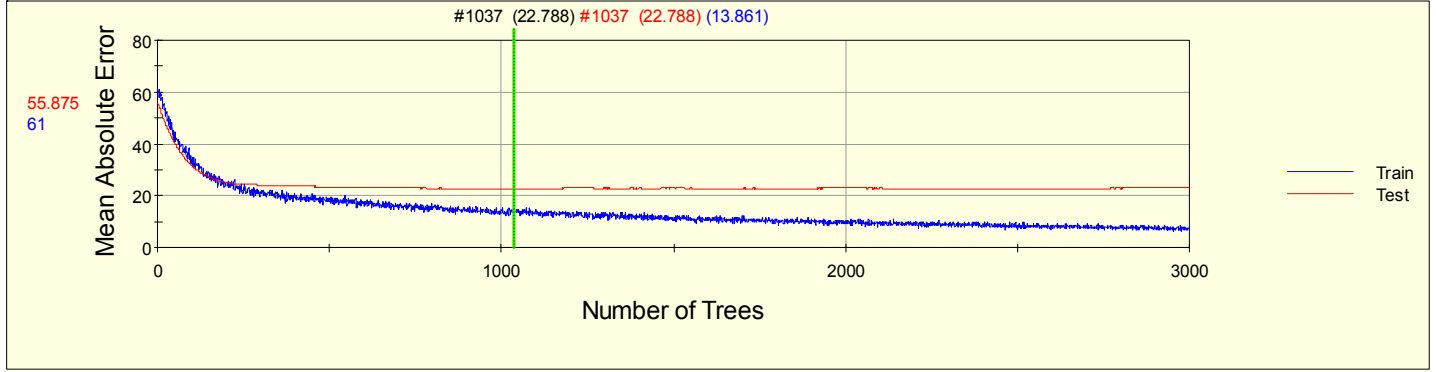

Figure 122: Response curve for the model of ocean layer H3 


\section{Ocean layer Wx}

The following graph shows the response curve for the model of the ocean layer Wx (Fig. 123).

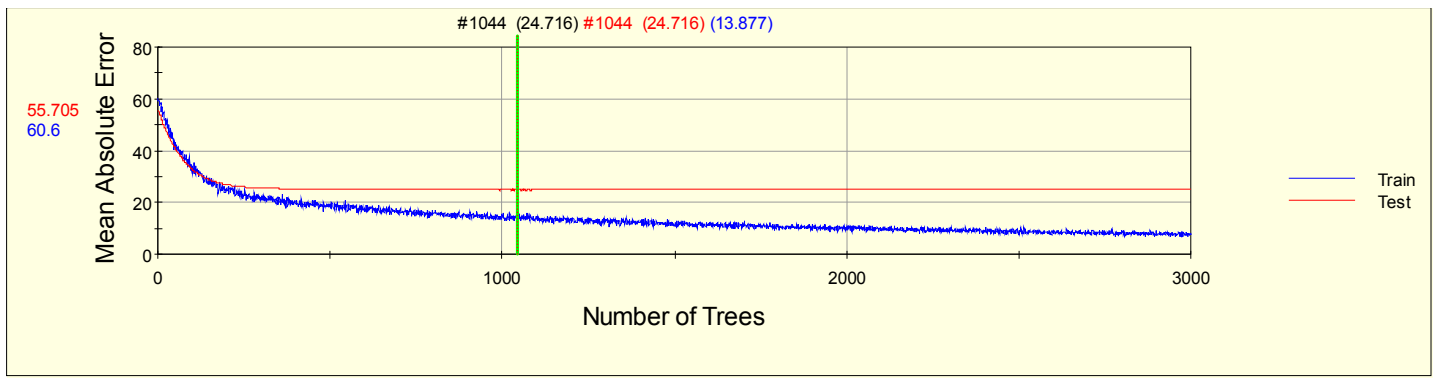

Figure 123: Response curve for the model of ocean layer Wx

\subsubsection{Zooplankton species}

\section{Calanus hyperboreus}

\section{Presence/random absence model}

The following graph shows the response curve for the presence/random absence model of $C$. hyperboreus

(Fig. 124).

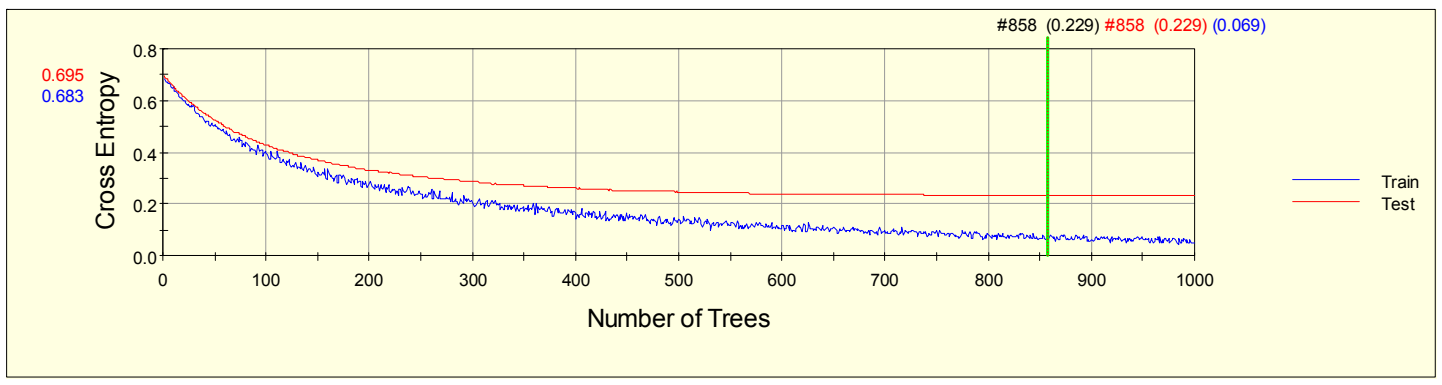

Figure 124: Response curve for the presence/random absence model of $C$. hyperboreus.

\section{Predicted relative index of depth model}

The following graph shows the response curve for the relative index of depth model of $C$. hyperboreus (Fig. 125).

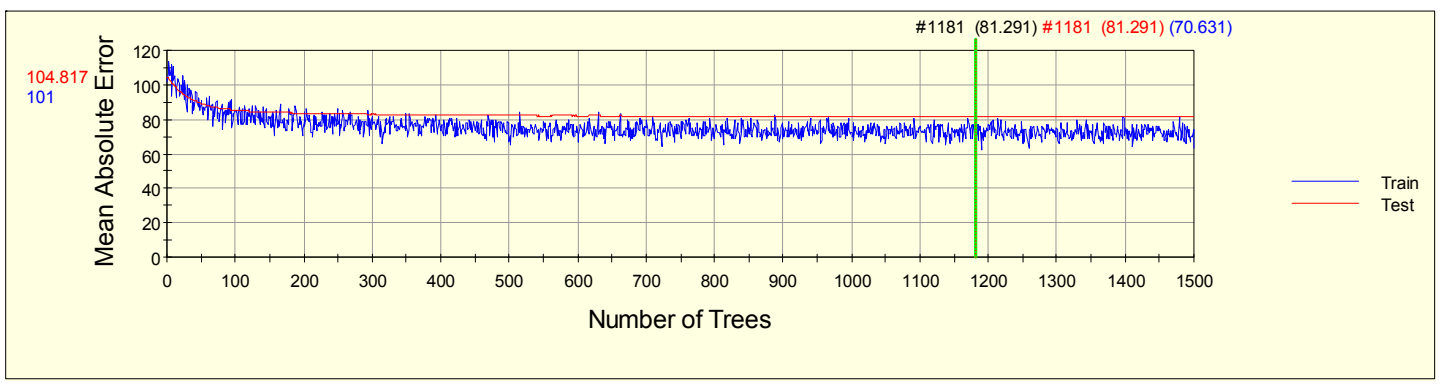

Figure 125: Response curve for the predicted relative index of depth model of $C$. hyperboreus. 


\section{Predicted life stage model}

The following graph shows the response curve for the life stage model of $C$. hyperboreus (Fig. 126).

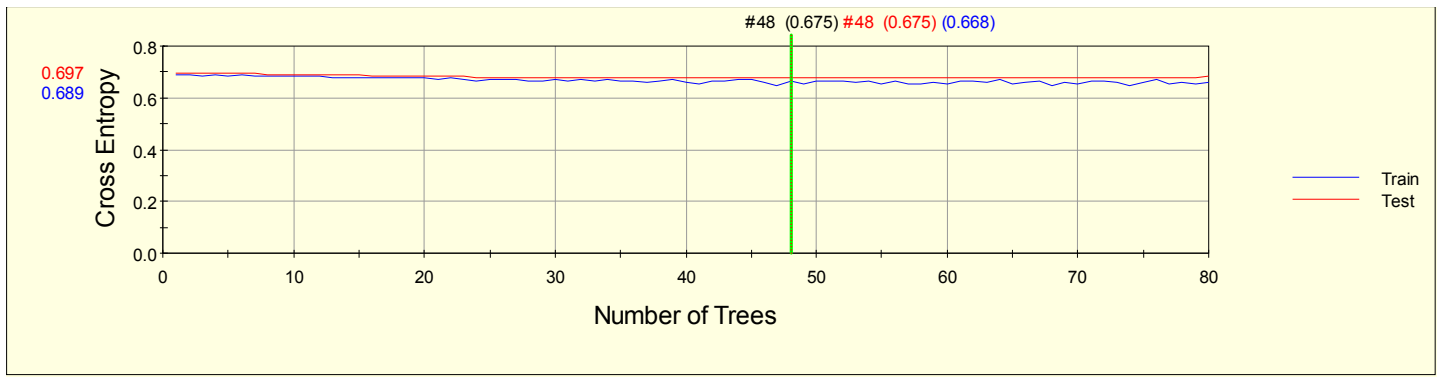

Figure 126: Response curve for the predicted life stage model of $C$. hyperboreus.

\section{Metridia longa}

\section{Presence/random absence model}

The following graph shows the response curve for the presence/random absence model of $M$. longa (Fig. 127).

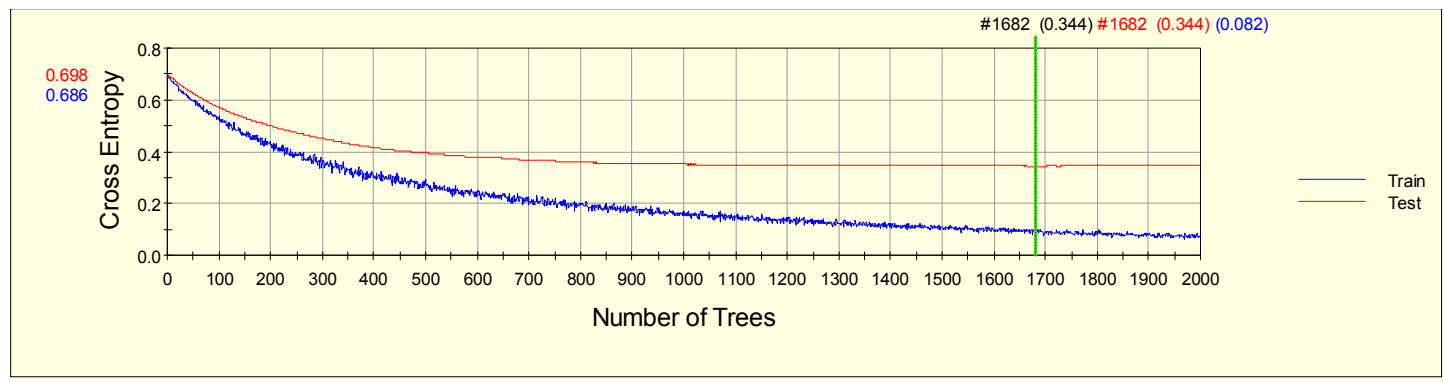

Figure 127: Response curve for the presence/random absence model of $M$. longa.

Predicted relative index of depth model

The following graph shows the response curve for the relative index of depth model of of $M$. longa (Fig. 128).

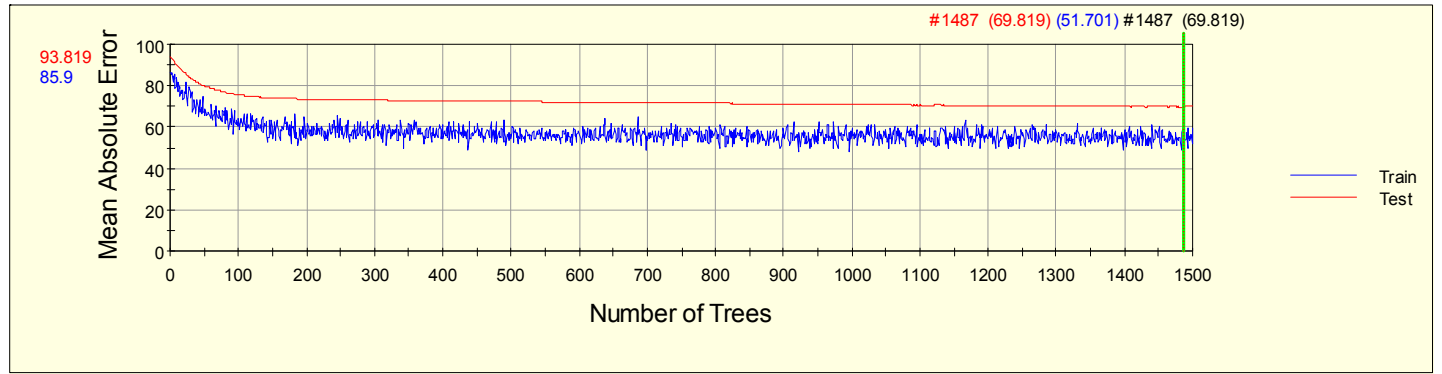

Figure 128: Response curve for the predicted relative index of depth model of $M$. longa. 


\section{Predicted life stage model}

The following graph shows the response curve for the life stage model of M. longa (Fig. 129).

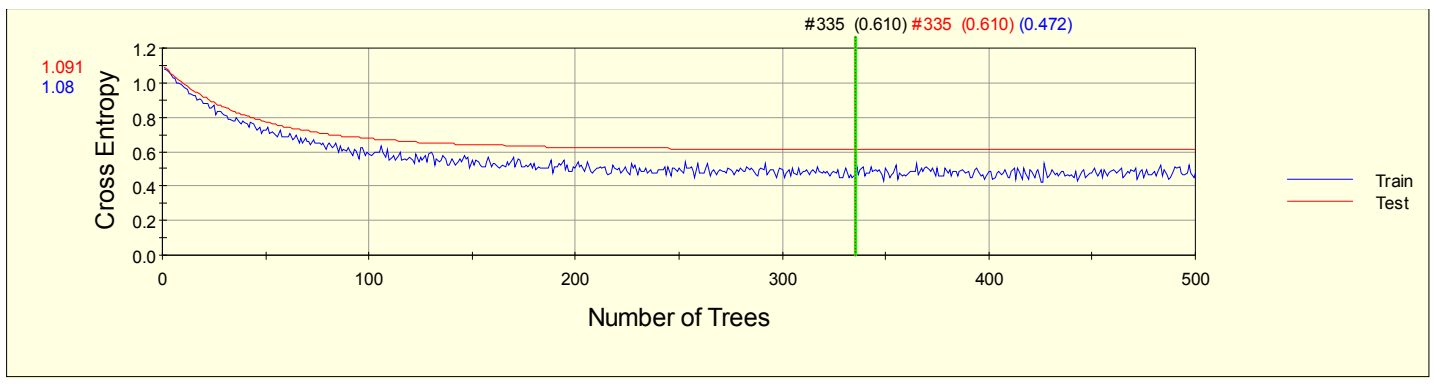

Figure 129 Response curve for the predicted life stage model of $M$. longa.

\section{Metridia pacifica}

\section{Presence/random absence model}

The following graph shows the response curve for the presence/random absence model of M. pacifica (Fig. 130).

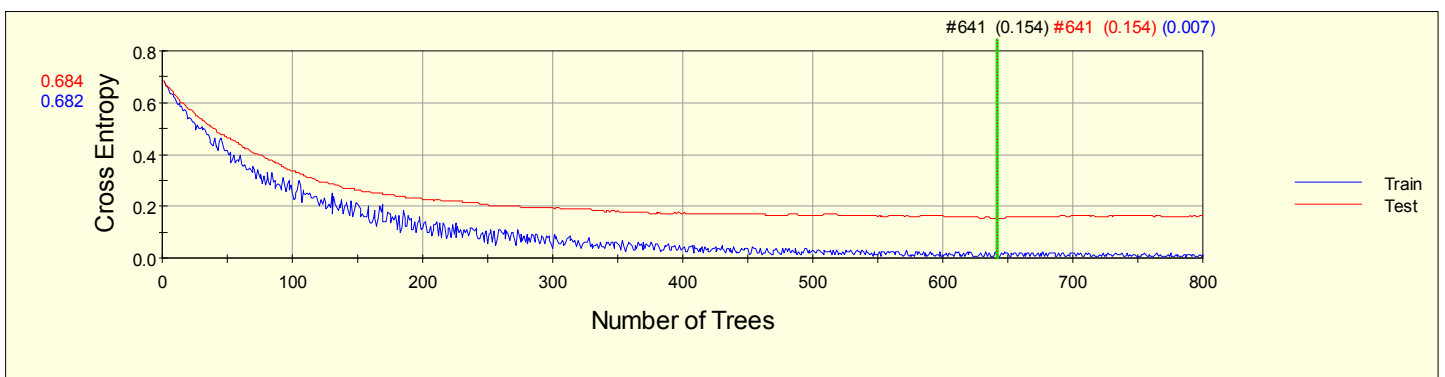

Figure 130: Response curve for the presence/random absence model of $M$. pacifica.

\section{Predicted relative index of depth model}

The following graph shows the response curve for the relative index of depth model of M. pacifica (Fig. 131).

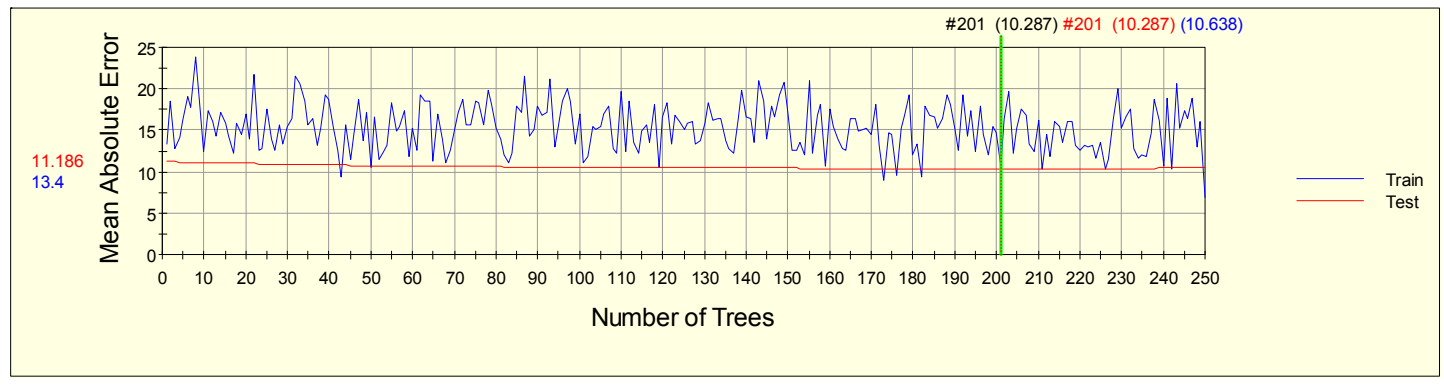

Figure 131: Response curve for the predicted relative index of depth model of M. pacifica. 


\section{Predicted life stage model}

The following graph shows the response curve for the life stage model of M. pacifica (Fig. 132).

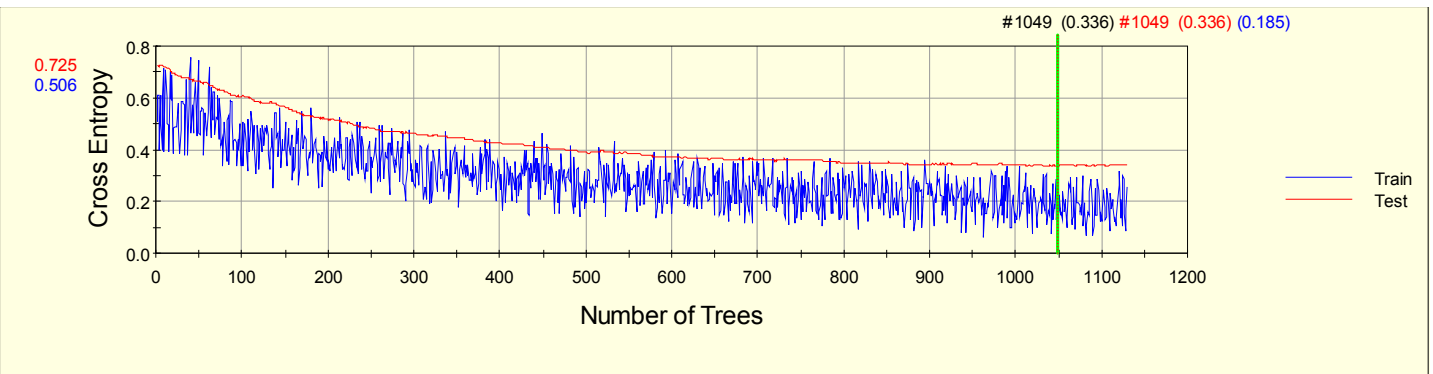

Figure 132: Response curve for the predicted life stage model of $M$. pacifica.

\section{Thysanoessa raschii}

\section{Presence/random absence model}

The following graph shows the response curve for the presence/random absence model of $T$. raschii (Fig. 133).

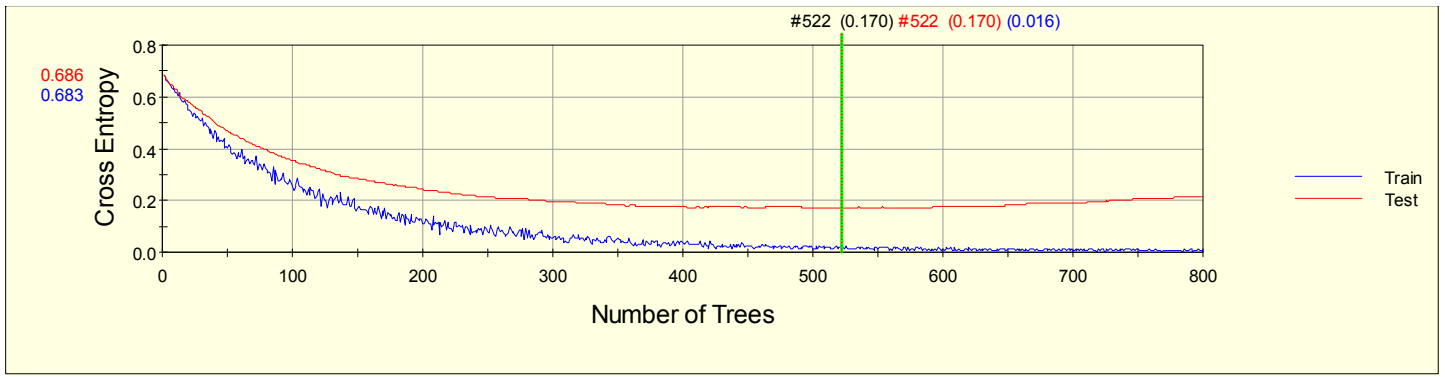

Figure 133: Response curve for the presence/random absence model of T. raschii.

\section{Predicted relative index of depth model}

The following graph shows the response curve for the relative index of depth model of T. raschii (Fig. 134).

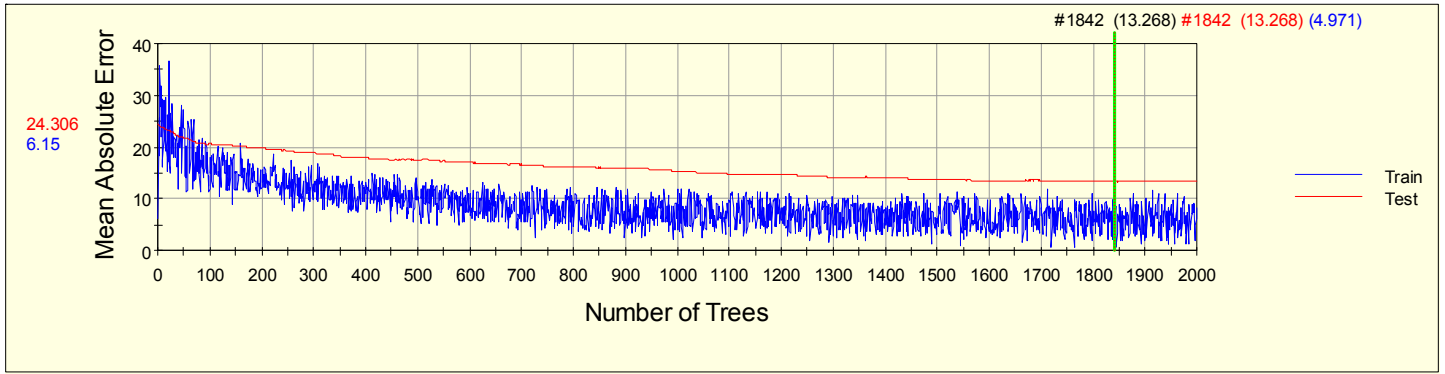

Figure 134: Response curve for the predicted relative index of depth model of $T$. raschii. 


\section{Predicted life stage model}

The following graph shows the response curve for the life stage model of T. raschii (Fig. 135).

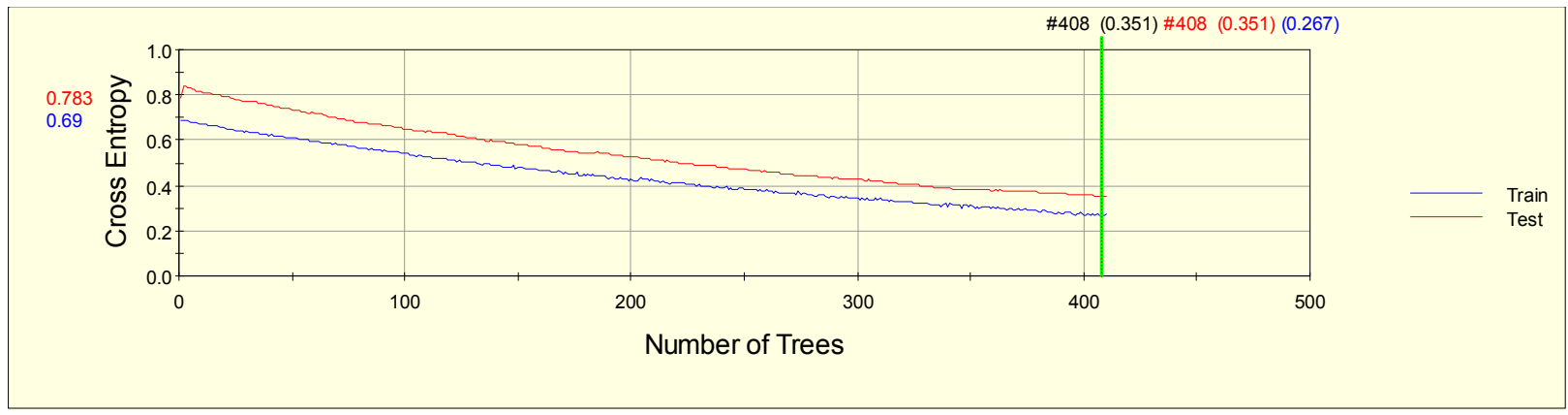

Figure 135: Response curve for the predicted life stage model of $T$. raschii.

\subsubsection{The ten most important predictors for each model}

\subsubsection{Ocean layer models}

The following graph shows the variable importance for the models of the ocean layers $H 1, H 2, H 3$ and $W x$ (Table 7).

Table 7: Variable importance for the three models of the ocean layers.

\begin{tabular}{|c|c|}
\hline a) H1 & \\
\hline Variable & Score \\
\hline BATHSLOP & 100 \\
\hline SSTSUMMER & 94.05 \\
\hline MIXEDLD & 89.03 \\
\hline BATHASP & 85 \\
\hline DSETTLE & $\mathbf{8 4 . 4 2}$ \\
\hline ICE85 & $\mathbf{8 1 . 1 3}$ \\
\hline PHOAUG 500 & $\mathbf{8 0 . 8 6}$ \\
\hline BATHY & 79.28 \\
\hline NIAUG 10 & 77.06 \\
\hline TAUG 20 & 73.15 \\
\hline
\end{tabular}

\begin{tabular}{|c|c|}
\hline b) H2 & \\
\hline Variable & Score \\
\hline PHOAUG 20 & 100 \\
\hline SALAUG 200 & 91.45 \\
\hline SIAUG 10 & 86.51 \\
\hline PHOAUG 10 & 67.32 \\
\hline TAUG 1500 & 42.77 \\
\hline DSETTLE & 36.57 \\
\hline PHOAUG 30 & 36 \\
\hline SALAUG 30 & 34.84 \\
\hline ICE85 & 34.82 \\
\hline PHOAUG 50 & 34.82 \\
\hline
\end{tabular}

\begin{tabular}{|c|c|}
\hline c)H3 & \\
\hline Variable & Score \\
\hline SALAUG 200 & 100 \\
\hline PHOAUG20 & 93.74 \\
\hline PHOAUG 10 & 70.75 \\
\hline SIAUG 10 & 44.94 \\
\hline TAUG1500 & 43.14 \\
\hline SALAUG100 & 33.44 \\
\hline TAUG200 & 30.06 \\
\hline SALAUG30 & 28.29 \\
\hline ICE85 & 27.88 \\
\hline PHOAUG50 & 26.28 \\
\hline
\end{tabular}

\begin{tabular}{|c|c|}
\hline WX & \\
\hline Variable & Score \\
\hline SALAUG200 & 100 \\
\hline PHOAUG 20 & 77.34 \\
\hline PHOAUG 10 & 68.53 \\
\hline TAUG 1500 & 37.93 \\
\hline SIAUG 10 & 29.33 \\
\hline TAUG200 & 28.94 \\
\hline SALAUG 0 & 28.58 \\
\hline DRUNOFF & 27.52 \\
\hline POAUG400 & 25.82 \\
\hline BATHSLOP & 25.59 \\
\hline
\end{tabular}

\subsubsection{Zooplankton species}

\section{Calanus hyperboreus}

The following graph shows the variable importance for the three models (presence/random absence, relative index of depth and life stage distribution) for C. hyperboreus. (Table 8). 
Table 8: Variable importance for the three models of $C$. hyperboreus.

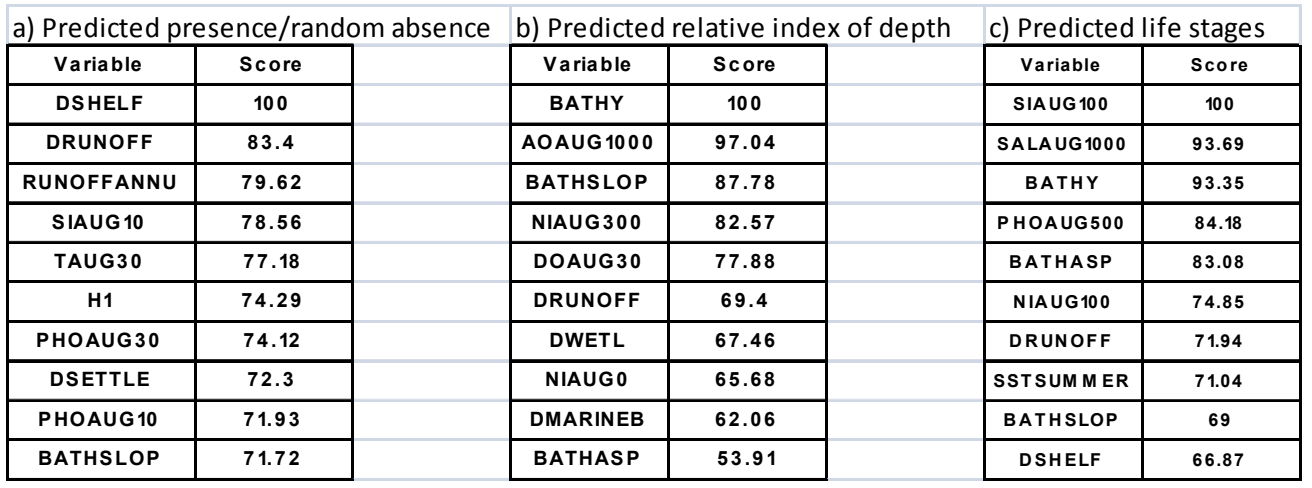

\section{Metridia longa}

The following graph shows the variable importance for the three models (presence/random absence, relative index of depth and life stage distribution) for $M$. longa (Table 9).

Table 9: Variable importance for the three models of $M$. longa.

a) Predicted presence/random absence

\begin{tabular}{|c|c|}
\hline Variable & score \\
\hline PHOAUG500 & 100 \\
\hline NIAUG500 & 90.18 \\
\hline NIAUG 100 & 84.59 \\
\hline H1 & 82.7 \\
\hline NIAUG 10 & 74.89 \\
\hline NIAUG300 & 67.97 \\
\hline DOAUG 10 & 65.87 \\
\hline TAUG 100 & 62.01 \\
\hline PHOAUG 300 & 61.36 \\
\hline MIXEDLD & 61.27 \\
\hline
\end{tabular}

b) Predicted relative index of depth

\begin{tabular}{|c|c|}
\hline Variable & Score \\
\hline BATHY & 100 \\
\hline BATHSLOP & 51.59 \\
\hline DWETL & 39.26 \\
\hline DSHELF & 38.75 \\
\hline BATHASP & 37.71 \\
\hline DRUNOFF & 37.36 \\
\hline NIAUG 0 & 35.42 \\
\hline PHOAUG 0 & 34.53 \\
\hline DMARINEB & 32.63 \\
\hline AOAUG 1000 & 32.21 \\
\hline
\end{tabular}

c) Predicted life stages

\begin{tabular}{|l|c|}
\hline \multicolumn{1}{|c|}{ Variable } & score \\
\hline SALAUG 1500 & 100 \\
\hline AOAUG 1500 & 69 \\
\hline NIAUG 30 & 53.09 \\
\hline BATHASP & 43.85 \\
\hline SS TSUMMER & 37.68 \\
\hline AOAUG 10 & 36.05 \\
\hline NIAUG 500 & 33.8 \\
\hline DSETTLE & 32.94 \\
\hline NIAUG 300 & 32.46 \\
\hline DOAUG50 & 32.37 \\
\hline
\end{tabular}

\section{Metridia pacifica}

The following graph shows the variable importance for the three models (presence/random absence, relative index of depth and life stage distribution) for M. pacifica (Table 10).

Table 10: Variable importance for the three models of $M$. pacifica.

a) Predicted presence/random absence

\begin{tabular}{|c|c|}
\hline Variable & Score \\
\hline AOAUG 10 & 100 \\
\hline PHOAUG20 & 84.95 \\
\hline $\begin{array}{c}\text { PHOAUG10 } \\
0\end{array}$ & 75.19 \\
\hline PHOAUG30 & 74.64 \\
\hline DOAUG 10 & 59.65 \\
\hline DOAUG0 & 55.34 \\
\hline POAUG0 & 49.07 \\
\hline PHOAUG 10 & 48.1 \\
\hline CHLORO & 42.56 \\
\hline NIAUG200 & 41.65 \\
\hline
\end{tabular}

b) Predicted relative index of depth

\begin{tabular}{|c|c|}
\hline Variable & Score \\
\hline BATHY & 100 \\
\hline WX & 66.95 \\
\hline BATHSLOP & 61.55 \\
\hline NIAUG 100 & 51.7 \\
\hline SALAUG 1000 & 50.89 \\
\hline AOAUG 1000 & 46.04 \\
\hline SALAUG 1500 & 41.27 \\
\hline H3 & 40.77 \\
\hline SIAUG 100 & 38.57 \\
\hline NIAUG300 & 36.71 \\
\hline
\end{tabular}

c) Predicted life stages

\begin{tabular}{|c|c|}
\hline Variable & Score \\
\hline DSHELF & 100 \\
\hline BATHASP & 66.23 \\
\hline SALAUG 1000 & 51.83 \\
\hline AOAUG 1500 & 48.32 \\
\hline BATHSLOP & 46.46 \\
\hline BATHY & 40.83 \\
\hline SIAUG 20 & 37.39 \\
\hline DRUNOFF & 35.21 \\
\hline AOAUG 1000 & 35.13 \\
\hline WX & 29.9 \\
\hline
\end{tabular}




\section{Thysanoessa raschii}

The following graph shows the variable importance for the three models (presence/random absence, relative index of depth and life stage distribution) for T. raschii (Table 11).

Table 11: Variable importance for the three models of $T$. raschii.

a) Predicted presence/random absence

\begin{tabular}{|c|c|}
\hline Variable & Score \\
\hline DPROTECT & 100 \\
\hline BATHY & 86.99 \\
\hline DSHELF & 68.62 \\
\hline DRUNOFF & 57.39 \\
\hline AOAUG 100 & 39.75 \\
\hline DWETL & 31.96 \\
\hline AOAUG 300 & 27.45 \\
\hline BATHSLOP & 27.12 \\
\hline DSETTLE & 26.77 \\
\hline H1 & 26.64 \\
\hline
\end{tabular}

b) Predicted relative index of depth

\begin{tabular}{|c|c|}
\hline Variable & Score \\
\hline BATHSLOP & 100 \\
\hline AOAUG 300 & 80.33 \\
\hline BATHASP & 66.37 \\
\hline BATHY & 53.45 \\
\hline AOAUG 100 & 49.02 \\
\hline PHOAUG 500 & 48.06 \\
\hline DSHELF & 46.43 \\
\hline AOAUG 10 & 45.97 \\
\hline POAUG 300 & 42.86 \\
\hline AOAUG400 & 39.81 \\
\hline
\end{tabular}

c) Predicted life stages

\begin{tabular}{|c|c|}
\hline Variable & Score \\
\hline AOAUG 10 & 100 \\
\hline DPROTECT & 74.07 \\
\hline AOAUG300 & 71.86 \\
\hline BATHSLOP & 51.69 \\
\hline BATHASP & 46.94 \\
\hline DSHELF & 40.07 \\
\hline AOAUG400 & 37.08 \\
\hline POAUG300 & 32.44 \\
\hline BATHY & 30.03 \\
\hline AOAUG 100 & 26.95 \\
\hline
\end{tabular}

\subsubsection{The Partial dependence plots}

For all partial dependence plots, a) is the most important predictor and c) the third most important predictor.

\subsubsection{Ocean layer models}

\section{Ocean layer $\mathrm{H} 1$}

The following graph shows the partial dependence plots for the 3 most important predictors in the $\mathrm{H} 1$ ocean layer model. (Fig. 136)

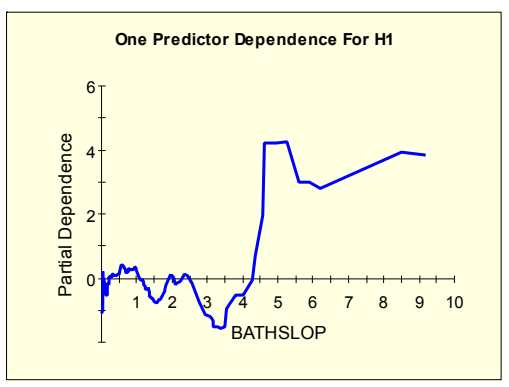

a)

Figure 136: Partial dependence plots for the three most important predictors in the H1 ocean layer model.

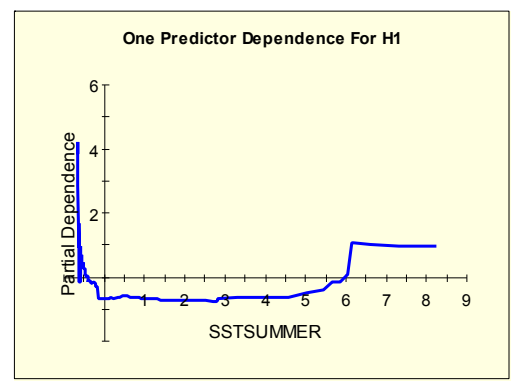

b)

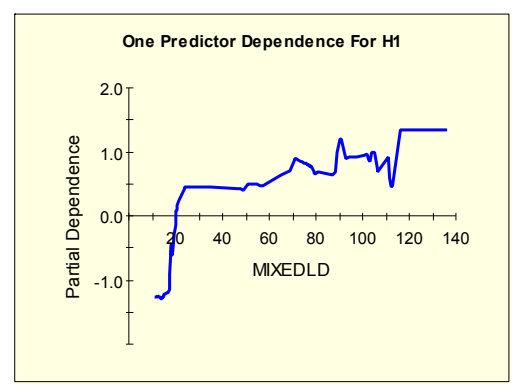

c) 


\section{$\underline{\text { Ocean layer } \mathrm{H} 2}$}

The following graph shows the partial dependence plots for the 3 most important predictors in the $\mathrm{H} 2$ ocean layer model. (Fig. 137)

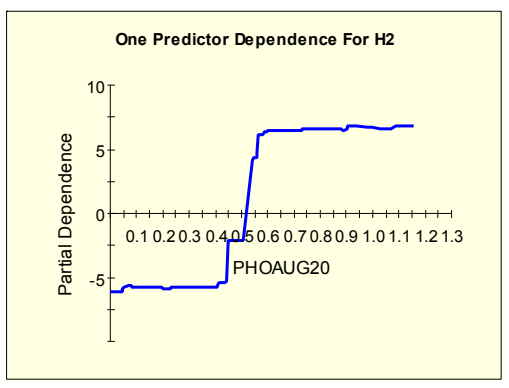

a)

Figure 137: Partial dependence plots for the three most important predictors in the $\mathrm{H} 2$ ocean layer model.

\section{Ocean layer $\mathrm{H} 3$}

The following graph shows the partial dependence plots for the 3 most important predictors in the H3 ocean layer model. (Fig. 138)

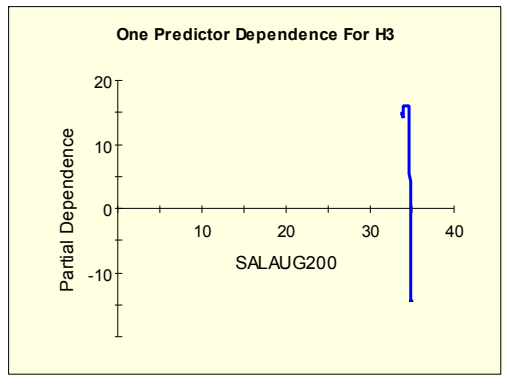

a)

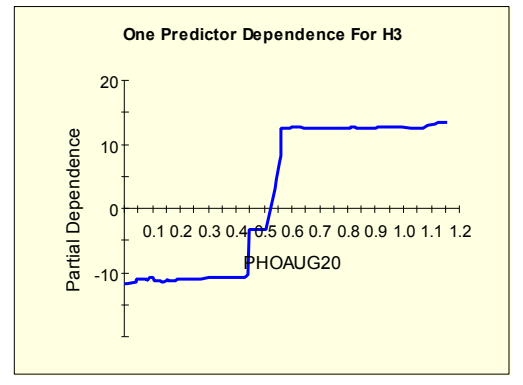

b)

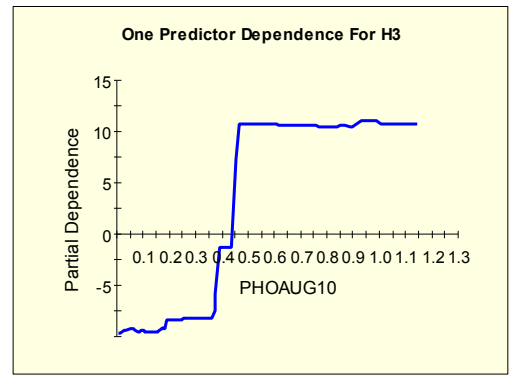

c)

Figure 138: Partial dependence plots for the three most important predictors in the H3 ocean layer model. 


\section{Ocean layer Wx}

The following graph shows the partial dependence plots for the 3 most important predictors in the $\mathrm{Wx}$ ocean layer model. (Fig. 139)

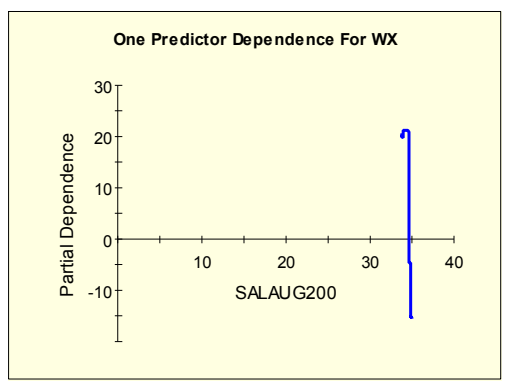

a)

Figure 139 Partial dependence plots for the three most important predictors in the Wx ocean layer model.

\subsubsection{Zooplankton species}

\section{Calanus hyperboreus}

The following graphs show the partial dependence plots for the 3 most important predictors and for the three C. hyperboreus models (Fig. 140,141,142).

\section{Presence/random absence model}

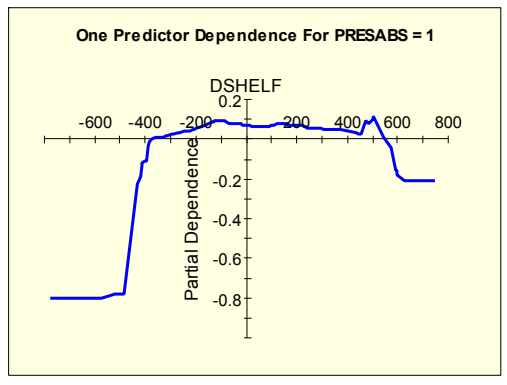

a)

Figure 140: Partial dependence plots for the three most important predictors and for the presence/random absence model of $C$. hyperboreus.

\section{Predicted relative index of depth model}
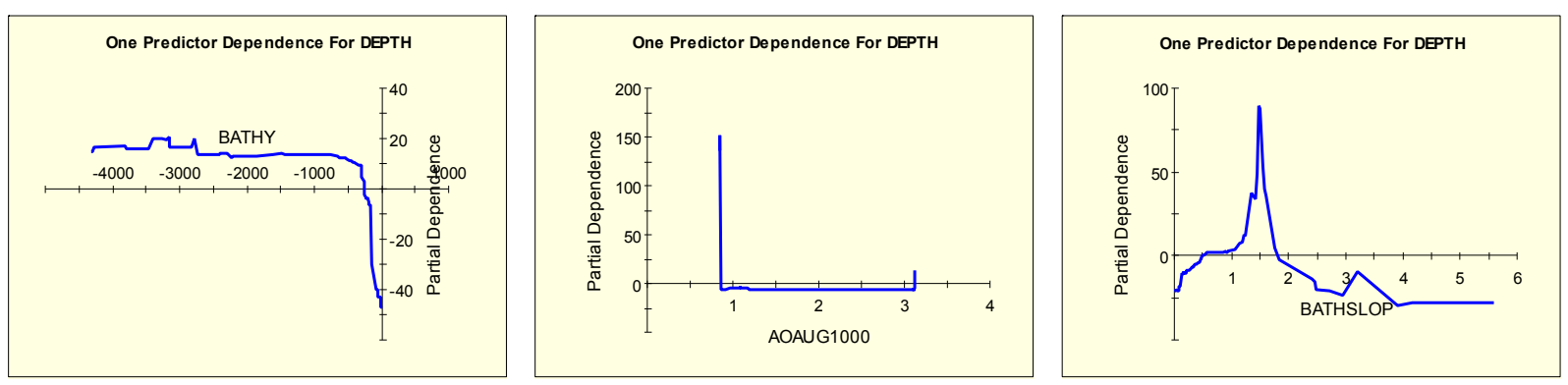

a)

b)

c) 
Figure 141: Partial dependence plots for the three most important predictors and for the predicted relative index of depth model of $C$. hyperboreus.

\section{Predicted life stage model}

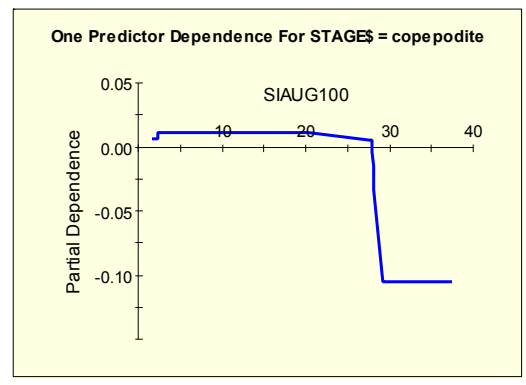

a)

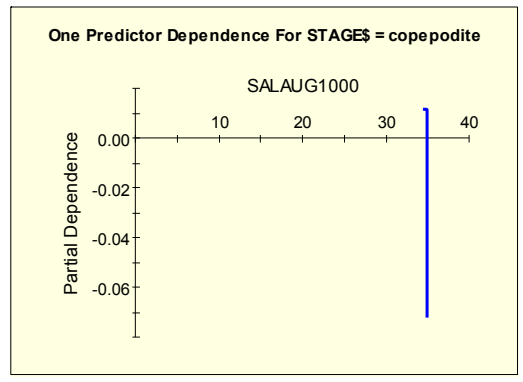

b)

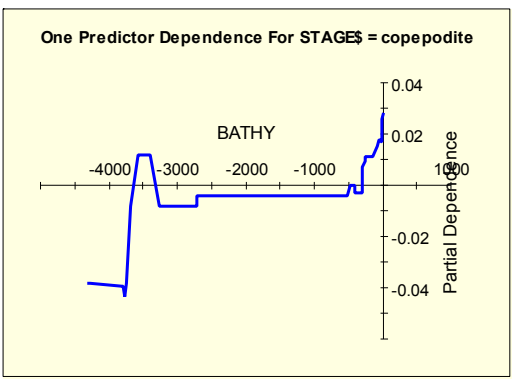

c)

Figure 142: Partial dependence plots for the three most important predictors and for the predicted life stage model of $C$. hyperboreus.

\section{Metridia longa}

The following graphs show the partial dependence plots for the 3 most important predictors and for the three M. longa models (Fig. 143,144,145).

\section{Presence/random absence model}

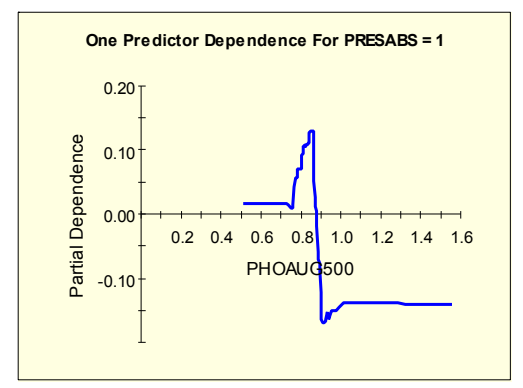

a)

Figure 143: Partial dependence plots for the three most important predictors and for the presence/random absence model of $M$. longa.

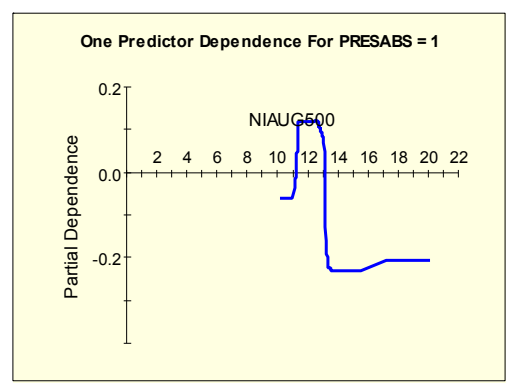

b)

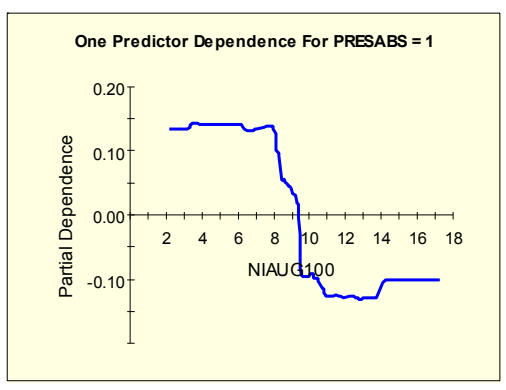

c) 


\section{Predicted relative index of depth model}

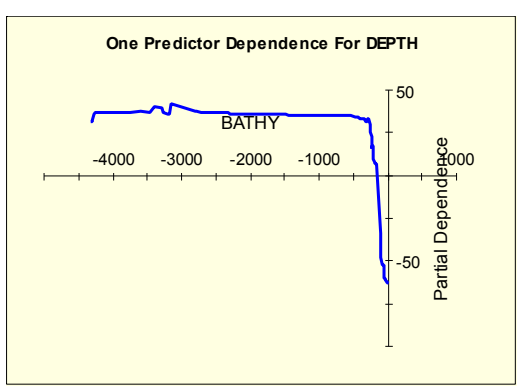

a)

Figure 144: Partial dependence plots for the three most important predictors and for the predicted relative index of depth model of $M$. longa.

\section{Predicted life stage model}
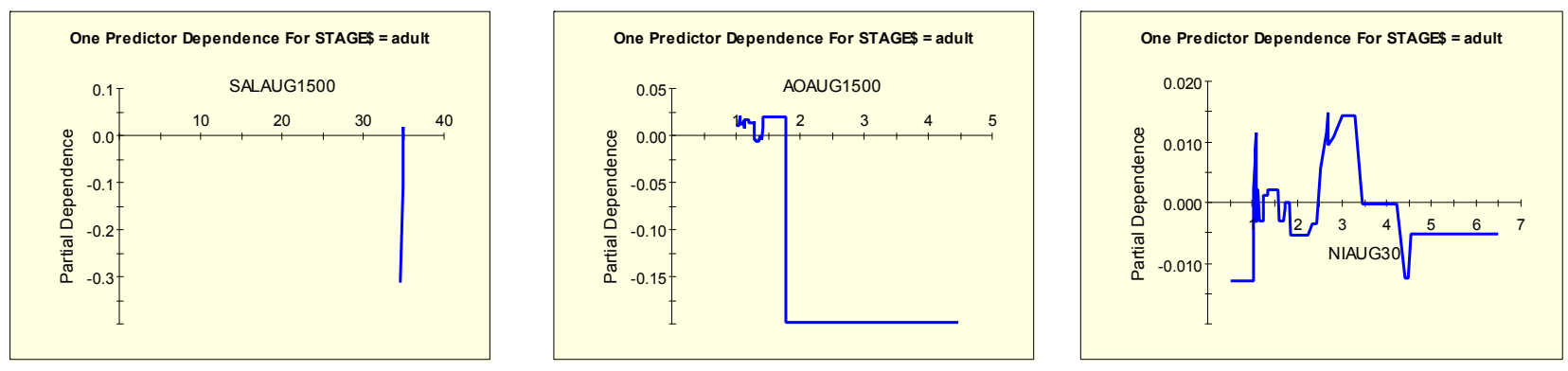

a)

b)

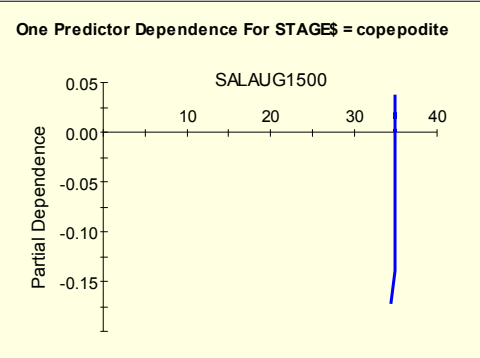

d)

e)

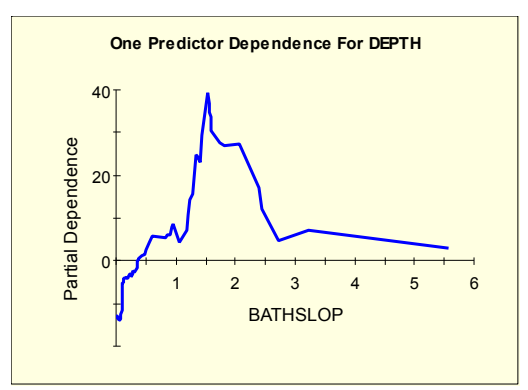

c)

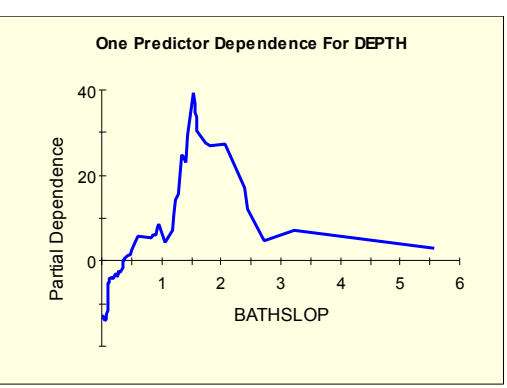

b)
. 


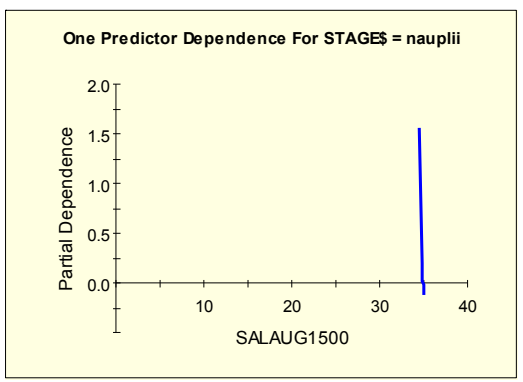

g)

g)

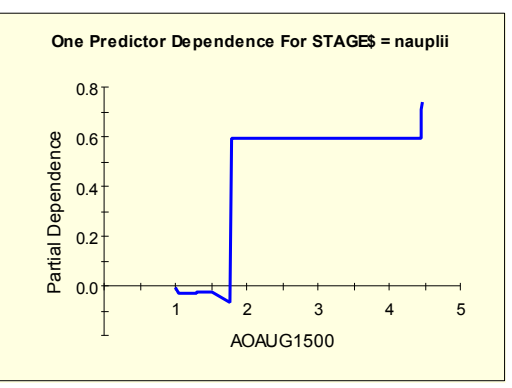

h)

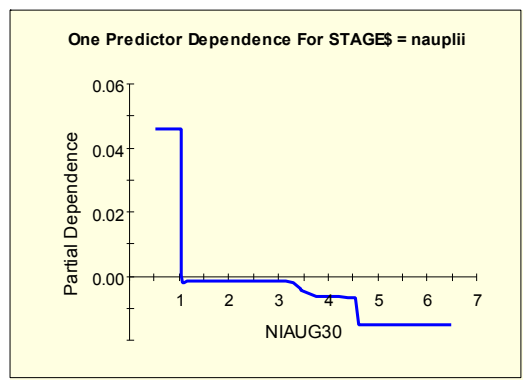

i)

Figure 145: Partial dependence plots for the three most important predictors and for the predicted life stage model of $M$. longa (adult, copepodite and nauplii). 


\section{Metridia pacifica}

The following graphs show the partial dependence plots for the 3 most important predictors and for the three M. pacifica models (Fig. 146,147,148).

\section{Presence/random absence model}

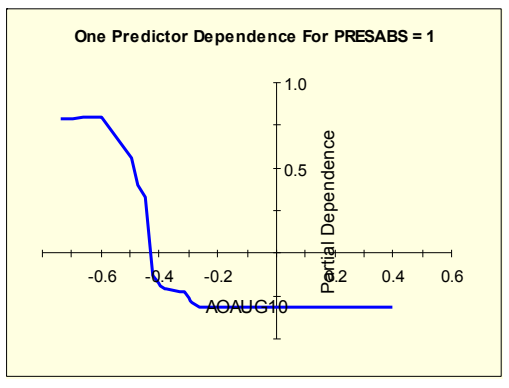

a)

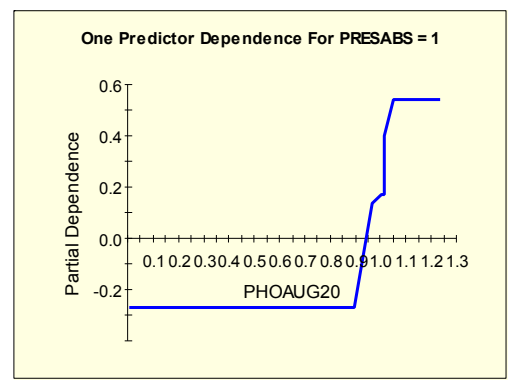

b)

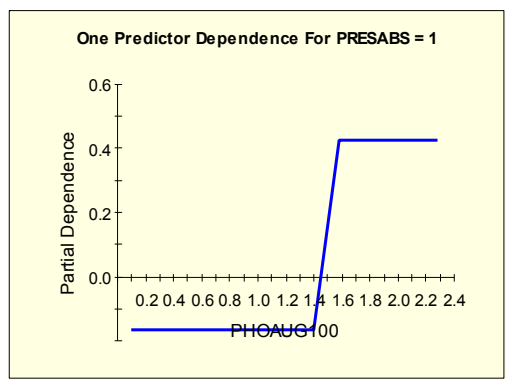

c)

Figure 146: Partial dependence plots for the three most important predictors and for the presence/random absence model of $M$. pacifica.

\section{Predicted relative index of depth model}

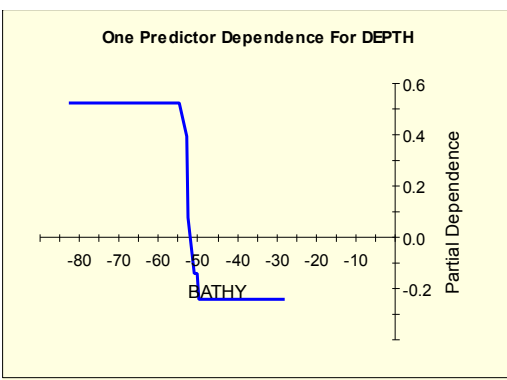

a)

Figure 147 Partial dependence plots for the three most important predictors and for the predicted relative index of depth model of M. pacifica.

\section{Predicted life stage model}

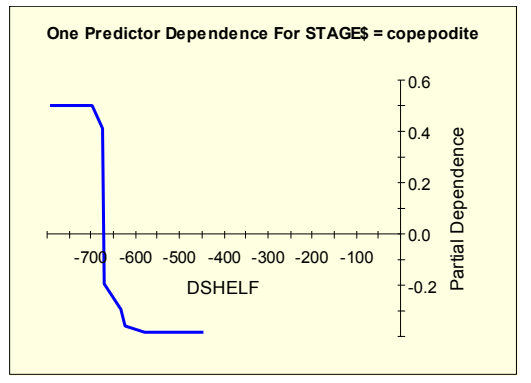

a)

Figure 148: Partial dependence plots for the three most important predictors and for the predicted life stage model of $M$. pacifica.
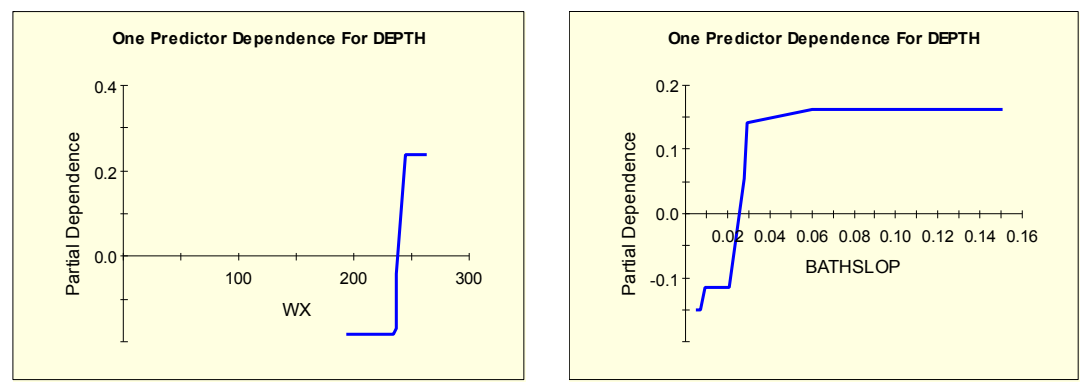

b)
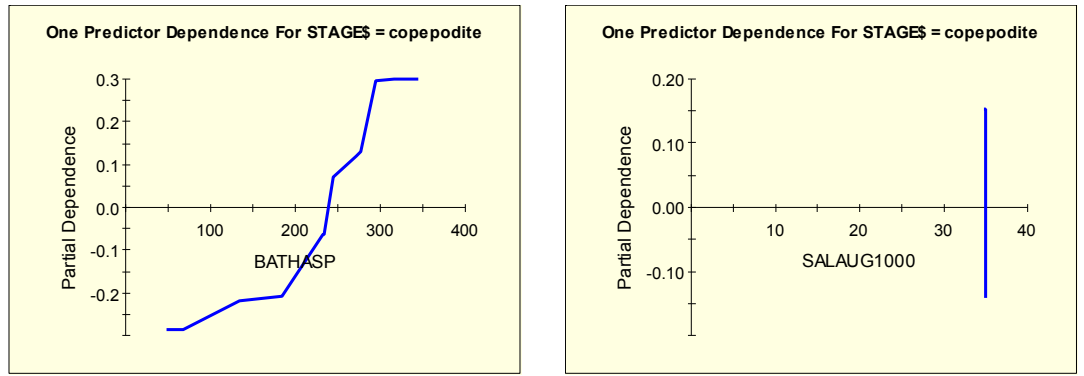

b)

c) 


\section{Thysanoessa raschii}

The following graphs show the partial dependence plots for the 3 most important predictors and for the three M. pacifica models (Fig. 149,150,151).

\section{Presence/random absence model}

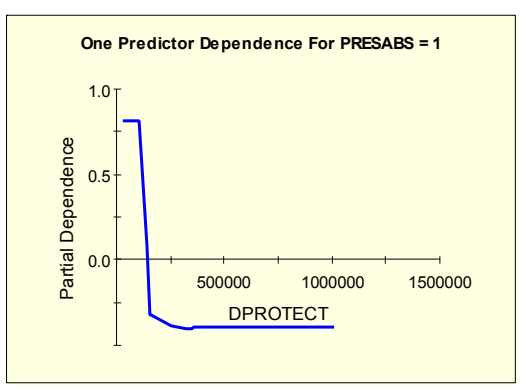

a)

Figure 149: Partial dependence plots for the three most important predictors and for the presence/random absence model of T.raschii.

\section{Predicted relative index of depth model}

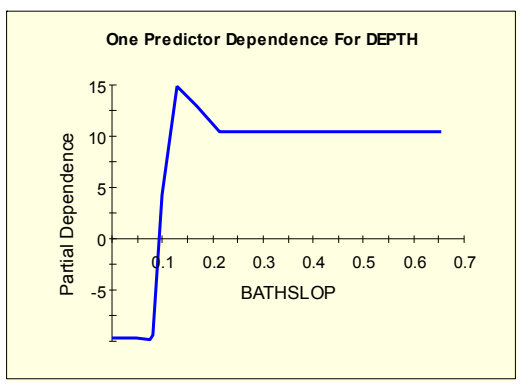

a)

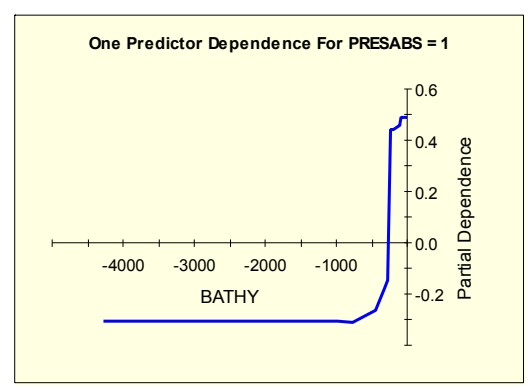

b)

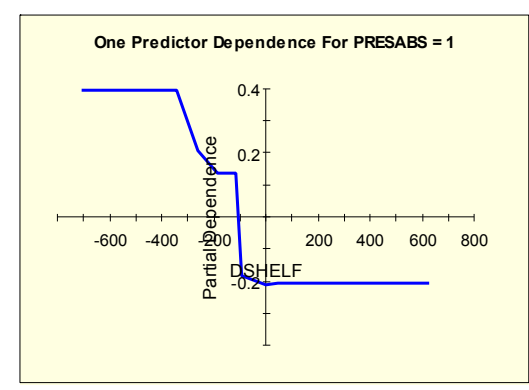

c)

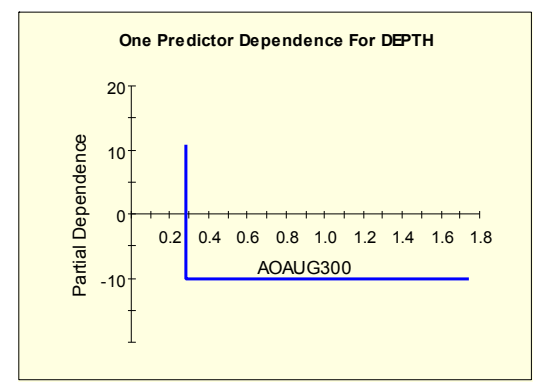

b)

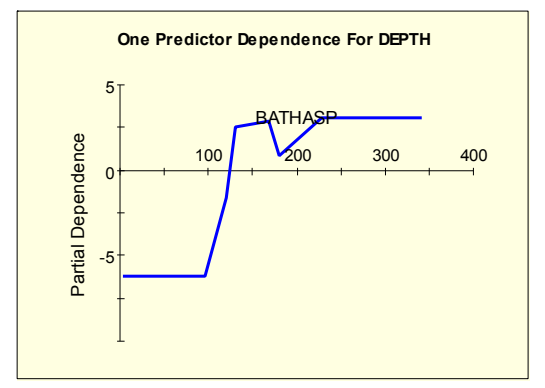

c)

Figure 150: Partial dependence plots for the three most important predictors and for the predicted relative index of depth model of T.raschii. 


\section{Predicted life stage model}

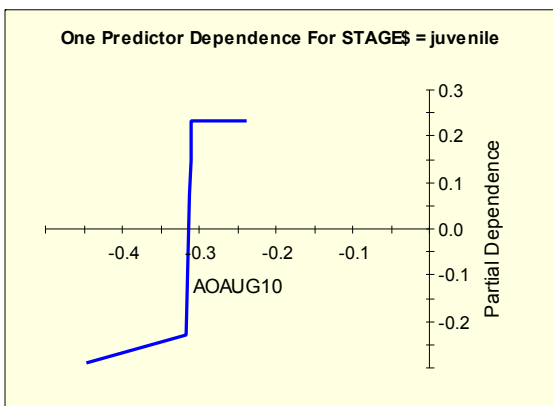

a)

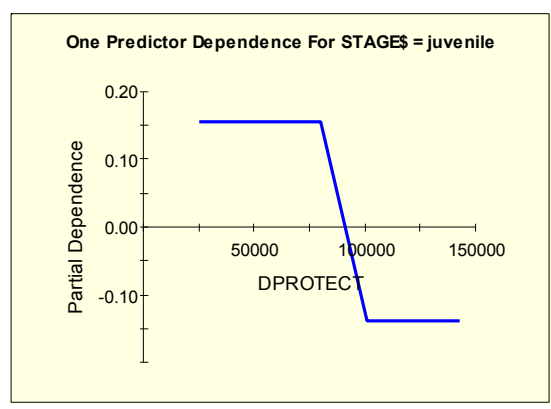

b)
One Predictor Dependence For STAGE\$ = juvenile

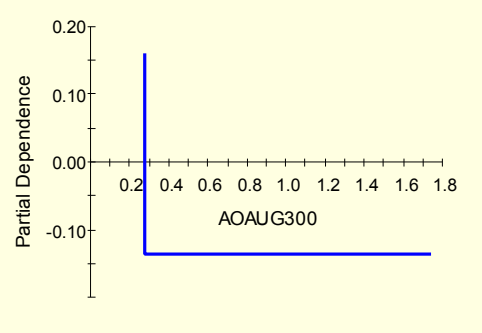

c)

Figure 151: Partial dependence plots for the three most important predictors and for the predicted life stage model of T.raschii.

\subsubsection{Misclassification in data sets}

\section{Calanus hyperboreus}

The misclassification in the test data for the presence/random absence model (Table 12) as well as the life stage model (Table 13).

Presence/random absence model

\begin{tabular}{|c|c|c|c|c|}
\hline Class & $\begin{array}{c}\mathrm{N} \\
\text { Cases }\end{array}$ & $\begin{array}{c}\text { N Mis- } \\
\text { Classed }\end{array}$ & $\begin{array}{c}\text { Pct. } \\
\text { Error }\end{array}$ & Cost \\
\hline 0 & 84 & 6 & 7.14 & 6.00 \\
\hline 1 & 30 & 3 & 10.00 & 3.00 \\
\hline
\end{tabular}

Table 12: Misclassification for test data and for the presence/random absence model of $C$. hyperboreus.

\section{Predicted life stage model}

\begin{tabular}{|c|c|c|c|c|}
\hline Class & $\begin{array}{c}\mathrm{N} \\
\text { Cases }\end{array}$ & $\begin{array}{c}\text { N Mis- } \\
\text { Classed }\end{array}$ & $\begin{array}{c}\text { Pct. } \\
\text { Error }\end{array}$ & Cost \\
\hline Adult & 145 & 85 & 58.62 & 85.00 \\
\hline Copepodite & 328 & 89 & 27.13 & 89.00 \\
\hline
\end{tabular}

Table 13: Misclassification for test data and for the predicted life stage model of C. hyperboreus. 


\section{Metridia longa}

The misclassification in the test data for the presence/random absence model (Table 14) as well as the life stage model (Table 15).

\section{Presence/random absence model}

\begin{tabular}{|c|c|c|c|c|}
\hline Class & $\begin{array}{c}\mathrm{N} \\
\text { Cases }\end{array}$ & $\begin{array}{c}\text { N Mis- } \\
\text { Classed }\end{array}$ & $\begin{array}{c}\text { Pct. } \\
\text { Error }\end{array}$ & Cost \\
\hline 0 & 99 & 11 & 11.11 & 11.00 \\
\hline 1 & 36 & 7 & 19.44 & 7.00 \\
\hline
\end{tabular}

Table 14: Misclassification for test data and for the presence/random absence model of $M$. longa.

Predicted life stage model

\begin{tabular}{|c|c|c|c|c|}
\hline Class & $\begin{array}{c}\mathrm{N} \\
\text { Cases }\end{array}$ & $\begin{array}{c}\text { N Mis- } \\
\text { Classed }\end{array}$ & $\begin{array}{c}\text { Pct. } \\
\text { Error }\end{array}$ & Cost \\
\hline adult & 165 & 95 & 57.58 & 95.00 \\
\hline copepodite & 197 & 69 & 35.03 & 69.00 \\
\hline nauplii & 13 & 0 & 0.00 & 0.00 \\
\hline
\end{tabular}

Table 15: Misclassification for test data and for the predicted life stage model of $M$. longa.

\section{Metridia pacifica}

The misclassification in the test data for the presence/random absence model (Table 16) as well as the life stage model (Table 17).

Presence/random absence model

\begin{tabular}{|c|c|c|c|c|}
\hline Class & $\begin{array}{c}\mathrm{N} \\
\text { Cases }\end{array}$ & $\begin{array}{c}\text { N Mis- } \\
\text { Classed }\end{array}$ & $\begin{array}{c}\text { Pct. } \\
\text { Error }\end{array}$ & Cost \\
\hline 0 & 7 & 1 & 14.29 & 1.00 \\
\hline 1 & 3 & 0 & 0.00 & 0.00 \\
\hline
\end{tabular}

Table 16: Misclassification for test data and for the presence/random absence model of $M$. pacifica. 


\section{Predicted life stage model}

\begin{tabular}{|c|c|c|c|c|}
\hline Class & $\begin{array}{c}\mathrm{N} \\
\text { Cases }\end{array}$ & $\begin{array}{c}\mathrm{N} \text { Mis- } \\
\text { Classed }\end{array}$ & $\begin{array}{c}\text { Pct. } \\
\text { Error }\end{array}$ & Cost \\
\hline adult & 3 & 1 & 33.33 & 1.00 \\
\hline copepodite & 2 & 0 & 0.00 & 0.00 \\
\hline
\end{tabular}

Table 17: Misclassification for test data and for the predicted life stage model of $M$. pacifica.

\section{Thysanoessa raschii}

The misclassification in the test data for the presence/random absence model (Table 18) as well as the life stage model (Table 19).

\section{Presence/random absence model}

\begin{tabular}{|c|c|c|c|c|}
\hline Class & $\begin{array}{c}\mathrm{N} \\
\text { Cases }\end{array}$ & $\begin{array}{c}\text { N Mis- } \\
\text { Classed }\end{array}$ & $\begin{array}{c}\text { Pct. } \\
\text { Error }\end{array}$ & Cost \\
\hline 0 & 20 & 3 & 15.00 & 3.00 \\
\hline 1 & 10 & 1 & 10.00 & 1.00 \\
\hline
\end{tabular}

Table 18: Misclassification for test data and for the presence/random absence model of $T$. raschii.

\section{Predicted life stage model}

\begin{tabular}{|c|c|c|c|c|}
\hline Class & $\begin{array}{c}\mathrm{N} \\
\text { Cases }\end{array}$ & $\begin{array}{c}\text { N Mis- } \\
\text { Classed }\end{array}$ & $\begin{array}{c}\text { Pct. } \\
\text { Error }\end{array}$ & Cost \\
\hline adult & 4 & 0 & 0.00 & 0.00 \\
\hline juvenile & 14 & 0 & 0.00 & 0.00 \\
\hline
\end{tabular}

Table 19: Misclassification for test data and for the predicted life stage model of $T$. raschii. 


\subsubsection{Receiver Operator Characteristics (ROC)}

\section{Calanus hyperboreus}

The following graphs show the Receiver Operator Characteristics (ROC) for C. hyperboreus and for the presence/random absence model (Fig. 152) as well as for the life stage model (Fig. 153).

\section{Presence/random absence model}

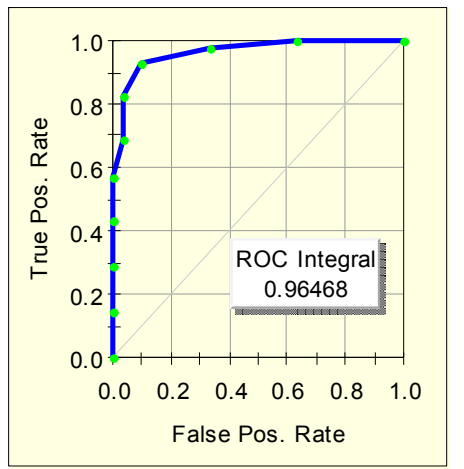

a)

Figure 152: ROC curves for the presence/random absence model of $C$. hyperboreus. a) ROC for random absence b) ROC for presence.

\section{Predicted life stage model}

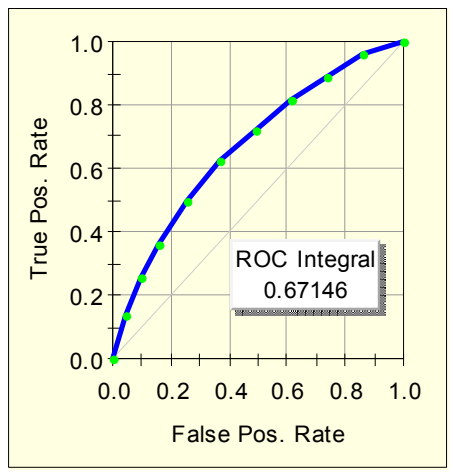

a)

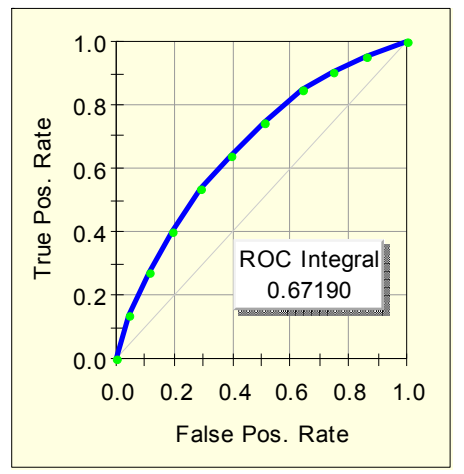

b)

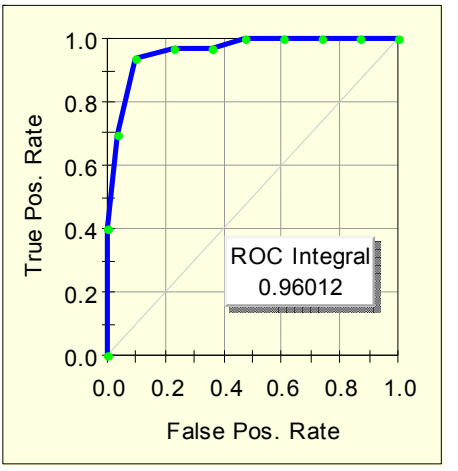

b) 


\section{Metridia longa}

The following graphs show the Receiver Operator Characteristics (ROC) for $M$. longa and for the presence/random absence model (Fig. 154) as well as for the life stage model (Fig. 155).

Presence/random absence model

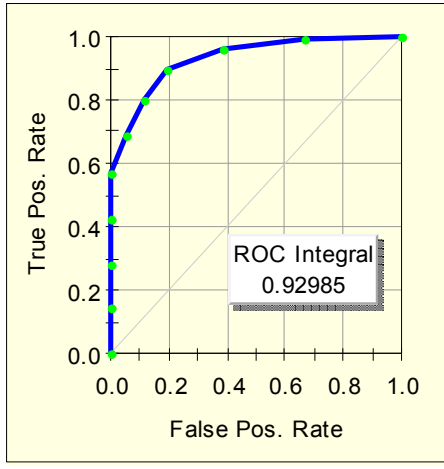

a)

Figure 154: ROC curve for the presence/random absence model of $M$. longa. a) ROC for random absence b) ROC for presence.

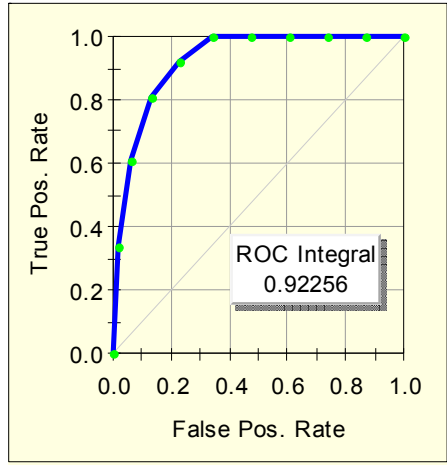

b)

\section{Predicted life stage model}

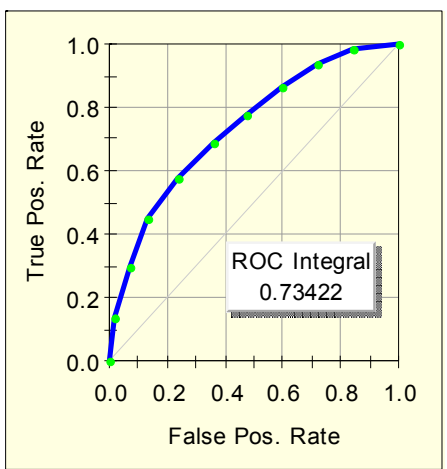

a)

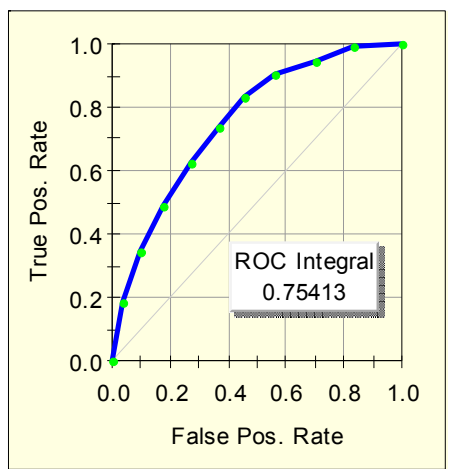

b)

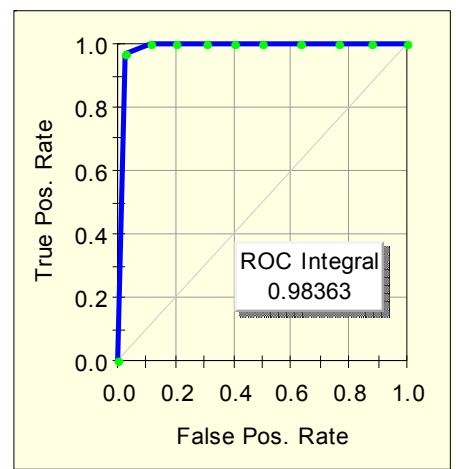

c)

Figure 155: ROC curve for the predicted life stage model of $M$. longa. a) ROC for adult life stage b) ROC for copepodite life stage c) ROC for nauplii life stage. 


\section{Metridia pacifica}

The following graphs show the Receiver Operator Characteristics (ROC) for M. pacifica and for the presence/random absence model (Fig. 156) as well as for the life stage model (Fig. 157).

\section{$\underline{\text { Presence/random absence model }}$}

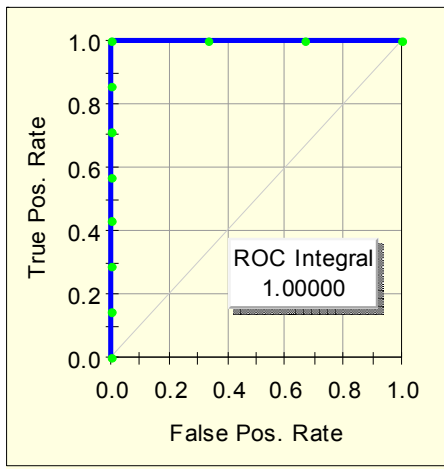

a)

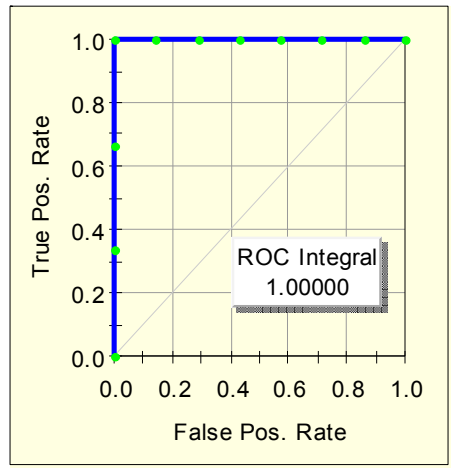

b)

Figure 156: ROC curve for the presence/random absence model of $M$. pacifica. a) ROC for random absence b) ROC for presence.

\section{Predicted life stage model}

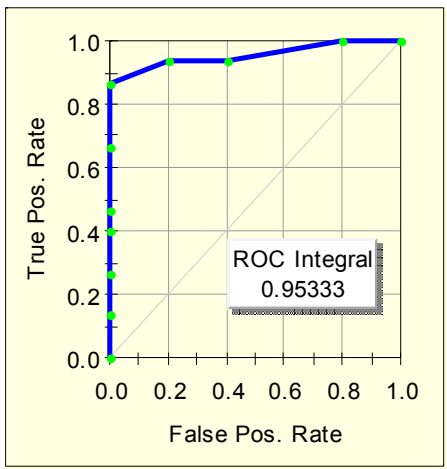

a)

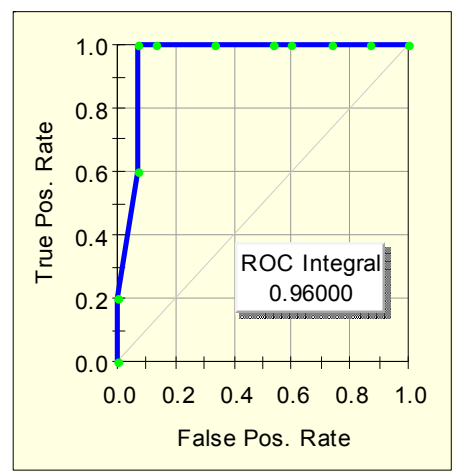

b)

Figure 157: ROC curve for the predicted life stage model of $M$. pacifica. a) ROC for adult life stage b) ROC for copepodite life stage. 


\section{Thysanoessa raschii}

The following graphs show the Receiver Operator Characteristics (ROC) for T. raschii and for the presence/random absence model (Fig. 158) as well as for the life stage model (Fig. 159).

\section{$\underline{\text { Presence/random absence model }}$}

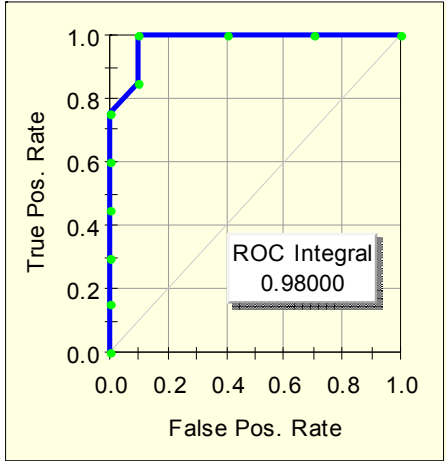

a)

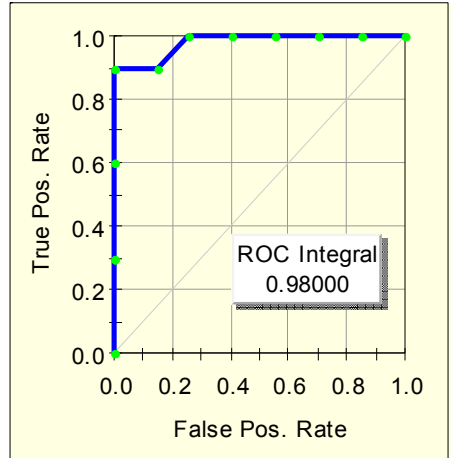

b)

Figure 158: ROC curve for the presence/random absence model of T. raschii. a) ROC for random absence b) ROC for presence.

\section{$\underline{\text { Predicted life stage model }}$}

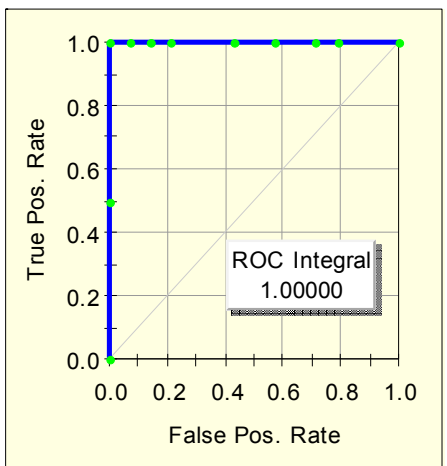

a)

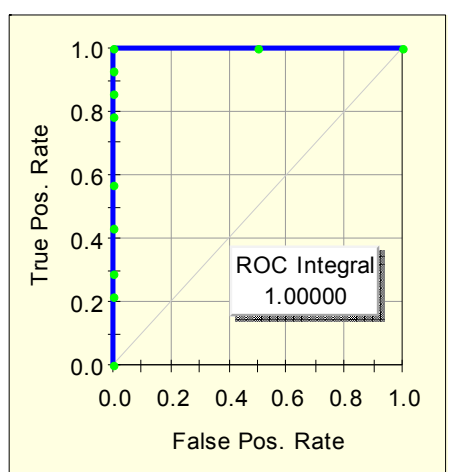

b)

Figure 159: ROC curve for the predicted life stage model of $T$. raschii. a) ROC for adult life stage b) ROC for copepodite life stage. 


\title{
6.4 Online published ISO Metadata
}

\section{One hundred seventy environmental GIS data layers for the circumpolar Arctic ocean region}

\author{
Metadata also available as
}

\section{Metadata:}

- Identification Information

- Data Quality Information

- Spatial_Data_Organization_Information

- Spatial_Reference_Information

- Entity and Attribute Information

- Distribution_Information

- Metadata_Reference_Information

Identification_Information:

Citation:

Citation_Information:

Originator: Schmid M, and F. Huettmann

Publication_Date: 20120501

Title:

One hundred seventy environmental GIS data layers for the circumpolar Arctic ocean region

Edition: 1

Series_Information:

Series_Name: 1

Issue_Identification: 1

Publication_Information:

Publication_Place: University of Alaska-Fairbanks (UAF), USA

Publisher: M. Schmid and F. Huettmann

Other_Citation_Details:

These data are part of a M.Sc. thesis by the first author M. Schmid with the MINC program Uni Goettingen (Germany) and Lincoln (New Zealand) carried out with the EWHALE lab, Inst. of Arctic Biology, Biology \& Wildlife Dept, University of Alaska-Fairbanks (UAF)

Online_Linkage: NA

Geospatial_Data_Presentation_Form: database

Description:

Abstract:

This dataset represents a unique compiled environmental data set for the circumpolar Arctic Ocean region $45 \mathrm{~N}$ to $90 \mathrm{~N}$ region. It consists of 170 layers (most marine, some terrestrial) in ArcGIS 10 format to be used with a Geographic Information System (GIS) and which are listed below in detail. Most layers are long-term average raster GRIDs for the summer season, often by ocean depth, and represent value-added products easy to use. The sources of the data are manifold such as World Ocean Atlas 2009 (WOA09),

International Bathimetric Chart of the Arctic Ocean (IBCAO), Canadian Earth System Model 2 (CanESM2) data (the newest generation of models available) and data sources such as plankton databases and OBIS. The following plankton species were 
included: Calanus hyperboreus (AphiaID104467), Metridia longa (AphiaID104632), M. pacifica (AphiaID 196784)

and Thysanoessa raschii (AphiaID 110711). Some layers are derived within ArcGIS. Layers have pixel sizes between 1215.819573 meters and 25257.72929 meters for the best pooled model, and between 224881.2644 and 672240.4095 meters for future climate data. Data was then reprojected into North Pole Stereographic projection in meters (WGS84 as the geographic datum). Also, future layers are included as a selected subset of proposed future climate layers from the Canadian CanESM2 for the next 100 years (scenario runs RCP26 and RCP85). The following layer groups are available: bathymetry (depth, derived slope and aspect); proximity layers (to,glaciers,sea ice, protected areas, wetlands, shelf edge); dissolved oxygen, apparent oxygen, percent oxygen, nitrogen, phosphate, salinity, silicate (all for August and for 9 depth classes); runoff (proximity, annual and August); sea surface temperature; waterbody temperature (12 depth classes); modeled ocean boundary layers ( $\mathrm{H} 1, \mathrm{H} 2, \mathrm{H} 3$ andWx). This dataset is used for a M.Sc. thesis by the author, and freely available upon request. For questions and details we suggest contacting the authors.

Purpose:

This set of environmental marine base layers for the Arctic region is part of a M.Sc. thesis by the first author; it provides value-added summary information in ArcGIS format that may be useful for purposes such as general modelling, regionalization, exploratory analyses and conservation management.

Time_Period_of_Content:

Time_Period_Information:

Range_of_Dates/Times:

Beginning_Date: 195001

Ending_Date: 210012

Currentness_Reference: publication date

Status:

Progress: Complete

Maintenance_and_Update_Frequency: None planned

Spatial_Domain:

Bounding_Coordinates:

West_Bounding_Coordinate: -180.00000

East_Bounding_Coordinate: 180.00000

North_Bounding_Coordinate: 90.00000

South_Bounding_Coordinate: 45.00000

Description_of_Geographic_Extent:

Circumpolar marine region of the Arctic (45 degrees north to 90 degrees north). Note: the traditional boundary box does not capture these extents well, and due to the Arctic projection and date line crossing.

Keywords:

Theme:

Theme_Keyword_Thesaurus: None

Theme_Keyword: Arctic

Theme_Keyword: Polar region

Theme_Keyword: GIS base layers

Theme_Keyword: ArcGIS

Theme_Keyword: Geographic Information Systems (GIS) 
Theme_Keyword: grids

Theme_Keyword: North Pole

Theme_Keyword: World Ocean Atlas WOA

Theme_Keyword: Calanus hyperboreus (AphiaID104467)

Theme_Keyword: Metridia longa (AphiaID 104632)

Theme_Keyword: Metridia pacifica (AphialD 196784)

Theme_Keyword: Thysanoessa raschii (AphialD 110711)

Theme:

Theme_Keyword_Thesaurus: National Park Service Theme Category Thesaurus

Theme:

Theme_Keyword_Thesaurus: ISO 19115 Topic Category

Place:

Place_Keyword_Thesaurus: None

Place_Keyword: Arctic

Place_Keyword: Polar region

Place_Keyword: Northpole

Place_Keyword: Bering Sea

Place_Keyword: Barents Sea

Place_Keyword: Kara Sea

Place_Keyword: Arctic Shelf

Place_Keyword: Arctic Deep Sea

Place:

Place_Keyword_Thesaurus: National Park System Unit Name Thesaurus

Place:

Place_Keyword_Thesaurus: National Park System Unit Code Thesaurus

Access_Constraints: none; but always suggested to contact authors for best use.

Use_Constraints:

none; these maps are not to be used for navigational and other purposes. Always suggested to contact authors.

Point_of_Contact:

Contact_Information:

Contact_Person_Primary:

Contact_Person: Moritz Schmid and Falk Huettmann

Contact_Organization: EWHALE lab

Contact_Position: M.Sc. 


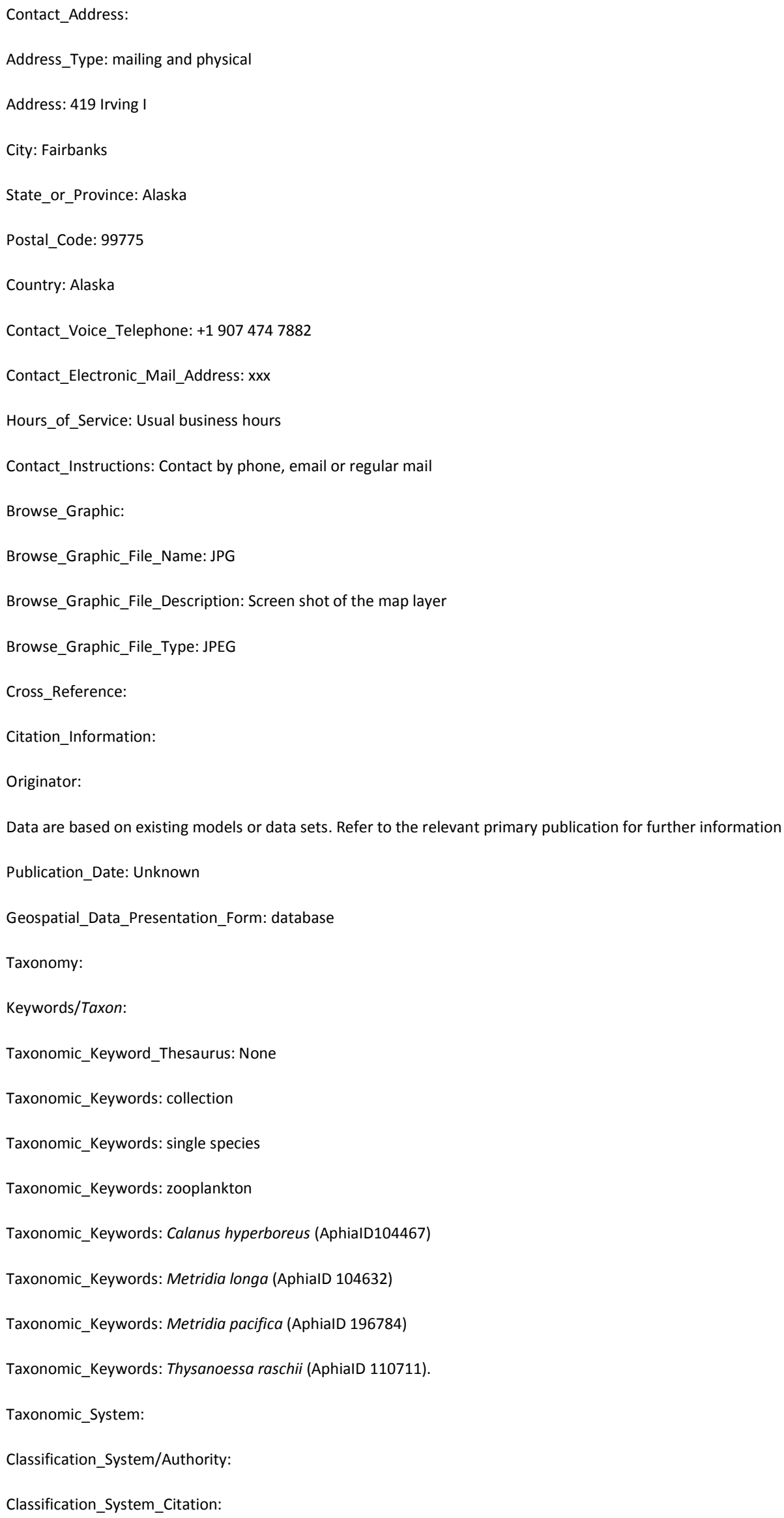


Citation_Information:

Originator: Unknown

Publication_Date: Unknown

Title:

Geospatial_Data_Presentation_Form:

Classification_System_Modifications: For zooplankton: ITIS, OBIS, WORMS

Identification_Reference:

Citation_Information:

Originator: For zooplankton: Online plankton species databases

Publication_Date: Unknown

Title:

Geospatial_Data_Presentation_Form: database

Taxonomic Procedures: see with plankton databases

Taxonomic_Classification:

Taxon_Rank_Name: Superdomain

Taxon_Rank_Value: Biota

Taxonomic_Classification:

Taxon_Rank_Name: Kingdom

Taxon_Rank_Value: Animalia

Taxonomic_Classification:

Taxon_Rank_Name: Phylum

Taxon_Rank Value: Arthropoda

Taxonomic_Classification:

Taxon_Rank_Name: Class

Taxon_Rank_Value: Malacostraca

Taxonomic_Classification:

Taxon_Rank_Name: Order

Taxon_Rank_Value: Euphausiacea

Taxonomic_Classification:

Taxon_Rank_Name: Family

Taxon_Rank_Value: Euphausiidae

Taxonomic_Classification:

Taxon_Rank_Name: Genus

Taxon_Rank_Value: Thysanoessa 
Taxonomic_Classification:

Taxon_Rank_Name: Species

Taxon_Rank_Value: Thysanoessa raschii

Taxonomic_Classification:

Taxon_Rank_Name: Class

Taxon_Rank_Value: Maxillopoda

Taxonomic_Classification:

Taxon Rank Name: Order

Taxon_Rank_Value: Calanoida

Taxonomic_Classification:

Taxon_Rank_Name: Family

Taxon_Rank_Value: Calanidae

Taxonomic Classification:

Taxon_Rank_Name: Genus

Taxon_Rank_Value: Calanus

Taxonomic_Classification:

Taxon_Rank_Name: Species

Taxon_Rank Value: Calanus hyperboreus

Taxonomic_Classification:

Taxon_Rank_Name: Family

Taxon_Rank_Value: Metridinidae

Taxonomic Classification:

Taxon_Rank_Name: Genus

Taxon_Rank_Value: Metridia

Taxonomic_Classification:

Taxon_Rank_Name: Species

Taxon_Rank_Value: Metridia longa

Taxonomic_Classification:

Taxon_Rank_Name: Species

Taxon_Rank_Value: Metridia pacifica

Data_Set_Credit:

This dataset is compiled by M. Schmid, thesis supervisor F. Huettmann. This dataset is a value-added ArcGIS product nd is based on many data archives and data authors, e.g. WOA, IPCAO, IPCC Canada, Canadian Centre for Climate Modelling and Analysis, OBIS and thesis data (Imme Rutzen, Grant Humphries and others). They are all thanked.

Security_Information: 
Security_Classification_System: none

Security_Classification: Unclassified

Security_Handling_Description: none

Native_Data_Set_Environment: Windows PC IBM

Analytical_Tool:

Analytical_Tool_Description: ArcGIS 10, Windows 32bit. IBM PC

Tool_Access_Information:

Online_Linkage:

See $\leq$ http://www.nodc.noaa.gov/OC5/WOA09/pr woa09.html $>$ for World Ocean Atlas

WOA, <http://www.ngdc.noaa.gov/mgg/bathymetry/arctic/> for IPCAO Bathymetry, www.ipcc.ch for IPCC, and www.iobis.org for plankton layers

Tool_Access_Instructions: See at websites or contact authors

Tool_Computer_and_Operating_System: PCIBM

Data_Quality_Information:

Attribute_Accuracy:

Attribute_Accuracy_Report:

Data are based on existing models or data sets. Refer to the relevant primary publication for accuracy information.

Logical_Consistency_Report:

For each subset schema, data are complete and produced with identical methods. But the projections mighty affect pixel sizes differently for each of the poles, and due to the location. Also, data products do NOT carry the same pixel sizes. For accuracy we also would like to refer to the initial and underlying data products and their authors and metadata (if exist and/or provided).

Completeness_Report: Data are complete.

Positional_Accuracy:

Horizontal_Positional_Accuracy:

Horizontal_Positional_Accuracy_Report: As provided by the data input layers and models.

Lineage:

Methodology:

Methodology_Type: Lab

Methodology_Description:

These data layers got compiled and processed in the EWHALE lab by Moritz Schmid. Most layers are based on data archives, some are based on the works by Imme Rutzen and by Grant Humphries for their M.Sc. thesis.

All works is based on ArcGIS 10.0 as the operational platform.

Exact details of these layers are described in the PROCESS STEPS.

Source_Information:

Source_Citation: 
Citation_Information:

Originator:

See also Conservation of Arctic Flora and Fauna (CAFF): www.caf.is

Publication_Date: Unknown

Title:

Geospatial_Data_Presentation_Form:

Source_Time_Period_of_Content:

Time_Period_Information:

Range_of_Dates/Times:

Beginning_Date: Unknown

Ending_Date: Unknown

Source_Currentness_Reference: publication date

Source_Contribution:

See for sources and data archives used: $\leq$ http://www.nodc.noaa.gov/OC5/WOA09/pr woa09.html $>$ for World Ocean Atlas

WOA, <http://www.ngdc.noaa.gov/mgg/bathymetry/arctic/> for IPCAO Bathymetry, www.ipcc.ch for IPCC, and www.iobis.org for plankton layers

Process_Step:

Process_Description:

Please contact Moritz Schmid for the thesis and detailed explanations.

Short version: We model predicted here for the first time ocean layers in the Arctic Ocean based on a unique dataset of physical oceanography. Moreover, we developed presence/random absence models that indicate where the studied zooplankton species are most likely to be present in the Arctic Ocean. Apart from that, we develop the first spatially explicit models known to science that describe the depth in which the studied zooplankton species are most likely to be at, as well as their distribution of life stages. We do not only do this for one present day scenario. We modeled five different scenarios and for future climate data.

First, we model predicted ocean layers using the most up to date data from various open access sources, referred here as best-pooled model data. We decided to model this set of ocean layers after discussions and input of expert knowledge by Professor Igor Polyakov from the International Arctic Research Center at the University of Alaska Fairbanks. We predicted those ocean layers because those are the boundaries and layers that the plankton has to cross for diel vertical migration and a change in those would most likely affect the migration. I assigned 4 variables to the ocean layers. H1, H2, H3 and Wx. H1 is the lower boundary of the mixed layer depth. Above this layer a lot of atmospheric disturbance is causing mixing of the water, giving the mixed layer its name. $\mathrm{H} 2$, the middle of the halocline is important because in this part of the ocean a strong gradient in salinity and temperature separates water layers. $\mathrm{H} 3$, the isotherm is important, because beneath it flows denser and colder Atlantic water. Wx summarizes the overall width of the described water column.

Ocean layers were predicted using machine learning algorithms (TreeNet, Salford Systems). Second, ocean layers were included as predictors and used to predict the presence/random absence, most likely depth and life stage layers for the zooplankton species: Calanus hyperboreus, Metridia longa, Metridia pacifica and Thysanoessa raschii,

This process was repeated for future predictions based on the CanESM2 data (see in the data section).

For zooplankton species the following layers were developed and for the future.

C. hyperboreus: Best-pooled model as well as future predictions (RCP26 including ocean layer(also excluding), RCP85 including oocean layers (also excluding) for 2010 and 2100.For parameters: Presence/random absence, most likely depth and life stage layers

M. longa: Best-pooled model as well as future predictions (RCP26 including ocean layer(also excluding), RCP 85 including oocean layers (also excluding) for 2010 and 2100. For parameters: Presence/random absence, most likely depth and life stage layers 
M. pacifica: Best-pooled model as well as future predictions (RCP26 including ocean layer (also excluding), RCP85 including ocean layers (also excluding) for 2010 and 2100. For parameters: Presence/random absence, most likely depth and life stage layers

T. raschii: Best-pooled model only due to coverage of future climate data. Presence/random absence, most likely depth and life stage layers

Process_Description: Data are organized by folder and get described that way below:

Data for best-pooled model: Folder: aoaug Apparent Oxygen August by depth (m) 1-11) Aoaugmask10, 20, 30, 50, 100, 200, 300, 400, 500, 1000, 1500 Source: World Ocean Atlas 2009 (WOA09) at the National Oceanographic Data Center (NODC) <http://www.nodc.noaa.gov/OC5/WOA09/woa09data.html> Folder: bathymetry 12) bathyaspect 13) bathymetry 14) bathyslope Source: Derived from the International Bathymetric Chart of the Arctic Ocean (IBCAO) <http://www.ngdc.noaa.gov/mgg/bathymetry/arctic/> Folder: distglacier 15) distglacier Source: Proximity layer derived from the Global Land Ice Measurements from Space (GLIMS) Glacier database at the National Snow and Ice Data Center (NSIDC): <http://glims.colorado.edu/glacierdata/>

Folder: distice 16) disticeaug Source: Sea Ice Data collection at the National Ice Center (NIC) <http://www.natice.noaa.gov/mission.html?bandwidth=high> Folder: distmarinebound 17) dmarinebound Source: Proximity layer derived from the VLIZ Maritime BoundariesGeodatabase <http://www.vliz.be/vmdcdata/marbound/>

Folder: distprotected 18) distprotected Source: World Database on Protected Areas (according to the United Nations). Now at: <http://protectedplanet.net/> Folder: distsettle 19) distsettle Source: Proximity layer derived from the Global Rural-Urban Mapping Project (GRUMP) at the Socioeconomic Data and Applications Center (SEDAC) <http://sedac.ciesin.columbia.edu/gpw/> Folder: distshelf 20) distshelf Source: FH metadatapack Folder: distwetland 21) distwetland Source: Proximity layer derived from the Global Lakes and Wetlands Database Request (GLWD) https://secure.worldwildlife.org/science/data/item1877.html Folder: doaug Dissolved Oxygen August by depth (m) 22-33) doaug0, 10, 20, 30, 50, 100, 200, 300, 400, 500, 1000, 1500 Source: World Ocean Atlas 2009 (WOA09) at the National Oceanographic Data Center (NODC) <http://www.nodc.noaa.gov/OC5/WOA09/woa09data.html> Folder: niaug Nitrate August by depth (m) 34-43) niaug0, 10, 20, 30, 50, 100, 200, 300, 400, 500 Source: World Ocean Atlas 2009 (WOA09) at the National Oceanographic Data Center (NODC) <http://www.nodc.noaa.gov/OC5/WOA09/woa09data.html> Folder:phoaug Phosphate August by depth (m) 44-53) phoaug0, 10, 20, 30, 50, 100, 200, 300, 400, 500 Source: World Ocean Atlas 2009 (WOA09) at the National Oceanographic Data Center (NODC) <http://www.nodc.noaa.gov/OC5/WOA09/woa09data.html> Folder: poaug Percent Oxygen, August by depth (m) 54-65) poaug0, 10, 20, 30, 50, 100, 200, 300, 400, 500, 1000, 1500 Source: World Ocean Atlas 2009 (WOA09) at the National Oceanographic Data Center (NODC) <http://www.nodc.noaa.gov/OC5/WOA09/woa09data.html> Folder: runoff 66) distrunoff Source: Derived proximity layer from R-ArcticNet: A Regional, Electronic, Hydrographic Data Network for the Arctic Region < http://www.rarcticnet.sr.unh.edu/v4.0/AllData/index.html> 67) runoffannual Source: Derived layer from the annual runoff $<$ http://www.rarcticnet.sr.unh.edu/v4.0/AllData/index.html $>68$ ) runoffaug Source: Derived layer from the runoff in August <http://www.rarcticnet.sr.unh.edu/v4.0/AllData/index.html > Folder: salaug Salitry August by Depth 69-80) salaug0, 10, 20, 30, 50, 100, 200, 300, 400, 500, 1000, 1500 Source: World Ocean Atlas 2009 (WOA09) at the National Oceanographic Data Center (NODC) <http://www.nodc.noaa.gov/OC5/WOA09/woa09data.html> Folder: siaug Silicate August by depth 81-90) siaug0, 10, 20, 30, 50, 100, 200, 300, 400, 500 Source: World Ocean Atlas 2009 (WOA09) at the National Oceanographic Data Center (NODC) <http://www.nodc.noaa.gov/OC5/WOA09/woa09data.html> Folder: sst Sea Surface Temperate summer 91) sstsummer Source: Falk Huettmann, Polarmacroscopelayers Folder: Ocean layers, predicted 92) H1 93) H2 94) H3 95) Wx Source: Model-predicted layers. Modeled by M. Schmid and based on data provided by Prof. Igor Polyakov Folder: taug Temperature August by depth (m) 96-107) taug0, 10, 20, 30, 50, 100, 200, 300, 400, 500, 1000, 1500 Source: World Ocean Atlas 2009 (WOA09) at the National Oceanographic Data Center (NODC) < http://www.nodc.noaa.gov/OC5/WOA09/woa09data.html> Data for future predictions: Canadian Earth System Model 2 (CanESM2) future data Superfolder: CanESM2 future data Representative Concentration Pathway 2.6 Folder: RCP26 SCENARIO Folder: chl Chlorophyll 1-2) chl2010, 2100 Source: Chlorophyll data from the Canadian Earth System Model 2 (CanESM2) at the Canadian Centre for Climate Modellingand Analysis <http://www.cccma.ec.gc.ca/data/cgcm4/CanESM2/rcp26/mon/index.shtml> Folder: mrro Run Off 3-4) mrro2010, 2100 Source: Total runoff data from the Canadian Earth System Model 2 (CanESM2) at the Canadian Centre for Climate Modelling and Analysis <http://www.cccma.ec.gc.ca/data/cgcm4/CanESM2/rcp26/mon/index.shtml> Folder: no3 5-6) no2010, 2100 Source: Nitrate data from the Canadian Earth System Model 2 (CanESM2) at the Canadian Centre for Climate Modelling and Analysis <http://www.cccma.ec.gc.ca/data/cgcm4/CanESM2/rcp26/mon/index.shtml> Folder: sos 7-8) sos2010, 2100 Source: Sea surface salinity data from the Canadian Earth System Model 2 (CanESM2) at the Canadian Centre for Climate Modelling and Analysis <http://www.cccma.ec.gc.ca/data/cgcm4/CanESM2/rcp26/mon/index.shtml> Folder: tos 9-10) tos2010, 2100 Source: Sea surface temperature data from the Canadian Earth System Model 2 (CanESM2) at the Canadian Centre for Climate Modelling and Analysis <http://www.cccma.ec.gc.ca/data/cgcm4/CanESM2/rcp26/mon/index.shtml> Folder: Ocean layers PREDICTED Folder: H1 11-12) H1 2010, 2100 Source: Model-predicted layers. Modeled by M. Schmid and based on data provided by Prof. Igor Polyakov and RCP26, CanESM2 future data. Folder: H2 13-14) H2_2010, 2100 Source: Model-predicted layers. Modeled by M. Schmid and based on data provided by Prof. Igor Polyakov and RCP26, CanESM2 future data. Folder: H3 15-16) H3 2010, 2100 Source: Model-predicted layers. Modeled by M. Schmid and based on data provided by Prof. Igor Polyakov and RCP26, CanESM2 future data. Folder: Wx 17-18) Wx 2010, 2100 Source: Model-predicted layers. Modeled by M. Schmid and based on data provided by Prof. Igor Polyakov and RCP26, CanESM2 future data. Representative Concentration Pathway 8.5 Folder: RCP85 Folder: chl 1-2) chl2010, 2100 Source: Chlorophyll data from the Canadian Earth System Model 2 (CanESM2) at the Canadian Centre for Climate Modelling and Analysis <http://www.cccma.ec.gc.ca/data/cgcm4/CanESM2/rcp85/index.shtml> Folder: mrro 3-4) mrro2010, 2100 Source: Total runoff data from the Canadian Earth System Model 2 (CanESM2) at the Canadian Centre for Climate Modelling and Analysis <http://www.cccma.ec.gc.ca/data/cgcm4/CanESM2/rcp85/index.shtml> Folder: no3 5-6) no2010, 2100 Source: Nitrate data from the Canadian Earth System Model 2 (CanESM2) at the Canadian Centre for Climate Modelling and Analysis

<http://www.cccma.ec.gc.ca/data/cgcm4/CanESM2/rcp85/index.shtml> Folder: sos 7-8) sos2010, 2100 Source: Sea surface salinity data from the Canadian Earth System Model 2 (CanESM2) at the Canadian Centre for Climate Modelling and Analysis <http://www.cccma.ec.gc.ca/data/cgcm4/CanESM2/rcp85/index.shtml> Folder: tos 9-10) tos2010, 2100 Source: Sea surface temperature data from the Canadian Earth System Model 2 (CanESM2) at the Canadian Centre for Climate Modelling and Analysis <http://www.cccma.ec.gc.ca/data/cgcm4/CanESM2/rcp85/index.shtml> Folder: Ocean layers PREDICTED Folder: H1 11-12) H1_2010, 2100 Source: Model-predicted layers. Modeled by M. Schmid and based on data provided by Prof. Igor Polyakov and RCP85, CanESM2 future data. Folder: H2 13-14) H2_2010, 2100 Source: Model-predicted layers. Modeled by M. Schmid and based on data provided by Prof. Igor Polyakov and RCP85, CanESM2 future data. Folder: H3 15-16) H3_2010, 2100 Source: Model-predicted layers. Modeled by 
M. Schmid and based on data provided by Prof. Igor Polyakov and RCP85, CanESM2 future data. Folder: Wx 17-18) Wx_2010, 2100 Source: Model-predicted layers. Modeled by M.Schmid and based on data provided by Prof. Igor Polyakov and RCP85, CanESM2 future data. Superfolder: General Folder: ArcticCircle 1) ArcticCircle Source: Extracted from the World GeoReference lines layer at the ArcGIS Resource Center <http://resources.arcgis.com/> Folder: PolarLand 2) PolarLand Source: Source: Extracted from the World topographic layer at the ArcGIS Resource Center <http://resources.arcgis.com/>

Superfolder: Zooplankton data; Raw presence points from OBIS (<http://www.iobis.org/>). Folder: C. hyperboreus

Folder: M. longa

Folder: M. pacifica Folder: T. raschii

Predicted layers: Best-pooled model: Presence/random absence, most likely depth and life stage layers

Folder: C. hyperboreus

Folder: M. longa

Folder: M. pacifica

Future predicted models from CanESM2:

Folder: Rcp 26 including ocean layers

Presence/random absence, most likely depth and life stage layers for 2010 and 2100

Folder: C. hyperboreus

Folder: M. longa

Folder: M. pacifica Folder: T. raschii

Folder: Rcp 26 excluding ocean layers

Presence/random absence, most likely depth and life stage layers for 2010 and 2100

Folder: C. hyperboreus

Folder: M. longa

Folder: M. pacifica Folder: T. raschii

Folder: Rcp 85including ocean layers

Presence/random absence, most likely depth and life stage layers for 2010 and 2100

Folder: C. hyperboreus

Folder: M. longa

Folder: M. pacifica Folder: T. raschii

Folder: Rcp 85 excluding ocean layers

Presence/random absence, most likely depth and life stage layers for 2010 and 2100

Folder: C. hyperboreus

Folder: M. longa

Folder: M. pacifica Folder: T. raschii 
Source_Used_Citation_Abbreviation:

see directly in the processing steps; data are organized by folder and described that way.

Process_Date: Unknown

Source_Produced_Citation_Abbreviation: Moritz Schmid,

Source_Produced_Citation_Abbreviation: EWHALE lab

Process_Contact:

Contact_Information:

Contact_Person_Primary:

Contact_Person: Moritz Schmid et al.

Contact_Organization: EWHALE lab

Contact_Position: M.Sc.

Contact Address:

Address Type: mailing and physical

Address: EWHALE lab

Address:

Inst of Arctic Biology, Biology \& Wildlife Dept. University of Alaska-Fairbanks 99775 USA

City: Fairbanks

State_or_Province: Alaska

Postal_Code: 99775

Country: USA

Contact_Voice_Telephone: +1 9074747882

Contact_Electronic_Mail_Address: fhuettmann@alaska.edu

Hours_of_Service: Business hours

Contact_Instructions: Contact by phone, email or regular mail

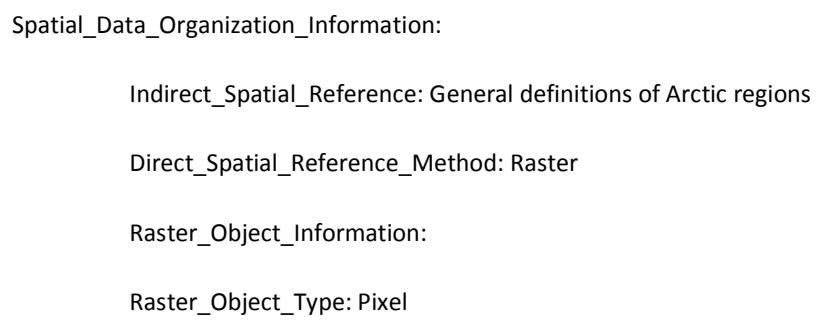

Planar: 


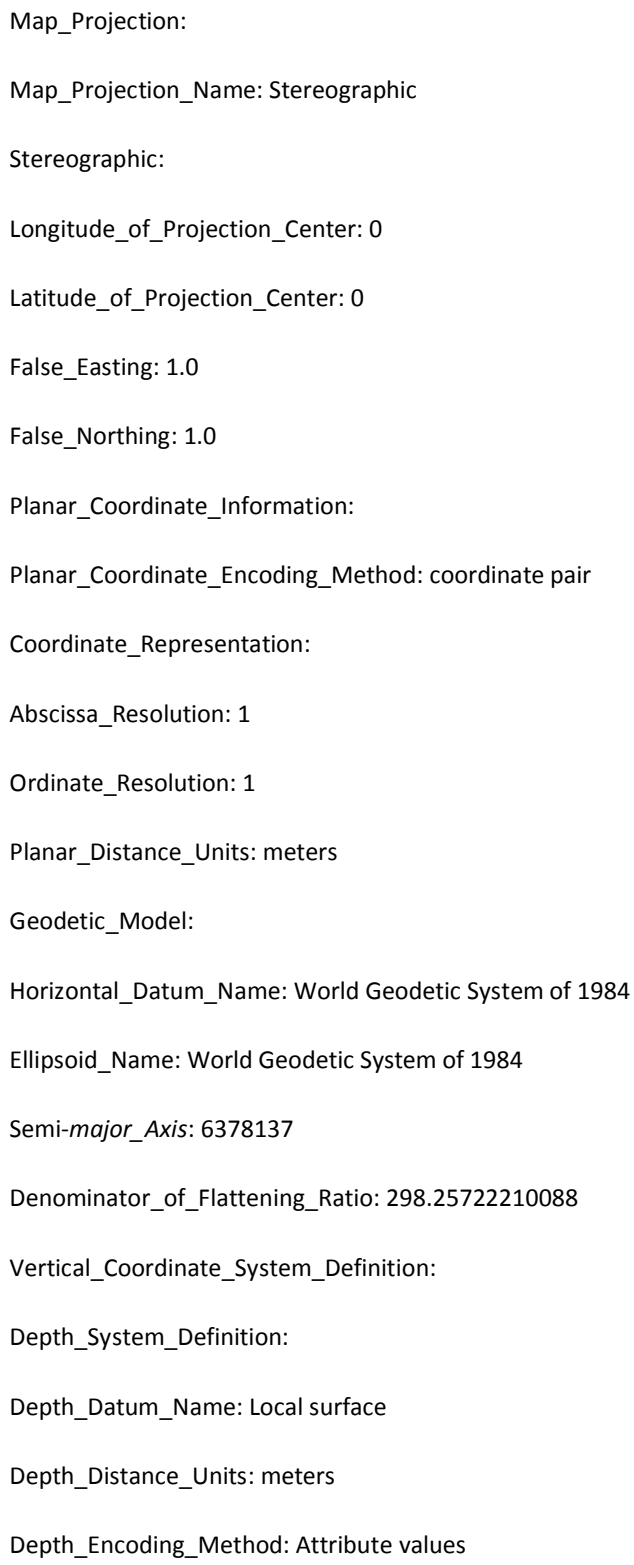


Distribution_Information:

Distributor:

Contact_Information:

Contact_Person_Primary:

Contact_Person: Moritz Schmid and Falk Huettmann

Contact_Address:

Address_Type: mailing and physical

Address: See earlier contact information in the metadata

Contact_Voice_Telephone: +1907474 7882

Contact_Electronic_Mail_Address: fhuettmann@alaska.edu

Distribution_Liability: No liability is assigned.

Standard_Order_Process:

Digital_Form:

Digital_Transfer_Information:

Format_Name: ASCII

Format_Version_Date: 20101231

ASCII_File_Structure:

Record_Delimiter: space

Number_Header_Lines: 6

Description_of_Header_Content:

For Arctic: ncols 3601 nrows 451 xllcenter -180.000000000 yllcenter 45.000000000 cellsize 0.100000 nodata_value -9999

File_Decompression_Technique: No compression applied

Digital_Transfer_Option:

Online_Option:

Computer_Contact_Information:

Network_Address:

Network_Resource_Name: ftp, CD rom, or otherwise

Access_Instructions: open data device upon receival

Online_Computer_and_Operating_System: PC compatible

Fees: None

Ordering_Instructions: Ask via phone, email or letter

Turnaround:

Download is quick, otherwise, whenever time allows, e.g. a week or less 
Resource_Description: 147 digital datasets in ArcGIS ESRI grid format

Custom_Order_Process: Contact authors

Technical_Prerequisites: GIS program like ArcGIS or R who can read ESRI grids

Metadata_Reference_Information:

Metadata_Date: 20120413

Metadata_Contact:

Contact_Information:

Contact_Person_Primary:

Contact_Person: Moritz Schmid and Falk Huettmann

Contact_Organization: EWHALE lab

Contact_Position: M.Sc. and supervising prof.

Contact_Address:

Address_Type: mailing and physical

Address: Moritz Schmid and Falk Huettmann

Address: -EWHALE lab-

Address: Inst of Arctic Biology,

Address: Biology \& Wildlife Dept.

Address: University of Alaska Fairbank

City: Fairbanks

State_or_Province: Alaska

Postal_Code: 99775

Country: USA

Contact_Voice_Telephone: +19074747882

Contact_Electronic_Mail_Address: fhuettmann@alaska.edu

Metadata_Standard_Name:

FGDC Biological Data Profile of the Content Standard for Digital Geospatial Metadata

Metadata_Standard_Version: FGDC-STD-001.1-1999

Metadata_Extensions:

Online_Linkage: 〈http://nrdata.nps.gov/profiles/NPS_Profile.xml>

Profile_Name: NPS NR and GIS Metadata Profile

Metadata_Access_Constraints: NA

Metadata_Use_Constraints: NA

Metadata_Security_Information: 
Metadata_Security_Classification_System: NA

Metadata_Security_Classification: Unclassified

Metadata_Security_Handling_Description: NA

Generated by $\underline{\text { mp }}$ version 2.8.25 on Fri Apr 20 10:21:23 2012 


\section{Declaration of independent work}

Hiermit versichere ich gemäß $\S 9$ Abs. 5 der Prüfungsordnung für den integrierten binationalen Master-Studiengang Internationaler Naturschutz (engl.: International Nature Conservation) vom 16.08.2006, dass ich die vorliegende Arbeit selbstständig verfasst und keine anderen als die angegebenen Hilfsmittel verwendet habe. Diese Arbeit wurde nicht in der gleichen oder einer ähnlichen Form bereits einem anderen Prüfungsausschuss vorgelegt und wurde bisher noch nicht veröffentlicht.

Hereby I affirm - according to $\S 9$ section 5 of the examination regulations for the integrated binational Master programme International Nature Conservation (deutsch: Internationaler Naturschutz) from 16.08.2006 - that I have penned the present thesis autonomously and that I did not use any other resources than those specified above. This work was not submitted previously in same or similar form to another examination committee and was not yet published.

\section{Ort/Place, Datum/Date Name/Name}

